
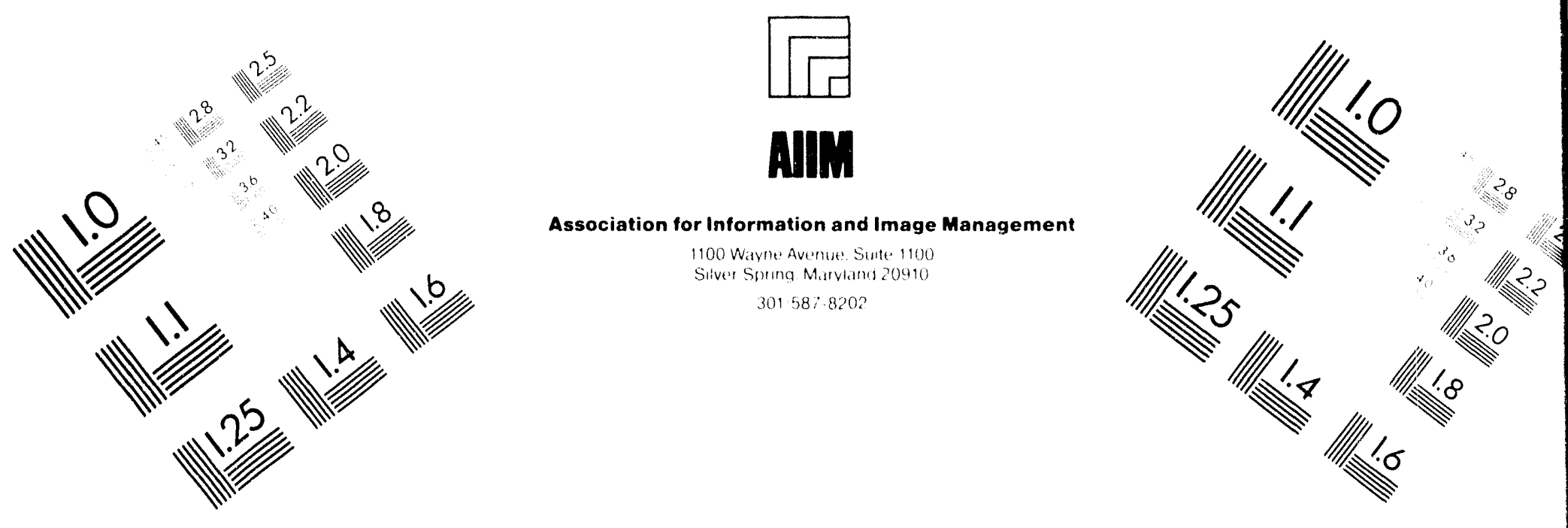

\title{
Centimeter
}

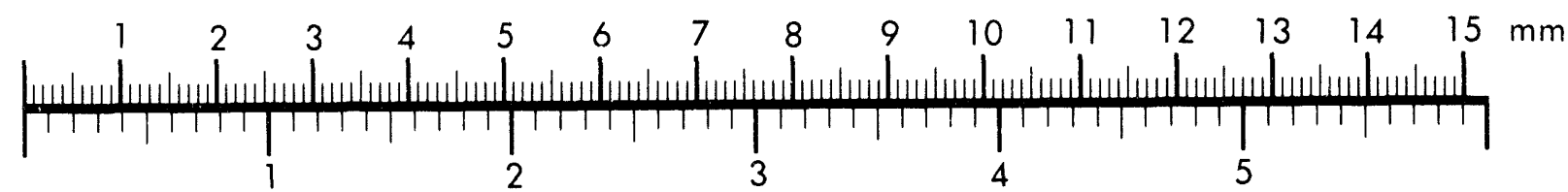

Inches
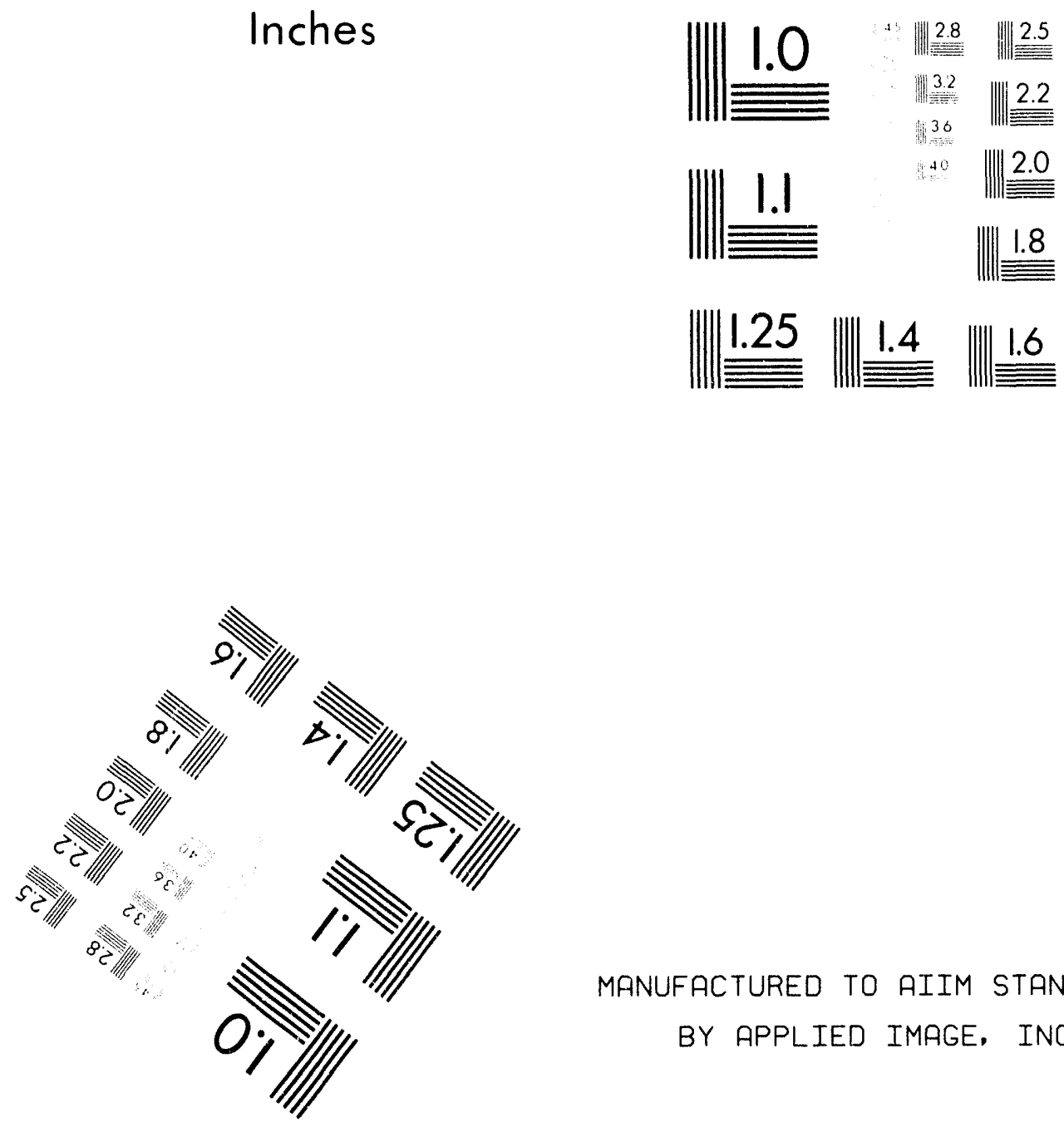

MANUFACTURED TO AIIM STANDARDS

BY APPLIED IMAGE, INC.

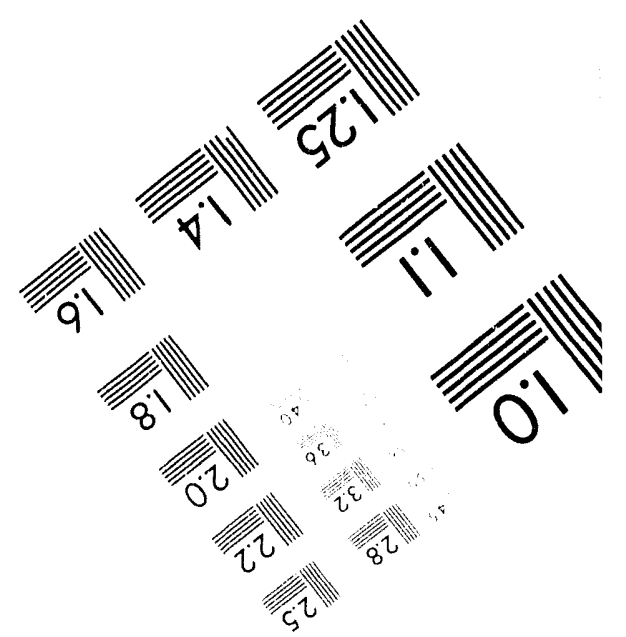



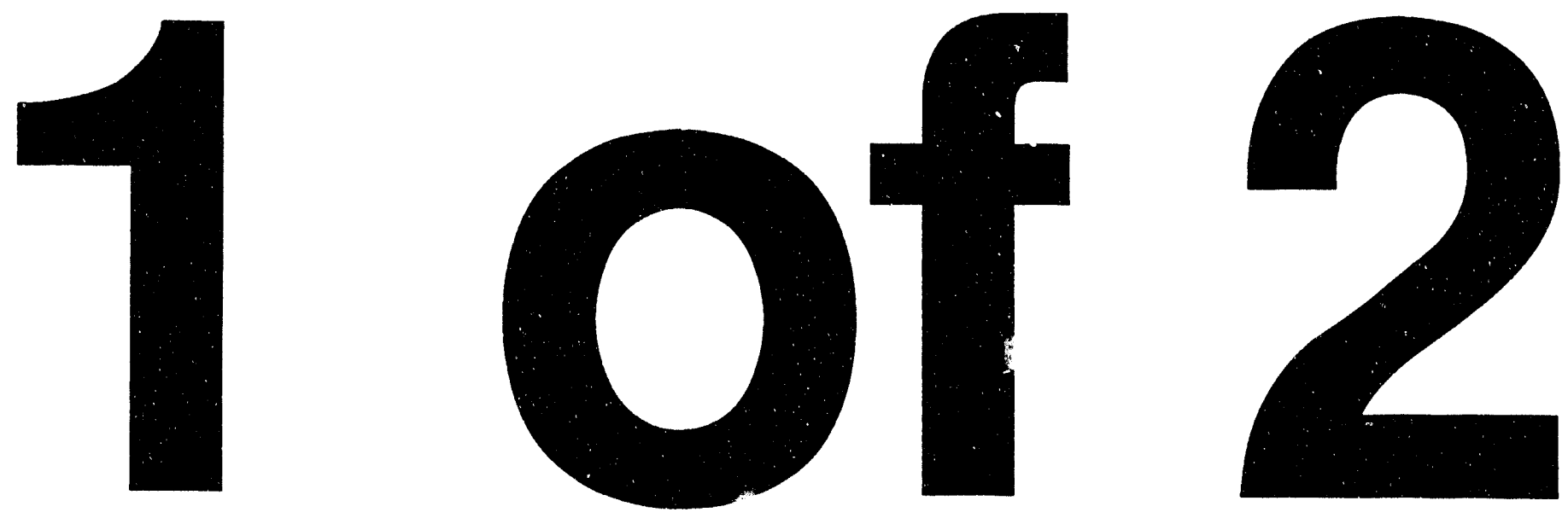


\title{
Model Documentation:
}

\section{Electricity Market Module}

\section{Electricity Fuel Dispatch Subm:odule}

\author{
March 1994
}

\author{
Energy Information Administration \\ Office of Integrated Analysis and Forecasting \\ Energy Supply and Conversion Division \\ Nuclear and Electricity Analysis Branch \\ U.S. Department of Energy \\ Washington, DC 20585
}

This report was prepared by the Energy Information Adminietration, the independent statistical and analytical agency within the Department of Energy. The information comtained herein should not be conetrued as advocating or roflecting any policy position of the Department of Energy or any other organization. 


\section{Table of Contents}

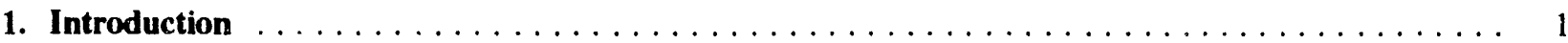

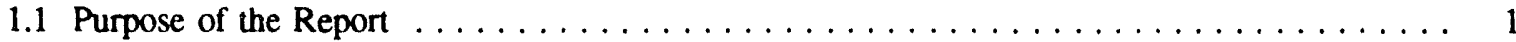

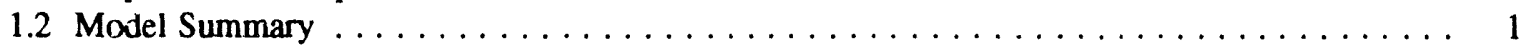

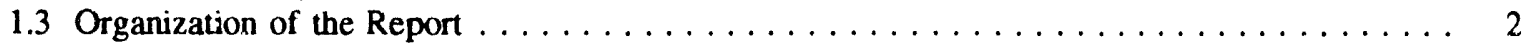

2. Model Purpose $\ldots \ldots \ldots \ldots \ldots \ldots \ldots \ldots \ldots \ldots \ldots \ldots \ldots \ldots \ldots \ldots \ldots$

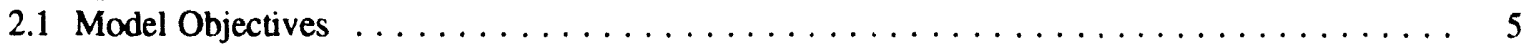

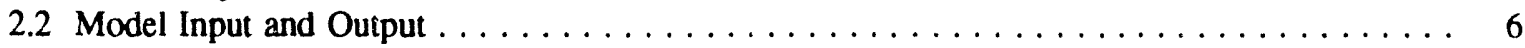

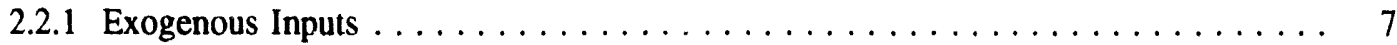

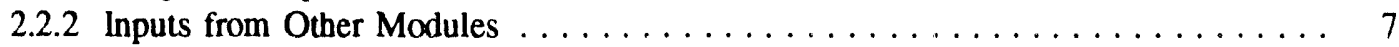

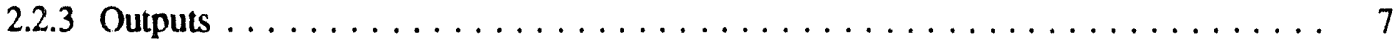

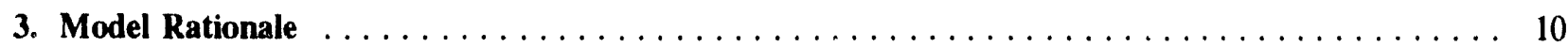

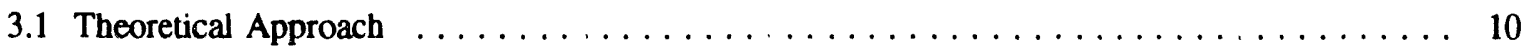

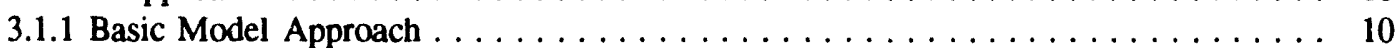

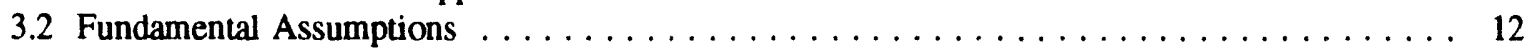

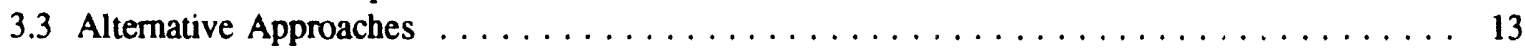

3.3.1 Modeling the Dispatch Decision . . . . . . . . . . . . . . . . . . . . 13

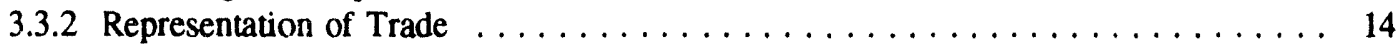

3.3.3 Modeling the Development of Nonutility Power Projects $\ldots \ldots \ldots \ldots \ldots \ldots$

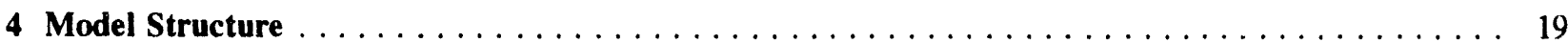

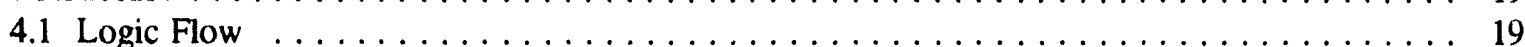

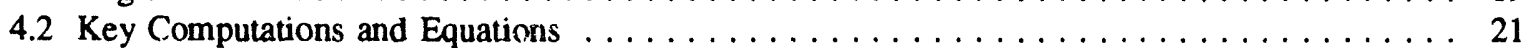

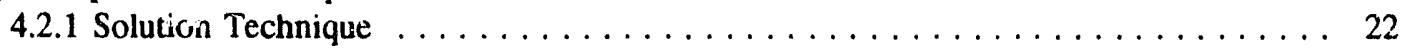

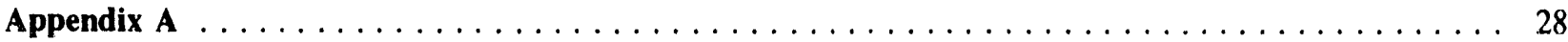

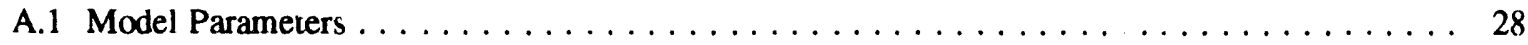

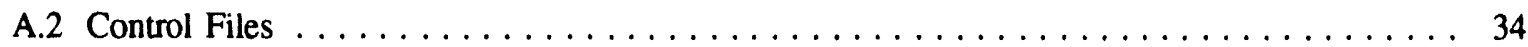

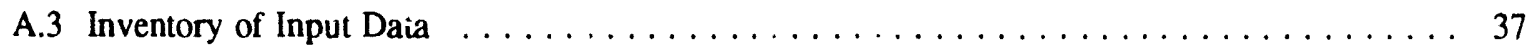

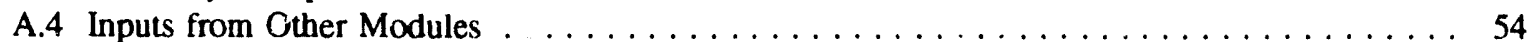

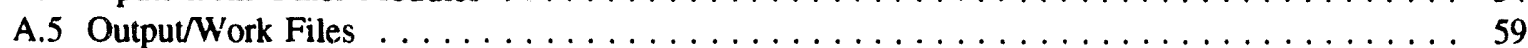

A.6 Variable Cross Reference Tables $\ldots \ldots \ldots \ldots \ldots \ldots \ldots \ldots \ldots \ldots \ldots \ldots \ldots \ldots \ldots$

A-7 Model Outputs . . . . . . . . . . . . . . . . . . . . . . . . . . . . . . . . . . . . 107

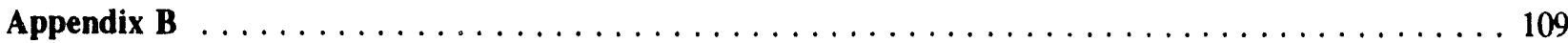

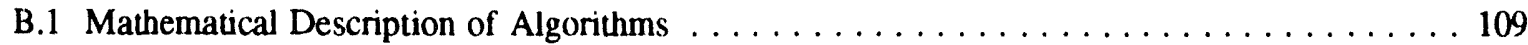

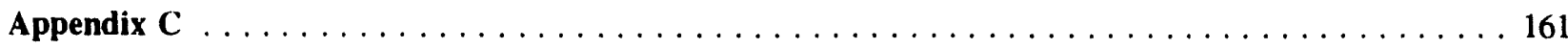

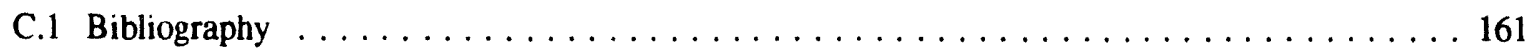

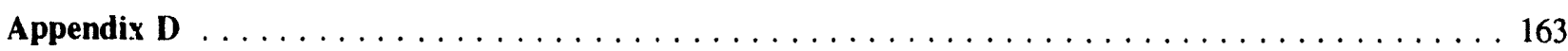

D.1 Summary of Title IV

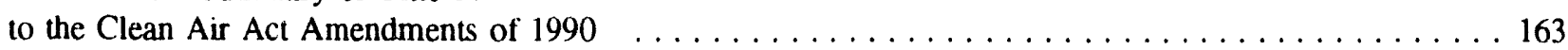

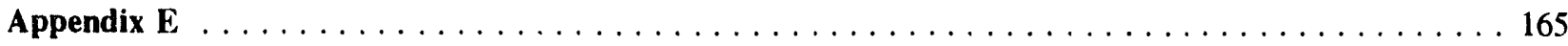

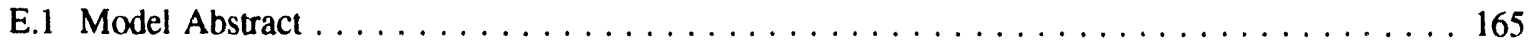

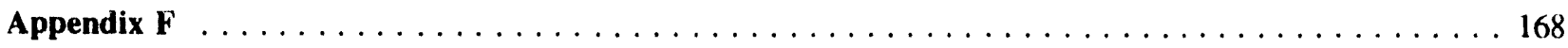

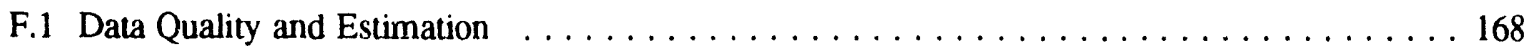




\section{Introduction}

\subsection{Purpose of the Report}

This report documents the objectives, analytical approach and development of the National Energy Modeling System Electricity Fuel Dispatch Submodule (EFD), a submodule of the Electricity Market Module (EMM). The report catalogues and describes the model assumptions, computational methodology, parameter estimation techniques, model source code, and forecast results generated through the synthesis and scenario development based on these components.

This document serves four purposes. First, it is a reference document providing a detailed description of the model for reviewers and potential users of the EFD including energy experts at the Energy Information Administration (EIA), other Federal agencies, state energy agencies, private firms such as utilities and consulting firms, and nonprofit groups such as consumer and environmental groups. Second, this report meets the legal requirement of the Energy Information Administration (EIA) to provide adequate documentation in support of its statistical and forecast reports (Public Law 93-275, section 57(b)(1)). Third, it facilitates continuity in model development by providing documentation for which energy analysts can undertake model enhanccments, data updates and parameter refinements as future projects. Last, because the major use of the EFD is to develop forecasts for EIA's Annual Energy Outlook, this documentation explains the calculations and major inputs and assumptions which were used to generate this forecast.

\subsection{Model Summary}

The Electricity Fuel Dispatch Submodule (EFD) determines the annual allocation of available capacity (as determined in the Electricity Capacity Planning Submodule) to meet demand on a least-cost (merit-order) basis subject to current environmental regulations (Figure 1). First, available capacity is ranked from the least to most costly units according to variable costs. Second, the units are dispatched in this order (from least to most costly) until demand is satisfied. (The Electricity Capacity Planning Submodule determines the capacity needed in each year to meet demand; Demand is determined in the Demand Modules with seasonal and hourly demands determined in the Load and Demand Side Management Submodule.) The utilities have the option to purchase or sell energy to neighboring regions if it is economic.

Fuel consumption and emissions of sulfur dioxide $\left(\mathrm{SO}_{2}\right)$, nitrogen oxide $\left(\mathrm{NO}_{\mathrm{x}}\right)$ and carbon are determined based on the utilization of capacity. Fuel consumption is provided to the fuel supply modules while fuel and variable operations and maintenance $(O \& M)$ costs are used to determine electricity prices in the Electricity Finance and Pricing (EFP) Submodule. Electricity prices are provided to the demand models to determine electricity demand.

Although the EFD is similar to its predecessor in the EMM-IFFS,' there has been significant improvement in the NEMS. The most significant improvement is the endogenous representation of the Clean Air Act Amendments

\footnotetext{
${ }^{1}$ For further information on the EMM/IFFS system, refer to the following documents: Energy information Administration, Intermediate Future Forecasting System Executive Summary, DOE/EIA-0430, (Washington, DC, October 1983), Energy Information Administration, Documentation of the Integrating Module and Stock Module of the Intermediate Future Forecasting System, DOE/EIA-M023 (Washington, D.C., May 1987), the Energy Information Administration, Model Documentation: Electricity Market Module, DOE/EIA-MOO2 (Washington, DC, December 1984).
} 
(CAAA) ${ }^{2}$. The segmentation and the maintenance of seasonality in the load duration curves (to better represent the demand for electricity and maintenance scheduling and fuel availability, and to account for trade) has also greatly enhanced the capability of the model. In IFFS, the strategies employed by utilities to comply with the CAAA were represented in the National Coal Model (NCM), which was not integrated in IFFS. ${ }^{3}$ The NCM was provided electricity demand and fuel prices from an appropriate IFFS run and in turn provided to the EMM-IFFS revised fuel mixes and the cost and quantity of equipment installed to achieve the emissions reductions. The EMM-IFFS would then re-run with these new costs and fuel mixes. If the run resulted in different slectricity demands and fuel prices, the cycle would be repeated using the new IFFS runs. This process continued until the results of the two models were closely calibrated. The exogenous representation of the CAAA in IFFS resulted in a time-consuming and awkward process.

The segmentation of the load duration curve and the maintenance of chronology in the load duration curve (the load duration curve is divided into 26 segments) allows for better representation of electricity demand, trade and demand side management.

Another enhancement is the representation of electricity supply by North American Electric Reliability Council (NERC) regions and subregions in place of 10 Federal Regions. Using NERC regions and subregions (referred to in this report as NEMS electricity supply regions) allows a better representation of electricity markets and the operations of electric utilities. Load data for electric utilities is collected by the NERC and is provided at the NERC regional level. NERC level forecasts also allow for comparison of EIA and NERC forecasts at the regional level.

The EFD also represents nonutility (excluding cogenerators) supply and interregional economy sales endogenously. Cogeneration and generation from intermittent renewable technologies are determined in the Demand Models and Renewable Models, respectively, with the demand curve adjusted to incorporate their contribution to load. The EFD dispatchs nonutility supply together with utility fossil-fueled and nuclear generating capacity. In EMM-IFFS, generation from these sources was determined exogenously and demand was adjusted by their generation. Economy sales are also represented in the EFD. Utilities now have the option to purchase electricity from another region in place of generating the power themselves. In IFFS, bulk power transactions were determined exogenously, based on historic interregional relationships.

\subsection{Organization of the Report}

Section 2 of this report discusses the purpose of the model, detailing its objectives, primary input and output quantities, and the relationship of the EFD to other modules of the EMM and NEMS systems. Section 3 of the report describes the rationale behind the model design, providing insights into the development of the assumptions utilized in the model. Section 3 also reviews alternative dispatching and interregional trade modeling methodologies drawn from existing literature, providing a comparison to the chosen approach. Section 4 details the model structure, using graphics and text to illustrate model flows and key computations.

The Appendices to this report provide supporting documentation for the input data and parameter files currently

${ }^{2}$ The Clean Air Act and its subsequent amendments contain federal regulations for $\mathrm{SO}_{2}$ and $\mathrm{NO}_{x}$ emissions by electric utilities. The most recent amendments to the CAAA in 1990 set up a system of marketable allowances to emit $\mathrm{SO}_{2}$. Each allowance entitles the holder to emit one ton of $\mathrm{SO}_{2}$. Allowances may be traded among utilities and nonutilities, so the limit on total emissions is a national rather than a unit level limit.

${ }^{3}$ The NCM could not be incorporated within the IFFS framework because of its size and execution time and because it would be too difficult to extract only the dispatching structure from the model. For a detailed description of the NCM, see Energy Information Administration, National Coal Model: Executive Summary, DOE/EIA-0325 (Washington, DC, April 1982).

${ }^{4}$ In future development of NEMS, renewable supply, demand side management programs and international economy trade will be represented endogenously. DSM impacts will be incorporated by adjusting the demand for capacity prior to the dispatching decision, i.e. the load curve will be revised. 
residing on the EIA mainframe. Appendix $\mathrm{A}$ lists and defines the input data used to generate parameter estimates and endogenous forecasts, along with the parameter estimates and the outputs of most relevance to the NEMS systems and the model evaluation process. A table referencing the equations and/or subroutine in which each variable appears is also provided in Appendix A. Appendix B contains a mathematical description of the computational algorithms, including model equations and variable transformations. Appendix $C$ contains the Bibliography. Appendix D contains a summary of the Clean Air Act Amendments of 1990 which are represented in the Electricity Market Module (EMM) and have a significant impact on the results of the dispatch decision. Appendix E contains the model abstract and Appendix F outlines the quality of the data and the techniques used as estimates in the EFD.

Volume II of this report documents technical detail on model data and equations. Volume II also provides sensitivity analysis and scenario output in support of the documentation of model performance and will be available in December 1994. 
Figure 1 Fuel Dispatch Algorithm

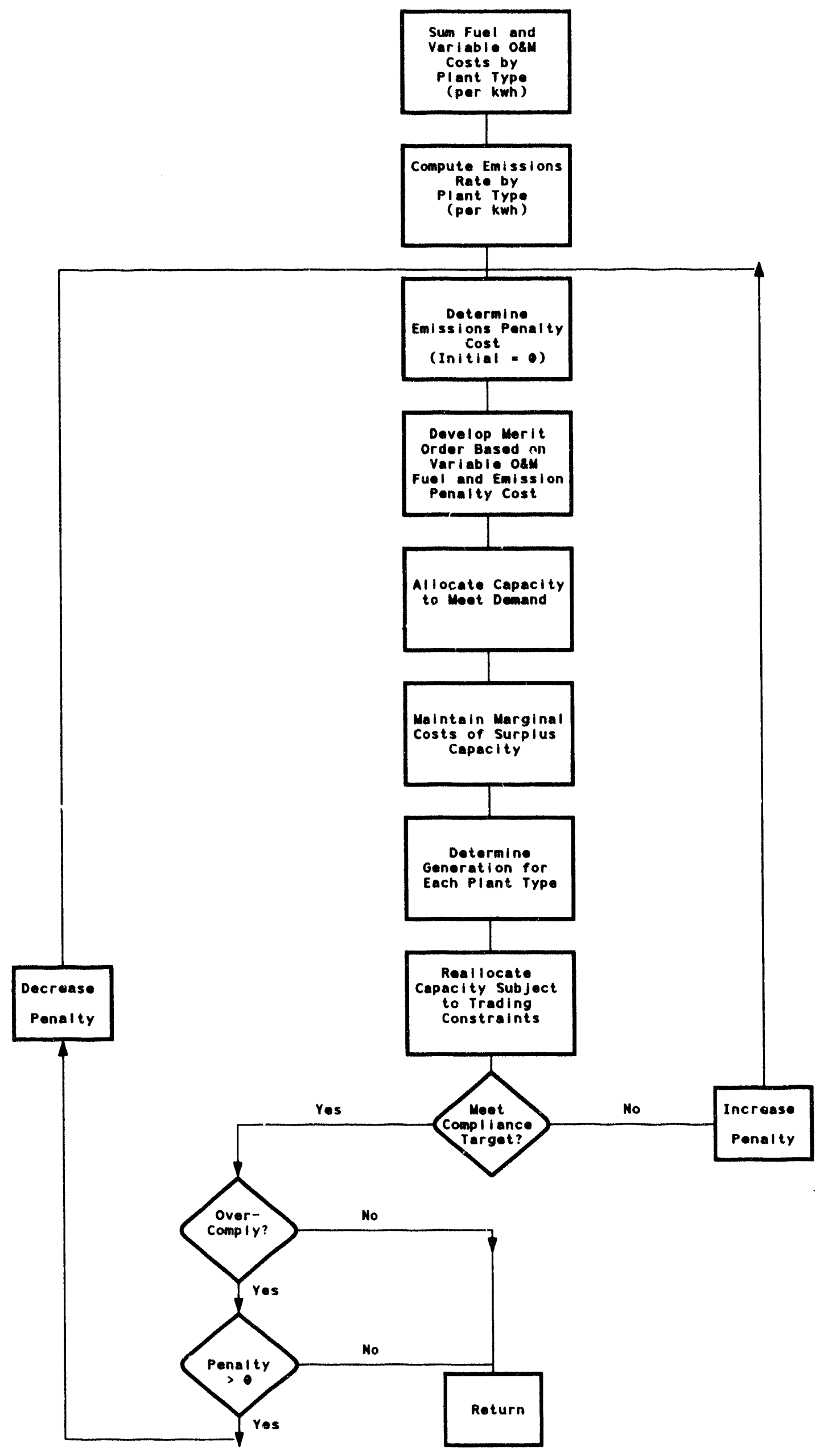




\section{Model Purpose}

\subsection{Model Objectives}

The objective of the EFD is to represent the economic, operational and environmental considerations in dispatching. The EFD allocates available generating capacity to meet the demand for electricity on a least-cost basis, subject to restrictions on emissions such as $\mathrm{SO}_{2}, \mathrm{NO}_{\mathrm{x}}$ and carbon. The primary use of the EFD is for inclusion in the Energy Information Administration's Annual Energy Outlook.

The EFD addresses utility and nonutility supplies endogenously; i.e. the EFD dispatches nonutility sources ${ }^{5}$ together with utility fossil-fuel and nuclear generating capacity. However, cogeneration and intermittent renewable technologies are represented exogenously with the load curve adjusted prior to dispatching.

The EFD represents the dispatch decision at the regional level. These regions, referred to as NEMS electricity supply regions, are North American Electric Reliability Council (NERC) regions and subregions. (Table 1 and Figure 2). The primary inputs from other NEMS modules are the demands for electricity and fuel prices. The resulting fuel consumption is passed to the respective fuel supply models. The fuel supply modules and end-use demand modules use other regional aggregations (Census regions and divisions, coal and gas supply regions, etc.). The interaction between the EFD and other modules of the NEMS and other regional issues, including the required transformations between different regional structures are described later in this section.

Table 1. NEMS Electricity Supply Regions

NERC Region/ Subregion $\quad$ Acronym

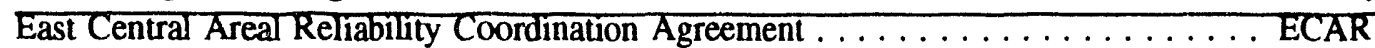

Electric Reliability Council of Texas $\ldots \ldots \ldots \ldots \ldots \ldots \ldots \ldots \ldots$ ERCOT

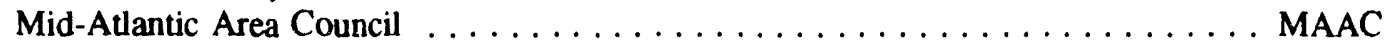

Mid-America Interconnected Network $\ldots \ldots \ldots \ldots \ldots \ldots \ldots \ldots \ldots \ldots \ldots \ldots \ldots \ldots$

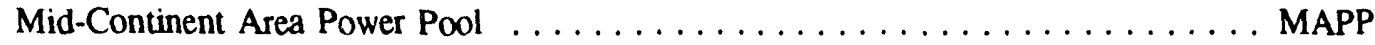

Northeast Power Coordinating Council/New England $\ldots \ldots \ldots \ldots \ldots \ldots \ldots$ NPCC/NE

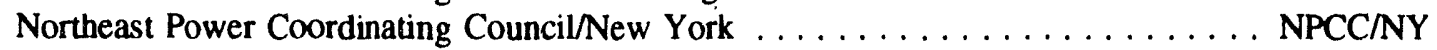

Southeastern Electric Reliability Council/excluding Florida $\ldots \ldots \ldots \ldots \ldots \ldots$ SERC/STV

Southeastern Electric Reliability Council/Florida $\ldots \ldots \ldots \ldots \ldots \ldots \ldots$ SERC/FL

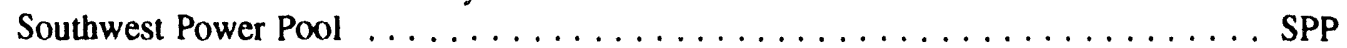

Western Systems Coordinating Council/Northwest Power Pool Area .........WSCC/NWP

Western Systems Coordinating Council/

Rocky Mountain Power Area and Arizona-New Mexico Power Area ........WWCC/RA

Western Systems Coordinating Council/California-Southern Nevada Power Area .... WSCC/CNV

The EFD incorporates current regulations, including the Clean Air Act Amendments of 1990 (CAAA). The EFD only incorporates strategies that can be implemented during dispatching, fuel switching and allowance trading (i.e. strategies for reducing $\mathrm{SO}_{2}$ and $\mathrm{NO}_{x}$ emissions such as retrofitting units with scrubbers and low $\mathrm{NO}_{n}$ burners are represented in the ECP). Allowance trading is represented by adding a penalty cost for each ton of $\mathrm{SO}_{2}$ emitted. (Note: In the first year and iteration of the model, the penalty cost is set to zero, as if there were no penalty for polluting). If the resulting dispatch decision results in emissions which are above the regulated limit, than the dispatch decision is re-done, with a higher penalty cost. Likewise, if the resulting dispatch decision results in

${ }^{5}$ In this document, the term "nonutilities" refers to independent and small power producers and exempt wholesale generators. Cogenerators will be referred to specifically. 
emissions which are below the regulated limit, the dispatch is re-done, with a lower penalty cost. This procedure is repeated until equilibrium it met.

Another feature of the EFD is the ability of certain regions to engage in interregional economy transactions. In the EFD, after the original dispatch decision has been completed, certain regions are allowed to purchase surplus, more economic power from neighboring regions. ${ }^{6}$ Again, this dispatch decision is subject to CAAA limits.

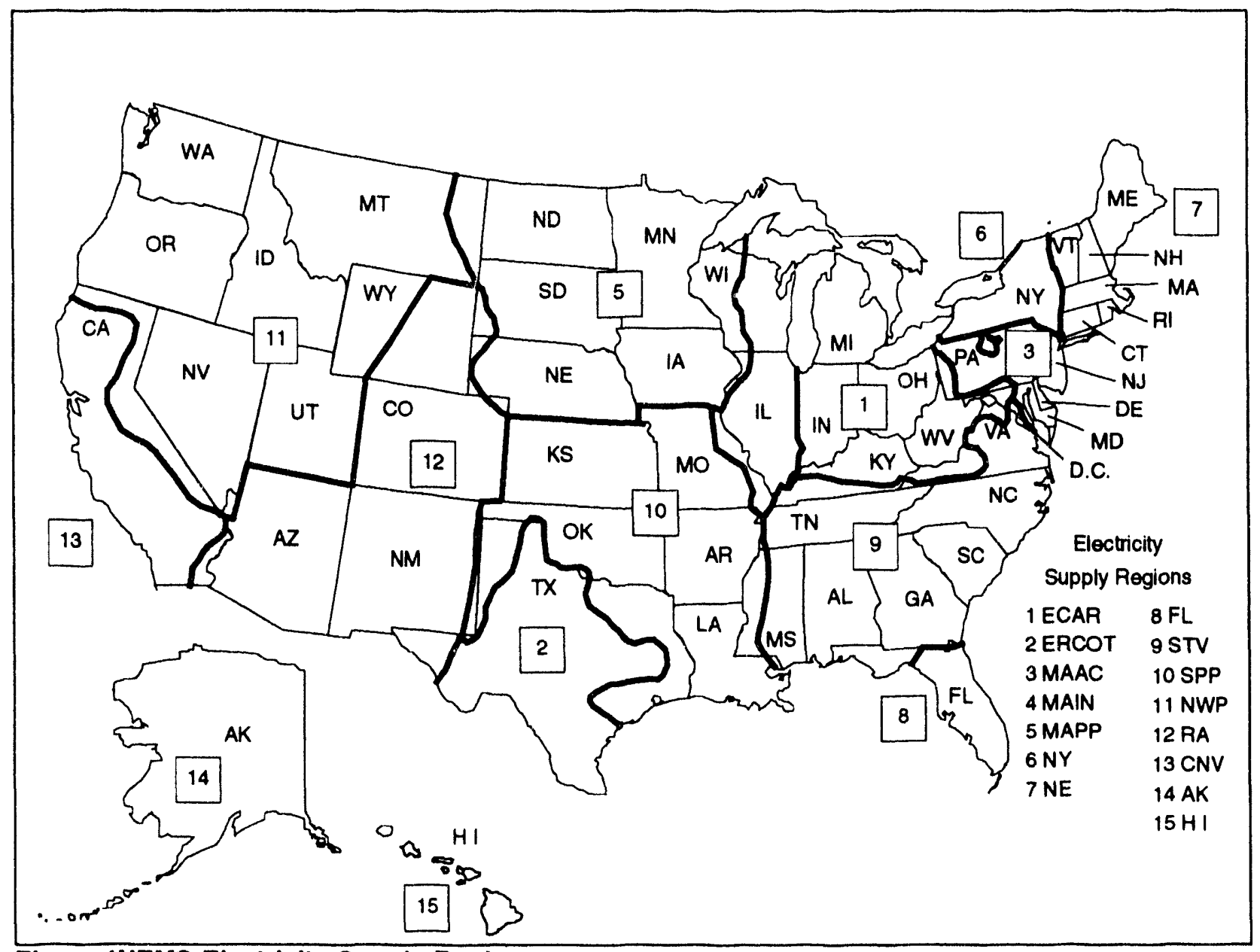

Figure 1NEMS Electricity Supply Regions

\subsection{Model Input and Output}

The EFD requires input data from exogenous sources, other modules of the NEMS, and other submodules of the Electricity Market Module. This section contains an overview of the data flows within the EFD. A more detailed discussion of these flows, including the layout of the inpl!t and output files, the sources for exogenous data,

${ }^{6}$ Currently, only select regions are allowed to engage in economy trade. These regions were selected based on historic trade relationships. Additional regions will be incorporated in future versions of NEMS if the potential for trade is identified in these regions and as time and resources allow. 
and an inventory of data flows among modules is presented in Appendix A. Table 2 contains an overview of the input, output and work files for the EFD, along with a reference to the file descriptions contained in Appendix A.

\subsubsection{Exogenous Inputs}

The EFD requires cost and performance data for both existing and future units to complete the dispatch decision. This information is obtained from various EIA forms for existing units, in particular from the Form EIA-423, "Monthly Report of Cost and Quality of Fuels for Electric Plants". Likewise, cost and performance data for future generating units are provided by the Argonne National Laboratories Cost and Performance Database for New and Existing Generating Technologies. Transmission constraints and trade relationships ${ }^{7}$ are also input to incorporate economy trade.

$\mathrm{SO}_{2}, \mathrm{NO}_{x}, \mathrm{CO}_{2}$, Carbon, $\mathrm{CO}$ and $\mathrm{VOC}$ emission rates and ash retention rates are also provided to determine annual emissions.

Load shape information is also provided exogenously and is based on historic load shapes.

\subsubsection{Inputs from Other Modules}

The demand modules provide electricity demand by sector. These demands are aggregated and mapped to a load duration curve in the EMM prior to the dispatch decision. In future versions of NEMS, the Load and Demand Side Management Submodule will be responsible for mapping demand to the load duration curve.

The commercial and industrial demand modules represent cogeneration and other electricity production at their facilities. The generation provided by these modules is converted to capacity (assuming a 100 percent capacity factor) with the resulting capacity subtracted from the load curve. In future versions of NEMS, this capacity will be mapped to the appropriate slices of the load curve in the Load and Demand Side Management Submodule. Likewise, generation from renewable sources is subtracted from the load duration curve prior to the dispatch decision using capacity factors provided by the Renewable Fuels Module.

Fossil fuel prices are provided by the Fuel Supply Modules. These prices are used in determining variable costs for each plant type and arranging the plants in merit order.

The Electricity Capacity Planning (ECP) Submodules provides information to the EFD. The ECP provides the annual available capacity to be used in the dispatch decision.

\subsubsection{Outputs}

The EFD determines the allocation of generating capacity to meet electricity demand subject to environmental restrictions. The output of this decision is needed to determine the price of electricity and to account for: 1) the utilization of the fuel inputs; 2 ) renewable generation; and, 3) emissions. In particular, the EFP requires fuel costs and variable O\&M to determine the price of electricity. The Renewable Fuels Modules is passed generation from renewable sources to compute net generation from renewable sources while the remaining Fuel Supply Modules require the amount of fuel consumed for the pricing of the fuel and for calculating "total" fuel use by all sectors. Emissions are provided to the integrating module.

Output reports provide projections of generation and fuel consumption by plant and fuel type, for both utilities and other.

\footnotetext{
${ }^{7}$ The transmission links tell the dispatch submodule that the region's have the ability to trade with each
} 
Table 2 Summary of Data Flows in the EFD

\begin{tabular}{|c|c|c|}
\hline \multicolumn{3}{|l|}{ Exogenous Inputs } \\
\hline Table & Table & \\
\hline File/Reference & Common/Reference & General Description \\
\hline None & EMMSPARM/Table A-1 & EMM Parameters \\
\hline None & PARAMETRTTable A-2 & NEMS Parameters \\
\hline None & ECPSCNTLTable A-3 & Control/Switch File \\
\hline None & NCNTRL/Table A-4 & Control/Switch File \\
\hline LOADDAF & LOADIN/Table A-5 & Load shape information (EFD \& ECP) \\
\hline PLNTDAF & PLNTIN/Table A-6 & $\begin{array}{l}\text { Plant level information } \\
\text { (Existing, planned and unplanned) }\end{array}$ \\
\hline FUELDAF & FUELIN/Table A-7 & Emission rates \\
\hline ETTIN/Table A-8 & Local & Constraints File \\
\hline ETTDEM/Table A-9 & DISPETT/Table A-10 & $\begin{array}{l}\text { Net Flows, Canadian Supply Curve Info. } \\
\text { Predominantly for ECP }\end{array}$ \\
\hline NUGPIPE/Table A-11 & Local & $\begin{array}{l}\text { 'Other' cogen } \\
\text { (not industrial/commercial) }\end{array}$ \\
\hline SO2CNTL & USO2GRP/Table A-12 & $\begin{array}{l}\text { \# of Compliance Groups, Tolerances, } \\
\text { and Price Jumps }\end{array}$ \\
\hline ELGNCR/Table A-13 & ELSSHRS/Table A-13 & $\begin{array}{l}\text { Data to Map Demand from Census } \\
\text { to NERC region }\end{array}$ \\
\hline ELDATYRTTable A-14 & DISPINYR/Table A-15 & Historical Data Overwrites \\
\hline INPTDAF & DISPIN/Table A-16 & $\begin{array}{l}\text { Overall input. } \\
\text { Read from DAF for each region \& year }\end{array}$ \\
\hline \multicolumn{3}{|c|}{ Inputs from Other Modules } \\
\hline Module(s) & $\begin{array}{c}\text { Table } \\
\text { Common/Reference }\end{array}$ & General Description \\
\hline \multicolumn{3}{|l|}{ Industrial \& } \\
\hline Commercial & COGEN/Table A-17 & $\begin{array}{l}\text { Cogeneration capacity to be removed } \\
\text { from load curve }\end{array}$ \\
\hline RFM & WRENEW/Table A-18 & Renewables cost and performance info. \\
\hline Fuel Supply & FUELIN/Table A-6 & Fuel prices \\
\hline Various & CONTROL/Table A-19 & Electricity Demand \\
\hline \multicolumn{3}{|l|}{ Output/Work Fles } \\
\hline File & $\begin{array}{c}\text { Table } \\
\text { Common/Reference }\end{array}$ & General Description \\
\hline ETT\$TMP/Table A-20 & DISPETT/Table A-11 & $\begin{array}{l}\text { Updated ETTDEM file } \\
\text { (with model result info) }\end{array}$ \\
\hline None & DISPUSE/Table A-21 & EFD working space \\
\hline OUTDAF/Table A-22 & DISPOUT & $\begin{array}{l}\text { Results of the EFD Decision } \\
\text { One region, current year } \\
\text { (Generation, Consumption \& Emissions) }\end{array}$ \\
\hline None & UEFDOUT/Table A-23 & $\begin{array}{l}\text { Same as DISPOUT but for all } \\
\text { regions and years (Reporting Purposes) }\end{array}$ \\
\hline None & UETTOUT/Table A-24 & Trade Results \\
\hline
\end{tabular}

Note: The inpuloutput files for the EMM have the following naming convention - \&6005PRJ.UTIL.<name2>. <scenario >.<datekey>. The common block (Column 2 of Table 2) refers to the member of the partitioned data set \&6005PRJ.NEMS.COMMON.PDS.D1123931 
nonutilities and interregional and international economy trade. ${ }^{8}$ Reports include emissions. These reports contain both national and regional projections. National projections are published in the Annual Energy Outlook 1994 and regional projections are published in the Supplement to the Annual Energy Outlook 1994. Appendix A contains sample outputs from actual model runs and a description of the files and common blocks where this information is stored.

${ }^{8}$ In future versions of NEMS, the information needed to graph the solution of the EFD will be saved in the variables stored in the DISPCRV common block (CN6005PRJ.NEMS.COMMON.PDS. D1123931:DISPCRV). Currently, nothing is saved in this common block. Nevertheless, a copy of the common block is included in Appendix A. 


\section{Model Rationale}

\subsection{Theoretical Approach}

\subsubsection{Basic Model Approach}

The EFD uses an heuristic approach to provide a least-cost solution to allocating (dispatching) capacity to meet demand. Dispatching involves deciding what generating capacity should be up and running to meet the demand for electricity, which is subject to seasonal, daily, and hourly fluctuations. The objective of the EFD is to provide an economic / environmental dispatching procedure. In an economic (least-cost) dispatch, the marginal source of electricity is selected to react to each change in load. ${ }^{9}$ In environmental dispatching, the demand for electricity must be satisfied without violating certain emissions restrictions. The EFD integrates the cost-minimizing solution with environmental compliance options to produce the least-cost solution that satisfies electricity demand and reduces emissions to specified limits.

Environmental issues that are incorporated in the EMM-NEMS include compliance with $\mathrm{SO}_{2}$ and $\mathrm{NO}_{x}$ restrictions specified in the Clean Air Act (New Source Performance Standards - NSPS, Revised New Source Performance Standards - RNSPS, and Clean Air Act Amendments - CAAA). The implications of Title V of the CAAA in the EFD decision-making process is discussed later in this Chapter in the Fundamental Assumptions section while the specifics of the CAAA outlined in Appsndix D.

Demand can be characterized by a load curve, which is a plot of power demand (load) versus time (Figure 3 ). The highest point on the curve, the peak point, defines the capacity requirement. The capacity allocated to meet this last increment of demand is used infrequently during the entire period. On the other hand, the capacity assigned to satisfy demand at the base, or minimum point of the curve is required on a continuous basis. The percent of time capacity is required at each slice of load is called a capacity factor (utilization rate). The capacity factor for the load at the base of the curve is 100 percent and it approaches 0 percent at the peak of the load curve.

The relationship between capacity requirements and capacity utilization can also be illustrated by a load duration curve, which is obtained by reordering the demands for power in descending order rather than chronologically (Figure 4). This curve shows the capacity utilization requirements for each increment of load. The height of each slice is a measure of capacity, and the width of each slice is a measure of the utilization rate or capacity factor. The product of the two is a measure of electrical energy (e.g. kilowatthours). The problem is to determine which capacity types to assign to each of these slices of load, and what fuels to use in each of these capacity types (in order to represent switching in multi-fuel units).

In the EFD, there are six load curves for each region with each load curve representing two months (see Appendix A for a description of this parameter and the mapping of the seasons). Each load curve contains twenty six vertical slices, categorizing the load by magnitude (height) and time. The EFD dispatches available capacity to meet load in each of these slices. (Note, although the load curve re-orders the load segments, the chronology is maintained to represent maintenance scheduling for capacity and to model economy trade.)

The algorithm used for the dispatch decisions is straightforward. First, a penalty cost for emitting

${ }^{9}$ If load is increasing then the cheapest available source of electricity is brought on-line. Similarly, if demand is decreasing then the most expensive source of electricity currently operating is shut down. 


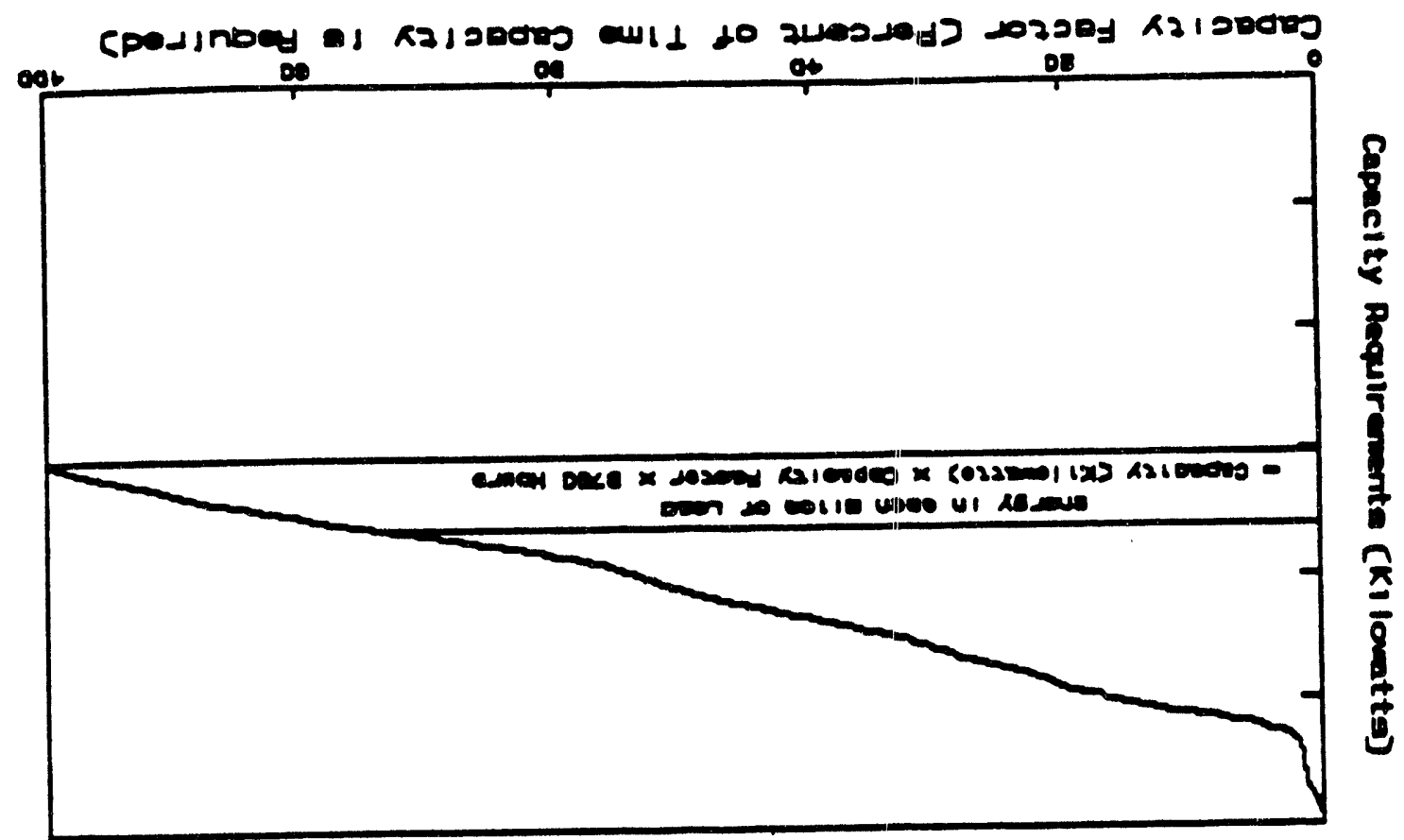

oung uolfesng peof IEo/d

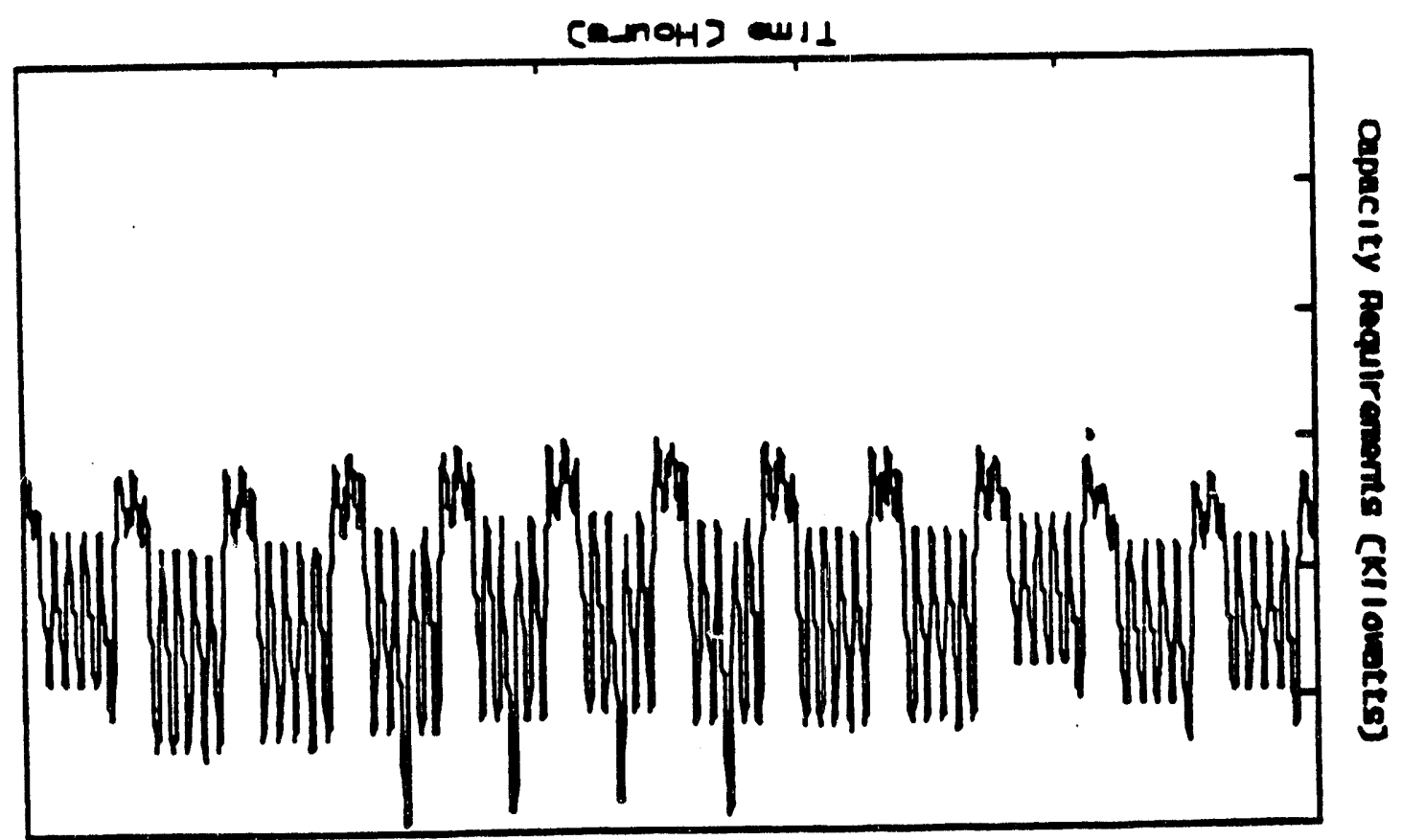

onno peof IEo/dR 'E anBis 
$\mathrm{SO}_{2}$ is added to units which emit $\mathrm{SO}_{2}$ (in the first iteration, the penalty cost is set to zero). Next, capacity to be dispatched is ranked from least to most costly. ${ }^{10}$ Capacity is then allocated under certain considerations/constraints until demand is satisfied (i.e. engineering considerations limit the range of operation for certain capacity types and are incorporated using minimum and maximum capacity factors and the emissions from the dispatch decision need to fall below the limits imposed by the CAAA). Next, generation is determined as the corresponding area for which the capacity has been allocated using a piece-wise, linear approximation to measure this area (Figure 4). This is done for the area under the original load curve as well as for the area under a curve representing excess production that would be available for export and for an area representing generation that could be displaced by cheaper imports. Economy trade is then performed. Fuel consumption and emissions are determined as a function of generation. Last, national $\mathrm{SO}_{2}$ emissions are computed and examined to see if they are within the CAAA limits. The solution to the dispatch algorithm is achieved by iterating this process to find the smallest penalty cost that satisfied the emissions restriction.

\subsection{Fundamental Assumptions}

The fundamental assumptions of the EFD include endogenizing the representation of the Clean Air Act Amendments of 1990 (CAAA) and aggregation issues related to electricity supply and demand.

While the marketable allowance program in the CAAA is economically attractive it is difficult to model. (See Appendix D for a summary of the relevant provisions of the CAAA.) The CAAA does not set plant specific emission rate limits. Rather, the CAAA sets national limits on the emissions of $\mathrm{SO}_{2}$. Utilities are free to choose from a wide array of options to reduce their $\mathrm{SO}_{2}$ emissions to the level of allowances allotted to them. Among the major options available to utilities are switching to the use of lower sulfur fuels, reducing the utilization of their relatively high emission units while increasing the utilization of their low emission units, adding emissions reduction equipment at some generating facilities, purchasing additional allowances from others or purchasing power from utilities in neighboring regions which have lower emissions. Thus, representing utility efforts to minimize their costs of complying with the CAAA involves a complex nationwide analysis.

The EFD includes operating options for reducing emissions, which are based on short-term, operating (fuel and variable O\&M) costs. During dispatching, emissions can be reduced by switching from fuels with "high" emission rates to fuels with "low" emission rates. This includes both intrafuel and interfuel switching. For example, required reductions in $\mathrm{SO}_{2}$ emissions can be accomplished in coal-fired or oil-fired units by using the same fuel type with a lower sulfur content. Another option is to decrease utilization of these fossil-fired units with comparatively high emission rates by increasing the utilization of capacity types that emit little or no $\mathrm{SO}_{2}$ (gas-fired, nuclear, and renewable plants). This 'fuel-switching' option is also available through interregional economy trade; i.e., a utility may lower its emissions by purchasing surplus power from a utility in a neighboring region which has lower emissions.

For each of the 13 electricity supply regions, the EFD also represents trading of $\mathrm{SO}_{2}$ allowances. That is, utilities with relatively low costs of reducing emissions may overcomply (i.e. reduce emissions beyond their required level) and sell their excess allowances to utilities with comparatively high reduction costs. This trading of allowances assumes that the market for allowance trading is 'perfect', i.e. is based only on a cost saving. However there are other factors involved in allowance trading which are not currently incorporated i.e., local pressure for utilities to reduce emissions in place of purchasing allowances. On a national level, allowance trading does not lower total emissions but it reduces the overall cost of achieving the specified emissions target. This emissions trading is represented via a penalty cost function which is discussed briefly in the "Theoretical Approach" oullined previously and in further detail in Appendix B.

\footnotetext{
${ }^{10}$ Note, cogeneration and renewables (excluding hydroelectric) are not currently dispatched in the EFD. Their capacity is removed from the load duration curve prior to the dispatch decision. Likewise, international economy trade is not currently represented in the EFD. It will be incorporated in the decision-making framework in future versions of NEMS.
} 
There are also assumptions regarding both the supply and demand for electricity in the EFD, particularly related to aggregation issues. On the supply side, forced outages are assumed to occur randomly with the amount of capacity that is out-of-service at any given time as the expected value. Also, utilities in each of the 13 electricity supply regions are operated as a "tight" power pool. This aggregation of generating capacity causes the EFD to overoptimized because transmission and other engineering constraints are not represented. Also, intraregional trade can not be incorporated. Also, unit level information is not maintained so projections by unit, utility or State (except New York and California) are not available; i.e., currently, only aggregate results are available (by region and for the Nation). On the demand side, the load duration curve aggregates loads from many utilities to 26 points per season and region. This may not fully represent load variations, however, the aggregation is necessary due to time and resource (particularly computer resources) constraints facing the analysts.

\subsection{Alternative Approaches}

Early in the NEMS development process, models from other organizations were reviewed as possible methodologies for modeling the dispatch decision in NEMS (including trade and nonutility supply). This section outlines the results of this study, including the reasons for not choosing the methodology discussed.

\subsubsection{Modeling the Dispatch Decision}

A Lagrangian approach" is used in the dispatch decision in NEMS. The Lagrangian approach was chosen because of its quick execution time and ability to manage many intervals for approximating the load duration curves. An LP approach was considered, however, LP models require a considerable execution time and storage.

A variety of models that evaluate methods for reducing emissions have been revicwed ${ }^{12}$. These models can be classified into three categories: planning models, site-specific air pollution models, and environmental impact screening models. Several of these models examine environmental issues and regu'ations that are required to be included in the EFD.

Three models use a linear programming methodology to represent acid deposition control. The Electric Power Research Institute (EPRI) uses its Electricity Generation Expansion Analysis System (EGEAS) model to determine the impacts of emissions on air and water quality. ICF Incorporated employs a linear programming approach in two models - the Integrated Planning Model (IPM) and the Coal and Electric Utilities Model (CEUM), which was originally derived from the NCM. Two other systems, Energy Management Associates' PROMOD III and Argonne National Laboratory's Argonne Utility Simulation (ARGUS) model, incorporate emissions limits on pollutants such as $\mathrm{SO}_{2}$ and $\mathrm{NO}_{\mathbf{x}}$ by including an emissions cost in the cost function.

None of these models are integrating systems consisting of a comprehensive set of supply and demand models. In some cases, there is a detailed representation of coal supply but few, if any, linkages to other fuel supply, energy conversion, or end-use demand modules as required for the NEMS. Some of the environmental models are designed to evaluate individual power pools, utilities, and generating units because the absence of detailed representations for other energy markets allows them to concentrate on the electric utility industry. However, the level-of-detail and system resources allocated exceed the corresponding requirements for a single sector within the NEMS so these models cannot be considered candidates for the EFD.

The LP model which was considered for inclusion in the EFD is similar to the EGEAS, IPM, and CEUM models.

\footnotetext{
${ }^{11}$ For a discussion of the Lagrangian approach see Cost and Optimization Engineering, F.C. Jelen, McGraw Hill, 1970, pages $249-261$.

${ }^{12} \mathrm{~A}$ more detailed discussion of environmental models is contained in the draft report Environmental Modeling Review Acid Deposition Control, prepared by the Decision Analysis Corporation and ICF Resources Incorporated, Contract No. DE-AC01-87EI19801, July 31, 1991.
} 
The heuristic procedure chosen uses an emissions penalty cost that resembles the emissions cost used in the PROMOD III and ARGUS models. In order to meet the system requirements for the NEMS, the approach in NEMS needed to be considerably smaller in size and scope than the environmental models reviewed.

\subsubsection{Representation of Trade}

Several electric utility models were examined to determine their potential for analyzing bulk power economy transactions. (See the ECP Documentation for a discussion of methodologies for firm power transactions.) These include:

- $\quad$ Gas Research Institute (GRI); GRI Baseline Projection Methodology

- $\quad$ ICF Resources, Inc.; Electric and Gas Utility Modeling System (EGUMS)

- DRI/McGraw Hill

- U.S. Department of Energy, Office of Policy; FOSSIL2

- $\quad$ Argonne Laboratories; Argonne Utility Simulation Model 1992 (ARGUS92)

- Bonneville Power Authority; Power Market Decision Analysis Model (PMDAM)

- $\quad$ American Gas Institute (AGI).

FOSSIL2, AGI and DRI do not currently model transmission or trade and will not be described further. The following models and utilities have bulk power economy transfer modelling capabilities which were considered for NEMS:

\section{GRI; Baseline Projection Methodology}

GRI represents firm and economy bulk power sales in its Baseline Projection Methodology in a similar fashion as in the EMM. ${ }^{13}$ Firm and economy power sales are determined in the capacity and generation submodels (comparable to the EMM's electricity capacity planning and fuel dispatch submodules) of the Electric Utility Sector Model (comparable to the EMM).

Economy power sales are only represented in the NERC Western Systems Coordinating Council (WSCC) region where bulk power is transferred into Califormia from the other three WSCC subregions. Generation is committed for sale to California after the baseload units have been dispatched, but before the generation at oil- and gas-fired peaking units has been determined.

Interregional transfers of power are priced in two ways. First, an exogenous input price for existing purchase power agreements is used for the known firm interregional transfers. Next, for model determined power purchases, the importing region's avoided cost is used. The regional avoided cost is calculated using the regional variable cost of electricity, regional net interchange cost of supplying electricity, and a regional loss factor.

The methodology to determine interregional transfers is similar to that in the EFD. Both models represent economy sales competing in the dispatch component. However, the EFD represents economy power sales in various regions (instead of just in WSCC) and contains a database summarizing existing and currently planned transactions by electric utilities. The EFD also represents international trade.

$\underline{\text { ICF Resources, Inc.; Electric and Gas Modeling System (EGUMS) }}$

\footnotetext{
${ }^{13}$ Gas Research Institute, 1987 GRI Baseline Projection Methodology, (Chicago, IL, December 1987) and conversations with Paul Holtberg of the Gas Research Institute.
} 
EGUMS, a linear programming model, endogenously represents economy trade. ${ }^{14}$ Eleven regions are represented in the model. These are the North American Electric Reliability Council (NERC) regions, California, and Florida. The model determines supply and demand for electricity on a regional level with the option for demand to be met using electricity supplied from another region, constrained by transmission capacity; i.e., dispatch decisions are made using the least cost plant (and other factors) regardless of where that plant is located so long as the interregional links to carry power have not reached their capacity.

Current and future transmission constraints are determined using NERC publications and discussions with reliability council members. ICF also assumes that the advantage of increased interregional trade does not balance the adritional cost for building new transmission capacity, so expansion to the transmission system (besides that reported in the NERC publications) is not modeled.

EGUMS prices these interregional flows by splitting the difference between the regional marginal variable costs in the regions involved in the trade. There is no representation of transmission costs; only variable generation costs are used in this calculation. This split in the marginal costs is treated as a cost to the receiving region and a revenue to the selling region.

This methodology is similar io the EFD; however, international trade is represented in the EFD while it is not represented in the ICF model. Also, firm power commitments are represented in the ECP while the ICF model does not represent firm power trade at all. Historically, firm power sales and international trade have played a significant role in some regions of the country.

Argonne Laboratories; ARGUS92

The Argonne Utility Simulation Model 1992 (ARGUS92) $^{15}$ does not explicitly model bulk power trade. It is possible to determine intraregional trade in the model by comparing a given State's demand and generation. The difference represents the level of intraregional economy trade for that State.

Interregional trading is represented by exogenous inputs. Historic values between regions are assumed to remain constant. No distinction has been made between firm and non-firm trades.

Bonneville Power Authority; PMDAM

The Bonneville Power Authority (BPA) owns and operates the major transmission lines within the Pacific Northwest and interconnects with utilities in California, the Pacific Northwest and British Columbia. BPA markets wholesale power in the Pacific Northwest. BPA does not own or operate any generating plants but facilitates the development of generating resources through contracts to purchase and market power. To help in BPA's market strategies and long-term power sales decision, the BPA developed the Power Market Decision Analysis Model (PMDAM). ${ }^{16}$

PMDAM simulates the West Coast wholesale power market, representing both the physics of the electric power system and the economics of trade in the West. PMDAM assumes that each utility attempts to find the least-cost plan to serve its native load. Each utility is represented by a distinct objective function, discount rate and environmental preference (i.e. utilities have different environmental standards). The model determines the economics of the system operations on an hourly basis, which is then aggregated to a daily, weekly, monthly and annual solutions.

\footnotetext{
${ }^{14}$ ICF Resources, Incorporated, The EGUMS Supply Model, (Washington, DC).

${ }^{15}$ Argonne National Laboratory, Introduction to the Argonne Utility Simulation (ARGUS) Model, (Argonne, IL, March 1990).

${ }^{16}$ Bonneville Power Administration, The BPA Power Market Decision Analysis Model: Methodology Report, (Portland, OR, July 24, 1991).
} 
As stated, PMDAM's planning objective is to meet firm capacity and energy requirements while minimizing each party's total fixed and variable costs. The model is dimensioned by region (regions are aggregates of the individual utilities on the West coast; a region may be represented by only one utility), time (hourly, daily, monthly, etc.) and uncertainty (hydro inflow, native load, natural gas price and generating unit forced outage). The decision variables are financial, reliability and environmental balances within the electric power system in the West with the electric power system represented by its basic physical elements including the individual loads, generation and transmission systems and power contracts. These physical elements form a system of thousands of nonlinear, simultaneous equations which determine the quantities, costs, prices and opportunity costs of the system operations. The opportunity costs (shadow prices) of each constraint in the model (transmission, hydro operation, firm capacity and energy, etc.) represents the change in a utility's total cost for a unit change in the constraint. The model requires an iterative process because the supply and demand balance among utilities depends on price while the price depends on the cost of supplying power at a given level of demand.

PMDAM models uncertainty using the Monte Carlo method, i.e. the model is run for several "games" with the likelihood of each game equal. For each game, the probability distributions are used to determine levels for each variable.

Although PMDAM models both the physical and economic considerations of transmission and trade, it is too complex and detailed for NEMS. Also, EIA does not have data to support such a detailed model.

\subsubsection{Modeling tha Development of Nonutility Power Projects}

Currently, many forecasting organizations do not explicitly represent IPP and SPP projects in the capacity planning algorithm, rather they use a simplistic market sharing approach to estimate nonutility development. Cogeneration is generally represented in the industrial or commercial sectors. ${ }^{17}$ This methodology is used to forecast IPPs and SPPs because of the lack of project financial and performance data for such facilities. EIA has recently conducted a study to acquire this data from electric utilities, equipment vendors and financial institutions. ${ }^{18}$ This information has been incorporated into NEMS.

An exception to this lack of data is the Applied Energy Services Corporation (AES), a nonutility developer, which uses financial and performance assumptions derived from their own project experience. AES has prepared several different nonutility supply models which vary by application. For the Department of Energy and the Gas Research Institute, AES developed Fossil2 and the Nonutility Generation Simulation Model (NUGSM), respectively. Although some of the detail in the models is different, the overall methodology of the modeling systems is similar. AES also developed models for the Bonneville Power Administration and for individual utilities to forecast nonutility potential in their service areas. A more detailed description of each AES modeling system follows. Because of the similarity between Fossil2 and the Nonutility Generation Simulation Model, the models are described together.

\footnotetext{
${ }^{17}$ Nonutility supply is referred to by various terms depending on the ownership and type of facility. Small power producers (SPP) are facilities as defined under the Public Utility Regulatory Policies Act of 1978 (PURPA) in which renewable sources provide at least 75 percent of the total energy input. Renewable sources include solar, wind, biomass, waste, geothermal and water (hydroelectric). Independent and affiliated power producers are facilities whose primary function is to produce electricity for sale to utilities (i.e., they are not involved in any industrial or other processes).
}

Exempt wholesale generators (EWGs) are functionally the same as IPPs/APPs but with a clear, regulatory definition for the corporate ownership of the projects. Prior to EPACT, competing in the wholesale generation market (under the Public Utility Holding Company Act) was restricted. EPACT reformed PUHCA allowing greater access to the wholesale electricity market without stringent Securities and Exchange Commission oversight.

${ }^{18}$ Deliverable Number 4 under Washington Consulting Group Task 92080, "Evaluation of Differences in Electric Utility versus Nonutility Projects", July 13, 1992. 
In Fossil 2 and NUGSM, ${ }^{19}$ the electricity sector determines new capacity needs based on forecasted load growth. Utility-owned combustion turbines and storage are used to fill peaking requirements. The remaining utility and nonutility teclmologies compete to meet the system's intermediate and baseload requirements. Only IPPS and SPPs compete in the electricity sector, while cogenerators are accounted for in the Industrial Sector.

A logit-based market penetration algorithm determines the nonutility market by comparing the nonutility's levelized costs to the utility's avoided cost for the least-cost baseload technology. Likewise, a least-cost mix of nonutility technologies is then chosen to fill this market share (up to a user-specified cap), with utility technologies filling the remainder of new capacity needs. Avoided cost payments to nonutilities are treated as allowed expenses in the model.

In the Non-Utility Generation Model (NUGM) developed by AES for the Bonneville Power Administration (BPA) nonutility generation is projected as a function of utility avoided costs, industrial electricity prices, and retail electricity prices. ${ }^{20}$ NUGM is a submodule of BPA's Conservation Policy Analysis Model (CPAM) and can also be used as a stand-alone model. Information on the resource potential at industrial facilities in the Northwest used in NUGM is from the report, Assessment of Commercial and Industrial Cogeneration Potential in the Pacific Northwest.

First, the CPAM determines the need for new resources. If a utility has surplus generating capability, CPAM sets the avoided cost to its marginal energy cost. Renewable small power producers are represented in the appropriate renewables submodules.

NUGM allows the utility to either post its avoided cost and see how much nonutility generation evolves in its service area at that price or it can use formal bidding to acquire new resources. Under a posted avoided cost policy, all projects which are economic at less than the avoided cost will be initiated. Under the bidding policy, only the least cost alternatives are accumulated and charged to the utility as purchased power payments. These payments are used in CPAM to calculate utility operating costs and electricity rates.

In addition to AES, the General Electric Company (GE), an equipment developer and servicer for generating units, models nonutility supply in order to determine future orders of generators. ${ }^{21}$ The GE model is composed of several submodels which interact sequentially. These models are: Economic, QF filing, Order, Classification and Installation. The Economic Model involves a yearly evaluation of the economics of eight representative nonutility technologies: five cogeneration technologies, one SPP and two IPPs. The QF Filing Model evaluates qualifying facilities in terms of the magnitudes and relative yearly changes in QF filings for each year (IPPs are not evaluated in this model.) Next, the Order Model performs linear regressions on the minimum yearly payback values for qualifying facilities and on the maximum return on equity for IPPs resulting in estimates of equipment orders. These orders are arranged by application (cogenerators or SPP), location (NERC region) and technology in the Classification Model and evaluated by utility regional capacity needs. The Installation Model forecasts the scheduling of the installation of the equipment orders.

The Data Resources Incorporated (DRI) compete IPPs and qualifying cogenerators with utility units. As in NUGS, the differences between IPP and utility units are reflected in their capital structures. Cogenerators are forecasted based on non-electric production at the facility, the price of natural gas, and avoided cost calculations. SPPs are

\footnotetext{
${ }^{19}$ Prepared by Applied Energy Services for the Department of Energy, The National Energy Strategy Integrating Energy Model - Fossil2 and the Gas Research Institute, Nonutility Generation Simulation Model, Arlington, VA, (October 1991).

${ }^{20}$ Prepared by Applied Energy Services and the University of Southern California under contract to Bonneville Power Administration (Contract number DE-AM799-88BP3721), Dynamic Analysis of Pacific Northwest Non-Utility Power Generation, September 1990.

${ }^{21}$ The General Electric Company, The Non-Utility Generation Market for the 1990's: A Comprehensive Economic Model-Based Forecast, December 1991, (Schenectady, New York).
} 
modeled exogenously. DRI uses Edison Electric Institute data for its historical base. North American Electric Reliability Council (NERC) data are evaluated to estimate viable projects for its planned capacity additions.

The American Gas Association uses a market share approach for IPPs and SPPs and uses the historical relationship between the use of heat, light and power in a facility to estimate generation at projected facilities.

NERC also prepares projections of nonutility development. Each year NERC aggregates the forecasts of its nine Regional Reliability Council's, which are in turn, aggregates of individual utility forecasts. ${ }^{22}$ NERC does not explicitly model the ele:'ric utility industry, it aggregates utilities' resource plans.

The Bechtel Power Corporation forecasts assume that a share of new supply will be met by nonutility supply (approximately 40 percent) based on analyst judgement.

AMOCO also projects nonutility supply to determine fossil-fuel consumption. AMOCO uses EEI data for its historical base and NERC projections for planned additions. AMOCO's nonutility supply forecast is based on historical trends and analyst judgement.

${ }^{22}$ North American Electric Reliability Council, Supply and Demand 1991-2000, July 1991. 


\section{Model Structure}

\subsection{Logic Flow}

Figure 5 is a flow diagram for the EFD. This flow chart includes: major exogenous inputs, inputs from other modules (both NEMS and other submodules of the EMM), and the model outputs and the destination for this information. 
Figure 5 EFD Data Inputs and Outputs
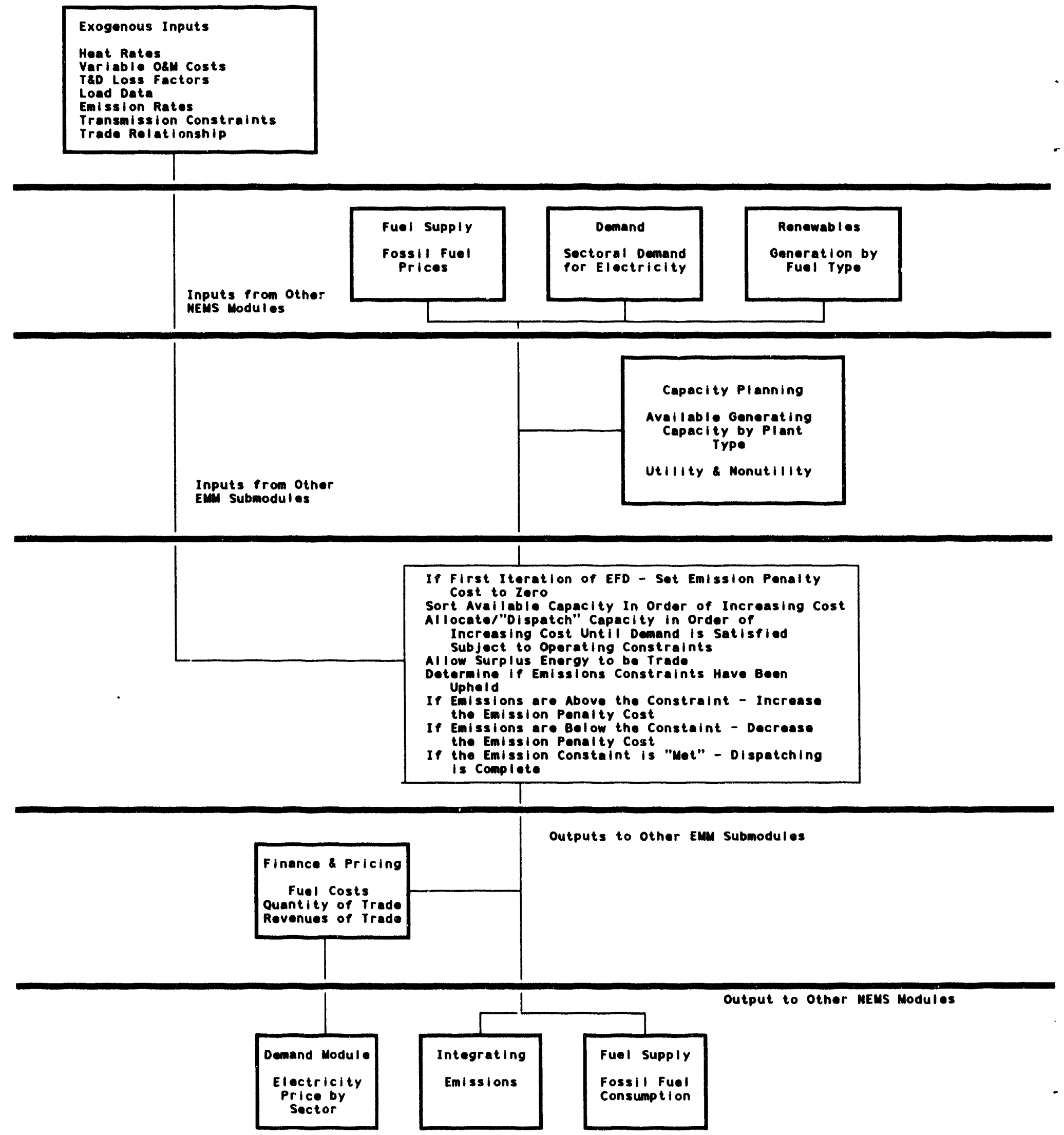


\subsection{Key Computations and Equations}

This section provides the mathematical specification of the EFD. The heuristic approach is a modified version of the dispatching components of the EMM-IFFS. As in IFFS, the EFD continues to rank available capacity in a leastcost manner and to dispatch capacity in this order until demand has been met (subject to certain operating and engineering constraints, discussed in detail in the Solution Technique section). Improvements to the approach include: 1) the endogenous representation of the Clean Air Act Amendments of 1990 (CAAA); 2) the alternative representation of the load duration curve to better represent demand; and 3) the implementation of economy trade.

The objective of the EFD is to provide an economic / environmental dispatching procedure. In an economic (leastcost) dispatch, the marginal source of electricity is selected to react to each change in load. ${ }^{23}$ In environmental dispatching, the demand for electricity must be satisfied without violating certain emissions restrictions. The EFD integrates the cost-minimizing solution with environmental compliance options to produce the least-cost solution that satisfies electricity demand and reduces emissions to specified limits.

Environmental issues incorporated into the NEMS include compliance with $\mathrm{SO}_{2}$ restrictions specified in the CAAA. Strategies for complying with the CAAA that are represented in NEMS include retrofitting existing capacity with pollution control equipment, fuel switching and trading of emissions allowances. These options are a combination of planning and operating decisions. Planning decisions typically involve changes in capital stock and require a longer time horizon and substantial capital investment. They are based on a life-cycle cost analysis that examines the tradeoff between investment and operating costs. Retrofitting existing units with scrubbers is considered a planning operation for reducing emissions of $\mathrm{SO}_{2}$. This decision to install a scrubber, which would allow the use of a lower-cost, higher-sulfur fuel, depends on whether the savings in fuel costs offset the initial capital investment. The results of planning decisions are reflected in the dispatch decision. For example, a coal-fired unit that has been retrofitted with a scrubber because of an earlier planning decision will have a lower emission rate than a coal-fired unit without a scrubber.

The EFD includes operating options for reducing emissions, which are based on short-term, operating (fuel and variable O\&M costs). During dispatching, emissions can be reduced by switching from fuels with "high" emissions rates to fuels with "low" emission rates. This includes both intrafuel and interfuel switching. For example, required reductions in SO2 emissions can be accomplished in coal-fired or oil-fired units by using the same fuel type with a lower sulfur content. Another option is to decrease utilization of these fossil-fired units with comparatively high emission rates by increasing the utilization of capacity types that emit little or not $\mathrm{SO}_{2}$ (gas-fired, nuclear, and renewable plants).

For each of the 13 electricity supply regions, the EFD also represents $\mathrm{SO}_{2}$ allowances. That is, utilities with relatively low costs of reducing emissions may overcomply (i.e., reduce emissions beyond their required level) and sell their excess allowances to utilities with comparatively high reduction costs.

On a national level, allowance trading does not lower total emissions but it reduces the overall cost of achieving the specified emissions target.

The approach to incorporate domestic economy trade into the NEMS is to extend the EFD to include the additional supply option of "dispatching" (i.e. purchasing) capacity in one region to serve a different region's demand. Several extensions to the EFD were made:

- The load representation was modified to preserve additional chronological information to allow for energy purchases from extraregional utilities within physical limits of the transmission system (the requirement was to be able to match the blocks of energy available in the exporting region to the

\footnotetext{
${ }^{23}$ If load is increasing, then the cheapest available source of electricity is brought on-line. Similarly, if demand is decreasing, then the expensive source of electricity currently operating is shut down.
} 
simultaneous need for power in the importing region.) $)^{24}$ This was accomplished with a modified load duration curve which describes the seasonal, day-of-week and time-of-day variations in the demand for electric power,

- The solution algorithm of the EFD was extended to compute the marginal costs associated with the surplus capacity in the exporting region, and to maintain this information to determine the savings from interregional trade. In other words, once the EFD regional utilization of capacity has been determined without allowing interregional trade, then a second stage process is used to refine the economic dispatch taking into consideration the opportunities and constraints associated with interregional trade.

In the EFD, merit ordering of resources to meet demand is simply ranking capacity from the least cost to the most costly and selecting the capacity from the rank ordering necessary to meet each region's demand. In the second stage, the merit ordering of resources is redone for selected importing regions (pre-determined), including the exporting region's surplus capacity in the dispatch decision.

- The initial implementation of interregional trade includes pre-determined importing and exporting regions. The regional dispatch decision processes the exporting regions first, followed by the importing regions, ordered from highest to lowest marginal cost. The EFD then attempts to improve the importing regions solution by substituting capacity from the exporting regions. This approach allows exporting regions to supply power to multiple importing regions by allocating the capacity to the importing region with the highest marginal cost first, and then to other, less costly regions. This approach should both limit the processing burden of representing trade and maintain the information required to measure the savings resulting from trade.;

- limits on total energy available during each demand slice are applied tc restrict trade by the transmission line constraints;

- additional transmission costs and energy losses are assigned to the exported power; and

- once a level of economic transfers has been identified by the EFD, the "savings" are allocated (currently split evenly) between the importing and exporting regions and between consumers and investors.

\subsubsection{Solution Technique}

Figure 1 provides an overview of the steps involved in the dispatch algorithm. Initial operating costs (fuel and operations and maintenance expenses) are accumulated by plant groups. Next, an emissions penalty cost is incurporated into the variable cost used to determine the merit order. The merit order is then determined by raking the groups in ascending order of the total variable costs.

The total cost used to determine the merit order now involves a tradeoff between the operating and emissions costs. Low-sulfur fuels typically have higher fuel prices but have lower emissions costs than high-sulfur fuels. Depending on the size of the $\mathrm{SO}_{2}$ penalty cost, a plant could have a lower total cost using a low-sulfur fuel instead of the lowerpriced high-sulfur fuel. Or, the result could be a repositioning of the merit order since plants that emit little or no $\mathrm{SO}_{2}$ become more economically attractive compared to plants using high-sulfur fuel.

Therefore, the use of a penalty cost can adjust the total level of emissions in either of two ways. It may result in changes in the merit order so that plants consuming high-sulfur fuels are utilized less intensively. Alternatuvely, fuel

\footnotetext{
${ }^{24}$ Note that it is possible for electrical energy to flow in one direction during a season and in the opposite direction during another season.
} 
switching may occur at plants that can use both high- and low-sulfur fuels. In either case, a higher penalty cost lowers the $\mathrm{SO}_{2}$ emissions by finding the least expensive dollar to pound of $\mathrm{SO}_{2}$ tradeoff in the merit order. This approach yields dispatch decisions that provide the lowest operating cost for the resulting sulfur dioxide emission level.

Using this merit-order, available capacity is then allocated to meet demand for electricity represented by the load duration curve. During dispatching, engineering considerations that may limit the range of operation for a given capacity type are incorporated using minimum and maximum capacity factors. For instance, nuclear units are not allowed to operate as peaking capacity because they cannot be started or stopped quickly. The operating range is represented by a set of trigger points that identify the point(s) on the $y$-axis that corresponds to the capacity factor limits. As each plant type in the merit order is allocated, the algorithm checks to insure that the corresponding trigger points are not violated.

When a given plant type has been allocated, the next step is to determine the generation, which is represented by the corresponding area under load duration curve. A piece-wise, linear approximation to the load duration curve is used along with a series of vertical slices so that the area under the curve is represented by a succession of trapezoids. This eases the computational burden for determining the area. For each plant type, fuel consumption is computed by multiplying generation by the fuel share and heat rate for each fuel. Emissions are then determined as the product of fuel consumption and the corresponding emission rate, accounting for any reduction resulting from pollution control equipment. For each Compliance Group, the emissions are then summed over all plant types and regions and compared to the corresponding emissions limit. Total U.S. emissions are determined because the CAAA permits emissions trading nationwide.

The solution to the economic/environmental dispatch problem is achieved by iterating to find the smallest penalty cost that satisfies the emissions restrictions. The penalty cost is set to zero in the first iteration. A zero penalty cost implies that the available generating capacity is allocated on the basis of fuel and $O \& \mathrm{M}$ costs, which represents the basic, least-cost approach. If no emissions constraint exists (e.g. before the CAAA requirements become effective in 1995) the penalty cost is zero. If a constraint is active, the procedure is still initially implemented with a zero penalty cost in order to determine if the restrictions can be met using economic dispatch. At the other extreme, an infinite emissions penalty corresponds to a least-emissions dispatch. This is equivalent to excluding the fuel and O\&M costs when determining the merit order so that plant types are ranked in ascending order of emission rates.

The optimum solution lies between these two extremes. Least-cost dispatching would result in undercompliance and least-emissions dispatching would result in overcompliance. If the emissions resulting from a particular dispatch pattern exceed the specified level then the penalty cost is increased, a revised merit order is computed, and the available capacity is reallocated. If a particular penalty cost results in overshooting the target (i.e. emissions are reduced below the required level) then the penalty cost is relaxed and a new dispatch pattern is determined. Once the emissions target has been bracketed by two solutions (i.e. One penalty cost results in overcompliance and another results in undercompliance), linear interpolation is used to search for the lowest penalty cost such that the actual emissions match the allowable emissions, within a given tolerance.

A particular option for reducing emissions is to lower the total cost in the objective function only if the resulting increase in the operating costs is less than the corresponding decrease in the emissions cost. Thus, the objective function is minimized by including all intrafuel and interfuel switching until the incremental operating cost exceeds the emissions penalty cost. In effect, the penalty cost represents the marginal dispatching cost of reducing emissions to the required level. Further reductions in emissions would increase the objective function in proportion to the penalty cost, which would be lower than the corresponding increase in operating costs. The penalty cost is equivalent to the dual variable of the emissions constraint in the LP formulation, which describes the change in the cost corresponding to a unit change in emissions.

Therefore, the heuristic procedure searches for the most economical methods for reducing emissions to required levels. In doing so, it represents a nationwide allowance trading market. Utilities in some regions can reduce emissions below the amount allocated in the CAAA at a cost that does not exceed the marginal cost. Conversely, utilities in other regions cannot meet their targets in a cost-effective manner. This simulates a market where utilities with comparatively low reduction costs overcomply and sell the extra allowances to utilities with comparatively high 
reduction costs. For each electricity supply region, the difference between the actual emissions and the allowances allocated represents the amount of allowances bought or sold.

Once $\mathrm{SO}_{2}$ compliance has been achieved, the economy trade algorithm is performed. This algorithm includes predetermined importing and exporting regions. It attempts to improve the importing systems solution by substituting less expensive capacity from the exporting systems by allocating the capacity to the importing system with the highest marginal cost first, and then to the other, less costly systems. It does this amongst load slices representing the same season and time-of-day. $\mathrm{SO}_{2}$ compliance is then reached.

The following provides the mathematical specification of the EFD's solution algorithm.

\section{Dimensions $^{25}$}

$\begin{array}{lll}\mathrm{e} & = & \text { EMM electricity supply region providing electricity for sale to another region. } \\ \mathrm{y} & = & \text { Years in the planning horizon } \\ \mathbf{r} & = & \text { EMM electricity supply region } \\ \mathrm{i} & = & \text { Capacity type } \\ \mathbf{f} & = & \text { Fuel choice } \\ \mathrm{h} & = & \text { Vertical load steps which define total electrici } \\ \mathrm{s} & = & \text { Season } \\ \mathrm{g} & = & \text { Sulfur dioxide compliance group }\end{array}$

\section{Decision Variables}
$A_{\text {rib }}=$
Assignment of Plant $i$ in Season $s$ and Region $r$ to Load Slice $h$ (i.e. fraction of load slice h satisfied by plant i)
$\mathrm{M}_{\mathrm{ari}} \quad$ = Average Capacity Out of Service in Season $s$ for Planned Maintenance for Plant $\mathrm{i}$ in Region r (kilowatts)
$\mathrm{S}_{\mathrm{rif}} \quad=\quad$ Fuel Share of Fuel $\mathrm{f}$ for Plant $\mathrm{i}$ in Region $\mathrm{r}$ (fraction)
$\mathrm{EA}_{\text {rieh }}=\quad$ Assignment of plant $i$ in season $s$ and region e to serve load slice $i$ in region $r$ (fraction of load slice $h$ in region $r$ satisfied by plant $i$ in region $e$ )

\section{Input Requirements}

Electricity Demand
$\mathrm{F}_{\mathrm{To}} \quad=$
Demand for Electricity in Region $\mathrm{r}$ and Seasonal Period $\mathrm{s}$ (billion kilowatthours)
$\mathrm{C}_{\mathrm{rab}}=$
Capacity Factor for Load Slice $\mathrm{h}$ in Region $\mathrm{r}$ and Seasonal Period $\mathrm{s}$ (fraction)
$D_{b} \quad=\quad$ Height of Load Slice h (kilowatts)

Thus, Generation Requirements are:

\footnotetext{
${ }^{25}$ The 'e' dimension was the only new dimension added to the EFD to incorporate trade.
} 


\section{$\sum_{s} \int_{h} C_{r a n} * D_{h}=\sum_{s} B_{r e}$}

Fuel Specific Information

$$
\begin{array}{lll}
\mathrm{P}_{\mathrm{rf}} & = & \text { Price of Fuel } \mathrm{f}(\$ \text { per million Btu) } \\
\mathrm{T}_{\mathrm{rf}} & =\quad \text { Quantity of Sulfur Dioxide per Unit of Fuel (pounds per million Btu) }
\end{array}
$$

Plant Specific Information by Capacity Grouping

$$
\begin{aligned}
& \mathrm{L}_{\mathrm{r}}=\mathrm{SO}_{2} \text { Allowances for Plant Type } \mathrm{i} \text { in Region } \mathrm{r} \text { (tons) } \\
& \mathrm{B}_{\mathrm{ri}}=\text { Scrubber Removal Rate for Plant Type } \mathrm{i} \text { in Region } \mathrm{r} \text { (fraction) } \\
& R_{\mathrm{ri}} \quad=\quad \text { Planned Maintenance Requirement for Plant Type i and Region r (kilowatts) } \\
& \mathrm{H}_{\mathrm{if}} \quad=\quad \text { Heat rate for Fuel } \mathrm{f} \text { used in Plant Type } \mathrm{i} \text { and Region } \mathbf{r} \text { (Btu per kilowathour) } \\
& \mathrm{X}_{\mathrm{rif}}=\text { Maximum Allowable Fuel Share for Fuel } \mathrm{f} \text { in Plant Type } \mathrm{i} \text { and Region } \mathbf{r} \text { (fraction) } \\
& \mathrm{O}_{\mathrm{rif}} \quad=\quad \text { Variable Operations and Maintenance Cost using Fuel } \mathrm{f} \text { in Plant Type } \mathrm{i} \text { and Region } \mathrm{r} \\
& \text { (mills per kilowatthour) }
\end{aligned}
$$

Transmission Specific Information

$$
\begin{aligned}
& \mathrm{EJ}_{\mathrm{re}}=\quad \begin{array}{l}
\text { Transmission and Distribution loss factor for energy transmitted from region e to region } \\
\mathrm{r} \text { (fraction) }
\end{array} \\
& \mathrm{EK}_{\mathrm{ric}}=\quad \begin{array}{l}
\text { Total derated capacity (i.e. accounting for forced outages and transmission and reliability } \\
\text { losses) of plant type } \mathrm{i} \text { in region } \mathrm{e} \text { to serve load in region } \mathrm{r} \text { (kilowatts) }
\end{array}
\end{aligned}
$$

\section{Objective Function}

The objective function for the merit-order dispatching algorithm minimizes total operating (fuel and variable O\&M costs by first deciding the least-cost fuel mix for each plant and then deciding which plant type(s) to assign to each slice of load. After the initial capacity allocation, plants are flagged as surplus to a region and are allowed to be dispatched by another region. In mathematical terms, the objective function for the purchasing region is:

$$
\begin{aligned}
& \text { Minimize } \\
& \Sigma_{i} \Sigma_{1} \int_{\mathrm{b}} \Sigma_{i}\left[\left\{\operatorname{Min} \Sigma_{\mathrm{f}}\left(\mathrm{O}_{\mathrm{rif}}+\mathrm{H}_{\mathrm{rif}} \cdot \mathrm{S}_{\mathrm{rif}} \cdot \mathrm{P}_{\mathrm{rf}} / 1000+\mathrm{EC}_{\mathrm{rif}}\right)\right] \cdot \mathrm{A}_{\mathrm{rih}}\right] \cdot \mathrm{C}_{\mathrm{rab}} \cdot \mathrm{D}_{\mathrm{h}} \cdot \\
& +\sum_{i} \Sigma_{\mathrm{i}} \int_{\mathrm{h}} \Sigma_{\mathrm{i}}\left[\left\{\operatorname{Min} \Sigma_{\mathrm{i}}\left(\mathrm{O}_{\mathrm{rif}}+\mathrm{H}_{\mathrm{rif}} \cdot \mathrm{S}_{\mathrm{rif}} \cdot \mathrm{P}_{\mathrm{r}} / 1000+\mathrm{EC}_{\mathrm{rif}}\right)\right\} \cdot \mathrm{EA}_{\mathrm{rib}}\right] \cdot \mathrm{C}_{\mathrm{rah}} \cdot \mathrm{D}_{\mathrm{b}} \text {. }
\end{aligned}
$$

In this equation, the quantity $\left(\mathrm{O}_{\mathrm{rif}}+\mathrm{H}_{\mathrm{rif}} \cdot \mathrm{S}_{\mathrm{rif}} \cdot \mathrm{P}_{\mathrm{r}} / 1000\right)$ represents the variable $\mathrm{O} \& \mathrm{M}$ and fuel costs (dollars per thousand kilowatthours) for a particular plant type $\mathrm{i}$ in region $\mathrm{r}$; (likewise for plants in region e, which are generating electricity for sale to utilities in region $r$ ). The fuel shares $S_{\text {rif }}$ specify the fraction of time alternative fuels are used in multi-fuel units. This accounts for fuel switching due to changes in the relative fuel prices or seasonal availability of fuels. For example, utility consumption of natural gas is limited in some regions during the winter because residential customers have priority over available supplies. Even though the price of gas may be less than the price of residual fuel oil, utilities may be unable to burn gas exclusively in dual-fired oil/gas plants. The variable cost is 
minimized by using the least expensive fuel as much as possible.

Multiplying per unit variable costs by $\mathrm{A}_{\text {trin }}$ produces a weighted-average operating cost, which is then multiplied by $C_{r b h} * D_{b}$, which corresponds to the area (energy) for load slice $h$. This result represents the total cost of generations for that slice. Within each region and season, the operating costs are then summed over all capacity types and slices under the load duration curve to produce the total operating cost associated with the energy requirement.

\section{Right Hand Side Values}

ETL $_{\text {yre }} \quad=\quad$ Transmission capacity limits from region $\mathrm{e}$ to region $\mathrm{r}$ in year $\mathrm{y}$ (megawatts).

Existing and planned transmission capacity limits are placed on the trade decision variables (using NERC data). These constraints may be relaxed in the future if transmission modeling is inconprated.

\section{Constraints}

The objective function is subject to the following conditions and constraints:

1) Planned maintenance must be performed for each plant type.

$$
\Sigma_{\mathrm{r}} \mathrm{M}_{\mathrm{min}} \geq \mathrm{R}_{\mathrm{ri}} \quad \forall \mathrm{r} \text { and } \mathrm{i}
$$

2) Allocated capacity cannot exceed available capacity, accounting for planned maintenance.

$$
\left.\int_{b} A_{\text {raib }}\right) \cdot D_{b}+M_{a r i} \leq K_{r i} \quad \forall r, s \text { and } \mathrm{i}
$$

3) Maximum fuel shares for multifuel plant types cannot be exceeded.

$$
\mathrm{S}_{\mathrm{rif}} \leq \mathrm{X}_{\mathrm{rif}} \quad \forall \mathrm{r}, \mathrm{s} \text { and } \mathrm{i}
$$

4) Each plant type consumes fuel to produce electricity and the fuel shares must sum to one.

$$
\Sigma_{\mathrm{f}} \mathrm{S}_{\mathrm{rif}}=1 \quad \forall \mathrm{r} \text { and } \mathrm{i}
$$

5) Generation requirements must include transmission and distribution losses

$$
\left.\int_{\mathrm{b}} \mathrm{C}_{\mathrm{rat}}\right) \cdot \mathrm{D}_{\mathrm{b}}=\mathrm{E}_{\mathrm{ts}} /\left(1-\mathrm{J}_{\mathrm{t}}\right)
$$

The representation of emissions restrictions, such as those specified for $\mathrm{SO}_{2}$ in the CAAA, required an additional set of constraints.

6) Emissions cannot exceed allowable limits placed on $\mathrm{SO}_{2}$ emissions. According to the CAAA, there are two classes of compliance groups - "affected" and "unaffected" units. Affected units are allocated allowances or permits to emit $\mathrm{SO}_{2}$. Since allowances can be traded among affected units, the CAAA implies that the collective emissions from all affected units cannot exceed the sum of allowances. Unaffected units are not required to reduce emissions so the limit is assumed to be the sum of their current emissions.

For each fuel $\mathrm{f}$, the quantity $\left(\mathrm{H}_{\mathrm{rif}} * \mathrm{~S}_{\mathrm{rif}} * \mathrm{~T}_{\mathrm{rf}} / 2 *\left(1-\mathrm{B}_{\mathrm{ri}}\right)\right)$ describes the $\mathrm{SO}_{2}$ emission rate, accounting for the conversion from pounds to tons and reductions due to pollution control equipment. It is summed over the applicable fuels to provide the total tons of $\mathrm{SO}_{2}$ per billion kilowatthour emitted by plant type i. The corresponding generation is given by $\left(A_{t i n} * C_{r b h} * D_{b}\right)$. The product of these two results summed over all plants within a Compliance Group gives the total emissions for that Group. 
This objective function is subject to the following transmission related conditions and constraints:

7) Each load slice must have capacity assigned to completely satisfy its energy requirements. That is, a region's energy requirement is met by the amount of domestic capacity assigned to meet load plus the amount of energy assigned for sale to region $r$ from region $e$.

$\Sigma_{i}\left(\mathrm{~A}_{\text {rib }}+\mathrm{EA}_{\text {rech }}\right)=1 \quad \forall \mathrm{r}, \mathrm{e}, \mathrm{s}$ and $\mathrm{h}$

and, in the exporting region e, its energy requirements is completely satisfied by the amount it assigned to meet demand less the amount assigned for sale to another region $r$.

$\Sigma_{\mathrm{i}}\left(\mathrm{A}_{\text {eaih }}-\mathrm{EA}_{\text {tree }}\right)=1 \quad \forall \mathrm{r}, \mathrm{e}, \mathrm{s}$ and $\mathrm{h}$

8) Transmission constraint

The amount of capacity that can be assigned in region e to meet demand in region $r$ is constrained by the interregional transmission capacity limit.

$\int_{\mathrm{h}} \Sigma_{\mathrm{i}}\left(\mathrm{EA}_{\mathrm{rich}}\right) \cdot \Sigma_{\mathrm{i}} \mathrm{EK}_{\mathrm{rie}} \leq \mathrm{ETL}_{\mathrm{yre}} \quad \forall \mathrm{r}, \mathrm{e}, \mathrm{s}$ and $\mathrm{h}$ 


\section{Appendix A}

This appendix contains a detailed description of the inputs, outputs and 'working' files of the Electricity Fuel Dispatch Submodule (EFD). An overview of the model inputs and outputs is provided in the body of the report, under the title, "Model Input and Output". The Model Input and Output section also has a listing (Table 2) of the files and common blocks which contain the data needed for the EFD. The following section describes these files in detail.

This appendix is organized as follows: First, the common blocks which contain the parameters used in the model are described (Tables A-1 and A-2), followed by a mapping of the parameter values which pertain to the EFD. Next, two control files are provided (Tables A-3 and A-4) which include the switches which turn modules and/or algorithms on or off and additional parameters. The exogenous model input section follows which contains the files and common blocks (Table A-5 through A-17) which serve as input to the EFD. Two of these files also serve as "working" files (LOADDAF/Table A-5, PLANTDAF/ Table A-6) where information is also passed from other modules or where results are saved. Tables A-18 through A-20 outline inputs from other NEMS modules. Tables A-21 through A-25 are output/work files which serve as input to other modules and/or are used for reporting purposes.

Note, in files and common blocks which are used by various modules, only the variables used in the EFD are described in detailed. The EFD variables are in bold when applicable.

\section{A.1 Model Parameters}

TABLE A-1: EMM\$PARM Common DESCRIPTION

\begin{tabular}{|c|c|c|c|c|}
\hline Field & $\underline{\text { Units }}$ & Variable & $\underline{\text { Value }}$ & Source \\
\hline ax. Number 0 & umeric & EFD\$MVS & 60 & \\
\hline umber of Seasonal Periods & Numeric & EFD\$MSP & 6 & Assumption \\
\hline Imber of Renewable Types & Numeric & EFD\$RNW & 8 & Assumption \\
\hline of Dispatchable Capacity Types & Numeric & EFDSDSP & 16 & Assumption \\
\hline umber of ECP Fuels per Plant & Numeric & EFD\$FPP & 4 & Assumption \\
\hline Imber of Plant Groups & Numeric & EFD\$MPG & 300 & Assumption \\
\hline imum Number of Trade Groups & Numeric & EFD\$MTG & 30 & Assumption \\
\hline Records in Constraints File & Numeric & EFD\$RECS & 200 & Assumption \\
\hline umber of Renewable Groups & Numeric & EFD\$MHG & 120 & Assumption \\
\hline umber of Horizontal Slices & Numeric & EFD\$MHS & EFD\$MPG & Assumption \\
\hline umber of SO2 Compliance Groups & Numeric & EFD\$SO2 & 2 & Assumption \\
\hline umber of Boiler Types & Numeric & EFD\$BTP & $\mathbf{6}$ & Assumption \\
\hline Ipply/Reporting Regions per Fuel & Numeric & EFDSFRG & 3 & Assumption \\
\hline ompliance Groups per Plant Group & Numeric & EFD\$CGP & 1 & Assumption \\
\hline wnership Type & Numeric & EFD\$OWN & 3 & Assumption \\
\hline umber of Fuel Types & Numeric & EFD\$NFL & 20 & Assumption \\
\hline lumber of Building Blocks/Season & Numeric & EFD\$LDG & 6 & Assumption \\
\hline otal Plant types DSP and RNW & Numeric & EFD\$CAP & 24 & Assumption \\
\hline Iax \# Regions for any Fuel Type & Numeric & EFD\$MFRG & 24 & Assumption \\
\hline Vintage $(1=$ Existing, $2=$ Pipeline, $3=N$ & Numeric & EFD\$VIN & 3 & Assumption \\
\hline eason/Time of Day Groups & Numeric & ELD\$DAY & 18 & Assumption \\
\hline in each Ssn/Time o & Numeric & ELD\$HRS & 32 & nption \\
\hline- & Numeric & TP & 9 & iption \\
\hline ECP Max Steps per Group & Jumeric & ECP\$SSZ & 5 & Assumption \\
\hline
\end{tabular}


ECP Seasons Periods

ECP \# Building Blocks/Season

ECP Number of Vertical Load Slices

Length of Explicit Planning Horizon

Length of Full Planning Horizon

ECP \# of Dispatchable Capacity Types

ECP \# of Intermittent Capacity Types

ECP \# of Other Renew. Capacity Types

ECP \# of DSM Program Types

ECP Length DSM Investment Profile

ECP \# of Clusters-Retrofit Candidates

ECP \# of Plant Groups/Retrofit Group

ECP \# of Fuel Types

ECP \# Fuels per Plant

ECP Longest Construction Profile

ECP Total Plant DSP, INT, and RNW

Ownersilip Type(1=Util,2=NonUtil)

\# of Canadian Imp. Spply Crv Steps

\# Coef for Coal Price Expectations

Vintage $(1=1990,2=1989 . . .34=1955)$

Ownership Type (1=Private, 2=Public)

Financial PI Types DSP,INT, and RNW

Max Number of Plant Records

Max Number of Plant Regions

Max Number of Groups per Region

$\begin{array}{lll}\text { Numeric } & \text { ECP\$MSP } & 3 \\ \text { Numeric } & \text { ECP\$LDG } & 6 \\ \text { Numeric } & \text { ECP\$VLS } & 22 \\ \text { Numeric } & \text { ECP\$XPH } & 6 \\ \text { Numeric } & \text { ECP\$FPH } & 30 \\ \text { Numeric } & \text { ECP\$DSP } & 17 \\ \text { Numeric } & \text { ECP\$INT } & 2 \\ \text { Numeric } & \text { ECP\$RNW } & 5 \\ \text { Numeric } & \text { ECP\$DSM } & 12 \\ \text { Numeric } & \text { ECP\$LINV } & 10 \\ \text { Numeric } & \text { ECP\$SCR } & 1 \\ \text { Numeric } & \text { ECP\$SGP } & 130 \\ \text { Numeric } & \text { ECP\$NFL } & 20 \\ \text { Numeric } & \text { ECP\$FPP } & 4 \\ \text { Numeric } & \text { ECP\$LCP } & 10 \\ \text { Numeric } & \text { ECP\$CAP } & 24 \\ \text { Numeric } & \text { ECP\$OWN } & 2 \\ \text { Numeric } & \text { ECP\$CIS } & 2 \\ \text { Numeric } & \text { ECP\$NCC } & 5 \\ \text { Numeric } & \text { EFP\$VIN } & 34 \\ \text { Numeric } & \text { EFP\$OWN } & 2 \\ \text { Numeric } & \text { EFP\$CAP } & 12 \\ \text { Numeric } & \text { WPLT\$REC } & 20000 \\ \text { Numeric } & \text { WPLT\$RGN } & 20 \\ \text { Numeric } & \text { WPLT\$GRP } & 400\end{array}$

Assumption

Assumption

Assumption

Assumption

Assumption

Assumption

Assumption

Assumption

Assumption

Assumption

Assumption

Assumption

Assumption

Assumption

Assumption

Assumption

Assumption

Assumption

Assumption

Assumption

Assumption

Assumption

Assumption

Assumption

Assumption

Notes: Common $=$ CN6005.PRJ.NEMS.COMMON.PDS.datekey $(E M M \$ P A R M)$

TABLE A-2: PARAMETR Common DESCRIPTION

\begin{tabular}{|c|c|c|c|c|}
\hline Field & Units & Variable & Value & Source \\
\hline$(1990-2015,2020$ & eric & MNUMYR & 29 & ssumption \\
\hline ensus Regions $(9+C A+U S)$ & Numeric & MNUMCR & 11 & Assumption \\
\hline PADD Regions (5 + US) & Numeric & MNUMPR & 6 & Assumption \\
\hline $\begin{array}{l}\text { Oil \& Gas (OGSM) Regions } \\
(6 \text { onshore }+3 \text { offshore }+3 \text { Alaska }+ \text { US) }\end{array}$ & Numeric & MNUMOR & 13 & Assumption \\
\hline $\begin{array}{l}\text { Number of NG Border Crossings } \\
\text { (Canada-6, Mexico-3, Japan, LNG(MA,MD }\end{array}$ & $\begin{array}{l}\text { Numeric } \\
, G A, L A)\end{array}$ & $\begin{array}{l}\text { MNUMBX } \\
\text { Can Tot, Mex }\end{array}$ & $\begin{array}{l}18 \\
\mathrm{ot}, \mathrm{LNG}\end{array}$ & $\begin{array}{l}\text { Assumption } \\
\text { Tot. Total) }\end{array}$ \\
\hline $\begin{array}{l}\text { NGTDM Regions } \\
(9 \text { Census }+3 \text { West }+A L+H W+\text { US })\end{array}$ & Numeric & MNUMGR & 15 & Assumption \\
\hline Coal Export Regions $(10+$ US $)$ & Numeric & MNUMXR & 11 & Assumption \\
\hline Coal Supply Regions (16 + US) & Numeric & MNUMLR & 17 & Assumption \\
\hline Coal Demand Regions & Numeric & NDREG & 23 & Assumption \\
\hline NEMS Regions $(13+A L+H W+U S)$ & Numeric & MNUMNR & 16 & Assumption \\
\hline Mfg: number of SIC's & Numeric & MNSICM & 40 & Assumption \\
\hline Non-mfg: number of SIC's & Numeric & MNSICNM & 12 & Assumption \\
\hline Oil \& Gas Categories & Numeric & MNOGCAT & 12 & Assumption \\
\hline (EOR + Convential + Tar S & + Syn Gas & from Liq\&Co & + Oth & Supplemental Gas) \\
\hline (EOR+Conventional+Offshr+AK+US) & Numeric & MNOGCRO & 5 & Assumption \\
\hline Coal Types Numeric & MNCLTY & & 16 & Assumption \\
\hline $\begin{array}{l}\text { Grades of Crude Oil } \\
\text { (3 API gravity }+2 \text { Sulfur) }\end{array}$ & Numeric & MNGRADR & 5 & Assumption \\
\hline
\end{tabular}




\begin{tabular}{|c|c|c|c|c|}
\hline $\begin{array}{l}\text { Number of DSM Residential Programs } \\
\text { \# of DSM Commercial Programs } \\
\text { Air Pollutants }\end{array}$ & $\begin{array}{l}\text { Numeric } \\
\text { Numeric } \\
\text { Numeric }\end{array}$ & $\begin{array}{l}\text { MNDSMPRS } \\
\text { MNDSMPCM } \\
\text { MNPOLLUT }\end{array}$ & $\begin{array}{l}10 \\
10 \\
8\end{array}$ & $\begin{array}{l}\text { Assumption } \\
\text { Assumption } \\
\text { Assumption }\end{array}$ \\
\hline$(\mathrm{C}, \mathrm{CO}, \mathrm{CO2}, \mathrm{SOx}, \mathrm{NOx}, \mathrm{VOC}, \mathrm{CH} 4$ & ART) & & & \\
\hline $\begin{array}{l}\text { Number of Manufacturing Types } \\
(1=\text { Nat, } 2-8=\text { Non-Mfg, } 9-29=\mathrm{Mfg})\end{array}$ & Numeric & MNFTYPE & 29 & Assumption \\
\hline $\begin{array}{l}\text { Number of Expectation Years } \\
(1990-2015,2016-2066)\end{array}$ & Numeric & MNXYR & 66 & Assumption \\
\hline $\begin{array}{l}\text { Number of Fuel Types } \\
\text { (Oil, Natural Gas, MCL, Scl, Ren, Al) }\end{array}$ & Numeric & FLTYPE & 6 & Assumption \\
\hline Emissions of Ethanol (5 Volume Steps) & Nur & MNE & 5 & ption \\
\hline Emissions (Corn \& Biomass) & $\mathrm{Nu}$ & MNCROP & 2 & Assumption \\
\hline Number of Historical SEDS Years & Numeric & MSEDYR & 2 & Assumption \\
\hline
\end{tabular}

Notes: $\quad$ Common $=$ CN6005.PRJ.NEMS.COMMON.PDS.datekey $($ PARAMETR $)$

\section{EMMSPARM common block - parameter definitions}

EFD\$MVS - 60 vertical slices (max), based on seasons and time

EFD\$MSP - Seasonal Periods

$\begin{array}{ll}1 & \text { January and February } \\ 2 & \text { December and March } \\ 3 & \text { May and April } \\ 4 & \text { June and September } \\ 5 & \text { July and August } \\ 6 & \text { November and October }\end{array}$

EFD\$RNW - Number of Renewable Types

$\begin{array}{ll}1 & \text { Conventional Hydroelectric } \\ 2 & \text { Hydro Pipeline } \\ 3 & \text { Hydro Reversible } \\ 4 & \text { Geothermal } \\ 5 & \text { Municipal Solid Waste } \\ 6 & \text { Wood/Biomass } \\ 7 & \text { Solar } \\ 8 & \text { Wind }\end{array}$

EFD\$DSP - Dispatchable Plant Type

$\begin{array}{ll}1 & \text { Bituminous } \\ 2 & \text { Bituminous/Subbituminous } \\ 3 & \text { Subbituminous } \\ 4 & \text { Subbituminous/Lignite } \\ 5 & \text { Lignite } \\ 6 & \text { Oil Steam } \\ 7 & \text { Oil/Gas Steam } \\ 8 & \text { Gas Steam } \\ 9 & \text { Oil Turbine } \\ 10 & \text { Oil/Gas Turbine } \\ 11 & \text { Gas Turbines }\end{array}$


12 Oil Combined Cycle

13 Oil/Gas Combined Cycle

14 Gas Combined Cycle

15 Nuclear BW

16 Nuclear PW

EFD\$FPP $=$ Number of Fuels Per Plant

1 = Primary Fuel

$2=$ Secondary Fuel

$3=$ Third Choice Fuel

4 = Fourth Choice

EFD\$MPG - Not Currently Used in the EFD

ETT\$MTG - Not Currently Used in the EFD

ETTSRECS - Maximum Number of Constraints in File

EFD\$MHG - Not Currently Used in the EFD

EFD\$MHS - Number of Horizontal Slices

EFD\$SO2 - Number of SO2 Compliance Groups

$1=$ Phase I Compliance

2 = Phase II Compliance

EFD\$BTP - Not Currently Used in the EFD

EFD\$FRG - Not Currently Used in the EFD

EFD\$CGP - Not Currently Used in the EFD

EFD\$OWN - Ownership Type

1 = Public

2 = Private

3 = Exempt Wholesale Generator

EFD\$NFL = Fuel Types

Note: Coal Categories are defined as follows:

\begin{tabular}{ll} 
Coal Category & $\mathrm{SO}_{2}$ Emission Level \\
\cline { 2 - 3 } Low & $0.00 \leq \mathrm{SO}_{2} \leq 0.80$ \\
Medium & $0.80<\mathrm{SO}_{2} \leq 1.20$ \\
High & $1.20<\mathrm{SO}_{2} \leq 2.50$ \\
Very High & $\mathrm{SO}_{2}>2.50$
\end{tabular}

$1=$ UILL = Low Sulfur Lignite Coal

$2=$ UILM $=$ Medium Sulfur Lignite Coal

$3=$ UILH $=$ High Sulfur Lignite Coal 


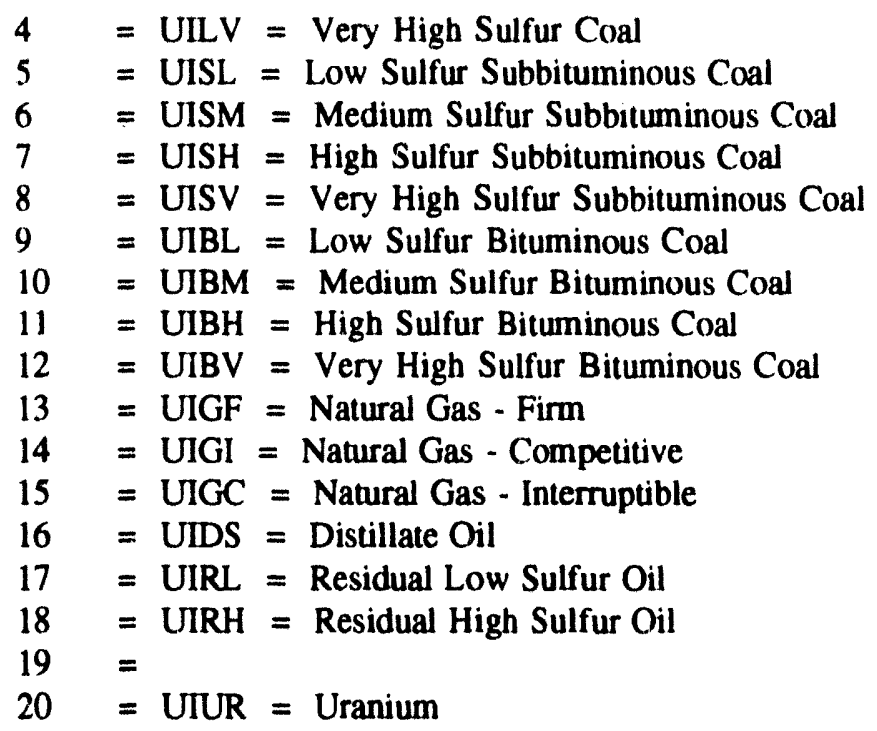

EFD\$CAP = Plant Types - EFD\$DSP + EFD\$RNW (with EFD\$RNW indexing beginning at 17; i.e. there are 24 EFD\$CAP types with 1-16 the sarne as EFD\$DSP)

EFD\$VIN - Plant Vintage

1 Existing

2 Planned

3 Unplanned

PARAMETR common block - parameter definitions

Note: See the Integrating Module Documentation for a description of the regions used by each module. The following parameter descriptions only gives a listing of the region's names.

\begin{tabular}{|c|c|c|}
\hline \multicolumn{3}{|c|}{ MNUMNR = Years $(1990-2015,2020,2025,2030$} \\
\hline \multicolumn{3}{|c|}{ MNUMCR = Census divisions - Demand Regions } \\
\hline 1 & $=$ & New England \\
\hline 2 & $=$ & Middle Atlantic \\
\hline 3 & $=$ & East North Central \\
\hline 4 & $=$ & West North Central \\
\hline 5 & $=$ & South Atlantic \\
\hline 6 & $=$ & East South Central \\
\hline 7 & $=$ & West South Central \\
\hline 8 & $=$ & Mountain \\
\hline 9 & $=$ & Pacific \\
\hline 10 & $=$ & California \\
\hline 11 & $=$ & U.S. Total \\
\hline
\end{tabular}

PADD Regions

$\begin{array}{lll}1 & = & \text { PADD I } \\ 2 & = & \text { PADD II } \\ 3 & = & \text { PADD III } \\ 4 & = & \text { PADD IV }\end{array}$




$$
\begin{aligned}
& 5=\text { PADD V } \\
& 6=\text { PADD VI }
\end{aligned}
$$

MNUMOR - Oil and Gas Regions

$\begin{array}{lll}1 & = & \text { Northeast } \\ 2 & = & \text { Gulf Cost (excluding South Louisiana) } \\ 3 & = & \text { South Louisiana } \\ 4 & = & \text { Midcontinent } \\ 5 & = & \text { Southwest } \\ 6 & = & \text { West Coast } \\ 7 & = & \text { Rocky Mountain } \\ 8 & = & \text { Pacific } \\ 9 & = & \text { Gulf of Mexico } \\ 10 & = & \text { Atlantic } \\ 11 & = & \text { Onshore North Slope Alaska } \\ 12 & = & \text { Off Shore North Slop Alaska } \\ 13 & = & \text { Other Alaska }\end{array}$

NDREG - Coal Demand Regions (Census/NERC region)

$\begin{array}{lll}1 & = & \text { New England/NE } \\ 2 & = & \text { Middle Atlantic/NY } \\ 3 & = & \text { Middle Atlantic/ECAR } \\ 4 & = & \text { Middle Atlantic/MAAC } \\ 5 & = & \text { South Atlantic/ECAR } \\ 6 & = & \text { South Atlantic/MAAC } \\ 7 & = & \text { South Atlantic/STV } \\ 8 & = & \text { South Atlantic/FL } \\ 9 & = & \text { East North Central/ECAR } \\ 10 & = & \text { East North Central/MAIN } \\ 11 & = & \text { East South Central/ECAR } \\ 12 & =\text { East South Central/STV/SPP } \\ 13 & =\text { West North Central/MAPP/RA } \\ 14 & =\text { West North Central/MAIN } \\ 15 & =\text { West North Central/SPP } \\ 16 & =\text { West South Central/SPP } \\ 17 & =\text { West South Centra//ERCOT/RA } \\ 18 & =\text { Mountain/NWP } \\ 19 & =\text { Mountain/RA/SPP } \\ 20 & =\text { Mountain/CNV } \\ 21 & =\text { Pacific/ASCC } \\ 22 & =\text { Pacific/NWP/CNV } \\ 23 & =\text { Total }\end{array}$

MNUMNR - NEMS Electricity Supply Regions

$1=$ ECAR - East Central Area Reliability Coordination Agreement

$2=$ ERCOT - Electric Reliability Council of Texas

$3=$ MAAC - Mid-Atlantic Area Council

$4=$ MAIN - Mid-America Interconnected Network

$5=$ MAPP - Mid-Continent Area Power Pool

$6=$ NPCC/NE - Northeast Power Coordinating Council/New England

$7=$ NPCC/NY - Northeast Power Coordinating Council/New York

$8=$ SERC/STV - Southeastern Electric Reliability Council/excluding Florida 


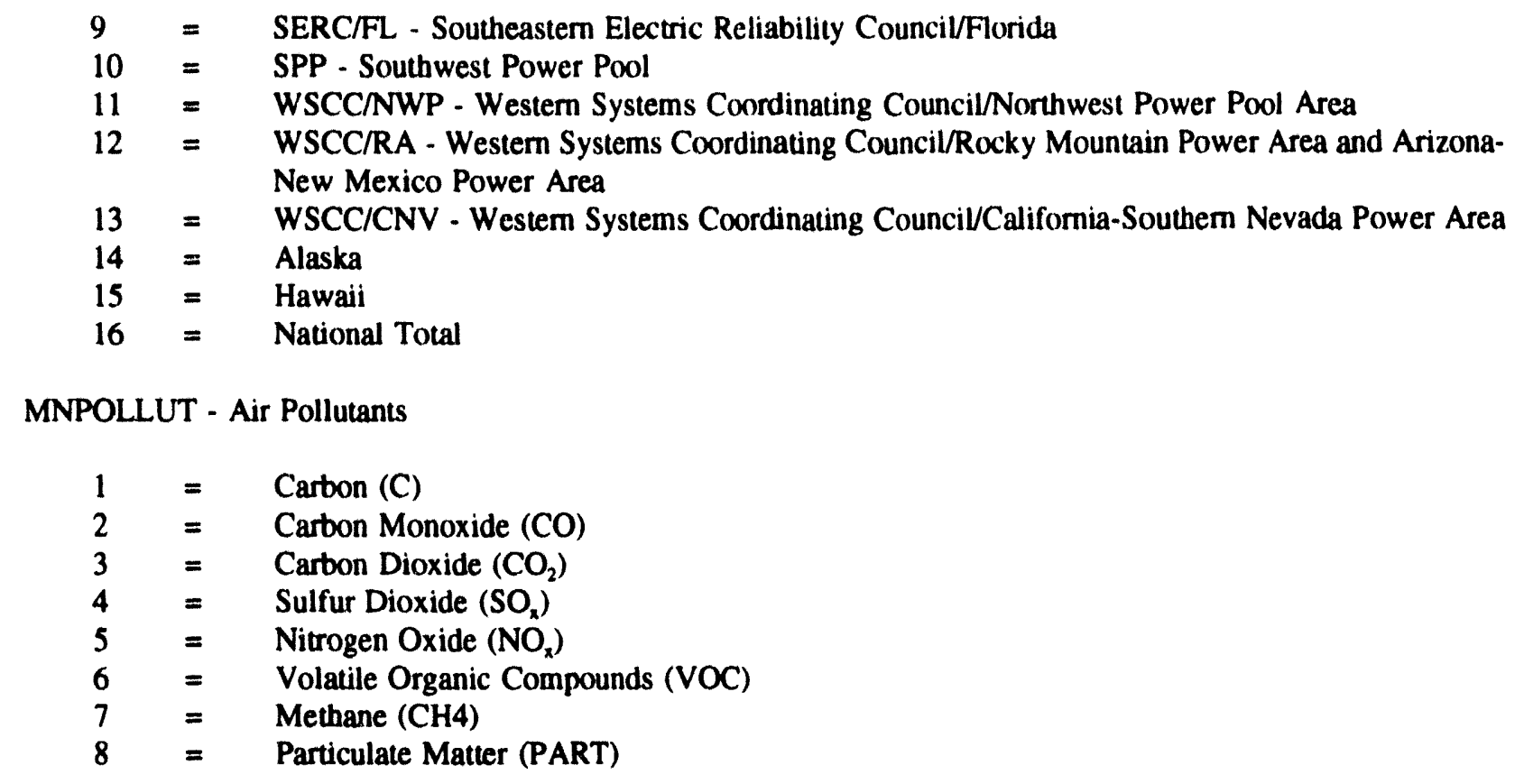

\section{A.2 Control Files}

TABLE A-3: ECPSCNTL Common DESCRIPTION

\begin{tabular}{|c|c|c|}
\hline Field & Units & Variable Name \\
\hline Technical Opt. - Disp. Capacity & GW & UPDOPT(DSP) \\
\hline Technical Opt. - Int. Capacity & GW & UPIOPT(INT) \\
\hline Technical Opt. - Ren. Capacity & GW & UPROPT(RNW) \\
\hline Learning Curve - Disp. Capacity & GW & UPDLC(DSP) \\
\hline Learning Curve - Int. Capacity & GW & UPILC(INT) \\
\hline Learning Curve - Ren. Capacity & GW & UPRLC(RNW) \\
\hline GNP Def.'s & Numeric & UPGNPD(MNUMYR+ECPSXPH) \\
\hline Real Cap Cost Def. - Disp. Capacity & GW & UPPCAPD(MNUMYR+ECP\$XP,DSP) \\
\hline Real Cap Cost Def. - Int. Capacity & GW & UPICAPD(MNUMYR+ECP\$XPH,INT) \\
\hline Real Cap Cost Def. - Ren. Capacity & GW & UPRCAPD(MNUMYR+ECP\$XFH,RNW) \\
\hline Target Cov Ratio-Pur. Constraint & Numeric & UPTCRT \\
\hline Initial Execution Year for ECP & Numeric & UPSTYR \\
\hline Length of Full Planning Horizon & Numeric & UNFPH \\
\hline Length of Expl. Planning Horizon & Numeric & UNXPH \\
\hline Vint. Type $-(0=$ Ex., $1=$ New $)-$ ECP Cap & Numeric & UPVTYP(CAP) \\
\hline Financial Type & Numeric & UPFTYP(CAP) \\
\hline NUG Bld $S W(0=$ Not, $1=$ Allowed $)$-DSP & Numeric & UPDNUG(DSP) \\
\hline NUG Bld SW(0=Not, $1=$ Allowed $)$-Int & Numeric & UPINUG(INT) \\
\hline NUG Bld SW(0=Not, $1=$ Allowed $)$-Ren & Numeric & UPRNUG(RNW) \\
\hline IRT Bld SW(0=Not, $1=$ Allowed $)$-DSP & Numeric & UPDETT(DSP) \\
\hline IRT Bld SW ( $0=$ Not, $1=$ Allowed)-Int & Numeric & UPIETT(INT) \\
\hline IRT BId SW ( $0=$ Not, 1=Allowed)-Ren & Numeric & UPRETT(RNW) \\
\hline $\begin{array}{l}\text { Print Mode } \\
(0=\text { No MPS Recs, } 1=\text { Print MPS recs })\end{array}$ & Numeric & ECP\$PRNT \\
\hline Revise Mode & Numeric & ECP\$MODE \\
\hline
\end{tabular}




$\begin{array}{llll}\text { EFD to ECP Fuel Mapping } & \text { Numeric } & \text { UFLSECP(NFL,FPP) } & \text { Assumption } \\ \text { Initialize Matrix }(1=\text { Yes, } 0=\text { No) } & \text { Numeric } & \text { ECP\$INT } \\ \text { EFP Type Retrofit }(=13) & \text { Numeric } & \text { EFPSSCR } \\ \text { EFP Type Transmission }(=14) & \text { Numeric } & \text { EFPSTRN } \\ \text { Yr to Write ACT File(0=Write 1st Yr) } & \text { Numeric } & \text { ECPACT } \\ \text { Basis Mode } & \text { Numeric } & \text { ECPBASIS } \\ \text { (0=From Previous Yr,1=From Input File) } & & & \\ \text { MPS Format Input File Name \& Path } & \text { Alpha } & \text { ECPSFILE } \\ \text { EMM Basis File Name } & \text { Alpha } & \text { ECP\$FILEB } \\ \text { Objective Function Name } & \text { Alpha } & \text { UPOBJ } \\ \text { Right Hand Side Name } & \text { Alpha } & \text { UPRHS } & \\ \text { Bound Row Name } & \text { Alpha } & \text { UPBND } & \\ \text { Database Name } & \text { Alpha } & \text { ECP\$DBNM } & \\ \text { Problem Name } & \text { Alpha } & \text { ECP\$PROB } & \\ \text { Deck Name } & \text { Alpha } & \text { ECP\$DECK } & \\ \text { Basis File Deck Name } & \text { Alpha } & \text { ECP\$DCKB(YR) } \\ \text { F860 Primary Fuel Code } & \text { Char } & \text { UPF860(CAP) } & \text { F860 } \\ \text { F860 Secondary Fuel Code } & \text { Char } & \text { USF860(CAP) } & \text { F860 } \\ \text { Dsp. Plant Codes } & \text { Char } & \text { UPPLCD(DSP) } & \text { Assumption } \\ \text { Int. Plant Codes } & \text { Char } & \text { UPIND(INT) } & \text { Assumption } \\ \text { Ren. Plant Codes } & \text { Char } & \text { UPRNCD(RNW) } & \text { Assumption } \\ \text { DSM Group Codes } & \text { Char } & \text { UPDMCD(DSM) } & \text { Assumption } \\ \text { Fuel Codes Char } & \text { UPFLCD(NFL) } & \text { Assumption } \\ \text { F860 Prime Mover Code } & \text { Char } & \text { UPM860(CAP) } & \text { F860 } \\ \text { EFP Type } & \text { Char } & \text { UPEFPT(CAP) } & \text { Assumption } \\ \text { Fin Ownership Type (1='U',2='N') } & \text { Char } & \text { UPOWNCD(OWN) } & \text { Assumption } \\ \text { Load Segment Codes } & \text { Char } & \text { UPLDCD(VLS) } & \text { Assumption } \\ \text { Mode of Operation Codes } & \text { Char } & \text { UPMDCD(VLS) } & \text { Assumption } \\ \text { Region Codes } & \text { Char } & \text { UPRGCD(RGN) } & \text { Assumption } \\ \text { Year Codes } & \text { Char } & \text { UPYRCD(FPH) } & \text { Assumption } \\ \text { Retrofit Cluster Code } & \text { Char } & \text { UPSCCD(CSR) } & \text { Assumption } \\ \text { F759 Prime Mover Code } & \text { Char } & \text { IPM759(CAP) } & \text { F759 } \\ \text { F759 Primary Fuel Code } & \text { Char } & \text { UPF759(CAP) } & \text { F759 } \\ \text { F759 Secondary Fuel Code } & \text { Char } & \text { USF759(CAP) } & \text { F759 } \\ & & & \\ & & & \end{array}$

Notes: $\quad$ F860: Form ElA-860, "Annual Electric Generator Report".

F759: Form EIA-759, "Monthly Power Plant Report".

Common $=$ CN6005.PRJ.NEMS.COMMON.PDS.datekey(ECP\$CNTL)

TABLE A-4: NCNTRL Common Block Description

\begin{tabular}{|c|c|c|c|c|}
\hline Variable & Description & Indices & Units & Source \\
\hline EXW & Execute World (international) & & Numeric & \\
\hline EXM & Execute Mac (Macroeconomic) & & Numeric & \\
\hline EXR & Execute Resd (Residential) & & Numeric & \\
\hline EXK & Execute Comm (Commercial) & & Numeric & \\
\hline EXI & Execute Ind (Industrial) & & Numeric & \\
\hline EXT & Execute Tran (Transportation) & & Numeric & \\
\hline EXE & Execute Util (Utility) & & Numeric & Assumption \\
\hline EXC & Execute Coal (Coal Supply) & & Numeric & \\
\hline
\end{tabular}


EXL

EXG

EXO

EXN

RUNMOD

PRTDBGW

PRTDBGM

PRTDBGR

PRTDBGK

PRTDBGI

PRTDBGT

PRTDBGE

PRTDBGC

PRTDBGL

PRTDBGG

PRTDBGO

PRTDBGN

FIRSYR

LASTYR

MAXITR

FRCTOL

ABSTOL

RLXPC

NYRS

I4SITE

I4SCNT

IRELAX

WWOP

MMAC

HISTORY

MACFDBK

ELASSW

DSMSWTCH

DBDUMP

MODELON

ECPSTART

CURITR

CURIYR

BASEYR

ENDYR

LOOPOP

CTEST

FCRL

NCRL

CNVTST

NMUMYR

ITIMNG

YEARPR

MORDER

SCALPR

SCEN

DATE

COMMENT

SUBR_NAMES

SUBR_DESCR
Execute Well (Oil and Gas Supply) Numeric

Execute Pipe (Gas Trans \& Distr)

Execute Refine (Petroleum Refinery) Numeric

Execute Renew (Renewables)

Flags (Is each model being run?)

Print Debug in World (International) Numeric

Print Debug in Mac (Macroeconomic)

Print Debug in Resd(Residential)

Print Debug in Comm (Commercial) Numeric

Print Debug in Ind (Industrial)

Print Debug in Tran (Transportation) Numeric

Print Debug in Util

Print Debug in Coal(Coal Supply)

Print Debug in Oil and Gas Supply Numeric

Print Debug in Gas Trans \& Distr

Print Debug in Refine(Petroleum Ref)

Print Debug in Renew (Renewables) Numeric

First Forecast Year Index

Last Forecast Year Index

Maximum Iterations

Min Fractional Conver Tol

Minimum Absolute Convergence Tol

Relaxation Percentage

Number of Growth Years

Foresight Option

Foresight Control

Option to run Heuristic Routine

World Oil Price Case

Macro Case

1990 History Data Flag

Macroeconomic Feedback Lever

Elasticity Switch

DSM Switch

Start Year for ECP Module

Current Iteration

Current Year Index

Yr Corresponding to FIRSYR

Yr Corresponding to LASTYR

NEMS Year Looping

Overall Convergence Test

Final Converg/Reporting Loop Sw Numeric

Reporting Loop Switch

Conver Flags for each Model NMODEL

Year

Timing Switch

For Reporting, Year Dollars

Holds Execution Order of Modules Numeric

For Reporting, Deflator, Yearpr \$

Scenario

Date Code

Comment Line frm Job Stream

Short Subroutine Names

Long Subroutine Names
Numeric

Numeric

Numeric

Numeric

Numeric

Numeric

Numeric

Numeric

Assumption

Numeric

Numeric

Numeric

Numeric

Numeric

Numeric

Numeric

Numeric

Numeric

Numeric

Numeric

Numeric

Numeric

Numeric

Numeric

Numeric

Numeric

Numeric

Numeric

Numeric

Numeric

Numeric

Numeric

Numeric

Numeric

Numeric

Numeric

Assumption Assumption Assumption

Assumption Assumption Assumption Assumption Assumption Assumption

Numeric Assumption

Numeric

Numeric Assumption

Numeric

Numeric

Numeric

$\begin{array}{ll}\text { Alpha } & \text { Assumption } \\ \text { Alpha } & \text { Assumption }\end{array}$

$\begin{array}{ll}\text { Alpha } & \text { Assumption } \\ \text { Alpha } & \text { Assumption }\end{array}$

Alpha

NMODEL Alpha

NMODEL Alpha

Assumption

Assumption

Assumption

Assumption

Assumption 
SUBR_VERS

FORE_SITE_CNTL

FORE_SITE_TYPE

LOOP
Subroutine Version Used

Description for I4SCNT

Description for I4SITE

Description for LOOPOP

$\begin{array}{ll}\text { MODEL+2 } & \text { Alpha } \\ 2 & \text { Alpha } \\ 3 & \text { Alpha } \\ 2 & \text { Alpha }\end{array}$

\section{A.3 Inventory of Input Data}

\section{TABLE A-5: LOAD DAF FILE DESCRIPTION}

This file contains the load shape information required to create both ECP and EFD load representations.

\section{Field}

Capacity of a slice

Maximum capacity within a time group

Minimum capacity within a time group

Number of hours in a

season/time of day group

Size of the step for ECP

Group Definition

\# of Time Slice Groups

Number of seasons

Number of time of day subgroups

in each season for EFD

A map to the GRP subscript (EFD)

\# of time slice groups for ECP

Number of time of day subgroups

in each season for ECP

A map to the GRP subscript (ECF)

ECP - Step

ECP - Planned/Unplanned

$\begin{array}{ll}\text { Units } & \text { Variable Na } \\ \text { MW } & \text { ULOAD } \\ \text { MW } & \text { UG_MAX } \\ \text { MW } & \text { UG_MIN } \\ \text { hours } & \text { UTIME } \\ \text { Numeric } & \text { ECPSTSZ } \\ \text { Numeric } & \text { UGROUPS } \\ \text { Numeric } & \text { UNGRPS } \\ \text { season } & \text { EFDNSP2 } \\ \text { subgroup } & \text { EFDNUM } \\ \text { Numeric } & \text { EFDMAP } \\ \text { Numeric } & \text { ECPGRP } \\ \text { subgroup } & \text { ECPNUM } \\ & \\ \text { Numeric } & \text { ECPMAP } \\ \text { Alpha } & \text { ECPSTEP } \\ \text { Alpha } & \text { ECPTYPE }\end{array}$

$\underline{\text { Indices }}$

Source

(HRS,GRP)

(GRP)

(GRP)

(GRP)

Assumption

Assumption

Assumption

Assumption

(STP,SSZ)

(GRP)

(SEASON)

Assumption

Assumption

Assumption

(SSN,SBGRP) Assumption

(STP)

(STP,SUBGRP)

(STP)

(GRP)

Notes: $\quad$ SEASON subscript values $=1$ through 6 ( 6 seasons $)$

GRP subscript values $=1$ through 18 (18 time of day/week groups)

SUBGRP subscript value $=1$ through 3 (time of day subgroupings)

STP $=1$ through 9 (ECP number of load groups)

$\mathrm{SSZ}=1$ through 5 (ECP maximum number of steps per group)

HRS = 1 through 32 (Number segments in each GRP)

$E F D N U M=3$ for all seasons (in latest run).

Each record represents 1 NEMS region of data.

LRECL $=16,384$

ACCESS $=$ DIRECT

Filename $=$ CN6005.PRJ.UTLL.LOADDAF.scenario.datekey

Common $=$ CN6005.PRJ.NEMS.COMMON.PDS.datekey(LOADIN)

NEMS use = Output from the Load Pre-Processor run

Input to ETT Pre-Processor and EMM

TABLE A-6: PLANT DAF DESCRIPTION 
This file contains the unit level data from a combination of the F860, F767, F867, F423, and the F759. New units are added to this inle as determined by the ECP module. This is the source of EFD and ECP capacity data.

Field

Total Name Plate Capacity of Unit

Name Plate Actually Owned by Identified Co.

Summer Capacity Owned

Winter Capacity Owned

Average Heatrate

Scrubber Efficiency in Removing $\mathrm{SO} 2$

SO2 Standard

Actual SO2 Rate Achieved in Last Recorded Year

Average Capacity Factor

Avg Cost of Electricity using Primary Fuel

Avg Cost of Electricity Using Secondary Fuel

Weighted Avg Cost of Electricity

Primary Fuel Share

Secondary Fuel Share

Cost per KW for Retrofit of Scrubber

Asset Value

Book CWIP

CWIP

Plant Cost

Is Company Identified as Plant Operator

Code for Sourc, of Average Capacity Factor

Code for Source of Heatrate

On-Line Year (9999 if not specified)

On-Line Month (12 if not specified)

Retire Year (9999 if not specified)

Retire Month (12 if not specified)

Scrubber On-Line Year

Flag

\author{
Plant Group \\ Plant Vintage \\ Plant Name \\ NEMS Fuel Codes for Actual Fuels Used (Prim.) \\ NEMS Fuel Codes for Actual Fuels Used (sec.) \\ Five Digit Company Identification Code \\ Zip Code for Plant Location \\ Code to Uniquely Identify Plant Location \\ Four Digit Plant Identification Code \\ Four Digit Unit Identification Code \\ NEMS Fuel Codes \\ F860 Primary Fuel Code \\ F860 Secondary Fuel Code \\ F860 Prime Mover Code \\ Two Digit NEMS Plant Type Code \\ NEMS Region Code for Plant Location \\ NEMS Region Code for Unit Owner \\ Two Digit Sate Code for Plant Location \\ Census Region Numt.
}

\begin{tabular}{|c|c|c|}
\hline Units & Variable & Source \\
\hline$\overline{\text { megawatt }}$ & $\overline{\text { WC_TOT }}$ & F860/F867 \\
\hline megawatt & WC_NP & F860/F867 \\
\hline megawatt & WC_SUM & F860 \\
\hline megawatt & WC_WIN & F860 \\
\hline btu/kwh & WHRATE & F423 \\
\hline numeric & WSBEF & F767 \\
\hline numeric & WS2STD & F767 \\
\hline numeric & WS2ACT & F767 \\
\hline numeric & W_CF & F860/F759/Various \\
\hline mill/kwh & WMKWH1 & F423 \\
\hline mills/kwh & WMKWH2 & F423 \\
\hline mill/kwh & WMKWH & F423 \\
\hline numeric & WPFSHR & F423 \\
\hline numeric & WSCBCST & F423 \\
\hline$\$ / \mathbf{k w}$ & WSCBCST & F767 \\
\hline dollars & WASVL & F412 \\
\hline dollars & WBCWP & F412 \\
\hline dollars & WRCWP & F412 \\
\hline$\$ / \mathbf{k w}$ & WPCST & F412 \\
\hline Numeric & W_OPER & $\begin{array}{l}0 \text {-Yes } \\
1 \text {-No }\end{array}$ \\
\hline Numeric & WCFLAG & \\
\hline Numeric & WHFLAG & \\
\hline Numeric & W_SYR & F860/F867 \\
\hline Numeric & W_SMO & F860/F867 \\
\hline Numeric & W_RYR & F860/F867 \\
\hline Numeric & W_RMO & F860/F867 \\
\hline Numeric & WSCBYR & F767 \\
\hline Numeric & W_CFLG & $\begin{array}{l}\text { 0-F860 } \\
\text { 1,3 Formula } \\
\text { 3-Shares }\end{array}$ \\
\hline Numeric & W_GRP & Assumption \\
\hline Numeric & WVIN & Assume (See values below) \\
\hline Alpha & W_PNM & F860/F867 \\
\hline Numeric & WPFLS & Assumption \\
\hline Numeric & WSFLS & Assumption \\
\hline Numeric & W_CID & F860/F867 \\
\hline Numeric & WZ̄IP & F860/F867 \\
\hline Numeric & WCPLUS & Assumption \\
\hline Numeric & W_PID & Assumption \\
\hline Numeric & W_UID & Assumption \\
\hline Numeric & WFL(FPP) & Assumption \\
\hline Numeric & WPF860 & F860 \\
\hline Numeric & WSF860 & F860 \\
\hline Numeric & WPM860 & F860 \\
\hline Numeric & WNEMST & F860/F867 \\
\hline Numeric & WNOPER & F860/F867 \\
\hline Numeric & WNOWN & F860/F867 \\
\hline Numeric & WSTATE & F860/F867 \\
\hline Numeric & W_CR & F860/F867 \\
\hline
\end{tabular}


Natural Gas Region Number

Coal Region Number

Current Status Code

Future Status Code

Financial Type Number for EFP

Plant Type Number for ECP

F759 Prime Mover Code

- F759 Primary Fuel Code

F759 Secondary Fuel Code

Scrubber Type Code

Ownership Type

Boiler Type 1=Nonboiler

Filler (Left Over)

\begin{abstract}
Numeric
Numeric

Numeric

Numeric

Numeric

Numeric

Numeric

Numeric

Numeric

Numeric

Numeric
\end{abstract}

Numeric

Spaces

$\begin{array}{lc}\text { W_GR } & \text { F860/F867 } \\ \text { W_CLRG } & \text { F860/F867 } \\ \text { WSTAT1 } & \text { F860/F867 } \\ \text { WSTAT2 } & \text { F860/F867 } \\ \text { WEFPT } & \text { F860/F867 } \\ \text { WECPT } & \text { F860/F867 } \\ \text { WPM759 } & \text { F759 } \\ \text { WPF759 } & \text { F759 } \\ \text { WSF759 } & \text { F759 } \\ \text { WSCBTP } & \\ \text { WFOWN } & 1=\text { Prvt } \\ & 2=\text { Pblc } \\ & 3=\text { NUG }\end{array}$

F767

Values for Plant Vintage

$0=$ Canceled or Retired $<1990$

$1=$ On Line by or before 1990

$2=$ Planned Additions

$3=$ Unplanned Additions

$4=$ Repowering (Before)

$5=$ Repowering (After)

$6=$ Planned Retrofit (Before)

7 = Planned Retrofit (After)

8 = Unplanned Retrotit (Before)

9 = Unplanned Retrofit (After)

Notes: $\quad$ FPP subscript values $=1$ through 4 (ECP fuels per plant)

Each record represents 1 year of data.

F860 - "Annual Electric Generator Report"

F867 - "Annual Nonutility Power Producer Report"

F759 - "Monthly Power Plant Report"

F423 - "Monthly Report of Cost and Quality of Fuels for Electric Plants"

F767 - "Steam-Electric Plan Operation and Design Report"

LRECL $=512$

ACCESS $=$ DIRECT

Filename $=$ CN6005.PRJ.UTIL.PLNTDAF.scenario.datekey

Common $=$ CN6005.PRJ.NEMS.COMMON.PDS.datekey(PLNTIN)

NEMS use $=$ Output from Plant Pre-Processor

Input to EMM

\section{- TABLE A-7: FUEL.DAF DESCRIPTION}

This file provides storage and archival of utility sector fuel prices.

Field

Units Variable Name

Source 
Delivered Fuel Prices

SO2 Emission Rate

NOX Emission Rate

$\mathrm{CO} 2$ Emission Rate

Carbon Emission Rate

CO Emission Rate

VOC Emission Rate

Ash Retention Rate

Heat Content

Maximum Fuel Shares

Filler (Left Over)

$\begin{array}{ll}\text { \$/MMBTU } & \text { UPFUEL(NFL,FRGN) } \\ \text { lbs/mmBtu } & \text { UFRSO2(NFL,FRG) } \\ \text { lbs/mmBtu } & \text { UFRNOX(NFL,FRG) } \\ \text { lbs/mmBtu } & \text { UFRCO2(NFL) } \\ \text { lbs/mmBtu } & \text { UFRCAR(NFL) } \\ \text { lbs/mmBtu } & \text { UFRCO1(NFL) } \\ \text { lbs/mmBtu } & \text { UFRVOC(NFL) } \\ \text { lbs/mmBtu } & \text { UFRASH(NFL) } \\ \text { MBTU } & \text { UFHCNT(NFL,FRG) } \\ \text { Numeric } & \text { UCMFSH(DSP,FPP,RGN) } \\ \text { Spaces } & \text { Unused bytes in } \\ & \text { FUELIN common }\end{array}$

Fuel Supply Modules

Assumption

Assumption

Assumption

Assumption

Assumption

Assumption

Assumption

Assumption

Assumption

Notes: $\quad$ RGN subscript values $=1$ through 16 (NEMS Rgns 1-13)

NFL subscript values $=1$ through 20 (number of fuel types)

FRG subscript values = 1 through 24 (maximum \# regions for any fuel type)

DSP subscript values $=1$ through 16 (dispatchable capacity types)

FPP subscript values $=1$ through 4 (ECP fuels per plant)

Each record represents 1 year of data.

$$
\begin{aligned}
& \text { LRECL }=16384 \\
& \text { ACCESS }=\text { DIRECT } \\
& \text { Filename }=\text { CN6005.PRJ.UTIL.FUELDAF.scenario.datekey } \\
& \text { Common }=\text { CN6005.PRJ.NEMS.COMMON.PDS.datekey(FUELIN) } \\
& \text { NEMS use = Output from Fuel Pre-Processor } \\
& \quad \text { Input to EMM }
\end{aligned}
$$

\section{TABLE A-8: $\quad$ ETTIN FILE DESCRIPTION}

Variable
Name
IRGEX
IRGIM
CNSTRE
CNSTRW
CNSTRE
CNSTRW
CNSTRE
CNSTRW
CNSTRE
CNSTRW
CNSTRE
CNSTRW
CNSTRE
CNSTRW
CNSTRE
CNSTRW
CNSTRE
CNSTRW
CNSTRE
CNSTRW

\section{Columns Description}

\section{1-3 Export Region}

4-6 Import Region

$7-450$

1990 Summer Constraint

1990 Winter Constraint

1991 Summer Constraint

1991 Winter Constraint

1992 Summer Constraint

1992 Winter Constraint

1993 Summer Constraint

1993 Winter Constraint

1994 Summer Constraint

1994 Winter Constraint

1995 Summer Constraint

1995 Winter Constraint

1996 Summer Constraint

1996 Winter Constraint

1997 Summer Constraint

1997 Winter Constraint

1998 Summer Constraint

1998 Winter Constraint

$\begin{array}{llll}\text { Units } & \text { Format } & \text { Comments } & \text { Source } \\ \text { Numeric } & 12 & \\ \text { Numeric } & 12 & \text { Assumption } \\ \text { GW } & \text { F7.3 } & \text { The 12 years of } & \text { Ossumption } \\ \text { GW } & \text { F7.3 } & \text { Summer and Winter } & \text { OE-411 } \\ \text { GW } & \text { F7.3 } & \text { constraints are read } & \text { OE-411 } \\ \text { GW } & \text { F7.3 } & \text { in unformatted. } & \text { OE-411 } \\ \text { GW } & \text { F7.3 } & & \text { OE-411 } \\ \text { GW } & \text { F7.3 } & \text { Each field should } & \text { OE-411 } \\ \text { GW } & \text { F7.3 } & \text { at have least } & \text { OE-411 } \\ \text { GW } & \text { F7.3 } & 3 \text { decimal places OE-411 } \\ \text { GW } & \text { F7.3 } & \text { The fields are } & \text { OE-411 } \\ \text { GW } & \text { F7.3 } & \text { separated from } & \text { OE-411 } \\ \text { GW } & \text { F7.3 } & \text { each other by a space. } & \text { OE-411 } \\ \text { GW } & \text { F7.3 } & & \text { OE-411 } \\ \text { GW } & \text { F7.3 } & & \text { OE-411 } \\ \text { GW } & \text { F7.3 } & & \text { OE-411 } \\ \text { GW } & \text { F7.3 } & & \text { OE-411 } \\ \text { GW } & \text { F7.3 } & & \text { OE-411 } \\ \text { GW } & \text { F7.3 } & & \text { OE-411 } \\ \text { GW } & \text { F7.3 } & & \text { OE-411 }\end{array}$




CNSTRE
CNSTRW
CNSTRE
CNSTRW
CNSTRE
CNSTRW
$\cdot$
$\cdot$
CNSTRW

\begin{abstract}
1999 Summer Constraint 1999 Winter Constraint 2000 Summer Constraint 2000 Winter Constraint 2001 Summer Constraint 2001 Winter Constraint
\end{abstract}

2020 Winter Constraint

$\begin{array}{ll}\text { GW } & \text { F7.3 } \\ \text { GW } & \text { F7.3 } \\ \text { GW } & \text { F7.3 } \\ \text { GW } & \text { F7.3 } \\ \text { GW } & \text { F7.3 } \\ \text { GW } & \text { F7.3 }\end{array}$

GW
OE-411

OE-411

OE-411

OE-411

OE-411

OE-411

Assumption

Assumption

Notes: $\quad$ LRECL $=500$

BLKSIZE $=5000$

OE-411: DOE Form OE-411, "Coordinated Bulk Power Supply Program Report".

Filename $=$ CN6005.PRJ.UTIL.ETTIN.scenario.datekey

NEMS use = Output from ETT Pre-processor and Input to the EMM.

This file contains region to region constraints for the years 1990-2020. The ETT Pre-Processor reads in the 'CNSRNT' file, subtracts out Firm Power Contracts from the constraints, and outputs the result in the 'ETTIN' file.

\section{TABLE A-8a: CONSTRANTS FILE DESCRIPTION (ETT Pre-Processor Input File)}

\begin{abstract}
Variable
Name

IRGEX

IRGIM

TEMPS

TEMPW

TEMPS

TEMPW

TEMPS

TEMPW

TEMPS

TEMPW

TEMPS

TEMPW

TEMPS

TEMPW

TEMPS

TEMPW

TEMPS

TEMPW

TEMPS

TEMPW

TEMPS

TEMPW

TEMPS

- TEMPW

TEMPS

TEMPW
\end{abstract}

\section{Columns Description}

1-2 Export Region

4-5 Import Region

6-255 1990 Summer Constraint

1990 Winter Constraint

1991 Summer Constraint

1991 Winter Constraint

1992 Summer Constraint

1992 Winter Constraint

1993 Summer Constraint

1993 Winter Constraint

1994 Summer Constraint

1994 Winter Constraint

1995 Summer Constraint

1995 Winter Constraint

1996 Summer Constraint

1996 Winter Constraint

1997 Summer Constraint

1997 Winter Constraint

1998 Summer Constraint

1998 Winter Constraint

1999 Summer Constraint

1999 Winter Constraint

2000 Summer Constraint

2000 Winter Constraint

2001 Summer Constraint

2001 Winter Constraint

\begin{tabular}{|c|c|c|c|}
\hline$\underline{\text { Unit }}$ & Forma & Comments & Source \\
\hline \multicolumn{2}{|c|}{ Numeric } & I2 & Assumption \\
\hline \multicolumn{2}{|c|}{ Numeric } & I2 & Assumption \\
\hline GW & F7.3 & The 12 years of & $\mathrm{OE}-411$ \\
\hline GW & F7.3 & Summer and Winter & OE-411 \\
\hline GW & F7.3 & constraints are read & OE-411 \\
\hline GW & F7.3 & in unformatted. & $\mathrm{OE}-411$ \\
\hline GW & F7.3 & & OE-411 \\
\hline GW & F7.3 & Each field should & OE-411 \\
\hline GW & F7.3 & have at least 3 & OE-411 \\
\hline GW & F7.3 & decimal places. & $\mathrm{OE}-411$ \\
\hline GW & F7.3 & The fields are & OE-411 \\
\hline GW & F7.3 & separated from & OE-411 \\
\hline GW & F7.3 & each other by a space. & $\mathrm{OE}-411$ \\
\hline GW & F7.3 & & $\mathrm{OE}-411$ \\
\hline GW & F7.3 & & $\mathrm{OE}-411$ \\
\hline GW & F7.3 & & OE-411 \\
\hline GW & F7.3 & & OE-411 \\
\hline GW & F7.3 & & OE-411 \\
\hline GW & F7.3 & & OE-411 \\
\hline GW & F7.3 & & OE-411 \\
\hline GW & F7.3 & & OE-411 \\
\hline GW & F7.3 & & OE-411 \\
\hline GW & F7.3 & & OE-411 \\
\hline GW & F7.3 & & OE-411 \\
\hline GW & F7.3 & & OE-411 \\
\hline GW & F7.3 & & OE-411 \\
\hline
\end{tabular}


$\begin{array}{llll}\text { Export Region Name } & \text { Alpha } & \text { A10 } & \text { Assumption } \\ \text { Import Region Name } & \text { Alpha } & \text { A10 } & \text { Assumption }\end{array}$

Notes: $\quad$ LRECL $=255$

BLKSIZE $=23460$

OE-411: DOE Form OE-411, "Coordinated Bulk Power Supply Program Report".

Filename $=$ CN6005.PRJ.UTIL.CNSTNT.scenario.datekey

NEMS use = Input to Pre-Processor Program

This file contains region to region constraints for the years 1990-2001. The ETT Pre-Processor reads in the 'CNSRNT' file, subtracts out firm power commitments from the constraints, and outputs the result in the 'ETTIN" file.

TABLE A-8b: CONTRACTS FILE DESCRIPTION (ETT Pre-Process Input File)

Variable

$\underline{\text { Name' }^{\prime}}$

TEMPI

TEMPE

MW

$S$

SYR

EYR

\begin{tabular}{ll} 
Columns Description \\
\hline $5-11$ & Buyer Utility Name \\
$17-21$ & Buyer Utility Code \\
$23-24$ & Buyer State \\
$32-35$ & Buyer Region \\
$41-45$ & Seller Utility Name \\
$53-57$ & Seller Utility Code \\
$59-60$ & Seller State \\
$68-73$ & Seller Region \\
$77-84$ & Capacity \\
86 & Season \\
& \\
$99-02$ & Start Year \\
$08-11$ & End Year \\
$13-20$ & Record Type
\end{tabular}

22-35 Source

\begin{tabular}{|c|c|c|c|}
\hline Units & Format & Comments & $\underline{\text { Source }}$ \\
\hline Alpha & A6 & & OE-411 \\
\hline Numeric & 15 & & F860 \\
\hline Alpha & A2 & & OE-411 \\
\hline Alpha & A4 & & OE-411 \\
\hline Alpha & A5 & & $\mathrm{OE}-411$ \\
\hline Numeric & I5 & & $\mathrm{OE}-411$ \\
\hline Alpha & $\mathrm{A} 2$ & & OE-411 \\
\hline Alpha & A6 & & OE-411 \\
\hline MW & F8.0 & & OE-411 \\
\hline Alpha & $\mathrm{A} 1$ & $\begin{array}{l}' S^{\prime}=\text { Summer } \\
' W '=\text { Winter }\end{array}$ & $\mathrm{OE}-411$ \\
\hline Numeric & F4.0 & & OE-411 \\
\hline Numeric & $\mathrm{F} 4.0$ & & \\
\hline Alpha & A8 & $\begin{array}{l}\text { 'S'= Sales } \\
\text { 'P'=Purchase } \\
\text { 'R'= Revised Re } \\
\text { 'Adj' = Adjustm }\end{array}$ & $\mathrm{OE}-411$ \\
\hline Alpha & Al4 & Pub Name & \\
\hline
\end{tabular}

1 Note, there are only variable names listed for those variables which are input from the file.

Notes: $\quad$ LRECL $=136$

BLKSIZE $=7344$

Filename $=$ CN6005.PRJ.UTIL.ETCNCT.scenario.datekey

NEMS use = Input to ETT Pre-Processor Program

OE-411: DOE Form OE-411, "Coordinated Bulk Power Supply Program Report".

F860 - "Annual Electric Generator Repnrt"

This file contains records for firm power contracts between NEMS regions, between NEMS regions and Canada, and between NEMS regions and Mexico. 
TABLE A-8c: CANADIAN SUPPLY FILE DESCRIPTION

(ETT Pre-Processor Input File)

Variable

Names

SPCNRGN

SPNEMS

SPSTEP

SPYR

SPRHS

SPPKRHS

SPCF

SPDOLL

SPMILLS

\begin{tabular}{ll} 
Columns & Description \\
\hline $9-12$ & Canadian Reg (Sell) \\
$18-21$ & NEMS Region (Buyer) \\
24 & Step \# \\
$27-30$ & Year \\
$33-39$ & Firm MW Available \\
$42-48$ & Peak MW Available \\
$54-57$ & Capacity Factor \\
$61-66$ & Fixed Cost \\
$71-75$ & Variable Cost
\end{tabular}

Units

Numeric

Numeric

Numeric

Numeric

MW

MW

Numeric

$\$ / \mathrm{Kw}$

Mills/Kwh

$\begin{array}{ll}\text { Format } & \text { Comments } \\ \text { F4.0 } & \text { UCI\$CRG } \\ \text { F4.0 } & \\ \text { I1 } & \\ \text { I4 } & \\ \text { F7.1 } & \text { UCI\$FMW } \\ \text { F7.1 } & \text { UCI\$PMW } \\ \text { F4.1 } & \text { UCI\$CF } \\ \text { F6.1 } & \\ \text { F5.2 } & \text { UCI\$CST }\end{array}$

Source

Assumption

Assumption

Assumption

Northem Lights

Northern Lights

Northern Lights

Northern Lights

Northem Lights

Northern Lights

Notes:

\author{
LRECL $=80$ \\ BLKSIZE $=7440$ \\ Filename $=$ CN6005.PRJ.UTLL.CANSPPLY.scenario.datekey \\ NEMS use $=$ Input to ETT Pre-processor program
}

Northern Lights: U.S. Department of Energy, Northern Lights: The Economic and Practical Potential of Imported Power from Canada (DOE/PE0079)

The Canadian Supply file is pre-dominantly used for input to the ECP; i.e. the input information is used in the competition between U.S. capacity and Canadian firm power imports. Its role is discussed in Section I of the report.

\title{
TABLE A-9: ETTDEM.DAF (ELJ File) DESCRIPTION
}

Description

Canadian Builds

T \& D Loss Factor

Max Summer Imp Cnstrnt

Max Summer Exp Cnstrnt

Max Winter Exp Cnstrnt

Max Winter Imp Cnstrnt

Firm Power Sales (Net)

Firm Power Sales (Gross)

Firm Power Sales (Net)

Firm Power Sales (Gross)
Net Interregional Flows

$\underline{\text { Units }}$

GW

GW

Numeric

GW

GW

GW

GW

MWH

MWH

MM\$

MM\$

Internatnl Firm Pwr Imports MWH

Internatnl Firm Pwr Imports MM\$

Internatnl Firm Pwr Exports MM\$
Variable Name Indices Source

UEITAJ

UCANBLD

UQTDLS

URNCSI

URNCST

URNCWT

URNCWI

ZTDMMF

ZTEXMF

ZTDMDF

ZTEXDF

ZTIMPF

ZTIMPD

ZTEXPD
(SSN,RG)

(RGN)

(RGN)

(RGN)

(RGN)

(RGN)

(RGN)

(RGN)

(RGN)

(RGN)

(RGN)

(RGN)

(RGN)

(RGN)
PreProcessor

ECP Output

Assumption

NERC

NERC

NERC

NERC

ECP Output

ECP Output

ECP Output

ECP Output

ECP Output

ECP Output

ECP Output 


\begin{tabular}{lllll} 
Internatnl Firm Pwr Exports & MWH & ZTEXPF & (RGN) & ECP Output \\
Firm Pwr Avail(Canadian) & MW & UCI\$FMW & (STP,RGN) Northern Lights \\
Peak Pwr Avail(Canadian) & MW & UCI\$PMW & (STP,RGN) Northern Lights \\
Cap Factor(Canadian) & Numeric & UCI\$CF & (STP,RGN) Northern Lights \\
Variable Cost (Canadian) & Mils/Kwh UCI\$CST & (STP,RGN) Northern Lights \\
Canadian Expt Rgn (Can.) & Numeric & UCI\$CRG & (STP,RGN) Northern Lights \\
Filler (Left Over) & Spaces & Unused bytes in \\
& \multicolumn{5}{c}{ DISPET3 common }
\end{tabular}
Notes: $\quad$ LRECL $=2048$
ACCESS $=$ Direct
Filename $=$ CN6005.PRJ.UTIL.ETTDEM.scenario.datekey
Common $=$ CN6005.PRJ.NEMS.COMMON.PDS.D1123931:DISPETT
NEMS Use = Output from ETT Pre-Processor/Input to EMM

Northern Lights - U.S. Department of Energy, Northern Lights: The Economic and Practical Potential of Imported Power from Canada (DOE/PE-0079).

NERC - North American Electric Reliability Council

RGN subscript values $=1$ through 16 (NEMS electricity supply regions STP subscript values $=1$ and $2(1=$ low cost, $2=$ high cost $)$

UPDATE SEASON subscript values = 1 through $6 ; 1=$ January and February; 2 = December and March; 3 = May and April; $4=$ June and September; $5=$ July and August; $6=$ November and October.

Each record represents 1 year of data.

\section{Table A-10: DISPETT Common Block Description}

Description

$\begin{array}{lll}\text { AREATR } & \text { (EFD\$MSP,ETT\$MTG,EFD\$MVS) } \\ \text { AREATI } & \text { (EFD\$MSP,ETT\$MTG,EFD\$MVS) } \\ \text { CAPTR } & \text { (EFD\$MSP,ETT\$MTG,EFD\$MVS) } \\ \text { CAPTRI } & \text { (EFD\$MSP,ETT\$MTG,EFD\$MVS) } \\ \text { ETDSPN } & \text { (EFD\$MSP) } \\ \text { ETDSPT } & \text { (EFD\$MSP,EFD\$MPG) } \\ \text { UCASTS } & \text { (EFD\$MPG) } \\ \text { ETFSHR } & \text { (EFD\$MSP,EFD\$MPG,EFD\$FPP) } \\ \text { IMMAP } & \text { (EFD\$MSP,ETT\$MTG,EFD\$MVS) } \\ & \text { EXMAP } & \text { (E FD \$ M P , ET T \$ M T G, E FD \$ V S ) } \\ & \text { UNTCOS } & \text { (EFD\$MSP,EFD\$MPG) } \\ & \text { IRGNUM } & \text { (MNUMNR) } \\ & \text { TTYVAL } & \text { (EFD\$MVS) }\end{array}$


Y values-ordered pairs-ETT curve Area under "original" load curve Area under "export" load curve Area under "import" load curve

International Interrupt Imports International Interrupt Exports

Net Interregional Electricity Flows

Canadian Build Decision

T\&D Loss Factor

Max Summer Import Constraint

Max Summer Export Constraint

Max Winter Export Constraint

Max Winter Import Constraint

Firm Power Sales(MWH)

Firm Power Sales (MM\$)

Canadian Firm Imports(mwh)

Canadian Firm Imports (MM\$)

Canadian Firm Exports (MM\$)

Canadian Firm Exports MWH

Firm MW Available

Peak MW Available

Capacity Factor

Cost (Mills/KWH)

Canadian Export
(TIYVAL (EFD\$MVS)

AREANT (EFD\$MPG,EFD\$MVS)

AREATT (EFD\$MPG,EFD\$MVS)

AREAIT (EFD\$MPG,EFD\$MVS)

IMAREA (EFD\$MVS)

EXAREA (EFD\$MVS)

2IMPCI (MNUMYR,MNUMNR)

EXPCI (MNUMYR,MNUMNR)

IDONE1

IDONE2

UEITAJ (EFD\$MSP,MNUMNR)

UCANBLD (MNUMNR)

UQTDLS (MNUMNR)

URNCSI (MNUMNR)

URNCST (MNUMNR)

URNCWT (MNUMNR)

URNCWI (MNUMNR)

ZTDMMF (MNUMNR)

ZTEXMF (MNUMNR)

ZTDMDF (MNUMNR)

ZTEXDF (MNUMNR)

ZTIMPF (MNUMNR)

ZTIMPD (MNUMNR)

ZTEXPD (MNUMNR)

ZTEXPF (MNUMNR)

UCI\$FMW (ECP\$CIS,MNUMNR)

UCI\$PMW (ECP\$CIS,MNUMNR)

UCI\$CF (ECP\$CIS,MNUMNR)

UCI\$CST (ECP\$CIS,MNUMNR)

UCI\$CRG (ECP\$CIS,MNUMNR)

TABLE A-11: NUGPIPE FILE DESCRIPTION

$\begin{array}{llll}\begin{array}{l}\text { Variable } \\ \text { Name }\end{array} & \text { Columns } & & \text { Description } \\ \text { LINELOSS } & 1-4 & & \text { Line Loss Factor } \\ \text { PRTHRESH } & 10-13 & & \text { Price Threshold } \\ \text { CGOTPV } & * 19-22 & & \text { 'Other' Cogen Var. Cost } \\ \text { CGOTPF } & * 28-31 & & \text { 'Other Cogen Fix. Cost } \\ \text { CGCOMPV } & * 37-40 & \text { Comm. Cogen Var. Cost } \\ \text { CGCOMPF } & * 46-49 & \text { Comm. Cogen. Fix. Cost } \\ \text { CGINDPV } & * 55-58 & \text { Ind. Cogen Var. Cost } \\ \text { CGINDPF } & * 64-67 & \text { Ind. Cogen Fix. Cost } \\ \text { IMPCI } & * 4-189 & \text { Canadian Interruptible Imports } \\ \text { EXPCI } & 4-189 & \text { Canadian Interruptible Exports } \\ \text { CID } & 1-6 & \text { Company Id } \\ \text { FID } & 8-12 & \text { Facility Id } \\ \text { SIC } & 14-15 & \text { SIC } \\ \text { STATE } & 19-20 & \text { State abbrev. }\end{array}$

\begin{tabular}{lll} 
Units & Format & Source \\
\cline { 2 - 3 } Pct. & F4.0 & Memo \\
mill/kwh & F4.0 & Assumption \\
mill/kwh & F4.0 & Assumption \\
\$/kw & F4.0 & Assumption \\
mill/kwh & F4.0 & Assumption \\
\$/kw & F4.0 & Assumption \\
mill/kwh & F4.0 & Assumption \\
\$/kw & & Assumption \\
Mwh & $21($ F 3.0$)$ & Exogenous \\
Mwh & $21($ F9.0) & Exogenous \\
num. & F6.0 & F867 \\
num. & F5.0 & F867 \\
num. & F2.0 & F867 \\
Alpha. & A2 & F867
\end{tabular}




$\begin{array}{llllll}\text { ZIP } & 22-26 & \text { Zip code } & \text { num. } & \text { F5.0 } & \text { F867 } \\ \text { NEMS } & 29-30 & \text { NEMS region id } & \text { num. } & \text { I2 } & \text { F867 } \\ \text { CENSUS } & 32-33 & \text { Census region id. } & \text { num. } & \text { F2.0 } & \text { F867 } \\ \text { GID } & 35-38 & \text { Generator id. } & \text { Alpha. } & \text { A4 } & \text { F867 } \\ \text { HRATE } & 40-44 & \text { Heatrate } & \text { num. } & \text { F5.0 } & \text { Assumption } \\ \text { PFL } & 45-47 & \text { Primary Fuel Type } & \text { Alpha } & \text { A3 } & \text { F867 } \\ \text { SFL } & 50-52 & \text { Secondary Fuel Type } & \text { Alpha } & \text { A3 } & \text { F867 } \\ \text { CAP } & 55-59 & \text { Capacity } & \text { MW } & \text { F5.2 } & \text { F867 } \\ \text { STATUS } & 60-61 & \text { Status } & \text { Alpha } & \text { A2 } & \text { F867 } \\ \text { PM } & 65-66 & \text { Prime Mover Type } & \text { Alpha } & \text { A2 } & \text { F867 } \\ \text { SMTH } & 70-71 & \text { Start Month } & \text { num. } & \text { F2.0 } & \text { F867 } \\ \text { SYR } & 75-78 & \text { Start Year } & \text { num. } & \text { F4.0 } & \text { F867 } \\ \text { RMTH } & 80-81 & \text { Retirement Month } & \text { num. } & \text { F2.0 } & \text { F867 } \\ \text { RYR } & 85-88 & \text { Retirement Year } & \text { num. } & \text { F4.0 } & \text { F867 } \\ \text { GENGRD } & 95-103 & \text { Sales to Grid Gener. } & \text { Kwh } & \text { F9.0 } & \text { F867 } \\ \text { GENOWN } & 105-113 & \text { Self Generation } & \text { Kwh } & \text { F9.0 } & \text { F867 }\end{array}$

Note: The NUGPIPE file is input to the EFD in the RDNUGS subroutine in the 'NUGS' code, i.e. through the \&6005PRJ.NEMS.FORTRN.UNUGS.D121593P code.

F867 - "Annual Nonutility Power Producer Report".

Memo - Memorandum from Less Goudarzi and Joanne Shore, OnLocation Inc., to Pat Toner "Deliverable 6, Draft Data Inputs for Implementation of ETT, Task 92086, Contract DE-AC01-88E121033", March 5, 1993.

\section{TABLE A-12: SO2 CONTROL FILE DESCRIPTION}

This file contains the number of SO2 compliance groups, the initial SO2 penalty costs, and additional allowances for each compliance group. There is one Type 1 record per year. The UNSO2 variable indicates the number of Type 2 records which follow it. Records are read in unformatted with a space between each data item.

\begin{tabular}{|c|c|c|c|c|c|}
\hline Record Type & Field & Units & Variable & Comments & Source \\
\hline 1 & Record Type Label & Alpha & DUMMY & '\#SO2,ALLOW' & Assumption \\
\hline 1 & \# of Compliance Groups & Numeric & UNSO2 & & Assumption \\
\hline 1 & Total $\mathrm{SO}_{2}$ Produced & & UTLSO2 & & EFD output \\
\hline 1 & Quantity Tolerance & & UTLSO2I & & Assumption \\
\hline 1 & Price Tolerance & & UTPSO2 & & Assumption \\
\hline 1 & Maximum Price Jumps & & UTJUMP & & Assumption \\
\hline 2 & Record Type Label & Alpha & DUMMY & 'INITIAL PSO2' & Assumption \\
\hline 2 & Initial SO2 Penalty Cost & \$/ton & UPNSO2( & RP) & Assumption \\
\hline 2 & Additional Allowances & tons & UIALLW & RP) & EFD Output \\
\hline
\end{tabular}

Notes: $\quad$ GRP subscript values $=1$ through most recently read UNS 2

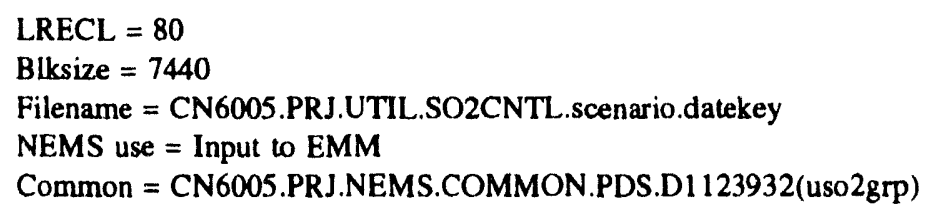

\section{TABLE A-13: ELGNRCR FILE DESCRIPTION}

This file contains electricity generation data for Census divisions within NEMS regions. The first record is a label record. Subsequent records contain data for one NEMS region. Records are read in unformatted with a space between each data item.

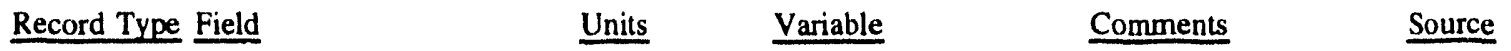




$\begin{array}{llllll}1 & \text { Label } & \text { Alpha } & \text { DUMMY } & \begin{array}{l}\text { 'EL DEM',then } \\ \text { Census div \#s }\end{array} & \text { Assumption } \\ 2 & \text { NEMS Region } & \text { Numeric } & \text { INERC } & 1 \text { through 16 } & \text { Assumptions } \\ 2 & \text { Generation Fields (11) } & \text { MWh } & \text { ELGNNRCR(INERC,CRG) } & \text { F759 }\end{array}$

Notes: $\quad$ INERC subscript values $=1$ through 16 (on input record)

CRG subscript values $=1$ through 11 (Census divisions, MNUMNCR parameter)

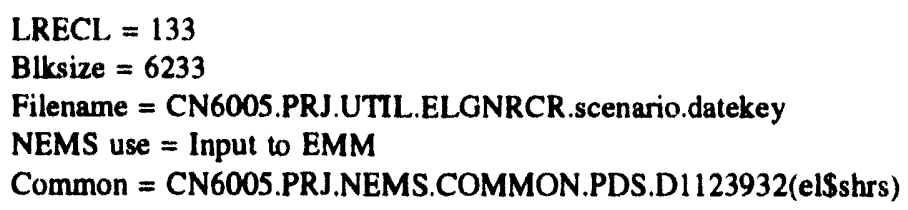

F759 - "Monthly Power Plant Report".

\section{TABLE A-14: ELDATYR FILE DESCRIPTION}

This file contains historic data to overwrite EMM output in certain reports and nuclear maximum capacity factors and annual costs. Records are read in unformatted with a space between each data item.

\begin{tabular}{|c|c|c|c|c|c|}
\hline Record Type & Field & Units & Variable & Comments & Source \\
\hline 1 & $\begin{array}{l}\text { Year } \\
\text { Nuclear Capacity Factors } \\
\text { Record Id }\end{array}$ & $\begin{array}{l}\text { Numeric } \\
\text { Alpha }\end{array}$ & $\begin{array}{l}\text { IYR } \\
\text { UNUCFNR(RG,YR) }\end{array}$ & $\begin{array}{l}4 \text { digits } \\
\text { YR = IYR }-1989 \\
\text { RG = 1,MNUMNR-1 } \\
\text { 'NUC CF' }\end{array}$ & OIAF \\
\hline 2 & $\begin{array}{l}\text { Year } \\
\text { Annual Nuclear Fuel Costs } \\
\text { Record Id }\end{array}$ & $\begin{array}{l}\text { Numeric } \\
\text { Alpha }\end{array}$ & $\begin{array}{l}\text { IYR } \\
\text { UPURELN(RG,YR) }\end{array}$ & $\begin{array}{l}4 \text { digits } \\
\text { YR = IYR }-1989 \\
\text { RG = MNUMNR } \\
\text { 'NUC FLCST" }\end{array}$ & OIAF \\
\hline 3 & $\begin{array}{l}\text { Year } \\
\text { Coal Generation } \\
\text { Record Id }\end{array}$ & Numeric & $\begin{array}{l}\text { IYR } \\
\text { HGNCLNR(1,RG, YR) }\end{array}$ & $\begin{array}{l}4 \text { digits } \\
\text { YR = IYR }-1989 \\
\text { RG }=1, \text { MNUMNR } \\
\text { 'CLGEN' }\end{array}$ & F759 \\
\hline 4 & $\begin{array}{l}\text { Year } \\
\text { Oil Generation } \\
\text { Record Id }\end{array}$ & $\begin{array}{l}\text { Numeric } \\
\text { Alpha }\end{array}$ & $\begin{array}{l}\text { IYR } \\
\text { HGNOLNR(1,RG,YR) }\end{array}$ & $\begin{array}{l}4 \text { digits } \\
\text { YR }=\text { IYR }-1989 \\
\text { RG }=1, \text { MNUMNR } \\
\text { 'OLGEN' }\end{array}$ & F759 \\
\hline 5 & $\begin{array}{l}\text { Year } \\
\text { Gas Generation } \\
\text { Record Id }\end{array}$ & $\begin{array}{l}\text { Numeric } \\
\text { Alpha }\end{array}$ & $\begin{array}{l}\text { IYR } \\
\text { HGNNGNR(1,RG,YR) }\end{array}$ & $\begin{array}{l}4 \text { digits } \\
\text { YR }=\text { IYR }-1989 \\
\text { RG }=1, \text { MNUMNR } \\
\text { 'NGGEN' }\end{array}$ & F759 \\
\hline 6 & $\begin{array}{l}\text { Year } \\
\text { Nuclear Generation } \\
\text { Record Id }\end{array}$ & $\begin{array}{l}\text { Numeric } \\
\text { Alpha }\end{array}$ & $\begin{array}{l}\text { IYR } \\
\text { HGNNUNR(1,RG,YR) }\end{array}$ & $\begin{array}{l}4 \text { digits } \\
Y R=I Y R-1989 \\
\text { RG }=1, \text { MNUMNR } \\
\text { 'NUGEN' }\end{array}$ & F759 \\
\hline 7 & $\begin{array}{l}\text { Year } \\
\text { Pumped Storage Generation }\end{array}$ & Numeric & $\begin{array}{l}\text { IYR } \\
\text { HGNPSNR(1,RG,YR) }\end{array}$ & $\begin{array}{l}4 \text { digits } \\
Y R=I Y R-1989 \\
R G=1, \text { MNUMNR }\end{array}$ & F759 \\
\hline
\end{tabular}


Record Id

8

9

10

11

13

14

17

Year

Record Id

Year

Record Id

Year

Record Id

Year

Record Id

Year

Record Id

Year

Record Id

Record Id

Year

Record Id

Year

Record Id

Year
Nat Gas Generation

MSW Generation

Wood Generation

Solar Generation

Photovoltaic Generation

Wind Generation

Year
Hydro Generation

Other Generation

Coal Fuel Consumption

Oil Fuel Consumption

Record Id

Year

Gas Fuel Consumption

Record Id

Year

Residential Sales
Alpha

Numeric

IYR

$Y R=I Y R \cdot 1989$

F759

Alpha

Numeric

IYR 'GEGEN'

HGNMSNR(1,RG,YR) YR

F759

Alpha

Numeric

IYR

HNWDNR(1,RG,YR) YR = IYR -1989

$R G=1$, MNUMNR

Alpha

Numeric

IYR 'WDGEN'

HGNSONR(1,RG, YR) YR = IYR -1989

RG $=1$, MNUMNR

Alpha

Numeric

IYR 'SOGEN'

HGNPVNR(1,RG,YR) YR = IYR -1989

$R G=1$, MNUMNR

Alpha

'PVGEN'

Numeric IYR 4 digits

HNWNNR(1,RG,YR) YR = IYR -1989

RG $=1$, MNUMNR

Alpha

Numeric

IYR 'WNGEN'

Alpha

Numeric

IYR

4 digits

HGNHYNR(1,RG,YR) YR = IYR - 1989

$R G=1$, MNUMNR

'HYGEN'

HGNOTNR(1,RG,YR) YR = IYR - 1989

$\mathrm{RG}=1, \mathrm{MNUMNR}$

Alpha

Numeric

IYR

'OTGEN'

HFL

Alpha

Numeric

IYR

HFLOLNR(1,RG,YR

YR $=$ IYR -1989

$\mathrm{RG}=1, \mathrm{MNUMNR}$

Alpha

Numeric

IYR

'OLCON'

HFLNGNR(1,RG,YR

4 digits

YR = IYR - 1989

RG $=1$, MNUMNR

Alpha

Numeric

IYR

YR $=$ IYR -1989

$\mathrm{RG}=1, \mathrm{MNUMNR}$

'NGCON'

HELRSNR(1,RG,YR) YR = IYR -1989
F759

F759

F759

F759

F759

F759

F759

F759 
Year

Emissions from Other

30

31

32

33

Year

Nonutility Coal Gen

Record Id

Year

Nonutility Oil Gen

Record Id

Year

Nonutility Gas Gen

Record Id

Year

Record Id

Year

Record Id

Year

Record Id

Year

Nonutility MSW Gen

Record Id

Year

Nonutil Wood Gen

Record Id

Year
Numeric

HEMCLTL

Nonutility Nuclear Gen

Nonutil Pumped Storage

Geothermal Generation

Nonutil Solar Gen

Numeric

IYR

Alpha

Numeric

Alpha

Numeric

IYR

Alpha

Numeric

IYR

Alpha

Numeric

IYR

Alpha

Numeric

IYR

Alpha

Numeric

IYR

Alpha

Numeric

IYR

Alpha

Numeric

IYR
$3=\mathrm{CO}_{2}$

$4=\mathrm{SO}_{2}$

$5=\mathrm{NO}_{x}$

$6=\mathrm{VOC}$

4 digits

$\mathrm{YR}=\mathrm{IYR}-1989$

EPA 92

Emission $=1,6$

$1=$ Carbon

$2=\mathrm{CO}_{1}$

$3=\mathrm{CO}_{2}$

$4=\mathrm{SO}_{2}$

$5=\mathrm{NO}_{\mathrm{x}}$

$6=\mathrm{VOC}$

4 digits

HGNCLNR(2,RG, YR) YR = IYR - 1989

$R G=1$, MNUMNR

'CLGEN'

IYR 4 digits

HGNOLNR(2,RG,YR) YR = IYR - 1989

RG $=1$, MNUMNR

'OLGEN'

4 digits

HGNNGNR(2,RG,YR) YR = IYR -1989

RGN = 1, MNUMNR

'NGGEN'

4 digits

HGNNUNR(2,RG, YR) YR = IYR -1989

RG $=1$, MNUMNR

'NUGEN'

4 digits

HGNPSNR(2,RG,YR) YR = IYR -1989

RGN = 1, MNUMNR

'PSGEN'

4 digits

HGNGENR(2,RG,YR) YR = IYR - 1989

RGN $=1$, MNUMNR

'GEGEN'

4 digits

HGNMSNR(2,RG, YR) YR = IYR -1989

RG $=1$, MNUMNR

'MSGEN'

4 digits

HNWDNR(2,RG, YR) YR = IYR -1989

RGN $=1$, MNUMNR

'WDGEN'

4 digits

HGNSONR(2,RG,YR) YR = IYR -1989
F867

F867

F867

F867

F867

F867

F867

F867

F867 
40

42

43

44

45

46

47

48

$\begin{array}{ll}\text { Notes: } & \text { LRECL }=200 \\ & \text { Blksize }=7400 \\ & \text { Filename }=\text { CN6005.PRJ.UTIL.ELDATYR.scenario.datekey } \\ & \text { NEMS use }=\text { Input to EMM }\end{array}$

Year
Nonutil Photovoltaic Gen

Numeric

IYR

Record Id

Alpha

Numeric

IYR

Record Id

Alpha

Year

Nonutil Hydro Gen

Record Id

Alpha

Year

Other Nonutility Gen

Numeric

Alpha

Year

Internat Firm Imports

Year

Internat Economy Imp

Numeric

IYR

IYR

IYR

Numeric

IYR

Numeric

IYR

Internat Firm Export

Year

Internat Economy Exp

Numeric

IYR

Numeric

IYR

Numeric

IYR
$\mathbf{R G}=1$, MNUMNR

'SOGEN'

4 digits

HGNPVNR(2,RG,YR) YR = IYR -1989

$\mathrm{RG}=1, \mathrm{MNUMNR}$

'PVGEN'

HNWNNR(2,RG,YR) YR = IYR -1989

RG $=1$, MNUMNR

Record Id

'WNGEN'

HGNHYNR(2,RG,YR) YR = IYR - 1989

RG $=1$, MNUMNR

'HYGEN'

4 digits

HGNOTNR(2,RG, YR) YR = IYR -1989

RGN $=1$, MNUMNR

'OTGEN'

HTIMPF(NERC,YR) YR = IYR - 1

$\mathrm{RG}=1, \mathrm{MNUMNR}$

HTEXPF(NERC,YR)

4 digits

$\mathrm{YR}=\mathrm{IYR}-1$

$\mathrm{RG}=1, \mathrm{MNUMN} \mathrm{R}$

HTEXPE(NERC,YR) YR = IYR -1

$R G=1$, MNUMNR

HCGGRD(NERC,YR) YR = IYR - I

RG $=1$, MNUMNR

4 digits

HCGOWN(NERC,YR) YR = IYR -1

RG $=1$, MNUMNR
FE-781R/NEB

FE-781R/NEB

F867

F867

F867

F867

FE-781R/NEB

FE-781R/NEB

F867

F867

F861 - "Annual Electric Utility Report".

F867 - "Annual Norutility Power Producer Report".

FE-781R - "Annual Report of International Electrical Export/Import Data".

EPA 92 - Department of Energy, Electric Power Annual 1992 (DOE/EIA - 0348(92)), draft report, January 1994. 
OIAF - Energy Information Administration, Office of Integrated Analysis and Forecasting, Energy Supply and Conversion Division.

Table A-15: DISPINYR Common Block Description

\begin{tabular}{|c|c|c|c|}
\hline Description & Variable & $\underline{\text { Indices }}$ & Source \\
\hline COAL GEN BY OWNERSHIP TYPE & HGNCLNR & $(2$, MNUMNR,5) & F759/F867 \\
\hline GAS (FIRM) GEN/OWNERSHIP TYPE & HGNNGNR & $(2$, MNUMNR,5) & F759/F867 \\
\hline DS GEN BY OWNERSHIP TYPE/NERC & HGNOLNR & (2,MNUMNR,5) & F759/F867 \\
\hline NUC GEN BY OWNERSHIP TYPE/NERC & HGNURNR & (2,MNUMNR,5) & F759/F867 \\
\hline PS GEN BY OWNERSHIP TYPE/NERC & HGNPSNR & (2,MNUMNR,5) & F759/F867 \\
\hline HYD (NOT PS) GEN/OWNERSHIP TYPE & HGNHYNR & $(2$, MNUMNR,5) & F759/F867 \\
\hline GEOTHERMAL GEN/OWNERSHIP TYPE & HGNGENR & $(2, M N U M N R, 5)$ & F759/F867 \\
\hline MSW GEN BY OWNERSHIP TYPE/NERC & HGNMSNR & $(2$, MNUMNR,5) & F759/F867 \\
\hline WIND GEN BY OWNERSHIP TYPE/NERC & HGNWDNR & $(2, M N U M N R, 5)$ & F759/F867 \\
\hline Solar Gen by Ownership tvpe/NERC & HGNSONR & $(2$, MNUMNR,5) & F759/F867 \\
\hline Photovoltaic Gen by Ownership type/NERC & HGNPVNR & (2,MNUMNR,5) & F759/F867 \\
\hline Wind Gen by Ownership type/NERC & HGNWNNR & $(2, M N U M N R, 5)$ & F759/F867 \\
\hline OTH GEN BY OWNERSHIP TYPE/NERC & HGNOTNR & $(2, M N U M N R, 5)$ & F759/F867 \\
\hline Tot. Gen by Ownership Type/NERC & HGNTLNR & $(2, M N U M N R, 5)$ & F759/F867 \\
\hline COAL CONS BY OWNERSHIP TYPE/NERC & HFLCLNR & (2,MNUMNR,5) & F759/F867 \\
\hline GAS CONS BY OWNERSHIP TYPE/NERC & HFLNGNR & (2,MNUMNR,5) & F759/F867 \\
\hline OIL CONS BY OWNERSHIP TYPE/NERC & HFLOLNR & (2,MNUMNR,5) & F759/F867 \\
\hline RESIDENTIAL & HELRSNR & (MNUMNR,5) & F861 \\
\hline COMMERCIAL & HELCMNR & (MNUMNR,5) & F861 \\
\hline INDUSTRIAL & HELINNR & (MNUMNR,5) & F861 \\
\hline TRANSPORTATION & HELTRNR & (MNUMNR,5) & F861 \\
\hline OTHER & HELOTNR & (MNUMNR,5) & F861 \\
\hline ALL SECTORS & HELASNR & (MNUMNR,5) & F861 \\
\hline PURCHASES FROM NONUTILITIES & HELNUNR & (MNUMNR,5) & F867 \\
\hline FIRM IMPORTS & HTIMPF & (MNUMNR,2) & FE-781R \\
\hline ECONOMY IMPORTS & HTIMPE & (MNUMNR,2) & FE-781R \\
\hline FIRM EXPORTS & HTEXPF & (MNUMNR,2) & FE-781R \\
\hline ECONOMY EXPORTS & HTEXPE & (MNUMNR,2) & FE-781R \\
\hline COGENERATION TO GRID & HCGGRD & (MNUMNR,2) & F867 \\
\hline COGENERATION OWN USE & HCGOWN & (MNUMNR,2) & F867 \\
\hline GAS (C,CO,CO2,SO2,NOX,VOC) & HEMNGTL & (MNPOLLUT,5) & EPA 92 \\
\hline OIL (C,CO,CO2,SO2,NOX,VOC) & HEMOLTL & (MNPOLLUT,5) & EPA 92 \\
\hline COAL (C,CO,CO2,SO2,NOX,VOC) & HEMCLTL & (MNPOLLUT,5) & EPA 92 \\
\hline REN (C,CO,CO2,SO2,NOX,VOC) & HEMOTTL & (MNPOLLUT,5) & EPA 92 \\
\hline CAPACITY FACTORS & UNUCFNR & (MNUMNR,MNUMYR) & OIAF \\
\hline FUEL PRICES & UPURELN & (MNUMNR,MNUMYR) & OIAF \\
\hline
\end{tabular}

F861 - "Annual Electric Utility Report".

F867 - "Annual Nonutility Power Producer Report".

FE-781R - "Annual Report of International Electrical Export/Import Data".

EPA 92 - Department of Energy, Electric Power Annual 1992 (DOE/EIA - 0348(92)), draft report, January 1994.

OIAF - Energy Information Administration, Office of Integrated Analysis and Forecasting, Energy Supply and Conversion Division.

\section{TABLE A-16: INPTDAF FILE DESCRIPTION}

The majority of the input data for the EFD is stored in the INPTDAF (CN6005.PRJ.UTIL.INPTDAF. <scenario>.<datekey>) file. This file contains exogenous inputs, load curve and demand information, trade constraints, and cost and performance information by plant group. Existing and planned units are grouped based on their physical locations (i.e. by census, fuel and electricity supply regions), their plant type and retirement year. The plants are grouped in this manner to speed and simplify the dispatch decision. The INPTDAF is loaded into ihe DISPIN common block by region and by 
year (since dispatching is done on a regional basis), again to speed the dispatch decision.

Field

- Y Value of Seasonal Load Curve

$X$ Value of Seasonal Load Curve

Number of Hours per Season

Seasonal Demand Share

Conversion Factor

Renewable Capacity

Renewable Heatrate

Variable O\&M

Total Electricity Demand

Transmission \& Distribution Loss Factor

Net Exports

Total Fixed O\&M

Conventional Capacity

Capacity Net of Planned Maintenance

Variable O\&M

Heatrate

Allowances

Maximum Fuel Shares

Capacity Factor Bounds

SO2 Penalty Cost

Summer Import Transmission Constraint

Summer Export Transmission Constraint

Winter Import Transmission Constraint

Winter Export Transmission Constraint

Number of Renewable Groups

Number of Seasonal Periods

Number of Points in Load Curve

Number of Capacity Groups

Number of Dsp. Plant Type Groups

Number of Renewable Plant Type Groups

Number of Fuels Per Plant

Number of SO2 Compliance Groups

Time of Day/Season Group Index

Time of Day/Season Segment Index

Number of Time of Day Groups

Time of Day per Day/Season Groups

Number of Segments per Group

Index for EFD Slice/Group Segment

Renewable Capacity Factor

Renewable Type

Fuel Type per Capacity Group

Fuel \& Cap. Group Index

Maximum Capacity Factor

Planned Maintenance Rate

Forced Outage Rate

Capacity Type

Scrubber Efficiency

- Compliance Group

Piant Group Ownership Type (pri,pub,ewg)

Plant Group Census Region

- Plant Group NEMS Region

Plant Group Gas Region

Renewable Group Ownership Type

Renewable Group Census Region

Renewable Group NEMS Region

\begin{tabular}{|c|c|c|c|}
\hline Units & Variable Name & Indices & Source \\
\hline GW & ELYVAL & (VS,SEASON) & Demand Modules \\
\hline Normalized Hours & ELXVAL & (VS,SEASON) & Assumption \\
\hline hours & EETIME & (SEASON) & Assumption \\
\hline Numeric & EESSHR & (SEASON) & Assumption \\
\hline Numeric & EFACTR & & Assumption \\
\hline GW & EHCAP & (REN,SSN) & F860/F867 \\
\hline Btw/Kwh & EHHTRT & (REN) & Assumption \\
\hline MM\$ & EHVOMR & (REN) & Assumption \\
\hline GWH & EQEL & & Demand Modules \\
\hline Numeric & EQTDLS & & Assumption \\
\hline GW & EEITAJ & (SEASON) & OE-411 \& EFD Output \\
\hline MM\$ & ERTOMF & & Assumption \\
\hline GW & ECCAP & (PLGRP,SSN) & F860/F867/ECP Output \\
\hline GW & ECCOPM & (PLGRP,SSN) & Assumption \\
\hline MM\$ & ECOMR & (PLGRP,FPP) & Assumption \\
\hline Btu/KWH & ECHTRT & (PLGRP,FPP) & Assumption \\
\hline Tons & ECALLW & (PLGRP) & \\
\hline Numeric & ECMFSH & (DSP,FPP,SSN) & F767 \\
\hline Numeric & ECCFBD & $(\mathrm{DSP}, 2)$ & Assumption \\
\hline \$/Ton & EPSO2 & (SO2) & Zero or EFD Output \\
\hline GW & TRNCSI & & OE -411 \\
\hline GW & TRNCST & & OE-411 \\
\hline GW & TRNCWI & & OE-411 \\
\hline GW & TRNCWT & & OE-411 \\
\hline Numeric & EHNTP & & Assumption \\
\hline Numeric & EENSP & & Assumption \\
\hline Numeric & ELNVCT & (SEASON) & Assumption \\
\hline Numeric & ECNTP & & Assuription \\
\hline Numeric & EIPGRP & & Assumption \\
\hline Numeric & EIHGRP & & Assumption \\
\hline Numeric & EIFPLT & & Assumption \\
\hline Numeric & EIMCG & & Assumption \\
\hline Numeric & ELGRP & (VS,SSN) & Assumption \\
\hline Numeric & ELSEG & (VS,SSN) & Assumption \\
\hline Numeric & ELNGRP & & Assumption \\
\hline Numeric & ELNSPG & (DAY) & Assumption \\
\hline Numeric & EFDNSP & (DAY) & Assumption \\
\hline Numeric & EFDGRP & (HR,DAY) & Assumption \\
\hline Numeric & EHHYCF & (REN,SSN) & Assumption \\
\hline Numeric & EHHYTP & (REN) & Assumption \\
\hline Numeric & ECFLTP & (PLGRP,FPP,FRG) & Assumption \\
\hline Numeric & ECFLRG & (PLGRP,FPP,FRG) & Assumption \\
\hline Numeric & ECMXCP & (PLGRP) & Assumption \\
\hline Numeric & ECPMR & (PLGRP) & Assumption \\
\hline Numeric & ECFOR & (PLGRP) & Assumption \\
\hline Numeric & ECASTS & (PLGRP) & F860/F867/ECP Output \\
\hline Numeric & ECSCRB & (PLGRP) & Assumption \\
\hline Numeric & EISO2 & (PLGRP.CGRP) & Assumption \\
\hline Numeric & ECFOWN & (PLGRP) & F860/F867 \\
\hline Numeric & ECCR & (PLGRP) & Assumption \\
\hline Numeric & ECNR & (PLGRP) & Assumption \\
\hline Numeric & ECGR & (PLGRP) & Assumption \\
\hline Numeric & EHFOWN & (REN) & Assumption \\
\hline Numeric & EHCR & (REN) & Assumption \\
\hline Numeric & EHNR & (REN) & Assumption \\
\hline
\end{tabular}


Name of Plant Types

Name of Renewable Plant Types

Name of Time of Day/Season Groups

Filler (Left Over)

$\begin{array}{llll}\text { Alpha } & \text { ENPGRP } & \text { (DSP) } & \text { Assumption } \\ \text { Alpha } & \text { ENHGRP } & \text { (RENTP) } & \text { Assumption } \\ \text { Alpha } & \text { ELNMGRP } & \text { (DAY) } & \text { Assumption } \\ \text { Spaces } & \text { Unused bytes in DISPIN common } & \end{array}$

Notes: $\quad$ VS subscript values $=1$ through 60 (Vertical Slices)

SEASON subscrip: values $=1$ through 6 ( 6 seasons)

REN subscript values $=1$ through 120 (Renewable Groups)

PLGRP subscript values $=1$ through 300 (Plant Groups)

FPP subscript values $=1$ through 4 (ECP Fuels per Plant)

DSP subscript values $=1$ through 16 (Dispatchable Capacity Types)

$\mathrm{SO} 2$ subscript values $=1$ through 2 (SO2 Compliance Groups)

DAY subscript values $=1$ through 18 (Season/Time of Day Groups)

HR subscript values $=1$ through 32 (Segments in each Season/Time of Day Group)

FRG subscript values $=1$ through 3 (Supply/Reporting Regions per Fuel Type)

RENTP subscript values $=1$ through 8 (Renewable Types)

CGRP subscript values $=1$ (Compliance Groups per Plant Group)

Each record represents 1 region/year of data.

OE-411: DOE Fonn OE-411, "Coordinated Bulk Power Supply Program Report".

F860 - "Annual Electric Generatcr Report"

F867 - "Annual Nonutility Power Producer Report"

F767 - "Steam-Electric Plant Operation and Design Report"

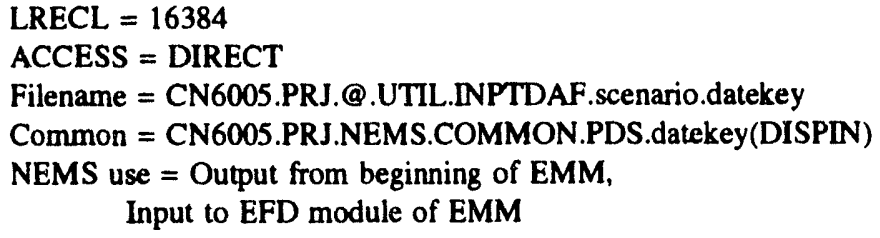

\section{A.4 Inputs from Other Modules}

\section{TABLE A-17: COGEN Common DESCRIPTION}

All these variables are from either the Industrial and/or Commercial NEMS model. The commercial, industrial and other capacity values are decremented from demand prior to the dispatch decision.

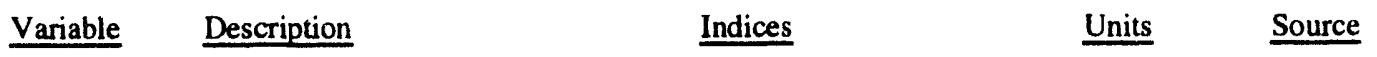

Cogeneration at Other Facilities

CGOTCAP Capacity (Other)

CGITGEN Generation (Other)

CGOTHR Heat Rates (Other)

(NRGN,YR,FUEL)

(NRGN,YR,FUEL) MWH $\quad$ F867

MW $\quad$ F867

Cogeneration Output from Refineries

$\begin{array}{lllrl}\text { CGREQ } & \text { Fuel Consumption (Refinery) } & \text { (CRGN,YR,FUEL,TYP) } & \text { MMM Btu } & \text { Refinery/F867 } \\ \text { CGRECAP } & \text { Capacity (Refinery) } & \text { (CRGN,YR,FUEL,TYP,VIN) } & \text { GW } & \text { Refinery/F867 } \\ \text { CGREGEN } & \text { Generation (Refinery) } & \text { (CRGN,YR,FUEL,TYP) } & \text { GWH } & \text { Refinery/F867 }\end{array}$

CGREGEN Generation (Refinery)

Cogeneration Output from Enhanced Oil Recovery (EOR) Facilities

\begin{tabular}{|c|c|c|c|c|}
\hline GQ & Heat $\mathbf{R a}$ & (CRGN,YR,FUEL,TYP) & Btu/kwh & \\
\hline Al & Oil \& & UEL,TYP,VIN) & GW & \\
\hline EN & Generation (EOR) & (CRGN,YR,FUEL,TYP) & GWH & \\
\hline
\end{tabular}

Total Cogen Output from Industrial Sector (including Refineries and EOR) 
CGENDQ

Fuel Consumption (Industrial)

CGINDCAP Capacity (Industrial)

CGINDGEN Generation (Industrial)

Commercial Module Cogen Variables

CGCOMGEN NUGS Generation

CGCOMQ NUGS Sales to Grid

CGCOMCAP NUGS Capacity

GRIDSHR Grid/Own Use Shares

Report Writer Variables

CGTLCAP Total Cogen Capacity

Cogen Renewables by Type

CGTLGEN Cogen Generation(Grid \& Own Use)

CGRWCAP Cogen Capacity (Renewables)

CGRWGEN Cogen Generation (Renewables)

CGRWQ

Fossil Fuel Equi. (Renewables)
(NRGN,YR)

GW

ECP Output/F867

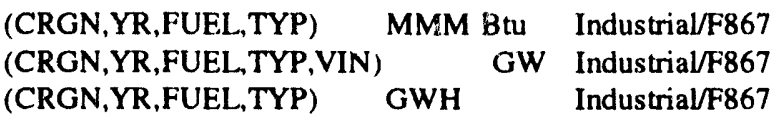

(CRGN,YR,FUEL) GWH Commercial/F867

(CRGN,YR,FURL) MMM Btu Commercial/F867

(CRGN,YR,FUEL,TYP) GWH Commercial/F867

(CRGN,YR) Numeric Commercial/F867

$\begin{array}{lll}\text { (NRGN,YR,TYP) } & \text { GWH } & \text { EFD Output/F867 } \\ \text { (NRGN,YR,TECH) } & \text { GW } & \text { ECP Output/F867 } \\ \text { (NRGN,YR,TECH) } & \text { GWH } & \text { EFD Output/F867 } \\ \text { (NRGN,YR,TECH) } & \text { trills } & \text { Assumption }\end{array}$

Notes: $\quad$ CRGN subscript values $=1$ through 9 (Census Regions)

NRGN subscript values $=1$ through 13 (NEMS Regions)

YR subscript values $=1$ through $29(1990-2015,2020,2025,2030)$

FUEL subscript values $=1$ through 4 (Fuel types, $1=$ coai, $2=0$ oil, $3=$ gas, $4=$ renew)

TYP subscript values $=1$ through 2 ( $1=$ electricity sold to utilities, $2=$ electricity for own-use)

VIN subscript values $=1$ through 2 ( 1 =existing and planned, $2=$ unplanned)

TECH subscript values $=1$ through 8 (renewable technology types)

Common $=$ CN6005.PRJ.NEMS.COMMON.PDS.datekey $($ COGEN $)$

Table A-18: WRENEW Common Description

Description

Variable

Indices

Source

TOTAL NUMBER OF SOLAR SUBPERIODS MNUMSO

TOTAL NUMBER OF WIND SUBPERIODS MNUMWI

RFM

TOTAL NUMBER OF WIND CLASSES

\# OF RENEWABLE TECHNOLOGIES

MNUMCL

WNTECH

TOTAL \# OF WORDS IN THIS COMMON

UTIL HYDRO GENER CAPACITY

WRSIZE

UTIL HYDRO CAPACITY FACTOR

WCAHYEL

(MNUMNR,MNUMYR)

WCFHYEL (MNUMNR,MNUMYR)

WCCHYEL (MNUMNR,MNUMYR)

WVCHYEL (MNUMNR,MNUMYR)

WHRHYEL (MNUMNR,MNUMYR)

UTIL HYDRO VAR OP COST

UTIL HYDRO HEAT RATE

UTIL HYDRO UNIT LIFE

WLIHYEL

UTIL FLASH GEOTH GENER CAPACITY

WCAGFEL

UTIL FLASH GEOTH CAPACITY FACTOR

UTIL FLASH GEOTH CAPITAL COST

UTIL FLASH GEOTH FIXED OP COST

UTIL FLASH GEOTH VAR OP COSTh

UTIL FLASH GEOTH HEAT RATE

UTIL FLASH GEOTH UNIT LIFE

(MNUMNR,MNUMYR)

WCFGFEL (MNUMNR,MNUMYR)

WCCGFEL (MNUMNR,MNUMYR)

WOCGFEL (MNUMNR,MNUMYR)

WVCGFEL (MNUMNR,MNUMYR)

WHRGFEL (MNUMNR,MNUMYR)

WLIGFEL

UTIL BINARY GEOTH GENER CAPACITY
UTIL BINARY GEOTH CAPACITY FACTOR UTIL BINARY GEOTH CAPITAL COST UTIL BINARY GEOTH FIXED OP COST UTIL BINARY GEOTH VAR OP COST

WCAGBEL (MNUMNR,MNUMYR)

(MNUMNR,MNUMYR)

$\begin{array}{ll}\text { WCCGBEL } & \text { (MNUMNR,MNUMYR) } \\ \text { WOCGBEL } & \text { (MNUMNR,MNUMYR) }\end{array}$

WVCGBEL (MNUMNR,MNUMYR)

RFM

RFM

RFM

RFM

RFM

RFM

RFM

RFM

RFM

RFM

RFM

RFM

RFM

RFM

RFM

RFM

RFM

RFM

RFM

RFM

RFM

RFM

RFM 
UTIL BINARY GEOTH HEAT RATE UTIL BINARY GEOTH UNIT LIFE RESIDEN GEOTH CAP RESIDEN GEOTH CAP FACTOR RESIDEN GEOTH CAP COST RESIDEN GEOTH FIXED OP COST RESIDEN GEOTH VAR OP COST RESIDEN GEOTH HEAT RATE RESIDEN GEOTH LIFE COMMERC GEOTH CAP COMMERC GEOTH CAP FACTOR COMMERC GEOTH CAP COST COMMERC GEOTH FIXED OP COST COMMERC GEOTH VAR OP COST COMMERC GEOTH HEAT RATE COMMERC GEOTH LIFE YRS UTIL MSW GENER CAPACITY UTIL MSW CAPACITY FACTOR UTIL MSW CAPITAL COST UTIL MSW FIXED OP COST UTIL MSW VAR OP COST UTIL MSW HEAT RATE UTIL MSW HEAT CONT UTIL MSW UNIT LIFE COMMERC MSW CAP COMMERC MSW CAP FACTOR COMMERC MSW CAP COST COMMERC MSW FIXED OP COST COMMERC MSW VAR OP COST COMMERC MSW HEAT RATE COMMERC MSW HEAT CONT COMMERC MSW LIFE INDUST MSW CAP INDUST MSW CAP FACTOR INDUST MSW CAP COST INDUST MSW FIXED OP COST INDUST MSW VAR OP COST INDUST MSW HEAT RATE INDUST MSW HEAT CONT INDUST MSW LIFE UTIL WOOD GENER CAPACITY UTIL WOOD CAPACITY FACTOR UTIL WOOD CAPITAL COST UTIL WOOD FIXED OP COST UTIL. WOOD VAR OP COST UTIL WOOD HEAT RATE UTIL WOOD HEAT CONT UTIL WOOD UNIT LIFE RESIDEN WOOD CAP RESIDEN WOOD CAP FACTOR RESIDEN WOOD CAP COST RESIDEN WOOD FIXED OP COST RESIDEN WOOD VAR OP COST RESIDEN WOOD HEAT RATE RESIDEN WOOD LIFE COMMERC WOOD CAP COMMERC WOOD CAP FACTOR COMMERC WOOD CAP COST COMMERC WOOD FIXED OP COST COMMERC WOOD VAR OP COST
WHRGBEL (MNUMNR,MNUMYR) WLIGBEL

WCAGERS (MNUMCR,MNUMYR)

WCFGERS (MNUMCR,MNUMYR)

WCCGERS (MNUMCR,MNUMYR)

WOCGERS (MNUMCR,MNUMYR)

WVCGERS (MNUMCR,MNUMYR)

WHRGERS (MNUMCR,MNUMYR)

WLIGERS

WCAGECM (MNUMCR,MNUMYR)

WCFGECM (MNUMCR,MNUMYR)

WCCGECM (MNUMCR,MNUMYR)

WOCGECM (MNUMCR,MNUMYR)

WVCGECM (MNUMCR,MNUMYR)

WHRGECM (MNUMCR,MNUMYR)

WLIGECM

WCAMSEL (MNUMNR,MNUMYR)

WCFMSEL (MNUMNR,MNUMYR)

WCCMSEL (MNUMNR,MNUMYR)

WOCMSEL (MNUMNR,MNUMYR)

WVCMSEL (MNUMNR,MNUMYR)

WHRMSEL (MNUMNR,MNUMYR)

WHCMSEL (MNUMNR,MNUMYR) WLIMSEL

WCAMSCM (MNUMCR,MNUMYR)

WCFMSCM (MNUMCR,MNUMYR)

WCCMSCM (MNUMCR,MNUMYR)

WOCMSCM (MNUMCR,MNUMYR)

WVCMSCM (MNUMCR,MNUMYR)

WHRMSCM (MNUMCR,MNUMYR)

WHCMSCM (MNUMCR,MNUMYR)

WLIMSCM

WCAMSIN (MNUMCR,MNUMYR)

WCFMSIN (MNUMCR,MNUMYR)

WCCMSIN (MNUMCR,MNUMYR)

WOCMSIN (MNUMCR,MNUMYR)

WVCMSIN (MNUMCR,MNUMYR)

WHRMSIN (MNUMCR,MNUMYR)

WHCMSIN (MNUMCR,MNUMYR)

WLIMSIN

WCABMEL (MNUMNR,MNUMYR)

WCFBMEL (MNUMNR,MNUMYR)

WCCBMEL (MNUMNR,MNUMYR)

WOCBMEL (MNUMNR,MNUMYR)

WVCBMEL (MNUMNR,MNUMYR)

WHRBMEL (MNUMNR,MNUMYR)

WHCBMEL (MNUMNR,MNUMYR)

WLIBMEL

WCABMRS (MNUMCR,MNUMYR)

WCFBMRS (MNUMCR,MNUMYR)

WCCBMRS (MNUMCR,MNUMYR)

WOCBMRS (MNUMCR,MNUMYR)

WVCBMRS (MNUMCR,MNUMYR)

WHRBMRS (MNUMCR,MNUMYR) WLIBMRS

WCABMCM (MNUMCR,MNUMYR)

WCFBMCM (MNUMCR,MNUMYR)

WCCBMCM (MNUMCR,MNUMYR)

WOCBMCM (MNUMCR,MNUMYR)

WVCBMCM (MNUMCR,MNUMYR)
RFM

RFM

RFM

RFM

RFM

RFM

RFM

RFM

RFM

RFM

RFM

RFM

RFM

RFM

RFM

RFM

RFM

RFM

RFM

RFM

RFM

RF:1

RFM

RFM

RFM

RFM

RFM

RFM

RFM

RFM

RFM

RFM

RFM

RFM

RFM

RFM

RFM

RFM

RFM

RFM

RFM

RFM

RFM

RFM

RFM

RFM

RFM

RFM

RFM

RFM

RFM

RFM

RFM

RFM

RFM

RFM

RFM

RFM

RFM

RFM 
COMMERC WOOD HEAT RATE COMMERC WOOD LIFE INDUST WOOD CAP INDUST WOOD CAP FACTOR INDUST WOOD CAP COST INDUST WOOD FIXED OP COST INDUST WOOD VAR OP COST INDUST WOOD HEAT RATE - INDUST WOOD LIFE UTIL SOLAR TH GENER CAPACITY UTIL SOLAR TH CAPACITY FACTOR UTIL SOLAR TH CAPITAL COST UTIL SOLAR TH FIXED OP COST UTIL SOLAR TH VAR OP COST UTIL SOLAR TH HEAT RATE UTIL SOLAR TH HEAT CONT UTIL SOLAR TH UNIT LIFE RESIDEN SOL TH CAP RESIDEN SOL TH CAP FACTOR RESIDEN SOL TH CAP COST RESIDEN SOL TH FIXED OP COST RESIDEN SOL TH VAR OP COST RESIDEN SOL TH HEAT RATE RESIDEN SOL TH LIFE RESIDEN SOL TH CAP RESIDEN SOL TH CAP FACTOR RESIDEN SOL TH CAP COST RESIDEN SOL TH FIXED OP COST RESIDEN SOL TH VAR OP COST RESIDEN SOL TH HEAT RATE RESIDEN SOL TH LIFE COMMERC SOL TH CAP COMMERC SOL TH CAP FACTOR COMMERC SOL TH CAP COST COMMERC SOL TH FIXED OP COST COMMERC SOL TH VAR OP COST COMMERC SOL TH HEAT RATE COMMERC SOL TH LIFE COMMERC SOL TH CAP COMMERC SOL TH CAP FACTOR COMMERC SOL TH CAP COST COMMERC SOL TH FIXED OP COST COMMERC SOL TH VAR OP COST COMMERC SOL TH HEAT RATE COMMERC SOL TH LIFE UTIL PHOTOV GENER CAPACITY UTIL PHOTOV CAPACITY FACTOR UTIL PHOTOV CAPITAL COST UTIL PHOTOV FIXED OP COST UTIL PHOTOV VAR OP COST UTIL PHOTOV HEAT RATE UTIL PHOTOV HEAT CONT

UTIL PHOTOV UNIT LIFE RESIDEN SOL PV CAP RESIDEN SOL. PV CAP FACTOR . RESIDEN SOL PV CAP COST RESIDEN SOL PV FIXED OP COST RESIDEN SOL PV VAR OP COST RESIDEN SOL, PV HEAT RATE RESIDEN SOL PV HEAT CONT
WHRBMCM (MNUMCR,MNUMYR) WLIBMCM

WCABMIN (MNUMCR,MNUMYR)

WCFBMIN (MNUMCR,MNUMYR)

WCCBMIN (MNUMCR,MNUMYR)

WOCBMIN (MNUMCR,MNUMYR)

WVCBMIN (MNUMCR,MNUMYR)

WHRBMIN (MNUMCR,MNUMYR)

WLIBMIN

WCASTEL

WCFSTEL

WCCSTEL

WOCSTEL

WVCSTEL

WHRSTEL

WHCSTEL

WLISTEL

WCASWRS (MNUMCR,MNUMYR)

WCFSWRS (MNUMCR,MNUMYR)

WCCSWRS (MNUMCR,MNUMYR)

WOCSWRS (MNUMCR,MNUMYR)

WVCSWRS (MNUMCR,MNUMYR)

WHRSWRS (MNUMCR,MNUMYR)

WLISWRS

WCASSRS

WCFSSRS

WCCSSRS

WOCSSRS

WVCSSRS

WHRSSRS

WLISSRS

WCASWCM (MNUMCR,MNUMYR)

WCFSWCM (MNUMCR,MNUMYR)

WCCSWCM (MNUMCR,MNUMYR)

WOCSWCM (MNUMCR,MNUMYR)

WVCSWCM (MNUMCR,MNUMYR)

WHRSWCM (MNUMCR,MNUMYR)

WLISWCM

WCASSCM

WCFSSCM

WCCSSCM

WOCSSCM

WVCSSCM

WHRSSCM

WLISSCM

WCAPVEL

WCFPVEL

WCCPVEL

WOCPVEL

WVCPVEL

WHRPVEL

WHCPVEL

WLIPVEL

WCAPVRS

WCFPVRS

WCCPVRS

WOCPVRS

WVCPVRS

WHRPVRS

WHCPVRS

(MNUMCR,MNUMYR)

(MNUMCR,MNUMYR)

(MNUMCR,MNUMYR)

(MNUMCR,MNUMYR)

(MNUMCR,MNUMYR)

(MNUMCR,MNUMYR)

(MNUMNR,MNUMYR)

(MNUMNR,MNUMYR)

(MNUMNR,MNUMYR)

(MNUMNR,MNUMYR)

(MNUMNR,MNUMYR)

(MNUMNR,MNUMYR)

(MNUMNR,MNUMYR)

(MNUMCR,MNUMYR)

(MNUMCR,MNUMYR)

(MNUMCR,MNUMYR)

(MNUMCR,MNUMYR)

(MNUMCR,MNUMYR)

(MNUMCR,MNUMYR)

(MNUMCR,MNUMYR)
RFM

RFM

RFM

RFM

RFM

RFM

RFM

RFM

RFM

RFM

RFM

RFM

RFM

RFM

RFM

RFM

RFM

RFM

RFM

RFM

RFM

RFM

RFM

RFM

RFM

RFM

RFM

RFM

RFM

RFM

RFM

RFM

RFM

RFM

RFM

RFM

RFM

RFM

RFM

RFM

RFM

RFM

RFM

RFM

RFM

RFM

RFM

RFM

RFM

RFM

RFM

RFM

RFM

RFM

RFM

RFM

RFM

RFM

RFM

RFM 
RESIDEN SOL PV LIFE

COMMERC SOL PV CAP

COMMERC SOL PV CAP FACTOR

COMMERC SOL PV CAP COST

COMMERC SOL PV FIXED OP COST

COMMERC SOL PV VAR OP COST

COMMERC SOL PV HEAT RATE

COMMERC SOL PV HEAT CONT

COMMERC SOL PV LIFE

UTIL WIND GENER CAPACITY

UTIL WIND CAPACITY FACTOR

UTIL WIND CAPITAL COST

UTIL WIND FIXED OP COST

UTIL WIND VAR OP COST

UTIL WIND HEAT RATE

UTIL WIND HEAT CONT

UTIL WIND UNIT LIFE

ETHANOL PRICE/STEP

E'THANOL QUAN/STEP

UTIL EMISSIONS FROM MSW

UTIL EMISSIONS FROM BIOMASS

UTIL EMISS FROM GEOTH FLASH

Year Available

SUBSIDY

SUBSIDY

Construction Lead Time

Percent Constructed

WIND PLANNED OUTAGE

WIND CAPACITY CREDIT

AVAIL WIND CAPACITY

WIND CAP FACTOR

SOLAR THERMAL SUPPLY SHAPE

PHOTOVOLTAICS SUPPLY SHAPE

MSW ELECTRICITY FOR INDUSTRIES

MSW STEAM FOR INDUSTRIES

\begin{tabular}{|c|c|c|}
\hline & RFM \\
\hline \multicolumn{2}{|c|}{$\begin{array}{l}\text { WLIPVRS } \\
\text { WCAPVCM (MNUMCR,MNUMYR) }\end{array}$} & RFM \\
\hline WCFPVCM & (MNUMCR,MNUMYR) & RFM \\
\hline WCCPVCM & (MNUMCR,MNUMYR) & RFM \\
\hline WOCPVCM & (MNUMCR,MNUMYR) & RFM \\
\hline WVCPVCM & (MNUMCR,MNUMYR) & RFM \\
\hline WHRPVCM & (MNUMCR,MNUMYR) & RFM \\
\hline WHCPVCM & (MNUMCR,MNUMYR) & RFM \\
\hline WLIPVCM & & RFM \\
\hline WCAWIEL & (MNUMNR,MNUMYR) & RFM \\
\hline WCFWIEL & (MNUMNR,MNUMYR) & RFM \\
\hline WCCWIEL & (MNUMNR,MNUMYR) & RFM \\
\hline WOCWIEL & (MNUMNR,MNUMYR) & RFM \\
\hline WVCWIEL & (MNUMNR,MNUMYR) & RFM \\
\hline WHRWIEL & (MNUMNR,MNUMYR) & RFM \\
\hline WHCWIEL & (MNUMNR,MNUMYR) & RFM \\
\hline WLIWIEL & & RFM \\
\hline WPETOH & & RFM \\
\hline WQETOH & & RFM \\
\hline WEMMSEL & (MNPOLLUT,MNUMYR) & RFM \\
\hline WEMBMEL & (MNPOLLUT,MNUMYR) & RFM \\
\hline WEMGFEL & (MNPOLLUT,MNUMYR) & RFM \\
\hline WCAV & (WNTECH) & RFM \\
\hline WCSU & (WNTECH,MNUMYR) & RFM \\
\hline WCSI & (WNTECH,MNUMYR) & RFM \\
\hline WCLT & (WNTECH) & RFM \\
\hline WCPC & (WNTECH8) & RFM \\
\hline WPOWIEL & (MNUMYR) & RFM \\
\hline WCRWIEL & (MNUMNR,MNUMYR) & RFM \\
\hline WSCWIEL & (MNUMNR,MNUMYR,MNUMC & RFM \\
\hline WSFWIEL & & RFM \\
\hline WSSSTEL & (MNUMNR,MNUMYR,MNUMSO) & RFM \\
\hline WSSPVEL & (MNUMNR,MNUMYR,MNUMSO) & RFM \\
\hline WQCMSINL & (44,MNUMYR) & RFM \\
\hline WQCMSINT & $(44, M N U M Y R)$ & QFM \\
\hline
\end{tabular}

Table A-19: Control Common Block Description

\begin{tabular}{|c|c|c|c|c|}
\hline Variable & Field & Indices & Units & Source \\
\hline UFPTOL & Fuel Price Tolerance & None & Numeric & Assumption \\
\hline EFD\$NERC & Demand - EFD & MNUMNR & GWH & Demand Modules \\
\hline EFDSCENSUS & Demand - EFD & MNUMCR & GWH & Demand Modules \\
\hline ECP\$NERC & Demand - ECP & MNUMCR,ECP\$FPH & GWH & Demand Modules \\
\hline ECP\$CENSUS & Demand - ECP & MNUMCR,ECP\$FPH & GWH & Demand Modules \\
\hline USYEAR & Year & MNUMYR & Numeric & \\
\hline UNYEAR & \multicolumn{2}{|l|}{ Number of Years } & Numeric & \\
\hline UNRGNS & \multicolumn{2}{|c|}{ Number of regions in current run } & Numeric & \\
\hline UF_IN & \multicolumn{2}{|c|}{ File ID (unit) for INPTDAF File (Local) } & Numeric & \\
\hline UF_OUT & \multicolumn{2}{|c|}{ File ID (unit) for OUTDAF File (Local) } & Numeric & \\
\hline UF_PLT & \multicolumn{2}{|c|}{ File ID (unit) for Plant DAF File (Local) } & Numeric & \\
\hline UF_CRV & \multicolumn{2}{|c|}{ File ID (unit) for Load Curve File(L) } & Numeric & \\
\hline UF_DBG & \multicolumn{2}{|c|}{ File ID (unit) for Debug File (Local) } & Numeric & \\
\hline UF_SO2 & \multicolumn{2}{|c|}{ File ID (unit) for SO2 Control File (L) } & Numeric & \\
\hline UZ_PLT & \multicolumn{2}{|c|}{ File ID (unit) for Plant DAF File(Global) } & Numeric & \\
\hline UZ_IN & \multicolumn{2}{|c|}{ File ID (unit) for an input File (Global) } & Numeric & \\
\hline UZ_CRV & \multicolumn{2}{|c|}{ File ID (unit) for Load Curve File (G) } & Numeric & \\
\hline UF_LD & \multicolumn{2}{|c|}{ File ID (unit) for Load DAF File (Local) } & Numeric & \\
\hline
\end{tabular}




\begin{tabular}{|c|c|c|c|c|}
\hline UZ_LD & \multicolumn{2}{|c|}{ File ID (unit) for Load DAF File (Global) } & \multicolumn{2}{|l|}{ Numeric } \\
\hline UF_TMP & File ID (unit) for Temp. File (Local) & & Numeric & \\
\hline UF_RP2 & File ID (unit) for 2 nd Report File (L) & & Numeric & \\
\hline UF_RPT & File ID (unit) for 1 st Report File (L) & & Numeric & \\
\hline UF_FL & File ID (unit) for Fuel DAF File (Loc & cal) & Numeric & \\
\hline UNFUELS & Number of Fuel Types & & Numeric & Assumption \\
\hline UNFLRG & Fuel Index & & Numeric & Assumption \\
\hline USW_ECP & Switch to turn on ECP & & Numeric & \\
\hline FLBASE & & & Numeric & \\
\hline FLLAST & & & Nunieric & \\
\hline UNFLRGS & & & Numeric & \\
\hline USW_NERC & Input Fuel Price Switch (NERC) & & Numeric & Assumption \\
\hline USW_CNES & Input Fuel Price Switch (CENSUS) & & Numeric & Assurnption \\
\hline USW_GASR & Input Fuel Price Switch (Gas) & & Numeric & Assumption \\
\hline USW_CLRG & Input Fuel Price Switch (Coal) & & Numeric & Assumption \\
\hline UF_ETT & File ID (unit) for ETTDBUG File & & Numeric & \\
\hline UF_ETTIN & File ID (unit) for ETTIN File & & Numeric & \\
\hline UF_ETTDF & File ID (unit) for ETTDF File & & Numeric & \\
\hline UF_BLD & File ID (unit) for BUILD File & & Numeric & \\
\hline UF_BOUT & File ID (unit) for BILDOUT File & & Numeric & \\
\hline UF_CNCT & File ID (unit) for ETCNCT (Contract & ts) File & Numeric & \\
\hline UF_ETDM & File ID (unit) for ETTDEM File & & Numeric & \\
\hline USW_ETT & Switch to turn on ETT & & Numeric & \\
\hline UZ_ETT & ETT Switch (not in use) & & Numeric & \\
\hline USW_UCAPE & Switch to turn on old ECP & & Numeric & \\
\hline USW_RNW & Switch to turn on Renewables & & Numeric & \\
\hline URGNME & Region Names & MNUMNR & Alpha & Assumption \\
\hline UNMFL & & EFDSNFL & Alpha & \\
\hline UF_SCEN & Name of Scenario & & Alpha & \\
\hline UCDFLRG & & $\begin{array}{l}\text { EFDSNFL, } \\
\text { EFDSMFRG }\end{array}$ & Alpha & \\
\hline UPFLRG & & EFD\$MFRG & Alpha & \\
\hline UILL & Low Sulfur Lignite Coal & & Numeric & Assumption \\
\hline UILM & Medium Sulfur Lignite Coal & & Numeric & Assumption \\
\hline UILH & High Sulfur Lignite Coal & & Numeric & Assumption \\
\hline UILV & Very High Sulfur Coal & & Numeric & Assumption \\
\hline UISL & Low Sulfur Subbituminous Coal & & Numeric & Assumption \\
\hline UISM & Medium Sulfur Subbituminous Coal & & Numeric & Assumption \\
\hline UISH & High Sulfur Subbituminous Coal & & Numeric & Assumption \\
\hline UISV & Very High Sul. Subbituminous Coal & & Numeric & Assumption \\
\hline UIBL & Low Sulfur Bituminous Coal & & Numeric & Assumption \\
\hline UIBM & Medium Sulfur Bituminous Coal & & Numeric & Assumption \\
\hline UIBH & High Sulfur Bituminous Coal & & Numeric & Assumption \\
\hline UIBV & Very High Sulfur Bituminous Coal & & Numeric & Assumption \\
\hline UIDS & Distillate Oil & & Numeric & Assumption \\
\hline UIRL & Residual Low Sulfur Oil & & Numeric & Assumption \\
\hline UIRH & Residual High Sulfur Oil & & Numeric & Assumption \\
\hline UIGF & Natural Gas - Firm & & Numeric & Assumption \\
\hline UIGI & Natural Gas - Interruptible & & Numeric & Assumption \\
\hline UIUR & Uranium & & Numeric & Assumption \\
\hline UIGC & Natural Gas - Competitive & & Numeric & Assumption \\
\hline
\end{tabular}

\section{A.5 Output/Work Files}

\section{TABLE A-20: ETT\$TMP DAF FILE DESCRIPTION}

This file has the same format as the ETTDEM DAF input file. 
Field

Net Interregional Electricity Flows Canadian Builds

Transmission \& Distrib. Loss Factor Max Summer Import Constraint Max Summer Export Constraint Max Winter Export Constraint Max Winter Import Constraint Firm Power Sales (Net)

Firm Power Sales (Gross)

Firm Power Sales (Net)

Firm Power Sales (Gross)

International Firm Power Imports

International Firm Power Imports

International Firm Power Exports

International Firm Power Exports

Firm Power Available(Canadian Supply)

Peak Power Available(Canadian Supply)

Capacity Factor(Canadian Supply)

Variable Cost (Canadian Supply)

Canadian Export Rgn (Can. Supply)

Filler (Left Over)

\begin{tabular}{ll} 
Units & Variable Name \\
\cline { 2 - 3 } GW & UEITAJ(SEASON,RGN) \\
GW & UCANBLD(RGN) \\
Numeric & UQTDLS(RGN) \\
GW & URNCSI(RGN) \\
GW & URNCST(RGN) \\
GW & URNCWT(RGN) \\
GW & URNCWI(RGN) \\
MWH & ZTDMMF(RGN) \\
MWH & ZTEXMF(RGN) \\
MM\$ & ZTDMDF(RGN) \\
MM\$ & ZTEXDF(RGN) \\
MWH & ZTIMPF(RGN) \\
MMS & ZTIMPD(RGN) \\
MM\$ & ZTEXPD(RGN) \\
MWH & ZTEXPF(RGN) \\
MW & UCISFMW(STEP,RGN) \\
MW & UCI\$PMW(STEP,RGN) \\
Numeric & UCI\$CF(STEP,RGN) \\
Mills/Kwh & UCISCST(STEP,RGN) \\
Numeric & UCI\$CRG(STEP,RGN) \\
Spaces & UnUSed bytes in \\
& DISPET3 common \\
&
\end{tabular}

Notes: $\quad$ RGN subscript values $=1$ through 16 (NEMS Rgns 1-13)

STEP subscript values $=1$ and 2 ( 2 steps)

SEASON subscript values $=1$ through 6 (6 seasons)

Each record represents 1 year of data.

LRECL $=2048$

ACCESS $=$ DIRECT

Filename $=$ CN6005.PRJ.@.UTIL.ETTSTMP.scenario.datekey

Common $=$ CN6005.PRJ.NEMS.COMMON.PDS.datekey(DISPETT)

NEMS use = Output/Work file in EMM

Table A-21: DISPUSE Common Block Description

\begin{tabular}{|c|c|c|c|}
\hline Description & Variable & Indices & Units \\
\hline Y-INT\&SLOPE CURRENT CUT LINE & ESLCUT & (2) & Numeric \\
\hline Y VALUES OF Ssnal LOAD CURVE & ETYVAL & (EFD\$MVS) & Numeric \\
\hline$X$ VALUES OF Ssnal LOAD CURVE & ETXVAL & (EFDSMVS) & Numeric \\
\hline AREA IN EACH VERTICAL SLICE & ETAREA & (EFD\$MVS) & Numeric \\
\hline TOT LOAD\&CUM AREA UND CUT LNE & EQLOAD & (2) & Numeric \\
\hline AVL CAP/SSNAL PER NET OF PMR & ECACAP & (EFD\$MPG) & Numeric \\
\hline LOAD FOLLOWING RATES & ECLFR & (EFDSMPG) & Numeric \\
\hline FUEL SHARES & ECFSHR & (EFD\$MPG,EFD\$FPP) & Numeric \\
\hline VARIABLE O\&M COST & ECVCST & (EFD\$MPG) & $\$$ \$kwh \\
\hline CAP IN EACH HORIZONTAL SLICE & ECDSPC & (EFD\$MHS) & gw \\
\hline NRG IN EACH HORIZONTAL SLICE & ECDSPE & (EFD\$MHS) & gw \\
\hline CUT LINE DEFINING HOR SLICE & ECDSPP & (EFD\$MHS,2) & Numeric \\
\hline FUEL CONS IN FUEL REGIONS & UQFUEL & (EFD\$NFL,EFD\$MFRG,E & FD\$OWN)trills \\
\hline FUEL PRC FR PREVIOUS ITR -1 & WPFUEL & (EFD\$NFL,EFD\$MFRG) & cents/mmBtu \\
\hline FUEL PRC FR PREVIOUS ITR -2 & XPFUEL & (EFD\$NFL,EFD\$MFRG) & cents/mmBtu \\
\hline FUEL CONS BY NERC/OWNER & UQFCONN & (EFD\$NFL,MNUMNR,EF & D\$OWN) trills \\
\hline GEN/FUEL TYPE IN NERC REGS & UQFGENN & (EFDSNFL,MNUMNR,EF & DSOWN) trills \\
\hline GEN/DSP CAP IN NERC REGS & UQPGENN & (EFDSDSP,MNUMNR,EF & D\$OWN) trills \\
\hline
\end{tabular}


GEN/FUEL TYPE IN CENSUS REGS GEN/DSP CAP IN CENSUS REGS GEN/REN CAPACITY IN FUEL REGS GEN/REN CAPACITY IN FUEL REGS SO2 Content by Fuel Type

- SO2 Emissions by Fuel/Census

NOX Emissions by Fuel/Census

$\mathrm{CO} 2$ Emissions by Fuel/Census

Car Emissions by Fuel/Census

CO Emissions by Fuel/Census

VOC Emissions by Fuel/Census

SO2 EMISSIONS BY Fuel/Census

NOX EMISSIONS BY Fuel/Census

CO2 EMISSIONS BY Fuel/Census

CAR EMISSIONS BY Fuel/Census

CO EMISSIONS BY Fuel/Census

VOC EMISSIONS BY Fuel/Census

* POINTS DEFINING LOAD CURVE

TEST VAR(LOAD MET=1,ELSE=0)

\# HOR SLICES REQ TO MEET LOAD

MERIT ORD MAP (1=MOST ECON)

PLT TYPE/EACH HOR SLICE

DUAL-FIRED RL USE--GAS REGS

DUAL-FIRED RH USE-GAS REGS

TEMP TOTAL FOR MIN GAS SHR

TEMP TOTAL FOR MIN G/O RAT

TEMP TOTAL FOR MAX GAS SHR

TEMP TOTAL FOR MAX G/O RAT

TEMP TOTAL. FOR PAR GAS SHR

TEMP TOTAL FOR PAR G/O RAT

MIN GAS SHR--DF PLANTS

G/O PRC RAT--MIN GAS USE

MAX GAS SHR--DF PLANTS

G/O PRC RAT--MAX GAS USE

MAX GAS SHR--DF PLANTS

G/O PRC RAT--MAX GAS USE

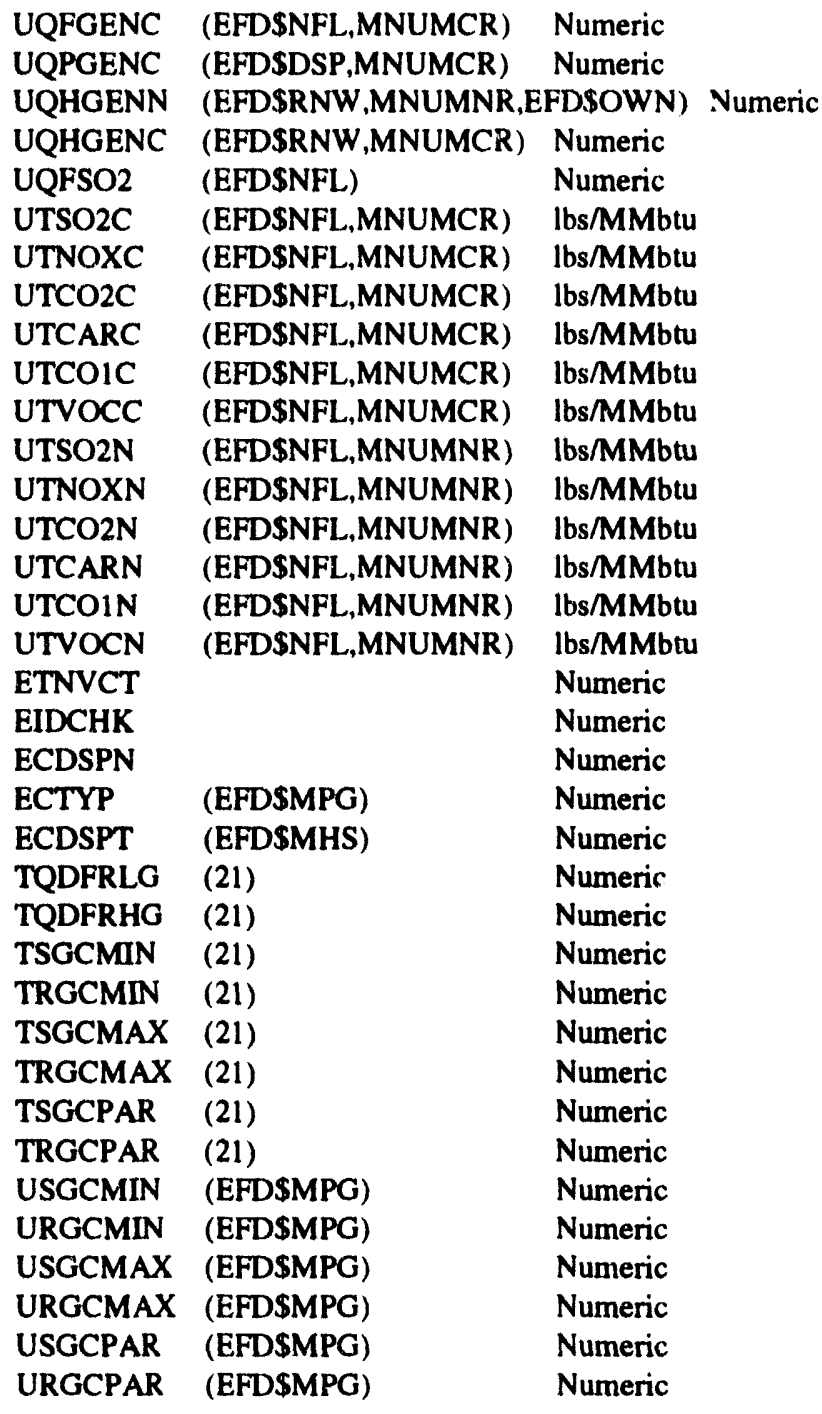

TABLE A-22: OUT DAF FILE DESCRIPTION

The OUTDAF file (loaded through the DISPOUT common block) stores EMM output information with each record containing information by region and year. The information is loaded into the DISPOUT by region and year and in turn, loads the information in the OUTDAF file (i.e., DISPOUT is overwritten for each region and year).

\begin{tabular}{lll} 
Description & Units & Variable Name \\
\cline { 2 - 3 } Variable O\&M & MM\$ & ERTOM(OWN) \\
Reserve Margin Achieved & Numeric & EEMRM \\
Total Fuel Cost & MM\$ & ERTFL(OWN) \\
Total SO2 Allowances & Tons & ETALLW \\
Total SO2 Emissions & Tons & ETSO2 \\
Total NOX Emissions & Tons & ETNOX \\
Total CO2 Emissions & Tons & ETCO2 \\
Total Car Emissions & Tons & ETCAR \\
Total CO1 Emissions & Tons & ETCO1 \\
Total VOC Emissions & Tons & ETVOC \\
Total Generation & GWH & ETGEN \\
Generation by NUGS for Own Use & GWH & EWGOWN
\end{tabular}


EWG -Rev. fr Utl

EWG Fixed \$ Compont

Commercial Cogen - Rev. fr UtI

Industrial Cogen - Rev. fr Utl

NUGS/Renewables - Rev. fr Utl

SO2 Allowances by Compliance Group

SO2 Penalty Cost by Compliance Group

SO2 Emissions by Compliance Group

Summer Capacity (End-Year)

Cum. Retirements (End-Year)

Variable O\&M by Plant Type

Fuel Cost by Plant Type

Generation by Plant Type

Avg. Annual Capacity by Plant Type

Fuel Consumption by Plant Type

SO2 Emissions by Plant Type

NOX Emissions by Plant Type

CO2 Emissions by Plant Type

Fuel Cost by Fuel Type

Generation by Fuel Type

Fuel Consumption by Fuel Type

SO2 Emissions by Fuel Type

NOX Emissions by Fuel Type

$\mathrm{CO} 2$ Emissions by Fuel Type

Avg. Fuel Price by Fuel Type

Avg. SO2 Content by Fuel Type

Avg. NOX Content by Fuel Type

Avg. $\mathrm{CO} 2$ Content by Fuel Type

Avg. Btu Content by Fuel Type

Summer Capacity (End-Year)

Cum. Retirements (End-Year)

Generation by Renewables Technology

Var. O\&M by Renewables Technology

Avg. Annual Cap. by Renewables Technology

Generation by Plant Type and Season

Capacity Req.?? by Plant Type and Season

Capacity Avail. by Plant Type and Season

Generation by Ren. Technology and Season

Capacity by Ren. Technology and Season

Peak Requirement by Season

Domestic Firm Power Sales

Domestic Economy Sales

Domestic Firm Power Sales

Domestic Economy Sales

Imports - Firm

Imports - Economy

Import Revenues

Exports - Firm

Exports - Economy

Domestic Economy Trade Profit

Exports - Revenues

Number of SO2 Compliance Groups

Number of Fuel Types

Name for Each Fuel Type

Filler (Left Over)

\begin{tabular}{|c|c|}
\hline MMS & EWGREV \\
\hline MM\$ & EWGFIX \\
\hline MM\$ & EWGRCC \\
\hline MM\$ & EWGRIC \\
\hline MMS & EWGRNW \\
\hline Tons & EGALLW(SO2) \\
\hline \$/Ton & EGPSO2(SO2) \\
\hline Tons & EGSO2(SO2) \\
\hline \multirow[t]{2}{*}{ GW } & ECSCAP(DSP,VIN,OWN) \\
\hline & ECSRET(DSP,OWN) \\
\hline MMS & ERPOM(DSP) \\
\hline MM\$ & ERPFL(DSP) \\
\hline GWH & EQPGN(DSP,OWN) \\
\hline GW & EQPCP(DSP) \\
\hline MMM Btu & EQPFL(DSP) \\
\hline Tons & EQPSO2(DSP) \\
\hline Tons & EQPNOX(DSP) \\
\hline Tons & EQPCO2(DSP) \\
\hline MM\$ & ERFFL(NFL) \\
\hline GWH & EQFGN(NFL,OWN) \\
\hline MMM Btu & EQFFL(NFL,OWN) \\
\hline Tons & EQFSO2(NFL) \\
\hline Tons & EQFNOX(NFL) \\
\hline Tons & EQFCO2(NFL) \\
\hline \$/kwh & EPFUEL(NFL) \\
\hline Ibs/MMBtu & EFRSO2(NFL) \\
\hline lbs/MMBtu & EFRNOX(NFL) \\
\hline lbs/MMBtu & EFRCO2(NFL) \\
\hline lbs/MMbtu & EFHCNT(NFL) \\
\hline GW & EHSCAP(RNW,VIN,OWN) \\
\hline GW & EHSRET(RNW,OWN) \\
\hline GWH & EQHGN(RNW,OWN) \\
\hline MM\$ & ERHOM(RNW,OWN) \\
\hline GW & $\mathrm{EQHCP}(\mathrm{RNW})$ \\
\hline GWH & EGENPS(DSP,SEASON) \\
\hline GW & EAVLPS(DSP,SEA,SON) \\
\hline GW & ECAPPS(DSP,SEASON) \\
\hline GWH & EGENHS(RNW,SEASON) \\
\hline GW & ECAPHS(RNW,SEASON) \\
\hline GW & EPEAK(SEASON) \\
\hline MWH & ETDMMF \\
\hline MWH & ETDMME \\
\hline MMS & ETDMDF \\
\hline MMS & ETDMDE \\
\hline MWH & ETIMPF \\
\hline MWH & ETIMPE \\
\hline MMS & ETIMPD \\
\hline MWH & ETEXPF \\
\hline MWH & ETEXPE \\
\hline MMS & ETDMPE \\
\hline MM\$ & ETEXPD \\
\hline Numeric & ENSO2 \\
\hline Numeric & ENFLTP \\
\hline Alpha & ENMFL(NFL) \\
\hline Spaces & $\begin{array}{l}\text { Unused bytes in } \\
\text { DISPOUT Common }\end{array}$ \\
\hline
\end{tabular}

Table A-23: UEFDOUT Common Block 
This common block contains the output of the EFD for reportwriting and to pass fuel consumption information to the fuel supply modules.

Description

Coal Gen by Ownership Type

Gas (Firm) Gen by Ownership Type

Gas (Int.) Gen by Ownership Type

Gas (Comp.) Gen by Ownership Type

DS Gen by Ownership type

RL Gen by Ownership type

RH Gen by Ownership type

Nuc Gen by Ownership type

PS Gen by Ownership type

Hyd (Not PS) Gen by Ownership type

Geothermal Gen by Ownership type

MSW Gen by Ownership type

Wind Gen by Ownership type

Solar Gen by Ownership type

Photovoltaic Gen by Ownership type

Wind Gen by Ownership type

Hyd/Oth Gen by Ownership type

Tot. Gen by Ownership Type

COAL CONS BY OWNERSHIP TYPE

GAS (FIRM) CONS BY OWNERSHIP TYPe

GAS (INT.) CONS BY OWNERSHIP TyPe

GAS (COMP.) CONS BY OWNERSHIp Type

DS CONS BY OWNERSHIP TYPE

RL CONS BY OWNERSHIP TYPE

RH CONS BY OWNERSHIP TYPE

NUC CONS BY OWNERSHIP TYPE

PS CONS BY OWNERSHIP TYPE

HYD(NOT PS) CONS BY OWNERSHIp Type

OTH. CONS BY OWNERSHIP TYPE

TOT CONS BY OWNERSHIP TYPE

Coal Price by Ownership Type

Gas (Firm) Price by Ownership Type

Gas (Int.) Price by Ownership Type

Gas (Comp) Price by Ownership Type

DS Price by Ownership Type

RL Price by Ownership Type

RH Price by Ownership Type

Nuc Yrice by Ownership Type

Ren. Price by Ownership Type

Total SO2 Emissions by NERC

Total NOX Emissions by NERC

Total $\mathrm{CO} 2$ Emissions by NERC

Total CO1 Emissions by NERC

Total CAR Emissions by NERC

Util Total Retirements by Nerc

Util BWR Nuclear gener. by CENSUS

Util PWR Nuclear gener. by CENSUS

VLS Bit Coal consumption by Coal Reg LS Bit Coal consumption by Coal Reg MS Bit Coal consumption by Coal Reg - HS Bit Coal consumption by Coal Reg VLS Sub Coal consumption by Coal Reg LS Sub Coal consumption by Coal Reg MS Sub Coal consumption by Coal Reg HS Sub Coal consumption by Coal Reg

\begin{tabular}{|c|c|}
\hline Variable & Indices \\
\hline UGNCLNR & (2,MNUMNR,MNUMYR) \\
\hline UGNGFNR & (2,MNUMNR,MNUMYR) \\
\hline UGNGINR & (2,MNUMNR,MNUMYR) \\
\hline UGNGCNR & (2,MNUMNR,MNUMYR) \\
\hline UGNDSNR & (2,MNUMNR,MNUMYR) \\
\hline UGNRLNR & (2,MNUMNR,MNUMYR) \\
\hline UGNRHNR & (2.MNUMNR,MNUMYR) \\
\hline UGNURNR & (2,MNUMNR,MNUMYR) \\
\hline UGNPSNR & (2,MNUMNR,MNUMYR) \\
\hline UGNHYNR & (2,MNUMNR,MNUMYR) \\
\hline UGNGENR & (2,MNUMNR,MNUMYR) \\
\hline UGNMSNR & (2,MNUMNR,MNUMYR) \\
\hline UGNWDNR & (2,MNUMNR,MNUMYR) \\
\hline UGNSONR & (2,MNUMNR,MNUMYR) \\
\hline UGNPVNR & (2,MNUMNR,MNUMYR) \\
\hline UGNWNNR & (2,MNUMNR,MNUMYR) \\
\hline UGNHONR & (2,MNUMNR,MNUMYR) \\
\hline UGNTLNR & (2,MNUMNR,MNUMYR) \\
\hline UFLCLNR & (2,MNUMNR,MNUMYR) \\
\hline UFLGFNR & (2,MNUMNR,MNUMYR) \\
\hline UFLGINR & (2,MNUMNR,MNUMYR) \\
\hline UFLGCNR & (2,MNUMNR,MNUMYR) \\
\hline UFLDSNR & (2,MNUMNR,MNUMYR) \\
\hline UFLRLNR & (2,MNUMNR,MNUMYR) \\
\hline UFLRHNR & (2,MNUMNR,MNUMYR) \\
\hline UFLURNR & (2,MNUMNR,MNUMYR) \\
\hline UFIPSNR & (2,MNUMNR,MNUMYR) \\
\hline UFLHYNR & (2,MNUMNR,MNUMYR) \\
\hline UFLOTNR & (2,MNUMNR,MNUMYR) \\
\hline UFLTLNR & (2,MNUMNR,MNUMYR) \\
\hline UPRCLNR & (MNUMNR,MNUMYR) \\
\hline UPRGFNR & (MNUMNR,MNUMYR) \\
\hline UPRGINR & (MNUMNR,MNUMYR) \\
\hline UPRGCNR & (MNUMNR,MNUMYR) \\
\hline UPRDSNR & (MNUMNR,MNUMYR) \\
\hline UPRRLNR & (MNUMNR,MNUMYR) \\
\hline UPRRHNR & (MNUMNR,MNUMYR) \\
\hline UPRURNR & (MNUMNR,MNUMYR) \\
\hline UPRHONR & (MNUMNR,MNUMYR) \\
\hline UTSO2 & (MNUMNR,MNUMYR) \\
\hline UTNOX & (MNUMNR,MNUMYR) \\
\hline UTCO2 & (MNUMNR,MNUMYR) \\
\hline UTCO1 & (MNUMNR,MNUMYR) \\
\hline UTCAR & (MNUMNR,MNUMYR) \\
\hline URETTLU & (MNUMNR,MNUMYR) \\
\hline UGNUBCR & (MNUMCR,MNUMYR) \\
\hline UGNUPCR & (MNUMCR,MNUMYR) \\
\hline QBCELNR & (NDREG,MNUMYR) \\
\hline QBDELNR & (NDREG,MNUMYR) \\
\hline QBMELNR & (NDREG,MNUMYR) \\
\hline QBHELNR & (NDREG,MNUMYR) \\
\hline QSCELNR & (NDREG,MNUMYR) \\
\hline QSDELNR & (NDREG,MNUMYR) \\
\hline QSMELNR & (NDREG,MNUMYR) \\
\hline QSHELNR & (NDREG,MNUMYR) \\
\hline
\end{tabular}

mwh

mwh

mwh

mwh

mwh

mwh

mwh

mwh

mwh

mwh

mwh

mwh

mwh

mwh

mwh

mwh

mwh

mwb

mwh

trills/MMBtu

trills/MMbtu

trills/MMbtu

trills/MMbtu

trills/MMbtu

trills/MMbtu

trills/MMbtu

trills/MMbtu

trills/MMbtu

trills/MMbtu

trills/MMbtu

cents/MMBtu

cents/MMBtu

cents/MMBtu

cents/MMBtu

cents/MMBtu

cents/MMBtu

cents/MMBtu

cents/MMBtu

cents/MMBtu

tons

tons

tons

tons

tons

Numeric

mwh

mwh

trills/MMBtu

trills/MMBtu

trills/MMBtu

trills/MMBtu

trills/MMBtu

trills/MMBtu

trills/MMBtu

trills/MMBtu 
VLS Lig Coal consumption by Coal Reg LS Lig Coal consumption by Coal Reg MS Lig Coal consumption by Coal Reg HS Lig Coal consumption by Coal Reg BIT COAL CONSUMPTION BY COAL REG QBTELNR SUB COAL CONSUMPTION BY COAL REG QSTELNR LIG COAL CONSUMPTION BY COAL REG QLTELNR PENALTY COST FLAG 0-NOT 1-YES BIT COAL CONVERGENCE FLAG SUB COAL. CONVERGENCE FLAG LIG COAL CONVERGENCE FLAG NG "firm" consumption by NGTDM NG "inter" consumption by NGTDM NG "compet" consumption by NGTDM

$\begin{array}{ll}\text { QLCELNR } & \text { (NDREG,MNUMYR) } \\ \text { QLDELNR } & \text { (NDREG,MNUMYR) } \\ \text { QLMELNR } & \text { (NDREG,MNUMYR) } \\ \text { QLHELNR } & \text { (NDREG,MNUMYR) } \\ \text { QBTELNR } & \text { (NDREG,MNUMYR) } \\ \text { QSTELNR } & \text { (NDREG,MNUMYR) } \\ \text { QLTELNR } & \text { (NDREG,MNUMYR) } \\ \text { FLAGSO2 } & \\ \text { FBTELNR } & \text { (NDREG) } \\ \text { FSTELNR } & \text { (NDREG) } \\ \text { FLTELNR } & \text { (NDREG-1) } \\ \text { QGFELGR } & \text { (21,MNUMYR) } \\ \text { QGIELGR } & \text { (21,MNUMYR) } \\ \text { QGCELGR } & \text { (21,MNUMYR) }\end{array}$

trills/MMBtu trills/MMBtu trills/MMBtu trills/MMBtu trills/MMBtu trills/MMBtu trills/MMBtu Numeric Numeric Numeric Numeric trills/MMBtu trills/MMBtu trills/MMBtu

Table A-24: UETTOUT Common Block

This subroutine contains trade output results for reportwriting purposes.

\begin{tabular}{|c|c|c|c|}
\hline Description & Variable & Indices & \\
\hline NET DOMESTIC FIRM POWER & UTDMMF & (MNUMNR,MNUMYR) & mwh \\
\hline NET DOMESTIC ECONOMY SALES & UTDMME & (MNUMNR,MNUMYR) & mwh \\
\hline NET DOMESTIC FIRM POWER & UTDMDF & (MNUMNR,MNUMYR) & MM\$ \\
\hline NET DOMESTIC ECONOMY SALES & UTDMDE & (MNUMNR,MNUMYR) & MMS \\
\hline FIRM POWER IMPORTS & UTIMPF & (MNUMNR,MNUMYR) & mwh \\
\hline ECONOMY POWER IMPORTS & UTIMPE & (MNUMNR,MNUMYR) & mwh \\
\hline FIRM POWER EXPORTS & UTEXPF & (MNUMNR,MNUMYR) & mwh \\
\hline ECONOMY POWER EXPORTS & UTEXPE & (MNUMNR,MNUMYR) & mwh \\
\hline GROSS DOM. FIRM POWER & UTEXMF & (MNUMNR,MNUMYR) & mwh \\
\hline GROSS DOM. ECONOMY SALES & UTEXME & (MNUMNR,MNUMYR) & mwh \\
\hline GROSS DOM. FIRM POWER & UTEXDF & (MNUMNR,MNUMYR) & MMS \\
\hline GROSS DOM. ECONOMY SALES & UTEXDE & (MNUMNR,MNUMYR) & MM\$ \\
\hline
\end{tabular}

Note:

This common block is includes in the following subroutines: ETTPRC, ETRADE, ETTCOST, TRDRPT (in the \&6005PRJ.NEMS.FORTRN.UETT. scenario.datekey code), ELEFD and ELDISP (in the \&6005PRJ. NEMS.FORTRN.UEFD.scenario.datekey). See above parameter listing for a description of the indices of the arrays.

\section{A.6 Variable Cross Reference Tables}

Table A-25: Alphabetical Variable Listing

This table contains an alphabetical listing of all the variables in the EFD source code. Beneath each variable/parameter name is the name of the subroutines in which this variable is used.

VARIABLE/PARAMETER $=$ ANINT

ELSO2L

VARIABLE/PARAMETER $=$ AREAIT

ELDISP

ELALOC

VARIABLE/PARAMETER $=$ AREANT

ELDISP 
ELALOC

ELLOAD

VARIABLE/PARAMETER $=$ AREATI

ELDISP

VARIABLE/PARAMETER = AREATR

ELDISP

VARIABLE/PARAMETER $=$ AREATT

ELDISP

ELALOC

VARIABLE/PARAMETER $=$ AREATV

ELDISP

VARIABLE/PARAMETER $=$ AREATX

ELDISP

VARIABLE/PARAMETER $=$ AREITV

ELDISP

VARIABLE/PARAMETER $=$ AREITX

ELDISP

VARIABLE/PARAMETER = AVAIL

ELPLNM

VARIABLE/PARAME'TER $=$ A_CRV

ELRNEW

VARIABLE/PARAMETER $=$ A_MAX

ELRNEW

VARIABLE/PARAMETER $=$ A_MIN

ELRNEW

VARIABLE/PARAMETER $=$ CAP

ELPLNM

VARIABLE/PARAMETER = CAPAVL

ELALOC

VARIABLE/PARAMETER $=$ CAPSW

ELALOC

VARIABLE/PARAMETER $=$ CAPTR

ELDISP

VARIABLE/PARAMETER $=$ CAPTRI

ELDISP

- VARIABLE/PARAMETER= CAPTRX ELDISP

VARIABLE/PARAMETER $=$ CAPTRY ELDISP

VARIABLE/PARAMETER $=$ CFLTMP 


\section{ELFSHR}

VARIABLE/PARAMETER $=$ COMTMP ELFSHR

VARIABLE/PARAMETER $=$ COST

ELFSHR

VARIABLE/PARAMETER $=$ COSTFL

ELFSHR

VARIABLE/PARAMETER $=$ COSTOM ELFSHR

VARIABLE/PARAMETER $=\mathrm{COSTSO} 2$ ELFSHR

VARIABLE/PARAMETER $=$ CPIVOT ELALOC

VARIABLE/PARAMETER $=$ CSO2TMP ELFSHR

VARIABLE/PARAMETER $=$ CSTTMP ELFSHR

VARIABLE/PARAMETER $=$ CST_FL ELMRIT

ELFSHR

VARIABLE/PARAMETER $=$ CST_OM ELMRIT

ELFSHR

VARIABLE/PARAMETER $=$ CST_SO 2 ELMRIT

ELFSHR

VARIABLE/PARAMETER $=$ CST_TOT ELMRIT

ELFSHR

VARIABLE/PARAMETER $=$ CUMAREA

ELDISP

VARIABLE/PARAMETER $=$ CUMAREI ELDISP

VARIABLE/PARAMETER $=$ CURITR

ELEFD

ELSO2L

VARIABLE/PARAMETER $=$ CUT

ELLOAD

VARIABLE/PARAMETER $=C_{-} 1$

ELRNEW

VARIABLE/PARAMETER $=C_{2} 2$

ELRNEW 
VARIABLE/PARAMETER $=$ C_DN ELRNEW

VARIABLE/PARAMETER $=C_{-}$UP ELRNEW

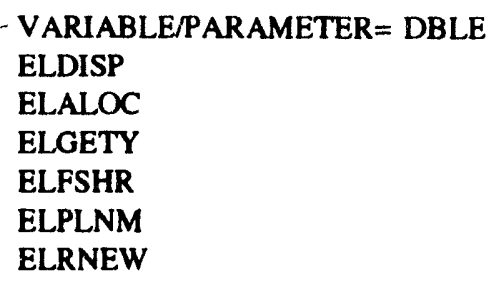

VARIABLE/PARAMETER $=$ DNC ELSO2L

VARIABLE/PARAMETER $=$ DNTRG 1 ELALOC

VARIABLE/PARAMETER $=$ DNTRG2 ELALOC

VARIABLE/PARAMETER $=$ DNTRG3 ELALOC

VARIABLE/PARAMETER $=$ DNXTRG ELALOC

VARIABLE/PARAMETER $=$ DOWN ELSO2L

VARIABLE/PARAMETER $=$ EAVLPS ELDISP

\footnotetext{
VARIABLE/PARAME $/ \mathrm{R}=\mathrm{ECACAP}$ ELDISP

ELALOC

VARIABLE/PARAMETER $=$ ECALLW ELDISP
}

VARIABLE/PARAMETER $=$ ECAPHS 
ELDISP

ELRNEW

VARIABLE/PARAMETER $=$ ECAPPS

ELDISP

ELCOST

VARIABLE/PARAMETER $=$ ECASTS

ELDISP

ELMRIT

ELALOC

ELCOST

ELFSHR

VARIABLE/PARAMETER $=$ ECCAP

ELDISP

ELFSHR

ELPLNM

VARIABLE/PARAMETER $=$ ECCFBD

ELALOC

VARIABLE/PARAMETER $=\mathrm{ECCOPM}$ ELDISP

ELPLNM

VARIABLE/PARAMETER $=\mathrm{ECCR}$

ELCOST

VARIABLE/PARAMETER $=\mathrm{ECDSPC}$ ELALOC

ELCOST

VARIABLE/PARAMETER= ECDSPE ELALOC

ELCOST

VARIABLE/PARAMETER $=$ ECDSPN ELDISP

ELALOC

ELLOAD

ELCOST

VARIABLE/PARAMETER $=$ ECDSPP

ELALOC

VARIABLE/PARAMETER $=$ ECDSPT ELDISP

ELALOC

ELCOST

VARIABLE/PARAMETER = ECFLRG ELMRIT

ELCOST

ELFSHR

VARIABLE/PARAMETER $=$ ECFLTP

ELMRIT

ELCOST 
ELFSHR

VARIABLE/PARAMETER $=E C F O R$

ELDISP

ELALOC

VARIABLE/PARAMETER $=$ ECFOWN

ELCOST

VARIABLE/PARAMETER $=$ ECFSHR

ELMRIT

ELCOST

ELFSHR

VARIABLE/PARAMETER $=$ ECGR

ELCOST

VARIABLE/PARAMETER $=$ ECHTRT

ELMRIT

ELCOST

ELFSHR

VARIABLE/PARAMETER $=$ ECLFR

ELDISP

ELALOC

VARIABLE/PARAMETER $=$ ECMFSH ELFSHR

VARIABLE/PARAMETER $=$ ECMXCP ELDISP

VARIABLE/PARAMETER $=$ ECNTP

ELDISP

ELMRIT

ELALOC

ELLOAD

ELFSHR

ELPLNM

VARIABLE/PARAMETER $=$ ECOMR

ELMRIT

ELCOST

ELFSHR

VARIABLE/PARAMETER $=$ ECP\$FPP ELCOST

VARIABLE/PARAMETER $=$ ECP\$NFL ELDISP

VARIABLE/PARAMETER $=$ ECPMR

ELDISP

ELPLNM

VARIABLE/PARAMETER = ECSCRB

ELMRIT

ELCOST

ELFSHR 
VARIABLE/PARAMETER $=$ ECTYP

ELMRIT

ELALOC

ELPLNM

VARIABLE/PARAMETER $=$ ECVCST ELMRIT

VARIABLE/PARAMETER $=$ EEITAJ

ELDISP

ELPLNM

VARIABLE/PARAMETER $=$ EEMRM

ELPLNM

VARIABLE/PARAMETER $=$ EENSP

ELDISP

ELFSHR

ELPLNM

VARIABLE/PARAMETER $=$ EESSHR ELFSHR

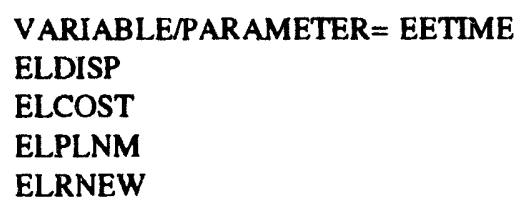

VARIABLE/PARAMETER $=$ EFACTR ELDISP

ELMRIT

ELALOC

ELCOST

ELFSHR

ELPLNM

ELRNEW

VARIABLE/PARAMETER $=$ EFDSMFRG

ELEFD

ELDISP

ELCOST

VARIABLE/PARAMETER = EFDSMHS

ELDISP

ELMRIT

ELALOC

VARIABLE/PARAMETER $=$ EFD\$MVS ELDISP

VARIABLE/PARAMETER $=$ EFD\$NFL

ELDISP

VARIABLE/PARAMETER $=$ EFD $\$ O W N$ ELDISP

VARIABLE/PARAMETER = EFDOK ELEFD 
VARIABLE/PARAMETER= EFHCNT ELDISP

ELCOST

- VARIABLE/PARAMETER = EFRCO2 ELDISP

- VARIABLE/PARAMETER = EFRNOX ELDISP

VARIABLE/PARAMETER $=\mathrm{EFRSO} 2$ ELDISP

VARIABLE/PARAMETER= EGALLW ELDISP

ELSO2F

ELSO2N

VARIABLE/PARAMETER= EGENHS ELDISP

ELRNEW

VARIABLE/PARAMETER = EGEINFS ELDISP

ELCOST

VARIABLE/PARAMETER $=$ EGNVCT ELDISP

VARIABLE/PARAMETER $=\mathrm{EGPSO} 2$ ELSO2F

VARIABLE/PARAMETER $=$ EGSO2 ELDISP

ELCOST

ELSO2F

ELSO2N

VARIABLE/PARAMETER = EGXVAL ELDISP

VARIABLE/PARAMETER = EGYVAL ELDISP

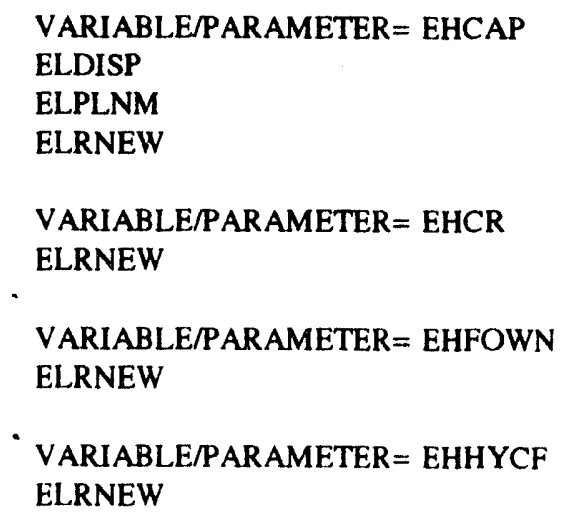

- VARIABLE/PARAMETER = EHHYCF ELRNEW

VARIABLE/PARAMETER $=$ EHHYTP 
ELDISP

ELRNEW

VARIABLE/PARAMETER $=$ EHNR

ELRNEW

VARIABLE/PARAMETER = EHNTP

ELDISP

ELPLNM

ELRNEW

VARIABLE/PARAMETER = EHVOMR

ELRNEW

VARIABLE/PARAMETER = EIDCHK

ELALOC

ELLOAD

VARIABLE/PARAMETER $=$ EIFPLT

ELMRIT

ELCOST

ELFSHR

VARIABLE/PARAMETER = EIHGRP

ELEFD

ELDISP

VARIABLE/PARAMETER $=$ EIMCG

ELDISP

ELMRIT

ELCOST

ELFSHR

VARIABLE/PARAMETER = EIPGRP

ELEFD

ELDISP

ELRNEW

VARIABLE/PARAMETER $=\mathrm{EISO} 2$

ELDISP

ELMRIT

ELCOST

ELFSHR

VARIABLE/PARAMETER $=$ ELNVCT

ELDISP

VARIABLE/PARAMETER $=$ ELXVAL

ELDISP

VARIABLE/PARAMETER = ELYVAL

ELDISP

ELPLNM

VARIABLE/PARAMETER $=$ ENFLTP

ELEFD

ELDISP

VARIABLE/PARAMETER $=$ ENSO2

ELDISP 


\section{ELSO2F \\ ELSO2N}

VARIABLE/PARAMETER = EPCRMP

ELDISP

ELCOST

VARIABLE/PARAMETER = EPEAK

ELDISP

VARIABLE/PARAMETER $=$ EPFLRG

ELDISP

ELCOST

VARIABLE/PARAMETER $=$ EPFMAP

ELDISP

ELCOST

VARIABLE/PARAMETER $=$ EPFTOL ELFSHR

VARIABLE/PARAMETER $=$ EPFUEL ELDISP

VARIABLE/PARAMETER $=\mathrm{EPSO} 2$

ELMRIT

ELFSHR

ELSO2F

VARIABLE/PARAMETER $=$ EQFCO2 ELDISP

ELCOST

VARIABLE $/ P A R A M E T E R=E Q F F L$ ELDISP

ELCOST

VARIABLE/PARAMETER $=$ EQFGN

ELDISP

ELCOST

VARIABLE/PARAMETER = EQFNOX

ELDISP

ELCOST

VARIABLE/PARAMETER $=\mathrm{EQFSO} 2$

ELDISP

ELCOST

VARIABLE/PARAMETER $=\mathrm{EQHCP}$

ELDISP

VARIABLE/PAEAMETER $=E Q H G N$

ELDISP

ELRNEW

VARIABLE/PARAMETER $=$ EQLOAD

ELDISP

ELALOC

ELLOAD 
VARIABLE/PARAMETER $=\mathrm{EQPCO} 2$ ELDISP

ELCOST

VARIABLE/PARAMETER $=$ EQPCP ELDISP

VARIABLE/PARAMEIER= EQPFL ELDISP

ELCOST

VARIABLE/PARAMETER $=$ EQPGN ELDISP

ELCOST

VARIABLE/PARAMETER = EQPNOX ELDISP

ELCOST

VARIABLE/PARAMETER $=\mathrm{EQPSO} 2$

ELDISP

ELCOST

VARIABLE/PARAMETER = ERFFL

ELDISP

ELCOST

VARIABLE/PARAMETER $=$ ERHOM

ELDISP

ELRNEW

VARIABLE/PARAMETER $=$ ERPFL

ELDISP

ELCOST

VARIABLE/PARAMETER $=$ ERPOM

ELDISP

ELCOST

VARIABLE/PARAMETER = ERTFL

ELDISP

ELCOST

VARIABLE/PARAMETER $=$ ERTOM

ELDISP

ELCOST

VARIABLE/PARAMETER $=$ ERYVAL ELDISP

VARIABLE/PARAMETER = ESLCUT

ELALOC

ELLOAD

VARIABLE/PARAMETER = ETALLW

ELDISP

VARIABLE/PARAMETER $=$ ETAREA 
ELDISP
ELLOAD

VARIABLE/PARAMETER $=$ ETCAR

ELDISP

ELCOST

VARIABLE/PARAMETER $=$ ETCO 1

ELDISP

ELCOST

VARIABLE/PARAMETER $=$ ETCO2

ELDISP

ELCOST

VARIABLE/PARAMETER= ETDSPN ELCOST

VARIABLE/PARAMETER $=$ ETDSPT ELCOST

VARIABLE/PARAMETER $=$ ETEXPE

ELDISP

ELPLNM

VARIABLEPARAMETER = ETFSHR

ELCOST

VARIABLE/PARAMETER $=$ ETGEN

ELDISP

ELCOST

VARIABLE/PARAMETER = ETIMPE

ELDISP

ELPLNM

VARIABLE/PARAMETER $=$ ETNOX

ELDISP

ELCOST

VARIABLE/PARAMETER $=$ ETNVCT

ELDISP

ELALOC

ELLOAD

ELGETY

ELGTXY

ELRNEW

VARIABLE/PARAMETER $=\mathrm{ETSO} 2$

ELDISP

ELCOST

VARIABLE/PARAMETER $=$ ETT\$MTG ELDISP

- VARIABLE/PARAMETER = ETVOC

ELDISP

ELCOST

VARIABLE/PARAMETER $=$ ETXVAL 


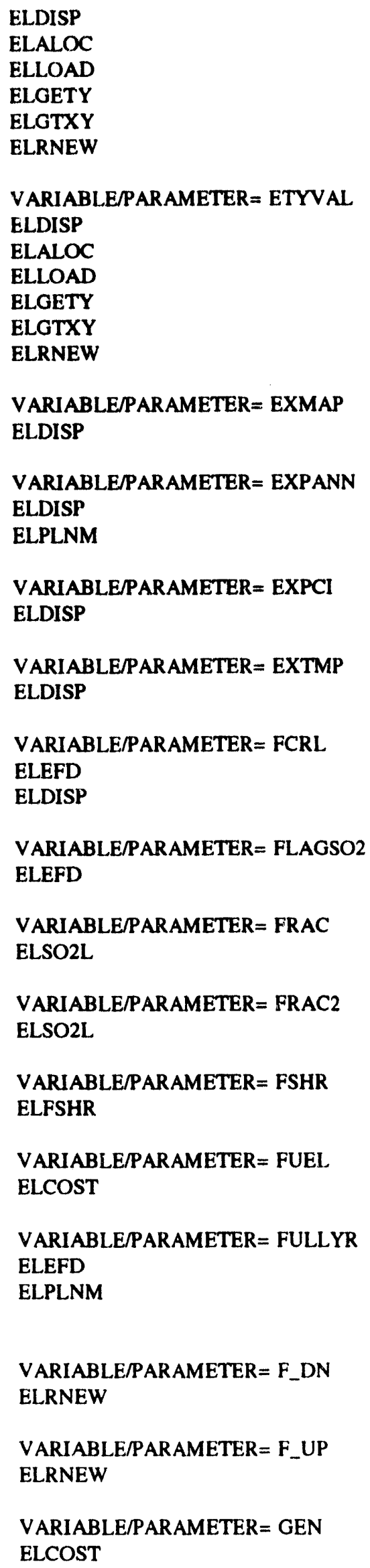


VARIABLE/PARAMETER $=H N$

ELLOAD

VARIABLE/PARAMETER = I

ELDISP

ELMRIT

ELALOC

ELLOAD

ELCOST

ELGETY

ELGTXY

ELFSHR

ELSO2F

ELSO2N

ELSO2L

VARIABLE/PARAMETER= IABOVE

ELLOAD

ELGTXY

VARIABLE/PARAMETER $=$ ICAP

ELDISP

ELALOC

VARIABLE/PARAMETER = ICCAP

ELALOC

VARIABLE/PARAMETER $=$ ICHK

ELALOC

VARIABLE/PARAMETER $=$ ICNT

ELFSHR

VARIABLE/PARAMETER $=$ ICNVG

ELEFD

ELSO2L

VARIABLE/PARAMETER $=$ ICR

ELCOST

ELRNEW

VARIABLE/PARAMETER $=$ ICTRG

ELALOC

VARIABLE/PARAMETER $=$ IDUAL ELCOST

ELFSHR

VARIABLE/PARAMETER $=$ IE

ELDISP

ELLOAD

ELCOST

VARIABLE/PARAMETER $=\mathbb{E} 1$

ELDISP

ELLOAD 


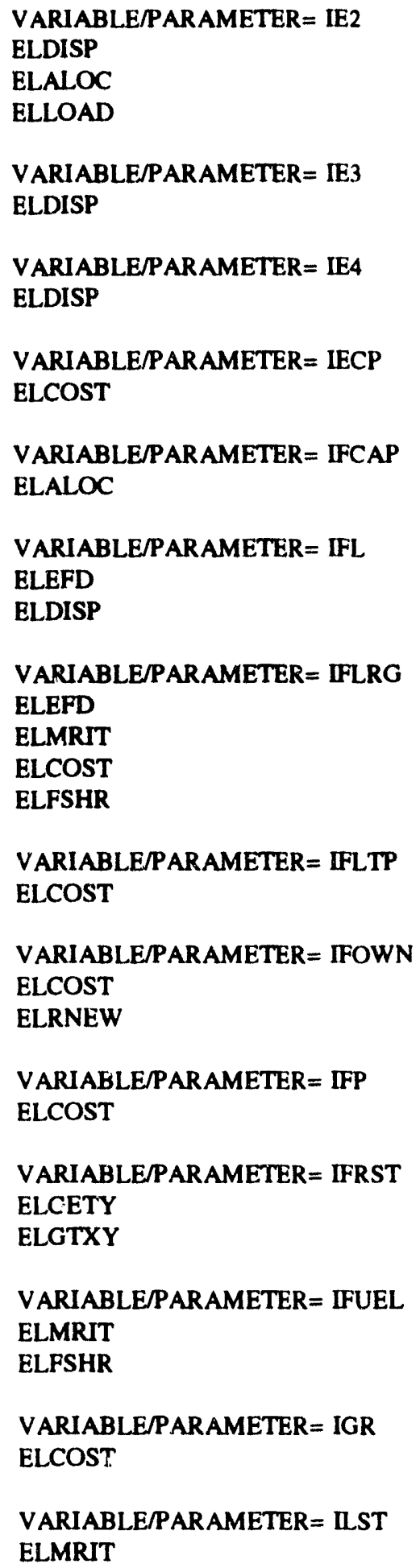




\section{ELPLNM}

VARIABLE/PARAMETER = IMPCI

ELDISP

VARIABLE/PARAMETER $=$ IMTMP

ELDISP

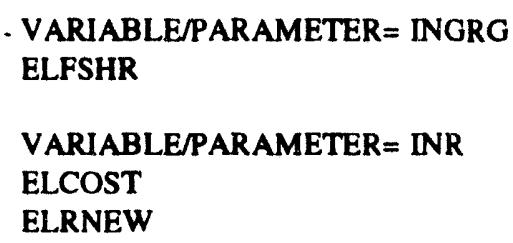

VARIABLE/PARAMETER = INTNUM

ELLOAD

VARIABLE/PARAMETER = INTRUP

ELDISP

ELPLNM

VARIABLE/PARAMETER = IOLRG

ELFSHR

VARIABLE/PARAMETER = IOUT

ELGETY

ELGTXY

VARIABLE/PARAMETER = IOWN

ELDISP

VARIABLE/PARAMETER = IPGRP

ELDISP

ELCOST

ELFSHR

VARIABLE/PARAMETER $=$ IPLNT ELPLNM

VARIABLE/PARAMETER = IPTYP ELMRIT

VARIABLE/PARAMETER $=$ IR ELFSHR

VARIABLE/PARAMETER $=$ IREC

ELDISP

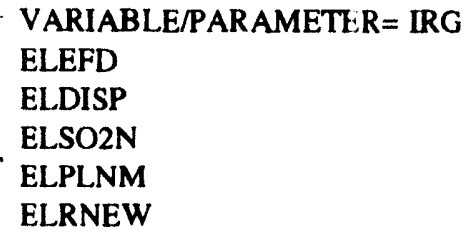

VARIABLE/PARAMETER $=$ IRNEW 
ELPLNM

VARIABLEAPARAMETER = IRNW

ELDISP

ELRNEW

VARIABLE/PARAMETER $=$ IRPTSW

ELALOC

VARIABIEEAPARAMETER= IRS

ELFSHR

tintid

VARIABLE/PARAMETER = IRT

ELFSHR

VARIABLE/PARAMETER $=$ ISO2

ELDISP

ELMRIT

ELCOST

ELFSHR

VARIABLE/PARAMETER $=I S O L$

ELEFD

ELDISP

ELSO2F

ELSO2N

ELSO2L

VARIABLE/PARAMETER $=$ ISP

ELMRIT

ELCOST

ELFSHR

ELPLNM

ELRNEW

VARIABLE/PARAMETER = ISTRT ELLOAD

VARIABLE/PARAMETER $=$ ISTRT3

ELLOAD

VARIABLE/PARAMETER $=$ IT

ELALOC

VARIABLE/PARAMETER = ITEMP

ELMRIT

ELALOC

VARIABLE/PARAMETER = IV AL

ELALOC

VARIABLE/PARAMETER $=$ IVCT

ELDISP

ELRNEW

VARIABLE/PARAMETER $=$ IYR

ELEFD

ELDISP

ELPLNM 


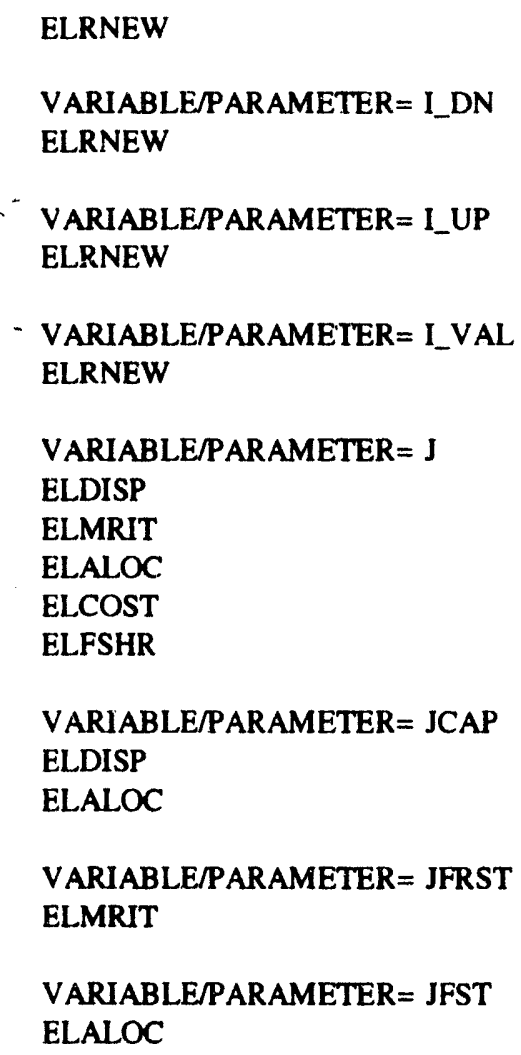

VARIABLE/PARAMETER $=J K$ ELEFD

VARIABLE/PARAMETER $=$ JPLNT ELPLNM

VARIABLE/PARAMETER $=$ JRG ELDISP

VARIABLE/PARAMETER $=J R N W$ ELRNEW

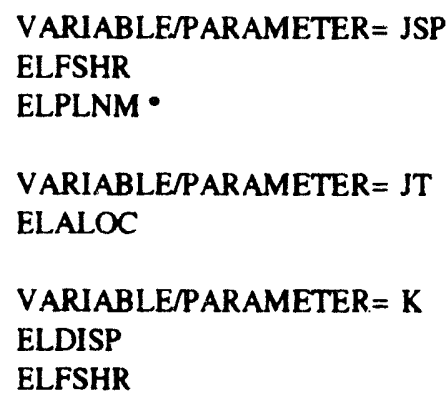

VARIABLE/PARAMETER $=\mathrm{KMXCP}$ 
ELDISP

VARIABLE/PARAMETER $=$ KPMR

ELDISP

ELPLNM

VARIABLE/PARAMETER $=K S C R B$

ELMRIT

ELCOST

ELFSHR

VARIABLE/PARAMETER $=K S P$

ELPLNM

VARIABLESPARAMETER $=$ KTRG

ELALOC

VARIABLE/PARAMETER $=$ MAX

ELDISP

ELMRIT

ELALOC

ELGETY

ELFSHR

ELSO2L

ELPLNM

ELRNEW

VARIABLE/PARAMETER $=$ MAXOSHR ELFSHR

VARIABLE/PARAMETER $=$ MAXSHR ELFSHR

VARIABLE/PARAMETER $=$ MAX_AVL ELPLNM

VARIABLE/PARAMETER = MAX_PK ELPLNM

VARIABLE/PARAMETER $=$ MIN

ELDISP

ELALOC

ELFSHR

ELSO2L

ELPLNM

ELRNEW

VARIABLE/PARAMETER = MINOSHR ELFSHR

VARIABLE/PARAMETER $=$ MINUS 1

ELALOC

VARIABLE/PARAMETER $=$ MNUMCR ELEFD

ELDISP

VARIABLE/PARAMETER $=$ MNUMNR ELEFD 
VARIABLE/PARAMETER $=\mathbf{N}$

ELALOC

ELCOST

VARIABLE/PARAMETER = NFLRG

- ELCOST

VARIABLE/PARAMETER= NGSHR

- ELFSHR

VARIABLE/PARAMETER $=$ N/MTRGR

ELALOC

VARIABLE/PARAMETER $=$ NPLINT

ELPLNM

VARIABLE/PARAMETER $=$ NT

ELALOC

VARIABLE/PARAMETER $=$ NTI

ELALOC

VARIABLE/PARAMETER $=$ NTJ

ELALOC

VARIABLE/PARAMETER $=$ NTRGOR

ELALOC

VARIABLE/PARAMETER $=$ NXTTRG

ELALOC

VARIABLE/PARAMETER $=$ OLSHR ELFSHR

VARIABLE/PARAMETER $=P C$

ELSO2L

VARIABLE/PARAMETER = PDIF ELFSHR

VARIABLE/PARAMETER $=$ PEAK ELPLNM

VARIABLE/PARAMETER $=$ PFUEL ELFSHR

VARIABLE/PARAMETER = PJUMP ELSO2L

VARIABLE/PARAMETER $=P L$ ELSO2L

- VARIABLE/PARAMETER = PMAX ELFSHR

VARIĀ̄LE/PARAMETER = PMIN ELFSHR

VARIABLE/PARAMETER $=$ PN

ELSO2L 
VARIABLE/PARAMETER $=$ PRINT

ELCOST

VARIABLE/PARAMETER $=$ PSHR ELFSHR

VARIABLE/PARAMETER $=\mathrm{PSO} 2$

ELMRIT

ELFSHR

VARIABLE/PARAMETER $=$ PTOL ELSO2L

VARIABLE/PARAMETER $=\mathrm{Q} 0$ ELSO2L

VARIABLE/PARAMETER $=\mathrm{QC}$ ELSO2L

VARIABLE/PARAMETER $=\mathrm{QL}$ ELSO2L

VARIABLE/PARAMETER $=Q N$ ELSO2L

VARIABLE/PARAMETER $=\mathrm{R} 1$ ELFSHR

VARIABLE/PARAMETER $=\mathrm{R} 2$ ELFSHR

VARIABLE/PARAMETER $=$ REQIR ELPLNM

VARIABLE/PARAMETER $=$ RQ ELPLNM

VARIABLE/PARAMETER $=$ RSHR ELFSHR

VARIABLE/PARAMETER $=$ RSHRTAV ELFSHR

VARIABLE/PARAMETER $=$ RSPRCAV ELFSHR

VARIABLE/PARAMETER $=$ RSSHR ELFSHR

VARIABLE/PARAMETER $=$ RSSO $2 \mathrm{AV}$ ELFSHR

VARIABLE/PARAMETER $=$ RSVOMAV EL.FSHR

VARIABLE/PARAMETER $=\mathrm{RX}$ ELFSHR

VARIABLE/PARAMETER $=$ R_AREA 
ELRNEW

VARIABLE/PARAMETER $=$ R_CAP

ELRNEW

- VARIABLE/PARAMETER= $\$ 1$

ELFSHR

- VARIABLE/PARAMETER= S2

ELFSHR

VARIABLE/PARAMETER = SAREA

ELALOC

ELLOAD

VARIABLE/PARAMETER $=$ SCHDLD

ELPLNM

VARIABLE/PARAMETER $=$ SHGHT

ELALOC

ELLOAD

VARIABLE/PARAMETER $=$ SLFR

ELALOC

ELLOAD

VARIABLE/PARAMETER $=$ SLFR0

ELALOC

VARIABLE/PARAMETER $=$ SLOPE ELGTXY

VARIABLE/PARAMETER = SOLSW

ELALOC

VARIABLE/PARAMETER $=$ SWGHT ELFSHR

VARIABLE/PARAMETER $=$ S_AREA ELRNEW

VARIABLE/PARAMETER $=$ S_CAP ELRNEW

VARIABLE/PARAMETER $=$ T2SHR ELFSHR

VARIABLE/PARAMETER $=$ TEMP

ELDISP

ELMRIT

ELCOST

ELFSHR

ELRNEW

VARIABLE/PARAMETER $=$ TEMP 2

ELFSHR

VARIABLE/PARAMETER $=$ TFUEL ELFSHR 
VARIABLE/PARAMETER $=$ TIYVAL

ELDISP

ELLOAD

VARIABLE/PARAMETER $=$ TLSO 2

ELSO2L

VARIABLE/PARAME'TER $=$ TOLRNC

ELALOC

VARIABLE/PARAMETER $=$ TOTAL

ELPLNM

VARIABLE/PARAMETER $=$ TOTAVL ELPLNM

VARIABLE/PARAMETER $=$ TOTGOIL ELCOST

VARIABLE/PARAMETER $=$ TOTHRS ELDISP

ELPLNM

VARIABLE/PARAMETER $=$ TQDFRHG ELEFD

ELCOST

VARIABLE/PARAMETER $=$ TQDFRLG ELEFD

ELCOST

VARIABLE/PARAMETER $=$ TQFFL

ELDISP

VARIABLE/PARAMETER $=$ TRGCMAX ELEFD

ELCOST

VARIABLE/PARAMETER $=$ TRGCMIN

ELEFD

ELCOST

VARIABLE/PARAMETER $=$ TRGCPAR ELEFD

ELCOST

VARIABLE/PARAMETER $=$ TRGSLP ELALOC

VARIABLE/PARAMETER $=$ TRIGER ELALOC

VARIABLE/PARAMETER $=$ TRNCSI

ELDISP

VARIABLE/PARAMETER $=$ TRNCST

ELDISP

ELPLNM

VARIABLE/PARAMETER $=$ TRNCWI 


\section{ELDISP}

VARIABLE/PARAMETER $=$ TRNCWT

ELDISP

ELPLNM

VARIABLE/PARAMETER $=$ TRSSHR

ELFSHR

VARIABLE/PARAMETER $=$ TSGCMAX

ELEFD

ELCOST

VARIABLE/PARAMETER $=$ TSGCMIN

ELEFD

ELCOST

VARIABLE/PARAMETER $=$ TSGCPAR

ELEFD

ELCOST

VARIABLE/PARAMETER $=$ TSHR

ELFSHR

VARIABLE/PARAMETER $=$ TSTSSN

ELPLNM

VARIABLE/PARAMETER $=$ TTYVAL

ELDISP

VARIABLE/PARAMETER = TWGHT

ELFSHR

VARIABLE/PARAMETER = TWSHR

ELFSHR

VARIABLE/PARAMETER $=T$ TAVL

ELPLNM

VARIABLE/PARAMETER $=$ T_CAP

ELRNEW

VARIABLE/PARAMETER $=$ T_DN

ELRNEW

VARIABLE/PARAMETER $=$ UCASTS

ELCOST

VARIABLE/PARAMETER $=$ UFHCNT

ELDISP

ELCOST

VARIABLE/PARAMETER $=$ UFLSECP

ELCOST

VARIABLE/PARAMETER $=$ UFPTOL

ELFSHR

VARIABLE/PARAMETER = UFRASH

ELCOST 
VARIABLE/PARAMETER = UFRCAR ELCOST

VARIABLE/PARAMETER = UFRCO 1 ELCOST

VARIABLE/PARAMETER = UFRCO2 ELDISP

ELCOST

VARIABLE/PARAMETER = UFRNOX ELDISP

ELCOST

VARIABLE/PARAMETER = UFRSO2

ELDISP

ELMRIT

ELCOST

VARIABLE/PARAMETER = UFRVOC ELCOST

VARIABLE/PARAMETER = UF_CRV ELDISP

VARIABLE/PARAMETER $=$ UF.. DBG ELEFD

ELPLNM

VARIABLE/PARAMETER $=$ UF_RPT ELEFD

VARIABLE/PARAMETER = UIALLW ELSO2N

ELSO2L

VARIABLE/PARAMETER $=$ UIGC

ELMRIT

ELCOST

ELFSHR

VARIABLE/PARAMETER = UIGF

ELMRIT

ELFSHR

VARIABLE/PARAMETER $=$ UIRH

ELCOST

ELFSHR

VARIABLE/PARAMETER = UIRL

ELCOST

ELFSHR

VARIABLE/PARAMETER $=$ UNFLRG

ELEFD

ELCOST

VARIABLE/PARAMETER = UNRGNS

ELEFD 
VARIABLE/PARAMETER $=$ UNSO2

ELEFD

ELSO2F

ELSO2L

VARIABLE/PARAMETER $=$ UNTCOS

ELDISP

- ELMRIT

VARIABLE/PARAMETER $=$ UNTCST

ELMRIT

VARIABLE/PARAMETER $=$ UP

ELSO2L

VARIABLE/PARAMETER $=\mathrm{UPCSO} 2$

ELSO2N

ELSO2L

VARIABLE/PARAMETER = UPFUEL

ELDISP

ELMRIT

ELCOST

ELFSHR

VARIABLE/PARAMETER $=$ UPLSO2

ELSO2N

ELSO2L

VARIABLE/PARAMETER $=$ UPNSO2

ELEFD

ELSO2F

ELSO2L

VARIABLE/PARAMETER = UPOLD

ELEFD

VARIABLE/PARAMETER = UQALLW ELSO2N

ELSO2L

VARIABLE/PARAMETER = UQCSO2

ELSO2N

ELSO2L

VARIABLE/PARAMETER = UQFCONN ELEFD

ELCOST

VARIABLE/PARAMETER = UQFGENC ELEFD

- ELCOST

VARIABLE/PARAMETER = UQFGENN

ELEFD

ELCOST

VARIABLE/PARAMETER $=$ UQFSO2

ELDISP 
ELCOST

VARIABLE/PARAMETER = UQFUEL

ELEFD

ELCOST

VARIABLE/PARAMETER = UQHGENC

ELEFD

ELRNEW

VARIABLE/PARAMETER = UQHGENN

ELEFD

ELRNEW

VARIABLE/PARAMETER $=$ UQLSO2

ELSO2N

ELSO2L

VARIABLE/PARAMETER= UQNSO2

ELEFD

ELSO2N

ELSO2L

VARIABLE/PARAMETER = UQPGENC ELEFD

ELCOST

VARIABLE/PARAMETER= UQPGENN ELEFD

ELCOST

VARIABLE/PARAMETER = UQPSO2

ELSO2N

ELSO2L

VARIABLE/PARAMETER= URGCMAX

ELCOST

ELFSHR

VARIABLE/PARAMETER= URGCMIN

ELCOST

ELFSHR

VARIABLE/PARAMETER= URGCPAR

ELCOST

ELFSHR

VARIABLE/PARAMETER = USGCMAX

ELCOST

ELFSHR

VARIABLE/PARAMETER = USGCMIN

ELCOST

ELFSHR

VARIABLE/PARAMETER $=$ USGCPAR

ELCOST

ELFSHR 


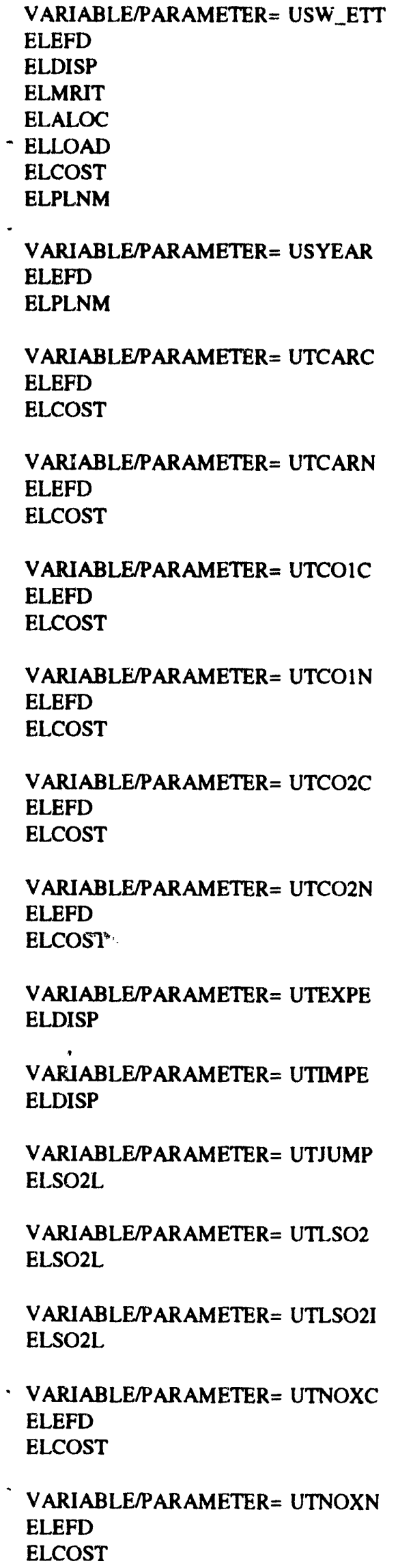

VARIABLE/PARAMETER= UTIMPE ELDISP

VARIABLE/PARAMETER= UTJUMP ELSO2L

VARIABLE/PARAMETER $=$ UTL $S O 2$ ELSO2L

VARIABLE/PARAMETER = UTLSO2I ELSO2L

- VARIABLE/PARAMETER= UTNOXC ELEFD

ELCOST

VARIABLE/PARAMETER $=$ UTNOXN ELEFD

ELCOST 
VARIABLE/PARAMETER $=$ UTPSO 2

ELSO2L

VARIABLE/PARAMETER = UTSO2C ELEFD

ELCOST

VARIABLE/PARAMETER $=$ UTSO2N

ELEFD

ELCOST

VARIABLE/PARAMETER = UTVOCC

ELEFD

ELCOST

VARIABLE/PARAMETER $=U_{-}$CAP

ELRNEW

VARIABLE/PARAMETER= WGYT

ELFSHR

VARIABLE/PARAMETER $=$ WRSSHR

ELFSHR

VARIABLE/PARAMETER $=X$

ELGETY

VARIABLE/PARAMETER $=$ XINT

ELLCAD

ELGTXY

VARIABLE/PARAMETER $=$ XPVPNT ELALOC

VARIABLE/PARAMETER $=X S H R$ ELGETY

VARIABLE/PARAMETER $=X$ X_VAL ELRNEW

VARIABLE/PARAMETER $=$ Y0

ELGTXY

VARIABLE/PARAMETER $=$ YINT

ELLOAD

ELGTXY

VARIABLE/PARAMETER $=$ YOUT

ELGETY

VARIABLE/PARAMETER $=$ YPVPNT

ELALOC

VARIABLE/PARAMETER = YVAL

ELALOC

VARIABLE/PARAMETER $=$ Y_VAL.

ELRNEW

VARIABLE/PARAMETER $=\mathrm{ZCFL}$ 
ELMRIT

VARIABLE/PARAMETER $=$ ZFAC

E!MRIT

- VARIABLE/PARAMETER $=$ ZHR

ELMRIT

- VARIABLE/PARAMETER= ZOMR

ELMRIT

VARIABLE/PARAMETER $=$ ZSCRB

ELMRIT

VARIABLE/PARAMETER $=$ ZSHR

ELMRIT

VARIABLE/PARAMETER $=$ ZSO2

ELMRIT

Table A-23 : Varlable, Common Block, Description Cross Reference

Variable Name

ABSTOL

APTR(EFD\$MSP,ETT\$MTG,EFD\$MVS)

APTRI(EFD\$MSP,ETT\$MTG,EFD\$MVS)

AREAIT(EFD\$MPG,EFD\$MVS)

AREANT(EFD\$MPG,EFD\$MVS)

AREATI(EFD\$MSP,ETT\$MTG,EFD\$MVS)

AREATR(EFD\$MSP,ETT\$MTG,EFD\$MVS)

AREATT(EFD\$MPG,EFD\$MVS)

BASEYR

CANBLD(MNUMNR)

CAPTR(EFD\$MSP,ETT\$MTG,EFD\$MVS)

CAPTRI(EFD\$MSP,ETT\$MTG,EFD\$MVS)

CASTS(EFD\$MPG)

CISCF(ECP\$CIS,MNUMNR)

CI\$CRG(ECP\$CIS,MNUMNR)

CI\$CST(ECPSCIS,MNUMNR)

CI\$FMW(ECP\$CIS,MNUMNR)

CI\$PMW(ECP\$CIS,MNUMNR)

CNVTST(NMODEL,MNUMYR)

COMMENT

CTEST

1:CONVERGED)

CURITR

CURIYR

DATE

DBDUMP

DONE1

DONE2

DSMSWTCH

EAVLPS(EFDSDSP,EFD\$MSP)

ECACAP(EFD\$MPG)

\section{Common}

NCNTRL

DISPETT

DISPETT

DISPETT

DISPETT

DISPETT

DISPETT

DISPETT

NCNTRL

DISPETT

DISPETT

DISPETT

DISPETT

DISPETT

DISPETT

DISPETT

DISPETT

DISPETT

NCNTRL

NCNTRL

NCNTRL

NCNTRL

NCNTRL

NCNTRL

NCNTRL

DISPETT

DISPETT

NCNTRL

DISPOUT

DISPUSE

\section{Description}

MINIMUM ABSOLUTE CONVERGENCE TOLERANCE

YEAR CORRESPONDING TO FIRSYR=1 (EG. 1990)

\section{CAPACITY FACTOR}

CANADIAN REGION NUMBER

COST MILLS/KWH

FIRM MW AVAILABLE

PEAK MW AVAILABLE

CONVERGENCE TEST FLAGS FOR EACH MODEL

COMMENT LINE FROM JOB STREAM

OVERALL CONVERGENCE TEST (0: NOT,

CURRENT ITERATIONS

CURRENT YEAR INDEX

DATE CODE

ON $->$ DB DUMP/YR $(0->\mathrm{OFF}, 1->\mathrm{ON})(\mathrm{DEF}=0)$

DSM SWITCH $(0 \rightarrow$ OFF, $1 \rightarrow$ ON) $(\mathrm{DEF}=1)$

Cap. Req. by Plant Type\&Season

AVL CAP/SSNAL PER NET OF PMR 

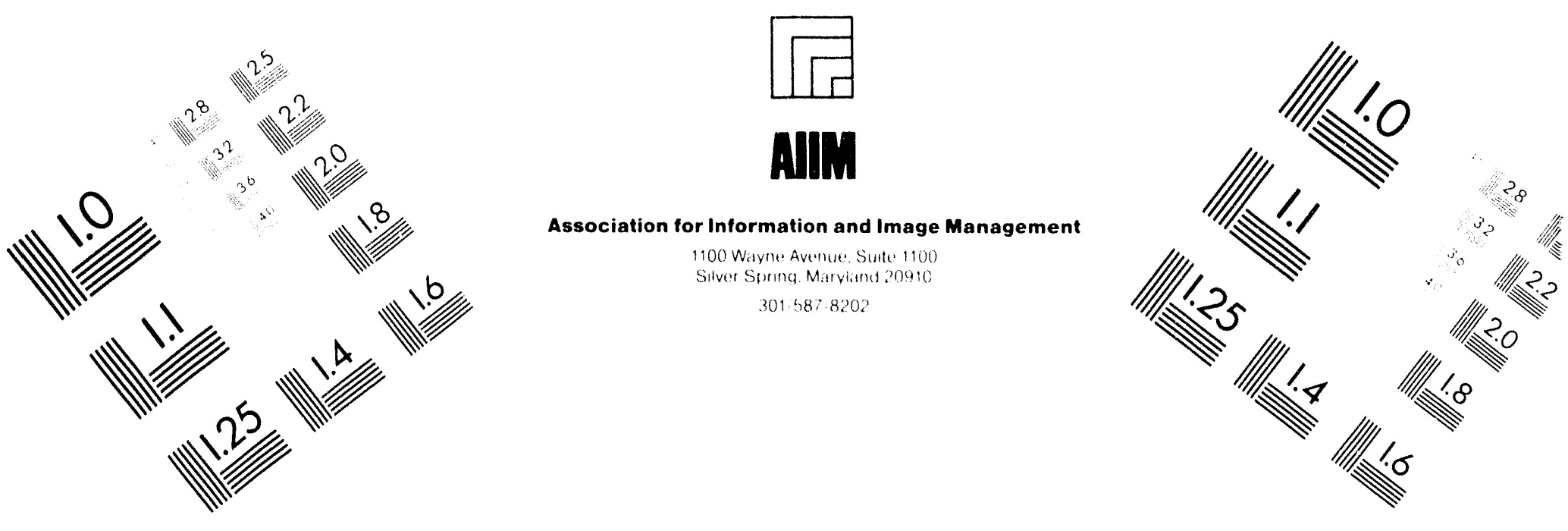

\section{Centimeter}

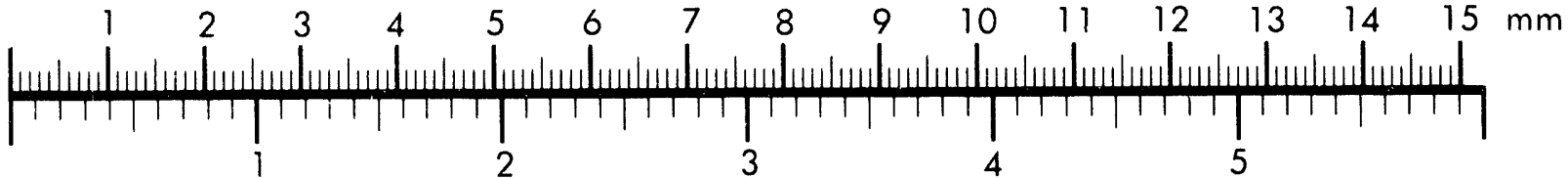

Inches
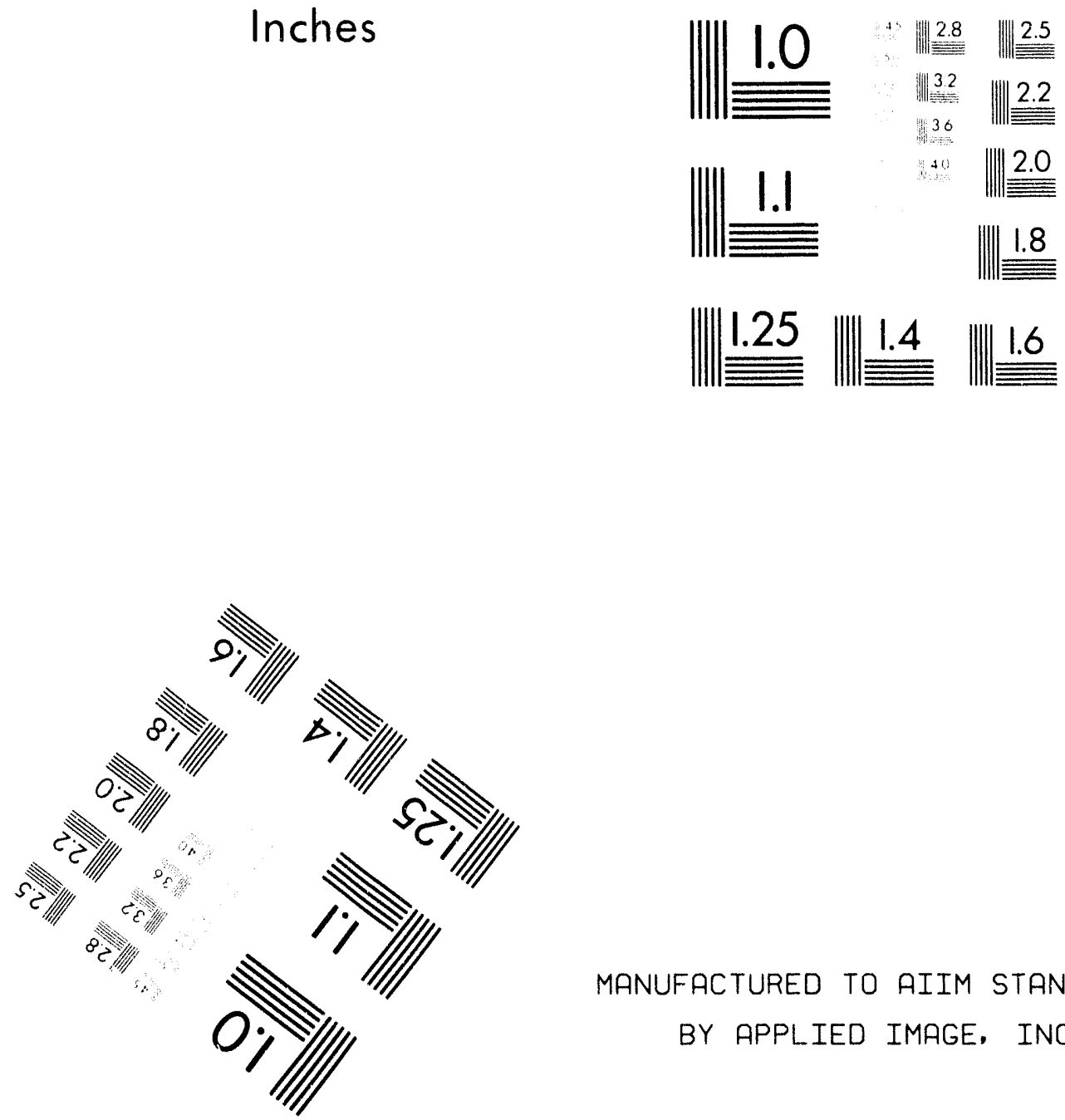

MANUFACTURED TO AIIM STANDARDS

BY APPLIED IMAGE, INC.

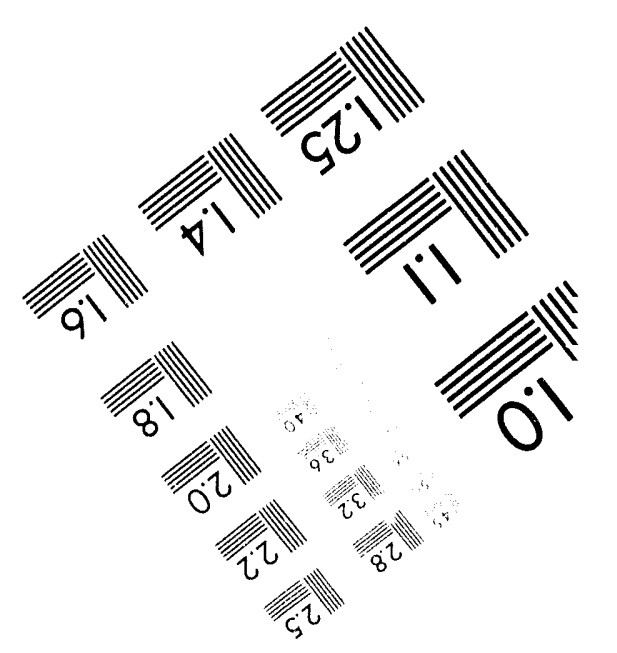



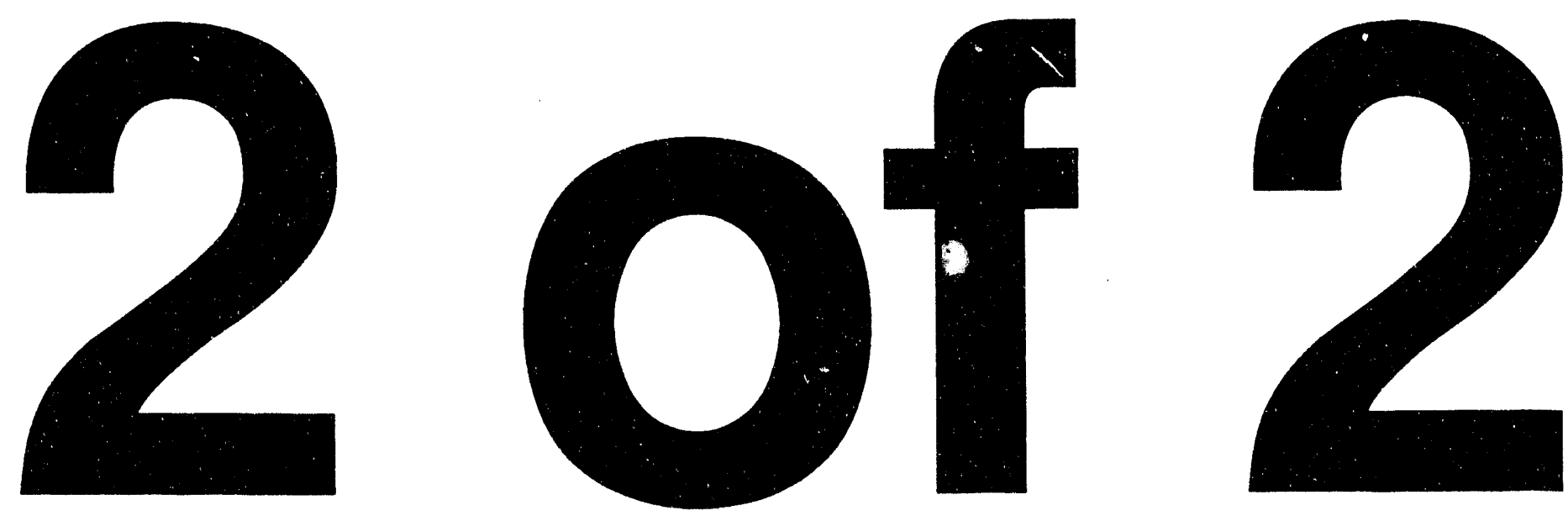
ECALLW(EFD\$MPG)

ECAPHS(EFD\$RNW,EFD\$MSP)

ECAPPS(EFD\$DSP,EFD\$MSP)

ECASTS(EFD\$MPG)

ECCAP(EFD\$MPG,EFD\$MSP)

ECCFBD(EFD\$DSP,2)

ECCOPM(EFD\$MFG,EFD\$MSP)

ECCR(EFD\$MPG)

ECDSPC(EFD\$MHS)

ECDSPE(EFD\$MHS)

ECDSPN

ECDSPP(EFD\$MHS,2)

ECDSPT(EFD\$MHS)

ECFLRG(EFD\$MPG,EFD\$FPP,EFD\$FRG)

ECFLTP(EFD\$MPG,EFD\$FPP)

ECFOR(EFD\$MPG)

ECFOWN(EFD\$MPG)

ECFSHR(EFD\$MPG,EFU\$FPP)

ECGR(EFD\$MPG)

ECHTRT(EFD\$MPG,EFD\$FPP)

ECLFR(EFD\$MPG)

ECMFSH(EFD\$DSP,EFD\$FPP,EFD\$MSP)

ECMXCP(EFD\$MPG)

ECNR(EFD\$MPG)

ECNTP

ECOMR(EFD\$MPG,EFD\$FPP)

ECP\$CAP

ECP\$CIS

ECP\$DBNM

ECP\$DECK

ECP\$DECKB(MNUMYR)

ECPSDSM

ECP\$DSP

ECP\$FILE

ECP\$FILEB

ECP\$FPH

ECP\$FPP

ECP\$INIT

ECP\$INT

ECP\$LCP

ECP\$LDG

ECP\$LINV

ECP\$MODE

ECP\$MSP

ECP\$NCC

EQUATIONS

ECP\$NFL

ECP\$OWN

ECP\$PRNT

ECP\$PROB

ECP\$RNW

TYPES

ECP\$SCR

ECP\$SGP

ECP\$SSP
DISPIN

DISPOUT

DISPOUT

DISPIN

DiSPIN

DISPIN

DISPIN

DISPIN

DISPUSE

DISPUSE

DISPUSE

DISPUSE

DISPUSE

DISPIN

DISPIN

DISPIN

DISPIN

DISPUSE

DISPIN

DISPIN

DISPUSE

DISPIN

DISPIN

DISPIN

DISPIN

DISPIN

EMMSPARM

EMM\$PARM

ECP\$CNTL

ECP\$CNTL

ECP\$CNTL

EMM\$PARM

EMM\$PARM

ECPSCNTL

ECP\$CNTL

EMMSPARM

EMMSPARM

ECP\$CNTL

EMM \$PARM

EMM\$PARM

EMM\$PARM

EMM\$PARM

ECP\$CNTL

EMM\$PARM

EMM\$PARM

EMM\$PARM

EMM\$PARM

ECP\$CNTL

ECPSCNTL

EMM\$PARM

EMM\$PARM

EMM\$PARM

EMM\$PARM

\section{ALLOWANCES}

Cap. by Ren. Technology\&Season

Cap. Avail. by Plant Type\&Ssn

CAPACITY TYPE

CONVENTIONAL CAPACITY

CAPACITY FACTOR BOUNDS

CAPACITY NET OF PLANNED MAINT.

CENSUS REGION

CAP IN EACH HORIZONTAL SLICE

NRG IN EACH HORIZONTAL SLICE

\# HOR SLICES REQ TO MEET LOAD

CUT LINE DEFINING HOR SLICE

PLT TYPE/EACH HOR SLICE

SUP./RPT. REG.--FUEL\&CAP. GRP

FUEL TYPE PER CAPACITY GROUP

FORCED OUTAGE RATE

OWNERSHIP TYPE (PRI,PUB,EWG)

FUEL SHARES

GAS REGION

HEATRATE

LOAD FOLLOWING RATES

MAXIMUM FUEL SHARES

MAXIMUM CAPACITY FACTOR

NERC REGION

NUMBER OF CAPACITY GROUPS

VARIABLE O\&M

ECP TOTAL PLANT TYPES - DSP, INT and RNW

ECP \# OF CANADIAN IMPORT SUPPLY CURVE STEPS

DATABASE NAME

DECK NAME

BASIS FILE DECK NAME

ECP NUMBER OF DSM PROGRAM TYPES

ECP NUMBER OF DISPATCHABLE CAPACITY TYPES

INPUT FILE NAME\&PATH

EMM BASIS FILE NAME

LENGTH OF FULL PLANNING HORIZON

ECP FUELS PER PLANT

INITIALIZE MATRIX $1=$ YES, $0=$ NO

ECP NUMBER OF INTERMITTENT CAPACITY TYPES

ECP LONGEST CONSTRUCTION PROFILE

ECP NUMBER OF BUILDING BLOCKS PER SEASON

ECP LENGTH OF DSM INVESTMENT PROFILE

REVISE MODE 0 - REPLACE EX. MTX.

ECP SEASONAL PERIOD

\# COEFFICIENTS FOR COAL PRICE EXPECTATIONS

ECP NUMBER OF FUEL TYPES

ECP OWNERSHIP TYPE $1=$ UTILITY $2=$ NON-UTLLITY

PRINT MODE 0 - NO MPS REC. PRINT

PROBLEM NAME

ECP NUMBER OF OTHER RENEWABLE CAPACITY

ECP NUMBER OFCLUSTERS--RETROFIT CANDIDATES ECP NUMBER OF PLANT GROUPS / RETROFIT GROUP ECP MAXIMUM NUMBER OF STEPS PER GROUP 


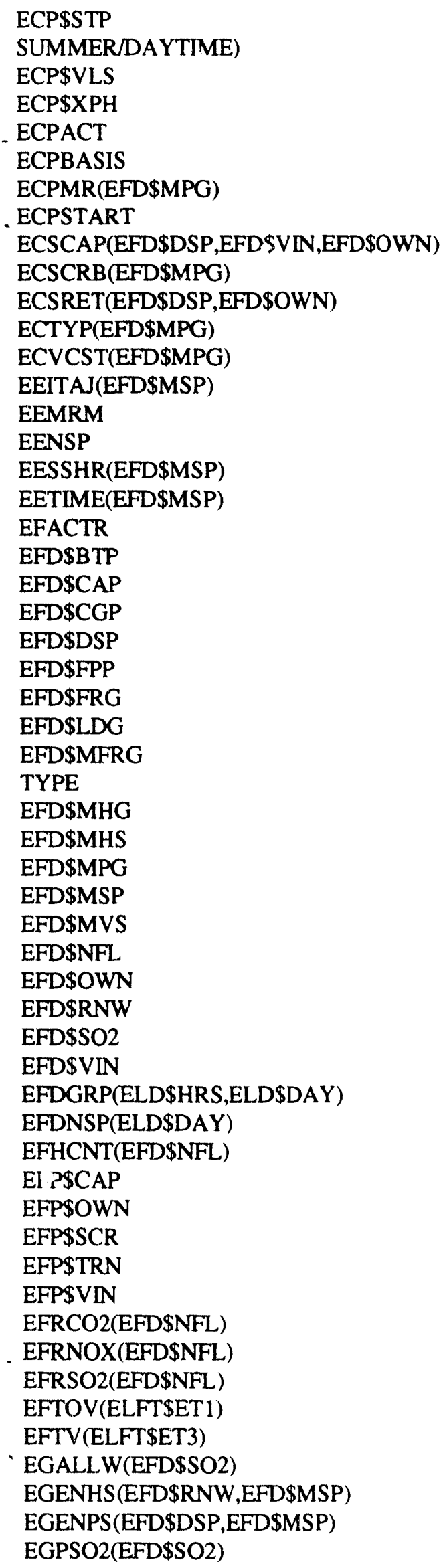

EMM\$PARM ECP NUMBER OF LOAD GROUPS (IE.

EMM\$PARM EMM\$PARM ECP\$CNTL ECP\$CNTL DISPIN NCNTRL DISPOUT DISPIN DISPOUT DISPUSE DISPUSE DISPIN DISPOUT DISPIN DISPIN DISPIN

DISPIN

EMM SPARM EMMSPARM EMM\$PARM EMMSPARM EMM\$PARM EMMSPARM EMM\$PARM EMMSPARM

EMM\$PARM EMM\$PARM EMM\$PARM EMM\$PARM EMM\$FARM EMM\$PARM EMM\$FARM EMM\$PARM EMM\$PARM EMM\$PARM DISPIN DISPIN DISPOUT

EMM\$PARM EMM\$PARM ECP\$CNTL ECP\$CNTL EMM\$PARM DISPOUT DISPOUT DISPOUT DISPETT DISPETT DISPOUT DISPOUT DISPOUT DISPOUT
ECP NUMBER OF VERTICAL LOAD SEGMENTS LENGTH OF EXPLICIT PLANNING HORIZON YEAR TO WRITE ACTFILE BASIS MODE 0-FRM PREVIOUS YEAR PLANNED MAINTENANCE RATE START YR FOR ECP MODULE (DEF = 1) Summer Capacity (End-Year) SCRUBBER EFFICIENCY Cum. Retirements (End-Year) MERIT ORD MAP (1=MOST ECON) VARIABLE O\&M COST NET IMPORTS/EXPORTS

Reserve Margin Achieved NUMBER OF SEASONAL PERIODS SEASONAL DEMAND SHARE NUMBER OF HOURS PER SEASON CONVERTS 12 TO R4(IE. * .001> BOILER TYPES TOTAL PLANT TYPES DSP AND RNW COMPLIANCE GROUPS PER PLANT GROUP DISPATCHABLE CAPACITY TYPES ECP FUELS PER PLANT SUPPLY/REPORTING REGIONS PER FUEL TYPE NUMBER OF BULDING BLOCKS PER SEASON MAXIMUM NUMBER OF REGIONS FOR ANY FUEL

RENEWABLE GROUPS HORIZONTAL SLICES

PLANT GROUPS

SEASONAL PERIODS

VERTICAL SLICES

NUMBER FUEL TYPES

OWNER.SHIP TYPE 1=PRIVATE 2=PUBLIC 3=EWG

RENEWABLE TYPES

SO2 COMPLIANCE GROUPS

VINTAGE 1=EXISTING, 2=PIPELINE, 3=NEW

INDEX FOR EFD SLICE/GRP SEG.

NUMBER OF SEGMENTS PER GROUP

Avg. Btu Content by Fuel Type

FINANCIAL PLANT TYPES DSP, INT, AND RNW

OWNERSHIP TYPE $1=$ PRIVATE $2=$ PUBLIC

EFP TYPE RETROFIT $=13$

EFP TYPE TRANSMISSION $=14$

VINTAGE $1=1990,2=1989 \ldots 34<=1955$

Avg. $\mathrm{CO} 2$ Content by Fuel Type

Avg. NOX Content by Fuel Type

Avg. SO2 Content by Fuel Type

SO2 Allowances by Compl. Grp

Gen. by Ren. Technology\&Season

Gen. by Plant Ty'pe and Season

$\mathrm{SO} 2$ Penalty Cost by Compl. Grp 
EGSO2(EFD\$SO2)

EHCAP(EFD\$MHG,EFD\$MSP)

EHCR(EFD\$MHG)

EHFOWN(EFD\$MHG)

EHHTRT(EFD\$MHG)

EHHYCF(EFD\$MHG,EFD\$MSP)

EHHYTP(EFD\$MHG)

EHNR(EFD\$MHG)

EHNTP

EHSCAP(EFD\$RNW,EFD\$VIN,EFD\$OWN)

EHSRET(EFD\$RNW,EFD\$OWN)

EHVOMR(EFD\$MHG)

EIDCHK

EIFPLT

EIHGRP

EIMCG

EIPGRP

EISO2(EFD\$MPG,EFD\$CGP)

EITAJ(EFD\$MSP,MNUMNR)

ELASSW

ELD\$DAY

ELD\$HRS

ELGRP(EFD\$MVS,EFD\$MSP)

ELNGRP

ELNMGRP(ELD\$DAY)

ELNSPG(ELD\$DAY)

ELNVCT(EFD\$MSP)

ELSEG(EFD\$MVS,EFD\$MSP)

ELXVAL(EFD\$MVS,EFD\$MSP)

ELYVAL(EFD\$MVS,EFD\$MSP)

ENDYR

ENFLTP

ENHGRP(EFD\$RNW)

ENMFL(EFD\$NFL)

ENPGRP(EFD\$DSP)

ENSO2

EPALCO2(ECP\$XPH)

EPALNOX(ECP\$XPH)

EPALSO2(ECP\$XPH)

EPCCRF(ECPSCAP)

EPCENSUS

EPCFOM(ECP\$CAP)

EPCLRG

EPCOVR(ECP\$CAP)

EPCRMP(EFD\$NFL,MNUMCR)

EPDCCR(ECP\$DSM,ECP\$XPH)

EPDINV(ECP\$DSM,ECP\$XPH)

EPDLSI(ECP\$DSM,ECP\$VLS,ECP\$XPH)

EPDSCRT

EPEAK(EFD\$MSP)

EPFCH4(EFD\$NFL)

EPFCO1(EFD\$NFL)

EPFCO2(EFD\$NFL)

EPFCRB(EFD\$NFL)

EPFLRG(EFD\$NFL,EFD\$MFR
DISPOUT

DISPIN

DISPIN

DISPIN

DISPIN

DISPIN

DISPIN

DISPIN

DISPIN

DISPOUT

DISPOUT

DISPIN

DISPUSE

DISPIN

DISPIN

DISPIN

DISPIN

DISPIN

DISPETT

NCNTRL

EMMSPARM

EMM\$PARM

DISPIN

DISPIN

DISPIN

DISPIN

DISPIN

DISPIN

DISPIN

DISPIN

NCNTRL

DISPOUT

DISPIN

DISPOUT

DISPIN

DISPOUT

BILDIN

BILDIN

BILDIN

BILDIN

BILDIN

BILDIN

BILDIN

BILDIN

BILDIN

BILDIN

BILDIN

BILDIN

BILDIN

DISPOUT

BILDIN

BILDIN

BILDIN

BILDIN

BILDIN
SO2 Emissions by Compl. Grp

RENEWABLE CAPACITY

CENSUS REGION

OWNERSHIP TYPE(PRI,PUB,EWG)

RENEWABLE HEATRATE

RENEWABLE CAPACITY FACTOR

RENEWABLE TYPE

NERC REGION

NUMBER OF RENEWABLE GROUPS

Summer Capacity (End-Year)

Cum. Retirements (End-Year)

VARIABLE O\&M

TEST VAR(LOAD MET $=1$, ELSE $=0$ )

NUMBER OF FUELS PER PLANT

NUMBER OF REN. PLANT TYPE GRPS

NUMBER COMPLIANCE GROUPS

NUMBER OF DSP. PLANT TYPE GRPS

COMPLIANCE GROUP

Elasticity Switch (0->No Elas Calc,1->Calc)

SEASON / TIME OF DAY GROUPS

SEGMENTS IN EACH SEASON/TIME OF DAY GROUPS

TIME OF DAY/SEASON GROUP INDEX

NUMBER OF TIME OF DAY GROUPS

TIME OF DAY/SSN GRPS

TIME OF DAY PER DAY/SEASON GRP

NUMBER OF POINTS IN LOAD CURVE

TIME OF DAY/SEASON SEG. INDEX

$X$ VALUE OF SEASONAL LOAD CURVE

Y VALUE OF SEASONAL LOAD CURVE

YEAR CORRESPONDING TO LASTYR=29 (EG. 2030)

Number of Fuel Types

RENEWABLE PLANT TYPES

NAME FOR EACH FUEL TYPE

NAME OF PLANT TYPES

Number of Compliance Groups

CO2 EMISSIONS ALLOWANCES

NOX EMISSIONS ALLOWANCES

SO2 EMISSIONS ALLOWANCES

FIXED CHARGE FACTOR TRANS.

CENSUS REGION

FIXED O\&M TRANSMISSION

COAL REGION

OVERNIGHT COST TRANSMISSION

NERC REG MAP TO CENSUS REG

CAPACITY CREDIT--DSM

CUMUL. NET PV-NOMINAL DSM INV.

DSM LOAD IMPACT BY SEGMENT\&YR

UTIL DSC RT (NOM, TAX ADJ ROR)

Peak Requirement by Season

CH4 EMISSION RATE BY FUEL

CO EMISSION RATE BY FUEL

CO2 EMISSION RATE BY FUEL

CARBON EMISSION RATE BY FUEL

NERC REG MAP TO EACH FUEL REG 


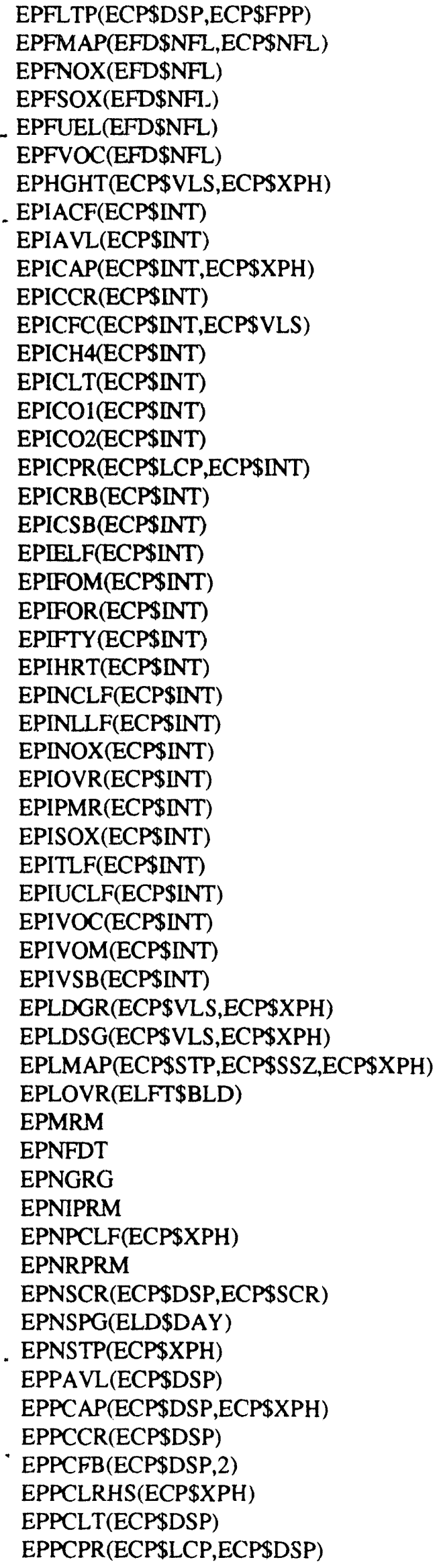

\begin{tabular}{|c|c|}
\hline BILDIN & ECP FUEL TYPES--DSP. CAP. \\
\hline BILDIN & EFD TO ECP FUEL TYPES \\
\hline BILDIN & NOX EMISSION RATE BY FUEL \\
\hline BILDIN & SOX EMISSION RATE BY FUEL \\
\hline DISPOUT & Avg. Fuel Price by Fuel Type \\
\hline BILDIN & VOC EMISSION RATE BY FUEL \\
\hline BILDIN & HEIGHT OF VERTICAL LOAD SEGS \\
\hline BILDIN & AVERAGE CAP FACTR/--INT. CAP. \\
\hline BILDIN & COMMERCIAL, OP. DATE--INT. CAP \\
\hline BILDIN & EXISTING INT. CAPACITY \\
\hline BILDIN & CAPACITY CREDIT--INT. CAP \\
\hline BILDIN & CAPACITY FACTR/LOAD--INT. CAP. \\
\hline BILDIN & CH4 EMISSION RATE--INT. CAP \\
\hline BILDIN & CONSTRUCTION LDTIME--INT. CAP \\
\hline BLLDIN & CO EMISSION RATE --INT. CAP \\
\hline BILDIN & CO2 EMISSION RATE--INT. CAP \\
\hline BILDIN & CONSTRUCTION PROFILE--INT. CAP \\
\hline BILDIN & CARBON EMISSION RATE--INT. CAP \\
\hline BLDIN & CAPITAL COST CREDIT-INT. CAP \\
\hline BILDIN & ECONOMIC LIFE--INT. CAP \\
\hline BILDIN & FIXED O\&M COST--INT. CAP \\
\hline BILDIN & FORCED OUTAGE RATE--INT. CAP. \\
\hline BILDIN & INPUT FUEL TYPE--INT. CAP \\
\hline BILDIN & HEAT RATE--INT. CAP. \\
\hline BILDIN & NUG CONTRACT LIFE--INT. CAP \\
\hline BILDIN & NUG LOAN LIFE $\quad$-INT. CAP \\
\hline BILDIN & NOX EMISSION RATE--INT. CAP \\
\hline BILDIN & OVERNIGHT CAP COST-INT. CAP \\
\hline BILDIN & PLANNED MAINT. RATE--INT. CAP. \\
\hline BILDIN & SO2 EMISSION RATE--INT. CAP \\
\hline BILDIN & TAX LIFE--INT. CAP \\
\hline BILDIN & UTIL CONTRACT LIFE--INT. CAP \\
\hline BILDIN & VOC EMISSION RATE--INT. CAP \\
\hline BILLDIN & VARIABLE O\&M COST--INT. CAP \\
\hline BILDIN & O\&M COST CREDIT--INT. CAP \\
\hline BILDIN & LOAD GROUP (E.G. SUMMER DAY) \\
\hline BILDIN & LOAD SEGMENT(E.G. PEAK,OFFPK) \\
\hline BILDIN & LOAD GROUP TO ECP STEP MAP \\
\hline BILDIN & LFTOVR BYTES \\
\hline BILDIN & MIN RESERVE MARGIN-PLANNING \\
\hline BILDIN & NUG DEBT FRACTION \\
\hline BILDIN & NATURAL GAS REGION \\
\hline BILDIN & NUG INTEREST PREMIUM \\
\hline BILDIN & PURCHASED CAP LIMIT FACT-NUG \\
\hline BILDIN & NUG RETURN ON EQUITY PREMIUM \\
\hline BILDIN & \# PLANTS IN A RETROFIT GROUP \\
\hline BILUIN & NUMBER OF STEPS PER GROUP \\
\hline BILDIN & NUMBER OF VERTICAL STEPS \\
\hline BILDIN & COMMERCIAL OP. DATE--DSP. CAP \\
\hline BILDIN & EXISTING DSP. CAPACITY \\
\hline BILDIN & CAPACITY CREDIT--DSP. CAP \\
\hline BILDIN & MIN/MAX CAP. FACTOR -.DSP. CAP. \\
\hline BILDIN & PURCHASED CAP LIMIT RHS VALUE \\
\hline BILDIN & CONSTRUCTION LDTIME--DSP. CAP \\
\hline LDIN & RUCTION PROFILE--DSP. CAP \\
\hline
\end{tabular}


EPPCSB(ECP\$DSP)

EPPEAK(ECP\$XPH)

EPPELF(ECP\$DSP)

EPPFL(ECP\$NFL,ECP\$XPH)

EPPFOM(ECP\$DSP)

EPPFOR(ECPSDSP)

EPPHRT(ECP\$DSP)

EPPMAP(ECP\$CAP,EFD\$CAP)

EPPMCF(ECP\$DSP)

EPPNCLF(ECP\$DSP)

EPPNLLF(ECP\$DSP)

EPPOVR(ECP\$DSP)

EPPPMR(ECP\$DSP)

EPPSEF(ECP\$DSP)

EPPSRT(ECPDSP)

EPPTLF(ECP\$DSP)

EPPUCLF(ECP\$DSP)

EPPVOM(ECP\$DSP)

EPPVSB(ECPSDSP)

EPRAVL(ECP\$RNW)

EPRCAP(ECP\$RNW,ECP\$XPH)

EPRCCR(ECP\$RNW)

EPRCFC(ECPSRNW)

EPRCH4(ECP\$RNW)

EPRCLT(ECP\$RNW)

EPRCO1(ECP\$RNW)

EPRCO2(ECP\$RNW)

EPRCPR(ECP\$LCP,ECP\$RNW)

EPRCRB(ECP\$RNW)

EPRCSB(ECP\$RNW)

EPRELF(ECP\$RNW)

EPRFOM(ECP\$RNW)

EPRFOR(ECP\$RNW)

EPRFTY(ECP\$RNW)

EPRHRT(ECP\$RNW)

EPRNCLF(ECP\$RNW)

EPRNLLF(ECP\$RNW)

EPRNOX(ECPSRNW)

EPROVR(ECPSRNW)

EPRPMR(ECP\$RNW)

EPRSOX(ECP\$RNW)

EPRTBS

EPRTLF(ECP\$RNW)

EPRUCLF(ECP\$RNW)

EPRVOC(ECP\$RNW)

EPRVOM(ECP\$RNW)

EPRVSB(ECP\$RNW)

EPSCAP(ECP\$DSP,ECP\$SCR)

EPSCLT

EPSCPEN(ECP\$DSP,ECP\$SCR)

EPSCPR(ECP\$LCP)

EPSCR2(ECP\$DSP)

EPSELF

EPSHPEN(ECP\$DSP,ECP\$SCR)

EPSNDX(ECP\$STP)
BILDIN

BILDIN

BILDIN

BILDIN

BILDIN

BILDIN

BILDIN

BILDIN

BILDIN

BILDIN

BILDIN

BILDIN

BILDIN

BILDIN

BILDIN

BILDIN

BILDIN

BILDIN

BILDIN

BILDIN

BILDIN

BLLDIN

BILDIN

BILDIN

BILDIN

BILDIN

BILDIN

BILDIN

BILDIN

BILDIN

BILDIN

BILDIN

BILDIN

BILDIN

BILDIN

BILDIN

BILDIN

BILDIN

BILDIN

BILDIN

BILDIN

BLDIN

BILDIN

BILDIN

BILDIN

BILDIN

BIIDIN

BILDIN

BILDIN

BILDIN

BILDIN

BILDIN

BILDIN

BILDIN

BILDIN
CAPITAL COST CREDIT-DSP. CAP

PEAK LOAD

ECONOMIC LIFE--DSP. CAP

PV OF NOMINAL ECP FUEL PRICES

FIXED O\&M COST--DISP. CAP

FORCED OUTAGE RATE--DSP. CAP.

HEAT RATE--DSP. CAP.

ECP TO EFD PLANT TYPE MAP

MAX CAP. FACTOR--DSP. CAP.

NUG CONTRACT LIFE--DSP. CAP

NUG LOAN LIFE --DSP. CAP

OVERNIGHT CAP COST-DSP. CAP

PLANNED OUTAGE RATE--DSP. CAP.

SCRUBBER EFFICIENCY--DSP. CAP.

SCRUBBER SO2 EMISSIONS RATE

TAX LIFE--DSP. CAP

UTIL CONTRACT LIFE--DSP. CAP

VARIABLE O\&M COST--DSP. CAP

O\&M COST CREDIT--DSP. CAP

COMMERCIAL OP. DATE--REN. CAP

EXISTING REN. CAPACITY

CAPACITY CREDIT--RNW. CAP

MAX CAPACITY FACTOR--RNW. CAP.

CH4 EMISSION RATE--RNW. CAP

CONSTRUCTION LDTIME--REN. CAP

CO EMISSION RATE --RNW. CAP

CO2 EMISSION RATE--RNW. CAP

CONSTRUCTION PROFILE--RNW. CAP

CARBON EMISSION RATE--RNW. CAP

CAPITAL COST CREDIT-RNW. CAP

ECONOMIC LIFE--REN. CAP

FIXED O\&M COST--RNW. CAP

FORCED OUTAGE RATE--RNW. CAP.

INPUT FUEL TYPE--RNW. CAP

HEAT RATE--RNW. CAP.

NUG CONTRACT LIFE--RNW. CAP

NUG LOAN LIFE --RNW. CAP

NOX EMISSION RATE--RNW. CAP

OVERNIGHT CAP COST-RNW. CAP

PLANNED MAINT. RATE--RNW. CAP.

SO2 EMISSION RATE--RNW. CAP

INITIAL RATE BASE

TAX LIFE--RNW. CAP

UTIL CONTRACT LIFE--RNW. CAP

VOC EMISSION RATE--RNW. CAP

VARIABLE O\&M COST--RNW. CAP

O\&M COST CREDIT--RNW. CAP

UPPER LIMIT-RETROFIT

CONSTRUCTION LEADTIME--RETRO.

CAPACITY PEN. (\%)-RETROFIT

CONS. PROFILE--RETROFIT

ECP CAPACITY TYPE CONVERTED TO

ECONOMIC LIFE--SCRUBBER RETRO.

HEAT RATE PEN. (\%)-RETROFIT

LOAD GROUP TO EFD SEASON MAP 


\begin{tabular}{|c|c|c|}
\hline EPSOVR(ECP\$DSP,ECP\$SCR) & BILDIN & OVERNIGHT CAP COST-RETROFIT \\
\hline EPSO2(EFD\$SO2) & DISPIN & SO2 PENALTY COST \\
\hline EPSPK(ECP\$MSP,ECP\$XPH) & BILDIN & SEASONAL PEAK LOAD \\
\hline EPSREC(ECP\$SGP,ECP\$DSP,ECP\$SCR) & BILDIN & REC \#/EACH PLNT IN A RET GRP \\
\hline EPTCRF(MNUMNR) & BILDIN & TRANSM. ANN. FACTOR-IRT BLDS \\
\hline EPTCST(MNUMNR) & BILDIN & TRANSM. COST FOR IRT BLDS \\
\hline EPTIRGN(MNUMNR) & BILDIN & TRANSM. IMPORT REG-IRT BLDS \\
\hline EPTLOSS(MNUMNR) & BILDIN & TRANSM. LOSS FOR IRT BLDS \\
\hline EPTXRT & BILDIN & NET TAX RATE \\
\hline EPUCRE & BILDIN & UTIL COMMON RETURN ON EQUITY \\
\hline EPUFDT & BILDIN & UTIL DEBT FRACTION \\
\hline EPUFPE & BILDIN & UTIL ((CE*FRAC+PE*FRAC)/ROR) \\
\hline EPUIRT & BILDIN & UTIL INTEREST RATE \\
\hline EPUPCLF(ECP\$XPH) & BILDIN & PURCHASED CAP LIMIT FACT-UTIL \\
\hline EPUROR & BILDIN & UTIL ROR (WGT AVG CE,PE,DEBT) \\
\hline EPWDTH(ECP\$VLS,ECP\$XPH) & BILDIN & WIDTH OF VERTICAL LOAD SEGS \\
\hline EPXPRT(ECP\$XPH) & BILDIN & ELECTRICITY EXPORT LIMITS \\
\hline EQEL & DISPIN & TOTAL ELECTRICITY DEMAND \\
\hline EQFCO2(EFD\$NFL) & DISPOUT & CO2 Emissions by Fuel Type \\
\hline EQFFL(EFD\$NFL,EFD\$OWN) & DISPOUT & Fuel Consumption by Fuel Type \\
\hline EQFGN(EFD\$NFL,EFD\$OWN) & DISPOUT & Generation by Fuel Type \\
\hline EQFNOX(EFD\$NFL) & DISPOUT & NOX Emissions by Fuel Type \\
\hline EQFSO2(EFD\$NFL) & DISPOUT & SO2 Emissions by Fuel Type \\
\hline EQHCP(EFD\$RNW) & DISPOUT & Avg. Annual Cap. by Ren. Tech \\
\hline EQHGN(EFD\$RNW,EFD\$OWN) & DISPOUT & Generation ty Ren. Technology \\
\hline EQLOAD(2) & DISPUSE & TOT LOAD\&CUM AREA UND CUT LNE \\
\hline EQPCO2(EFD\$DSP) & DISPOUT & CO2 Emissions by Plant Type \\
\hline EQPCP(EFD\$DSP) & DISPOUT & Avg. Annual Cap. by Plant Type \\
\hline EQPFL(EFD\$DSP) & DISPOUT & Fuel Consumption by Plant Type \\
\hline EQPGN(EFD\$DSP,EFD\$OWN) & DISPOUT & Generation by Plant Type \\
\hline EQPNOX(EFD\$DSP) & DISPOUT & NOX Emissions by Plant Type \\
\hline EQPSO2(EFD\$DSP) & DISPOUT & SO2 Emissions by Plant Type \\
\hline EQTDLS & DISPIN & T\&D LOSS FACTOR \\
\hline ERFIJ(EFD\$NFL) & DISPOUT & Fuel Cost by Fuel Type \\
\hline ERHOM(EFD\$RNW,EFD\$OWN) & DISPOUT & Var. O\&M by Ren. Tech, OWN \\
\hline ERPFL(EFD\$DSP) & DISPOUT & Fuel Cost by Plant Type \\
\hline ERPOM(EFD\$DSP) & DISPOUT & Variable O\&M by Plant Type \\
\hline ERTFL(EFD\$OWN) & DISPOUT & Total Fuel Cost by Co. Type \\
\hline ERTOM(EFDSOWN) & DISPOUT & Variable O\&M by Company Type \\
\hline ERTOMF & DISPIN & TOTAL FIXED O\&M \\
\hline ESLCUT(2) & DISPUSE & Y-INT\&SLOPE CURRENT CUT LINE \\
\hline ETALLW & DISPOUT & Total SO2 Allowances \\
\hline ETAREA(EFD\$MVS) & DISPUSE & AREA IN EACH VERTICAL SLICE \\
\hline ETCAR & DISPOUT & Total Car Emissions \\
\hline ETCO1 & DISPOUT & Total CO1 Emissions \\
\hline ETCO2 & DISPOUT & Total CO2 Emissions \\
\hline ETDMDE & DISPOUT & Domestic Economy Sales (MM\$) \\
\hline ETDMDF & DISPOUT & Domestic Firm Pwr Sales (MM\$) \\
\hline ETDMME & DISPOUT & Domestic Economy Sales (MWH) \\
\hline ETDMMF & DISPOUT & Domestic Firm Pwr Sales (MWH) \\
\hline ETDMPE & DISPOUT & Dom. - Econ. Trade Profit(MM\$) \\
\hline ETDSPN(EFD\$MSP) & DISPETT & \\
\hline ETDSPT(EFD\$MSP,EFD\$MPG) & DISPETT & \\
\hline ETEXPD & DISPOUT & Exports - Revenues (MM\$) \\
\hline ETEXPE & DISPOUT & Exports - Economy(MWH) \\
\hline
\end{tabular}


ETEXPF

ETFSHR(EFD\$MSP,EFD\$MPG,EFD\$FPP)

ETGEN

ETIMPD

ETIMPE

ETIMPF

ETNOX

ETNVCT

ETSO2

ETT\$MTG

ETT\$RECS

ETVOC

ETXVAL(EFD\$MVS)

ETYVAL(EFD\$MVS)

EWGFIX

EWGOWN

EWGRCC

EWGREV

EWGRIC

EWGRNW

EXAREA(EFD\$MVS)

EXC

EXE

EXG

EXI

EXK

EXI.

EXM

EXMAP(EFD\$MSP,ETT\$MTG,EFD\$MVS)

EXN

EXO

REFINERY)

EXR

EXT

EXW

FBTELNR(NDREG)

FCRL

SWITCH $(1=\mathrm{ON})$

FIRSYR

FLAGSO2

FLTELNR(NDREG-1)

FLTYPE=6)

FORE_SITE_CNTL(2)

FORE_SITE_TYPE(3)

FRCTOL

FSTELNR(NDREG)

HISTORY

IDONE1

IDONE2

IMAREA(EFD\$MVS)

IMMAP(EFD\$MSP,ETT\$MTG,EFD\$MVS)

IRELAX

IRGNUM(MNUMNR)

ITIMNG

IYVAL(EFD\$MVS)
DISPOUT

DISPETT

DISPOUT

DISPOUT

DISPOUT

DISPOUT

DISPOUT

DISPUSE

DISPOUT

EMM\$PARM

EMM\$PARM

DISPOUT

DISPUSE

DISPUSE

DISPOUT

DISPOUT

DISPOUT

DISPOUT

DISPOUT

DISPOUT

DISPETT

NCNTRL

NCNTRL

NCNTRL

NCNTRL

NCNTRL

NCNTRL

NCNTRL

DISPETT

NCNTRL

NCNTRL

NCNTRL

NCNTRL

NCNTRL

UEFDOUT

NCNTRL

NCNTRL

UEFDOUT

UEFDOUT

PARAMETR

NCNTRL

NCNTRL

NCNTRL

UEFDOUT

NCNTRL

DISPETT

DISPETT

DISPETT

DISPETT

NCNTRL

DISPETT

NCNTRL

DISPETT
Exports - Firm (MWH)

Total Generation

Import Revenues (MM\$)

Imports - Economy (MWH)

Imports - Firm (MWH)

Total NOX Emissions

\# POINTS DEFINING LOAD CURVE

Total SO2 Emissions

MAXIMUM NUMBER OF TRADE GROUPS

MAXIMUM \# OF RECORDS IN CONSTRAINT FILE

Total VOC Emissions

$X$ VALUES OF Ssnal LOAD CURVE

Y VALUES OF Ssnal LOAD CURVE

EWG FIXED \$ COMPONT

Generation by NUGS for Own Use

Commercial Cogen - Rev. fr Ut

EWG - Rev. fr Utl

Industrial Cogen - Rev. fr Utl

NUGS/Renewables - Rev. fr Uu

RUNMOD( 8) EXECUTE COAL (COAL SUPPLY)

RUNMOD( 7) EXECUTE UTIL (UTILITY)

RUNMOD(10) EXECUTE PIPE (GAS TRANS.\& DISTR.)

RUNMOD( 5) EXECUTE IND (INDUSTRIAL)

RUNMOD( 4) EXECUTE COMM (COMMERCIAL)

RUNMOD( 9) EXECUTE WELL (OIL AND GAS SUPPLY)

RUNMOD( 2) EXECUTE MAC (MACROECONOMIC)

RUNMOD(12) EXECUTE RENEW (RENEWABLES)

RUNMOD(11) EXECUTE REFINE (PETROLEUM

RUNMOD( 3) EXECUTE RESD (RESIDENTIAL)

RUNMOD ( 6) EXECUTE TRAN (TRANSPORTATION)

RUNMOD ( 1) EXECUTE WORLD (INTERNATIONAL)

BIT COAL CONVERGENCE FLAG

FINAL CONVERGENCE AND REPORTING LOOP

FIRST FORECAST YEAR INDEX (EG. 2)

PENALTY COST FLAG

LIG COAL CONVERGENCE FLAG

Fuel type (Oil, NG, MCL, SCL, Ren, Al)

DESCRIPTION FOR I4SCNT

DESCRIPTION FOR I4SITE

MINIMUM FRACTIONAL CONVERGENCE TOLERANCE

SUB COAL CONVERGENCE FLAG

1990 HISTORY DATA FLAG

OPTION TO RUN HEURISTIC ROUTINE TO SPEED

TIMING SWITCH (ITIMNG=1 MEANS TIMING ON) 
I4SCNT

I4SITE

LASTYR

LEFTOV(ELFT\$ET1)

- LEFTV(ELFTSET3)

LFTOUT(ELFTSOUT)

LFTOVR(ELFT\$IN)

LFTSO2(ELFT\$SO2)

LOOP(2)

LOOPOP

MACFDBK

MAREA(EFD\$MVS)

MAXITR

MMAC

MMAP(EFD\$MSP,ETT\$MTG,EFD\$MVS)

MNCLTYPE $=16$ )

MNCROP=2)

MNDSMPCM $=10$ )

MNDSMPRS $=10$ )

MNETOH $=5$ )

$M N G R A D C R=5$ )

MNMFTYPE $=29$ )

MNOGCAT $=12$ )

$M N O G C R O=5$ )

MNPOLLUT $=8$ )

MNSICM $=40$ )

$\mathrm{N}$.NSICNM=12)

MNUMBX $=18$ )

MNUMCR $=11$ )

MNUMGR=15)

MNUMLR=17)

MNUMNR=16)

MNUMOR=13)

MNUMPR $=6$ )

MNUMXR=11)

MNUMYR=29)

$M N X Y R=66$ )

MODELON

MORDER(NMODEL)

MSEDYR=2)

NCRL

NDREG $=23$ )

NTCOS(EFD\$MSP,EFD\$MPG)

NYRS

PRTDBGC

PRTDBGE

PRTDBGN

PRTDBGI

PRTDBGK

PRTDBGL

PRTDBGM

PRTDBGN

PRTDBGO

PRTDBGR

PRTDBGT
NCNTRL

NCNTRL

NCNTRL

DISPETT

DISPETT

DISPOUT

DISPIN

USO2GRP

NCNTRL

NCNTRL

NCNTRL

DISPETT

NCNTRL

NCNTRL

DISPETT

PARAMETR

PARAMETR

PARAMETR

PARAMETR

PARAMETR

PARAMETR

PARAMETR

PARAMETR

PARAMETR

PARAMETR

PARAMETR

PARAMETR

PARAMETR

PARAMETR

PARAMETR

PARAMETR

PARAMETR

PARAMETR

PARAMETR

PARAMETR

PARAMETR

PARAMETR

NCNTRL

NCNTRL

PARAMETR

NCNTRL

PARAMETR

DISPETT

NCNTRL

NCNTRL

NCNTRL.

NCNTRL

NCNTRL

NCNTRL

NCNTRL

NCNTRL

NCNTRL

NCNTRL

NCNTRL

NCNTRL
FORESIGHT CONTROL: (1: MAIN, 2: SUBMODULE) FORESITE OPTION (1:MYOPIC,2:ADAPTIVE,3: PERFECT) LAST FORECAST YEAR INDEX (EG. 26)

LEFTOVER BYTES

LEFTOVER BYTES

LEFTOVER BYTES

DESCRIPTION FOR LOOPOP

NEMS YR LOOPING (1:ONE YR AT A TIME,2:ALL YR)

MACROECONOMIC FEEDBACK LEVER $(1=\mathrm{ON})$

MAXIMUM ITERATIONS

MACRO CASE

Coal type

Emissions (Corn \& Biomass)

Number of DSM programs - commercial

Number of DSM programs - residential

Emissions of Ethanol, 5 Volume steps

Grades of crude oil \{3(API gravity)+2(sulfur)\}

No of Mfg Types (1=Nat, 2-8=Non-Mfg, 9-29=Mfg)

Oil \& Gas categories (EOR+Convential+

(EOR+Conventional+Offshore+Ak+US)

Air Pollutants (C,CO,CO2,SOx,NOx, VOC,CH4,PART)

Mfg: number of SIC's

Non-mfg: number of SIC's

No. NG border crossings (Canada-6,

Census regions $(9+\mathrm{CA}+\mathrm{US})$

NGTDM regions $\{9$ (census) +3 (west) $+\mathrm{AL}+\mathrm{HW}+\mathrm{US}\}$

Coal supply regions (16+US)

NERC regions (13+Alaska+Ha+US)

Oil \& Gas (OGSM) regions

PADD regions $(5+U S)$

Coal export regions (10+US)

Years $=1990-2015,2020,2025,2030$

No of Expectation years (1990-2015, 2016-2066)

ON->MODS NEVER OFF $(0->\mathrm{OFF}, 1->\mathrm{ON})(\mathrm{DEF}=0)$

HOLDS EXECUTION ORDER OF MODULES

Number of Historical SEDS years

REPORTING LOOP SWTTCH FOR EACH MODEL ( $1=\mathrm{ON}$ )

Coal demand regions

NUMBER OF GROWTH YEARS

PRINT DEBUG IN COAL (COAL SUPPLY)

PRINT DEBUG IN UTIL (UTILITY)

PRINT DEBUG IN PIPE (GAS TRANS. $\alpha$ DISTR.)

PRINT DEBUG IN IND (INDUSTRIAL)

PRINT DEBUG IN COMM (COMMERCIAL)

PRINT DEBUG IN WELL (OIL AND GAS SUPPLY)

PRINT DEBUG IN MAC (MACROECONOMIC)

PRINT DEBUG IN RENEW (RENEWABLES)

PRINT DEBUG IN REFINE (PETROLEUM REFINERY)

PRINT DEBUG IN RESD (RESIDENTIAL)

PRINT DEBUG IN TRAN (TRANSPORTATION) 
PRTDBGW

QBCELNR(NDREG,MNUMYR)

QBDELNR(NDREG,MNUMYR)

QBHELNR(NDREG,MNUMYR)

QBMELNR(NDREG,MNUMYR)

QBTELNR(NDREG,MNUMYR)

QGCELGR(21,MNUMYR)

QGFELGR(21,MNUMYR)

QGIELGR(21,MNUMYR)

QLCELNR(NDREG,MNUMYR)

QLDELNR(NDREG,MNUMYR)

QLHELNR(NDREG,MNUMYR)

QLMELNR(NDREG,MNUMYR)

QLTELNR(NDREG,MNUMYR)

QSCELNR(NDREG,MNUMYR)

QSDELNR(NDREG,MNUMYR)

QSHELNR(NDREG,MNUMYR)

QSMELNR(NDREG,MNUMYR)

QSTELNR(NDREG,MNUMYR)

QTDLS(MNUMNR)

REAIT(EFD\$MPG,EFD\$MVS)

REANT(EFD\$MPG,EFD\$MVS)

REATI(EFD\$MSP,ETT\$MTG,EFD\$MVS)

REATR(EFD\$MSP,ETT\$MTG,EFD\$MVS)

REATT(EFD\$MPG,EFD\$MVS)

RGNUM(MNUMNR)

RLXPC

RNCSI(MNUMNR)

RNCST(MNUMNR)

RNCWI(MNUMNR)

RNCWT(MNUMNR)

RUNMOD(NMODEL)

SCALPR

SCEN

SUBR_DESCR(NMODEL)

SUBR_NAMES(NMODEL)

SUBR_VERS(NMODEL+2)

TDMDF(MNUMNR)

TDMMF(MNUMNR)

TDSPN(EFD\$MSP)

TDSPT(EFD\$MSP,EFD\$MPG)

TEXDF(MNUMNR)

TEXMF(MNUMNR)

TEXPD(MNUMNR)

TEXPF(MNUMNR)

TFSHR(EFD\$MSP,EFD\$MPG,EFD\$FPP)

TIMPD(MNUMNR)

TIMPF(MNUMNR)

TIYVAL(EFD\$MVS)

TQDFRHG(21)

TQDFRLG(21)

TRGCMAX(21)

TRGCMIN(21)

TRGCPAR(21)

TRNCSI
NCNTRL

UEFDOUT

UEFDOUT

UEFDOUT

UEFDOUT

UEFDOUT

UEFDOUT

UEFDOUT

UEFDOUT

UEFDOUT

UEFDOUT

UEFDOUT

UEFDOUT

UEFDOUT

UEFDOUT

UEFDOUT

UEFDOUT

UEFDOUT

UEFDOUT

DISPETT

DISPETT

DISPETT

DISPETT

DISPETT

DISPETT

DISPETT

NCNTRL

DISPETT

DISPETT

DISPETT

DISPETT

NCNTRL

NCNTRL

NCNTRL

NCNTRL

NCNTRL

NCNTRL

DISPETT

DISPETT

DISPETT

DISPETT

DISPETT

DISPETT

DISPETT

DISPETT

DISPETT

DISPETT

DISPETT

DISPETT

DISPUSE

DISPUSE

DISPUSE

DISPUSE

DISPUSE

DISPIN
PRINT DEBLIG IN WORLD (INTERNATIONAL) VLS BIT COAL CONSUMPTION BY COAL Reg LS BIT COAL CONSUMPTION BY COAL Reg HS BIT COAL CONSUMPTION BY COAL Reg MS BIT COAL CONSUMPTION BY COAL Reg BIT COAL CONSUMPTION BY COAL REG NG "COMPET" CONSUMPTION BY NGTDM NG "FIRM" CONSUMPTION BY NGTDM NG "INTER" CONSUMPTION BY NGTDM VLS LIG COAL CONSUMPTION BY COAL REG LS LIG COAL CONSUMPTION BY COAL REG HS LIG COAL CONSUMPTION BY COAL REG MS LIG COAL CONSUMPTION BY COAL REG LIG COAL CONSUMPTION BY COAL REG VLS SUB COAL CONSUMPTION BY COAL Reg LS SUB COAL CONSUMPTION BY COAL Reg HS SUB COAL CONSUMPTION BY COAL REG MS SUB COAL CONSUMPTION BY COAL REG SUB COAL CONSUMPTION BY COAL REG

RELAXATION PERCENTAGE

FLAGS FOR WHETHER EACH MODEL IS BEING RUN FOR REPORTING, DEFLATOR, YEARPR \$ (EG 1.315) SCENARIO

LONG SUBROUTINE NAMES

SHORT SUBROUTINE NAMES

SUBROUTINE VERSION USED:

DUAL-FIRED RH USE--GAS REGS

DUAL-FIRED RL USE--GAS REGS

TEMP TOTAL FOR MAX G/O RAT TEMP TOTAL FOR MIN G/O RAT TEMP TOTAL FOR PAR G/O RAT

SUMMER IMP. TRANSM. CONSTRAINT 
TRNCST

TRNCWI

TRNCWT

TSGCMAX(21)

- TSGCMIN(21)

TSGCPAR(21)

TTYVAL(EFD\$MVS)

TYVAL(EFD\$MVS)

UCANBLD(MNUMNR)

UCASTS(EFD\$MPG)

UCI\$CF(ECPSCIS,MNUMNR)

UCI\$CRG(ECP\$CIS,MNUMNR)

UCI\$CST(ECP\$CIS,MNUMNR)

UCI\$FMW(ECP\$CIS,MNUMNR)

UCI\$PMW(ECP\$CIS,MNUMNR)

UCMFSH(EFD\$DSP,EFD\$FPP,MNUMNR)

UEITAJ(EFD\$MSP,MNUMNR)

UFHCNT(EFD\$NFL,EFD\$MFRG)

UFL SECP(EFD\$NFL,ECPSFPP)

UFLCLNR (2,MNUMNR,MNUMYR)

UFLDSNR(2,MNUMNR,MNUMYR)

UFLGCNR (2,MNUMNR,MNUMYR)

UFLGFNR (2,MNUMNR,MNUMYR)

UFLGINR(2,MNUMNR,MNUMYR)

UFLHYNR(2,MNUMNR,MNUMYR)

UFLOTNR(2,MNUMNR,MNUMYR)

UFL.PSNR (2,MNUMNR,MNUMYR)

UFLRHNR(2,MNUMNR,MNUMYR)

UFLRLNR(2,MNUMNR,MNUMYR)

UFL TLNR (2,MNUMNR,MNUMYR)

UFLURNR(2,MNUMNR,MNUMYR)

UFRASH(EFD\$NFL)

UFRCAR(EFD\$NFL)

UFRCO1(EFD\$NFL)

UFRCO2(EFD\$NFL)

UFRNOX(EFD\$NFL,EFD\$MFRG)

UFRSO2(EFD\$NFL,EFD\$MFRG)

UFR VOC(EFD\$NFL)

UGNCLNR(2,MNUMNR,MNUMYR)

UGNDSNR (2,MNUMNR,MNUMYR)

UGNGCNR(2,MNUMNR,MNUMYR)

UGNGENR(2,MNUMNR,MNUMYR)

UGNGFNR(2,MNUMNR,MNUMYR)

UGNGINR (2,MNUMNR,MNUMYR)

UGNHONR (2,MNUMNR,MNUMYR)

UGNHYNR(2,MNUMNR,MNUMYR)

UGNMSNR (2,MNUMNR,MNUMYR)

UGNPSNR(2,MNUMNR,MNUMYR)

UGNPVNR(2,MNUMNR,MNLMYR)

UGNRHNR (2,MNUMNR,MNUMYR)

UGNRLNR(2,MNUMNR,MNUMYR)

- UGNSONR(2,MNUMNR,MNUMYR)

UGNTLNR(2,MNUMNR,MNUMYR)

UGNUBCR(MNUMCR,MNUMYR)

UGNUPCR(MNUMCR,MNUMYR)
DISPIN

DISPIN

DISPIN

DISPUSE

DISPUSE

DISPUSE

DISPETT

DISPETT

DISPETT

DISPETT

DISPETT

DISPETT

DISPETT

DISPETT

DISPETT

FUELIN

DISPETT

FUELIN

ECP\$CNTL

UEFDOUT

UEFDOUT

UEFDOUT

UEFDOUT

UEFDOUT

UEFDOUT

UEFDOUT

UEFDOUT

UEFDOUT

UEFDOUT

UEFDOUT

UEFDOUT

FUELIN

FUELIN

FUELIN

FUELIN

FUELIN

FUELIN

FUELIN

UEFDOUT

UEFDOUT

UEFDOUT

UEFDOUT

UEFDOUT

UEFDOUT

UEFDOUT

UEFDOUT

UEFDOUT

UEFDOUT

UEFDOUT

UEFDOUT

UEFDOUT

UEFDOUT

UEFDOUT

UEFDOUT

UEFDOUT
SUMMER EXP. TRANSM. CONSTRAINT

WINTER IMP. TRANSM. CONSTRAINT

WINTER EXP. TRANSM. CONSTRAINT

TEMP TOTAL FOR MAX GAS SHR

TEMP TOTAL FOR MIN GAS SHR

TEMP TOTAL FOR PAR GAS SHR

CAPACITY FACTOR

CANADIAN REGION NUMBER

COST MILLS/KWH

FIRM MW AVAILABLE

PEAK MW AVAILABLE

MAXIMUM FUEL SHARES

HEAT CONTENT

EFD TO ECP FUEL MAPPING

COAL CONS BY OWNERSHIP TYPE/NERC

DS CONS BY OWNERSHIP TYPE/NERC

GAS (COMP.) CONS BY OWNERSHIP TYPE PE/NERC

GAS (FIRM) CONS BY OWNERSHIP TYP E/NERC

GAS (INT.) CONS BY OWNERSHIP TYP E/NERC

HYD(NOT PS) CONS BY OWNERSHIP TYPE/NERC

OTH. CONS BY OWNERSHIP TYPE/NERC

PS CONS BY OWNERSHIP TYPE/NERC

RH CONS BY OWNERSHIP TYPE/NERC

RL CONS BY OWNERSHIP TYPE/NERC

TOT CONS BY OWNERSHIP TYPE/NERC

NUC CONS BY OWNERSHIP TYPE/NERC

ASH RETENTION RATE

CARBON EMISSION RATE

EMISSION RATE

SO2 EMISSION RATE

NOX EMISSION RATE

SO2 EMISSION RATE

VOC EMISSION RATE

COAL GEN BY OWNERSHIP TYPE NERC

DS GEN BY OWNERSHIP TYPE INERC

GAS (COMP.) GEN BY OWNERSHIP Type/NERC

GEOTHERMAL GEN BY OWNERSHIP type/NERC

GAS (FIRM) GEN BY OWNERSHIP TyPe/NERC

GAS (INT.) GEN BY OWNERSHIP Type/NERC

HYD/OTH GEN BY OWNERSHIP type/NERC

HYD (NOT PS) GEN type/NERC

MSW GEN BY OWNERSHIP TYPE/ NERC

PS GEN BY OWNERSHIP TYPE INERC

PHOTOVOLTAIC GEN BY OWNERSHIP type/NERC

RH GEN BY OWNERSHIP TYPE NERC

RL GEN BY OWNERSHIP TYPE INERC

SOLAR GEN BY OWNERSHIP TYPE/NERC

TOT. GEN BY OWNERSHIP TYPE INERC

UTIL BWR NUCLEAR GENER. BY CENSUS S

UTIL PWR NUCLEAR GENER. BY CENSUS $S$ 
UGNURNR(2,MNUMNR,MNUMYR)

UGNWDNR(2,MNUMNR,MNUMYR)

UGNWNNR(2,MNUMNR,MNUMYR)

UIALLW(EFD\$SO2)

UNFPH

UNSO2

UNTCOS(EFD\$MSP,EFD\$MPG)

UNXPH

UPBND

UPCOEFC(MNUMNR,ECP\$NCC)

UPCSO2(EFD\$SO2)

UPDETT(ECP\$DSP)

UPDLC(ECP\$DSP)

UPDMCD(ECP\$DSM)

UPDNUG(ECP\$DSP)

UPDOPT(ECP\$DSP)

UPEFPT(ECP $\$$ CAP)

UPFLCD(ECP\$NFL)

UPFTYP(ECP\$CAP)

UPFUEL(EFD\$NFL,EFD\$MFRG)

UPF759(ECP\$CAP)

UPF860(ECPSCAP)

UPGNPD(MNUMYR+ECP\$FPH)

UPICAPD(MNUMYR+ECP\$XPH,ECP\$INT)

UPIETT(ECP\$INT)

UPILC(ECP\$INT)

UPINCD(ECPSINT)

UPINUG(ECP\$INT)

UPIOPT(ECPSINT)

UPLDCD(ECPSVLS)

UPLSO2(EFDSSO2)

UPMDCD(ECP\$VLS)

UPM759(ECP\$CAP)

UPM860(ECP\$CAP)

UPNSO2(EFD\$SO2)

UPOBJ

UPOLD(EFD\$SO2)

UPOWNCD(ECP\$OWN)

UPPCAPD(MNUMYR+ECP\$XPH,ECP\$DSP)

UPPLCD(ECP\$DSP)

UPRCAPD(MNUMYR+ECP\$XPH,ECP\$RNW)

UPRCLNR(MNUMNR,MNUMYR)

UPRDSNR(MNUMNR,MNUMYR)

UPRETT(ECP\$RNW)

UPRGCD(MNUMNR)

UPRGCNR(MNUMNR,MNUMYR)

UPRGFNR(MNUMNR,MNUMYR)

UPRGINR(MNUMNR,MNUMYR)

UPRHONR(MN:MNR,MNUMYR)

UPRHS

UPRLC(ECP\$RNW)

UPRNCD(ECP\$RNW)

UPRNUG(ECP\$RNW)

UPROPT(ECP\$RNW)

UPRRHNR(MNUMNR,MNUMYR)
UEFDOUT

UEFDOUT

UEFDOUT

USO2GRP

ECP\$CNTL

USO2GRP

DISPETT

ECP\$CNTL

ECP\$CNTL

BILDIN

USO2GRP

ECP\$CNTL

ECP\$CNTL

ECP\$CNTL

ECPSCNTL

ECP\$CNTL

ECP\$CNTL

ECP\$CNTL

ECP\$CNTL

FUELIN

ECP\$CNTL

ECP\$CNTL

ECP\$CNTL

ECP\$CNTL

ECP\$CNTL

ECP\$CNTL

ECP\$CNTL

ECP\$CNTL

ECP\$CNTL

ECP\$CNTL

USO2GRP

ECP\$CNTL

ECP\$CNTL

ECP\$CNTL

USO2GRP

ECP\$CNTL

USO2GRP

ECP\$CNTL

ECP\$CNTL

ECP\$CNTL

ECP\$CNTL

UEFDOUT

UEFDOUT

ECP\$CNTL

ECP\$CNTL

UEFDOUT

UEFDOUT

UEFDOUT

UEFDOUT

ECP\$CNTL

ECP\$CNTL

ECP\$CNTL

ECP\$CNTL

ECP\$CNTL

UEFDOUT
NUC GEN BY OWNERSHIP TYPE INERC WIND GEN BY OWNERSHIP TYPE /NERC WIND GEN BY OWNERSHIP TYPE /NERC INITIAL SO2 ALLOWANCES

LENGTH OF FULL PLANNING HORIZON

NUMBER OF COMPLIANCE GROUPS

LENGTH OF EXPL. PLANNING HORIZON

BOUND ROW NAME

COEFF-COAL PRC EXP. EQUATIONS

CURRENT SO2 PENALTY COST

IRT BLD SW $0=$ NOT 1=ALLOWED - DSP

LEARNING CURVE - DSP. CAPACITY

DSM GROUP CODES

NUG BLD SW $0=$ NOT $1=A L L O W E D$ - DSP

TECHNICAL OPT. - DSP. CAPACITY

EFP TYPE

FUEL CODES

FINANCIAL TYPE

DELIVERED FUEL PRICES

F759 PRIMARY FUEL, CODE

F860 PRIMARY FUEL CODE

GNP DEF.S

CAP COST DEF.- INT. CAPACITY

IRT BLD SW 0=NOT 1=ALLOWED - INT

LEARNING CURVE - INT. CAPACITY

INT. PLANT CODES

NUG BLD SW $0=$ NOT 1=ALLOWED - INT

TECHNICAL OPT. - INT. CAPACITY

LOAD SEGMENT CODES

LAGGED SO2 PENALTY COST

MODE OF OPERATION CODES

F759 PRIME MOVER CODE

F860 PRIME MOVER CODE

NEXT SO2 PENALTY COST

OBJECTIVE FUNCTION NAME

PENALTY COST FROM PREVIOUS NEMS ITER

FIN. OWNERSHIP TYPE 1-'U' 2-'N'

CAP COST DEF.- DSP. CAPACITY

DSP. PLANT CODES

CAP COST DEF.- REN. CAPACITY

COAL PRICE BY OWNERSHIP TYPE/NERC

DS PRICE BY OWNERSHIP TYPE/NERC

IRT BLD SW $0=$ NOT $1=A L L O W E D$ - REN

REGION CODES

GAS (COMP) PRICE BY OWNERSHIP TYPE/NERC

GAS (FIRM) PRICE BY OWNERSHIP TYPE/NERC

GAS (INT.) PRICE BY OWNERSHIP TYPE/NERC

REN. PRICE BY OWNERSHIP TYPE/NERC

RIGHT HAND SIDE NAME

LEARNING CURVE - REN. CAPACITY

REN. PLANT CODES

NUG BLD SW $0=$ NOT $1=A L L O W E D$ - REN

TECHNICAL OPT. - REN. CAPACITY

RH PRICE BY OWNERSHIP TYPE/NERC 
UPRRLNR(MNUMNR,MNUMYR)

UPRURNR(MNUMNR,MNUMYR)

UPSCCD(ECP\$SCR)

UPSRHEL(MNUMCR)

UPSRLEL(MNUMCR)

UPSTYR

UPTCRT

UPVTYP(ECP\$CAP)

UPYRCD(ECP\$FPH)

UQALLW(EFD\$SO2)

UQCSO2(EFD\$SO2)

UQFCONN(EFD\$NFL,MNUMNR,EFD\$OWN)

UQFGENC(EFD\$NFL,MNUMCR)

UQFGENN(EFD\$NFL,MNUMNR,EFD\$OWN)

UQFSO2(EFD\$NFL)

UQFUEL(EFD\$NFL,EFD\$MFRG,EFD\$OWN)

UQHGENC(EFD\$RNW,MNUMCR)

UQHGENN(EFD\$RNW,MNUMNR,EFD\$OWN)

UQLSO2(EFD\$SO2)

UQNSO2(EFD\$SO2)

UQPGENC(EFD\$DSP,MNUMCR)

UQPGENN(EFD\$DSP,MNUMNR,EFD\$OWN)

UQPSO2(EFD\$SO2)

UQTDLS(MNUMNR)

URETTLU(MNUMNR,MNUMYR)

URGCMAX(EFD\$MPG)

URGCMIN(EFD\$MPG)

URGCPAR(EFD\$APG)

URNCSI(MNUMNR)

URNCST(MNUMNR)

URNCWI(MNUMNR)

URNCWT(MNUMNR)

USF759(ECPSCAP)

USF860(ECPSCAP)

USGCMAX(EFD\$MPG)

USGCMIN(EFD\$MPG)

USGCPAR(EFD\$MPG)

UTCAR(MNUMNR,MNUMYR)

UTCARC(EFD\$NFL,MNUMCR)

UTCARN(EFD\$NFL,MNUMNR)

UTCO1(MNUMNR,MNUMYR)

UTCO1C(EFD\$NFL,MNUMCR)

UTCO1N(EFD\$NEL,MNUMNR)

UTCO2(MNUMNR,MNUMYR)

UTCO2C(EFD\$NFL,MNUMCR)

UTCO2N(EFD\$NFL,MNUMNR)

UTDMDE(MNUMNR,MNUMYR)

UTDMDF(MNUMNR,MNUMYR)

UTDMME(MNUMNR,MNUMYR)

UTDMMF(MNUMNR,MNUMYR)

UTEXDE(MNUMNR,MNUMYR)

- UTEXDF(MNUMNR,MNUMYR)

UTEXME(MNUMNR,MNUMYR)

UTEXMF(MNUMNR,MNUMYR)

UTEXPE(MNUMNR,MNUMYR)
UEFDOUT

UEFDOUT

ECP\$CNTL

DISPUSEC

DISPUSEC

ECP\$CNTL

ECP\$CNTL

ECP\$CNTL

ECP\$CNTL

USO2GRP

USO2GRP

DISPUSE

DISPUSE

DISPUSE

DISPUSE

DISPUSE

DISPUSE

DISPUSE

USO2GRP

USO2GRP

DISPUSE

DISPUSE

USO2GRP

DISPETT

UEFDOUT

DISPUSE

DISPUSE

DISPUSE

DISPETT

DISPETT

DISPETT

DISPETT

ECP\$CNTL

ECP\$CNTL

DISPUSE

DISPUSE

DISPUSE

UEFDOUT

DISPUSE

DISPUSE

UEFDOUT

DISPUSE

DISPUSE

UEFDOUT

DISPUSE

DISPUSE

UETTOUT

UETTOUT

UETTOUT

UETTOUT

UETTOUT

UETTOUT

UETTOUT

UETTOUT

UETTOUT
RL PRICE BY OWNERSHIP TYPE/NERC NUC PRICE BY OWNERSHIP TYPE/NERC RETROFIT CLUSTER CODE

AVG SULFUR PENALTY--RH AVG SULFUR PENALTY'--RL INITIAL EXECUTION YEAR FOR ECP TARGET COV RATIO-PUR. CONSTRAINT VINT. TYPE $0=E X .1=N E W--E C P$ CAP YEAR CODES

ALLOWANCE FOR SO2 CURRENT QUANTITY OF SO2 PRODUCED FUEL CONS BY NERC/OWNER GEN/FUEL TYPE IN CENSUS REGS GEN/FUEL TYPE IN NERC REGS SO2 CONTENT BY FUEL TYPE FUEL CONS IN FUEL REGIONS GEN/REN CAPACITY IN FUEL REGS GEN/REN CAPACITY IN FUEL REGS LAGGED QUANTITY OF SO2 PRODUCED NEXT QUANTITY OF SO2 PRODUCED GEN/DSP CAP IN CENSUS REGS GEN/DSP CAP IN NERC REGS PREVIOUS QUANTITY OF SO2 PRODUCED

UTIL TOTAL RETIREMENTS BY NERC G/O PRC RAT--MAX GAS USE G/O PRC RAT--MIN GAS USE G/O PRC RAT--MAX GAS USE

F759 SECONDARY FUEL CODE F860 SECONDARY FUEL CODE MAX GAS SHR--DF PLANTS MIN GAS SHR--DF PLANTS MAX GAS SHR--DF PLANTS TOTAL CAR EMISSIONS BY NERC CAR EMISSIONS BY FUEL/CENSUS CAR EMISSIONS BY FUEL/CENSUS TOTAL CO1 EMISSIONS BY NERC CO EMISSIONS BY FUEL/CENSUS CO EMISSIONS BY FUEL/CENSUS TOTAL CO2 EMISSIONS BY NERC CO2 EMISSIONS BY FUEL/CENSUS CO2 EMISSIONS BY FUEL/CENSUS NET DOMESTIC ECONOMY SALES-- Nerc (MM\$) NET DOMESTIC FIRM POWER -Nerc (MM\$) NET DOMESTIC ECONOMY SALES-Nerc (Mkwh) NET DOMESTIC FIRM POWER --Nerc (Mkwh) GROSS DOM. ECONOMY SALES--Nerc (MM\$) GROSS DOM. FIRM POWER -NErc (MM\$) GROSS DOM. ECONOMY SALES-Nerc (Mkwh) GROSS DOM. FIRM POWER --NERc (Mkwh) ECONOMY POWER EXPORTS--NERC (Mwh) 
UTEXPF(MNUMNR,MNUMYR)

UTIMPE(MNUMNR,MNUMYR)

UTIMPF(MNUMNR,MNUMYR)

UTJUMP

UTLSO2

UTLSO2I

UTNOX(MNUMNR,MNUMYR)

UTNOXC(EFD\$NFL,MNUMCR)

UTNOXN(EFD\$NFL,MNUMNR)

UTPSO2

UTSO2(MNUMNR,MNUMYR)

UTSO2C(EFD\$NFL,MNUMCR)

UTSO2N(EFD\$NFL,MNUMNR)

UTVOCC(EFD\$NFL,MNUMCR)

UTVOCN(EFD\$NFL,MNUMNR)

WPFUEL(EFD\$NFL,EFD\$MFRG)

WPLT\$GRP

WPLT\$REC

WPLT\$RGN

WWOP

XAREA(EFD\$MVS)

XMAP(EFD\$MSP,ETT\$MTG,EFD\$MVS)

XPCLELN(MNUMNR,MNXYR)

XPFUEL(EFD\$NFL,EFD\$MFRG)

YEARPR

ZTDMDF(MNUMNR)

ZTDMMF(MNUMNR)

ZTEXDF(MNUMNR)

ZTEXMF(MNUMNR)

ZTEXPD(MNUMNR)

ZTEXPF(MNUMNR)

ZTIMPD(MNUMNR)

ZTIMPF(MNUMNR)
UETTOUT

UETTOUT

UETTOUT

USO2GRP

USO2GRP

USO2GRP

UEFDOUT

DISPUSE

DISPUSE

USO2GRP

UEFDOUT

DISPUSE

DISPUSE

DISPUSE

DISPUSE

DISPUSE

EMM\$PARM

EMMSPARM

EMMSPARM

NCNTRL

DISPETT

DISPETT

BILDIN

DISPUSE

NCNTRL

DISPETT

DISPETT

DISPETT

DISPETT

DISPETT

DISPETTF

DISPETT

DISPETT
FIRM POWER EXPORTS--NERC (MW h)

ECONOMY POWER IMPORTS--NERC (Mkwh)

FIRM POWER IMPORTS--NERC (mwh)

MAXIMUM PRICE JUMPS

TOTAL SO2 PRODUCED

QUANTITY TOLERANCE

TOTAL NOX EMISSIONS BY NERC

NOX EMISSIONS BY FUEL/CENSUS

NOX EMISSIONS BY FUEL/CENSUS

PRICE TOLERANCE

TOTAL SO2 EMISSIONS BY NERC

SO2 EMISSIONS BY FUEL/CENSUS

SO2 EMISSIONS BY FUEL/CENSUS

VOC EMISSIONS BY FUEL/CENSUS

VOC EMISSIONS BY FUEL/CENSUS

FUEL PRC FR PREVIOUS ITR - 1

MAXIMUM NUMBER OF PLANT GROUPS PER REGION MAXIMUM NUMBER OF PLANT RECORDS

MAXIMUM NUMBER OF PLANT REGIONS

WORLD OIL PRICE CASE

EXPECTED COAL PRICE--NERC RGN

FUEL PRC FR PREVIOUS ITR - 2

FOR REPORTING, YEAR DOLLARS (EG. 1990)

Net Domestic Firm Power(MWH)

Net Domestic Firm Power (MM\$)

Gross Domestic Firm Power (MMW) Gross Domestic Firm Power (MM\$) International Firm Pwr Exports (MM\$) Internat Firm Power Exports(MWH) Internat Firm Power Imports (MM\$) Internat Firm Power Imports (MWH) 


\section{A-7 Model Outputs}

TABLE A-24: OUTPUT VARIABLES DESCRIPTION

\begin{tabular}{|c|c|c|c|c|c|c|}
\hline Variable & Field & Indices & $\underline{\text { Units }}$ & Subroutine & Output Common & Cammenss \\
\hline UTDMMF & Net Domestic Firm Power & MNUMNR,MNUMYR & Mkwh & ETTCOST & UETTOUT & \\
\hline UTDMME & Net Domestic Economy Sales & MNUMNR,MNUMYR & Mkwh & ETTCOST & UETTOUT & \\
\hline UTDMDF & Net Domestic Firm Power & MNUMNR,MNUMYR & MM\$ & ETTCOST & UETTOUT & \\
\hline UTDMDE & Net Domestic Economy Sales & MNUMNR,MNUMYR & MM\$ & ETTCOST & UETTOUT & \\
\hline UTIMPF & Firm Power Imports & MNUMNR,MNUMYR & Mkwh & ETTCOST & UETTOUT & \\
\hline UTIMPE & Economy Power Exports & MNUMNR,MNUMYR & Mkwh & \multicolumn{2}{|c|}{ ETTCOST,ELDISP } & UETTOUT \\
\hline UTEXPF & Firm Power Exports & MNUMNR,MNUMYR & Mwh & ETTCOST & UETTOUT & \\
\hline UTEXPE & Economy Power Exports & MNUMNR,MNUMYR & Mwh & \multicolumn{2}{|c|}{ ETTCOST,ELDISP } & UETTOUT \\
\hline UTEXMF & Gross Domestic Firm Power & MNUMNR,MNUMYR & Mkwh & ETTCOST & UETTOUT & \\
\hline UTEXME & Gross Domestic Economy Sales & MNUMNR,MNUMYR & Mkwh & ETTCOST & UETTOUT & \\
\hline UTEXDF & Gross Domestic Firm Power & MNUMNR,MNUMYR & MM\$ & ETTCOST & UETTOUT & \\
\hline UTEXDE & Gross Domestic Economy Sales & MNUMNR,MNUMYR & MM\$ & ETTCOST & UETTOUT & \\
\hline UGNCLNR & Coal Generation & \multirow{2}{*}{\multicolumn{2}{|c|}{ OWN,MNUMNR,MNUMYR }} & GWH & EMMDSPO & \\
\hline UEFDOUT & OWN & & & & & \\
\hline UGNGFNR & Gas (Firm) Generation & \multirow{2}{*}{\multicolumn{2}{|c|}{ OWN,MNUMNR,MNUMYR }} & GWH & EMMDSPO & \\
\hline UEFDOUT & $1=$ Utility & & & & & \\
\hline UGNGINR & Gas (Int.) Generation & \multirow{2}{*}{\multicolumn{2}{|c|}{ OWN,MNUMNR,MNUMYR }} & GWH & EMMDSPO & \\
\hline UEFDOUT & $2=$ Nonutility & & & & & \\
\hline UGNGCNR & Gas (Comp.) Generation & \multicolumn{2}{|c|}{ OWN,MNUMNR,MNUMYR } & GWH & EMMDSPO & UEBDOUT \\
\hline UGNDSNR & DS Generation & \multicolumn{2}{|c|}{ OWN,MNUMNR,MNUMYR } & GWH & EMMDSPO & UEADOT \\
\hline UGNRLNR & RL Generation & \multicolumn{2}{|c|}{ OWN,MNUMNR,MNUMYR } & GWH & EMMDSPO & UBDOUT \\
\hline UGNRHNR & RH Generation & \multicolumn{2}{|c|}{ OWN,MNUMNR,MNUMYR } & GWH & EMMDSPO & UEDOUT \\
\hline UGNURNR & Nuc Generation & \multicolumn{2}{|c|}{ OWN,MNUMNR,MNUMYR } & GWH & EMMDSPO & UEPDOT \\
\hline UGNPSNR & PS Generation & \multicolumn{2}{|c|}{ OWN,MNUMNR,MNUMYR } & GWH & EMMDSPO & UEFDOT \\
\hline UGNHYNR & Hyd (Not PS) Generation & \multicolumn{2}{|c|}{ OWN,MNUMNR,MNUMYR } & GWH & EMMDSPO & UEPDOUT \\
\hline UGNGENR & Geothermal Generation & \multicolumn{2}{|c|}{ OWN,MNUMNR,MNUMYR } & GWH & EMMDSPO & UABDOT \\
\hline UGNMSNR & MSW Generation & \multicolumn{2}{|c|}{ OWN,MNUMNR,MNUMYR } & GWH & EMMDSPO & UEADOT \\
\hline UGNWDNR & Wind Generation & \multicolumn{2}{|c|}{ OWN,MNUMNR,MNUMYR } & GWH & EMMDSPO & UEDDOT \\
\hline UGNSONR & Solar Generation & \multicolumn{2}{|c|}{ OWN,MNUMNR,MNUMYR } & GWH & EMMDSPO & UEPDOT \\
\hline UGNPVNR & Photovoltaic Generation & \multicolumn{2}{|c|}{ OWN,MNUMNR,MNUMYR } & GWH & EMMDSPO & UEPDOT \\
\hline UGNWNNR & Wind & \multicolumn{2}{|c|}{ OWN,MNUMNR,MNUMYR } & GWH & EMMDSPO & UEADOUT \\
\hline UGNHONR & Hyd/Other Generation & \multirow{2}{*}{\multicolumn{2}{|c|}{$\begin{array}{l}\text { OWN,MNUMNR,MNUMYR } \\
\text { OWN,MNUMNR,MNUMYR }\end{array}$}} & GWH & EMMDSPO & UEPDOUT \\
\hline UGNTLNR & Total Generation & & & GWH & EMMDSPO & UAPDOT \\
\hline UFLCLNR & Coal Consumption & \multicolumn{2}{|c|}{ OWN,MNUMNR,MNUMYR } & MMM Btu & EMMDSPO & UEPDOT \\
\hline UFLGFNR & Gas (Firm) Consumption & \multicolumn{2}{|c|}{ OWN,MNUMNR,MNUMYR } & MMM Btu & EMMDSPO & UEFDOT \\
\hline UFLGINR & Gas (Int.) Consumption & \multicolumn{2}{|c|}{ OWN,MNUMNR,MNUMYR } & MMM Btu & EMMDSPO & UFPOUT \\
\hline UFLGCNR & Gas (Comp) Consumption & \multicolumn{2}{|c|}{ OWN,MNUMNR,MNUMYR } & MMM Btu & EMMDSPO & LERDOUT \\
\hline UFLDSNR & DS Consumption & OWN,MNUMNR,MNU & AYR & MMM Btu & EMMDSPO & UEDOUT \\
\hline UFLRLNR & RL Consumption & OWN,MNUMNR,MNU & AYR & MMM Btu & EMMDSPO & UEDOUT \\
\hline UFLRHNR & RH Consumption & OWN,MNUMNR,MNU & AYR & MMM Btu & EMMDSPO & UEDDOT \\
\hline UFLURNR & Nuc Consumption & OWN,MNUMNR,MNU & AYR & MMM Btu & EMMDSPO & UEDOUT \\
\hline UFLPSNR & PS Consumption & OWN,MNUMNR,MNU & AYR & MMM Btu & EMMDSPO & UEHOUT \\
\hline UFLHYNR & Hyd (Not PS) Consumption & OWN,MNUMNR,MNU & AYR & MMM Btu & EMMDSPO & UEDOUT \\
\hline UFLOTNR & Oth Consumption & OWN,MNUMNR,MNU & AYR & MMM Btu & EMMDSPO & UBDOUT \\
\hline UFLTLNR & Total Consumption & OWN,MNUMNR,MNU & AYR & MMM Btu & EMMDSPO & UBADQUT \\
\hline
\end{tabular}




\begin{tabular}{|c|c|}
\hline UPRCLNR & Coal Price \\
\hline UPRGFNR & Gas (Firm) Price \\
\hline UPRGINR & Gas (Int) Price \\
\hline UPRGCNR & Gas (Comp) Price \\
\hline UPRDSNR & DS Price \\
\hline UPRRLNR & RL Price \\
\hline UPRRHNR & RH Price \\
\hline UPRURNR & Nuc Price \\
\hline $\begin{array}{l}\text { UPRHONR } \\
U\end{array}$ & Renewables Price \\
\hline UTSO2 & Total SO2 Emissions \\
\hline UTNOX & Total NOX Emissions \\
\hline UTCO2 & Total CO2 Emissions \\
\hline UTCO1 & Total CO1 Emissions \\
\hline UTCAR & Total CAR Emissions \\
\hline URETTLU & Utility Total Retirements \\
\hline UGNUBCR & Util BWR Nuclear Generation \\
\hline UGNUPCR & Utility PWR Nuclear Generatior \\
\hline QBCELNR & VLS Bit Coal Consumption \\
\hline QBDELNR & LS Bit Coal Consumption \\
\hline QBMELNR & MS Bit Coal Consumption \\
\hline QBHELNR & HS Bit Coal Consumption \\
\hline QSCELNR & VLS Sub Coal Consumption \\
\hline QSDELNR & LS Sub Coal Consumption \\
\hline QSMELNR & MS Sub Coal Consumption \\
\hline QSHELNR & HS Sub Coal consumption \\
\hline QLCEELNR & VLS Lig Coal Consumption \\
\hline QLDELNR & LS Lig Coal Consumption \\
\hline QLMELNR & MS Lig Coal Consumption \\
\hline QLHELNR & HS Lig Coal Consumption \\
\hline QBTELNR & Bit Coal Consumption \\
\hline QSTELNR & Sub Coal Consumption \\
\hline QLTELNR & Lig Coal Consumption \\
\hline FLAGSO2 & $\begin{array}{l}\text { Penalty Cost Flag } \\
0=\text { Not, } 1=\text { Converged }\end{array}$ \\
\hline FBTELNR & Bit Coal Convergence Flag \\
\hline FSTELNR & Sub Coal Convergence Flag \\
\hline FLTELNR & Lig Coal Convergence Flag \\
\hline QGFELGR & NG Firm Consumption \\
\hline UEFDOUT & NGTDM $=1$ through 21 \\
\hline QGIELGR & NG Inter. Consumption \\
\hline QGCELGR & NG Comp. Consumption \\
\hline
\end{tabular}

MNUMNR,MNUMYR MNUMNR,MNUMYR MNUMNR,MNUMYR MNUMNR,MNUMYR MNUMNR,MNUMYR MNUMNR,MNUMYR MNUMNR,MNUMYR MNUMNR,MNUMYR MNUMNR,MNUMYR

MNUMNR,MNUMYR MNUMNR,MNUMYR MNUMNR,MNUMYR MNUMNR,MNUMYR MNUMNR,MNUMYR MNUMNR,MNUMYR MNUMCR,MNUMYR MNUMCR,MNUMYR NDREG,MNUMYR NDREG,MNUiUYR NDREG,MNUMYR NDREG,MNUMYR NDREG,MNUMYR NDREG,MNUMYR NDREG,MNUMYR NDREG,MNUMYR NDREG,MNUMYR NDREG,MNUMYR NDREG,MNUMYR NDREG,MNUMYR NDREG,MNUMYR NDREG,MNUMYR NDREG,MNUMYR None

NDREG

NDREG

NDREG-1

NGTDM,MNUMYR

NGTDM,MNUMYR NGTDM,MNUMYR
EFDOUT

UEFDOUT

UEFDOUT

UEFDOUT

UEFDOUT

UEFDOUT

UEFDOUT

UEFDOUT

Tons
Tons
Tons
Tons
Tons

EFDOUT

EMMDSPO UEFDOUT

EMMDSPO UEFDOUT

EMMDSPO UEFDOUT

EMMDSPO UEFDOUT

EMMDSPO UEFDOUT

EMMCAPO UEFDOUT

UEFDOUT

UEFDOUT

MMM Btu

EMMDSPO

EMMDSPO

EMMDSPO

EMMDSPO

EMMDSPO

EMMDSPO

EMMDSPO

EMMDSPO

EMMDSPO

EMMDSPO

EMMDSPO

EMMDSPO

EMMDSPO

EMMDSPO

EMMDSPO

UEFDOUT

MMM Btu

Numeric ELEFD

MMM Btu

MMM Btu

MMM Btu
UEFDOUT

UEFDOUT

UEFDOUT

MMDSPO

EMMDSPO

UEFDOT

UADOT

UEDOUT

UEPDOT

UEDDOUT

UEDOUT

UEDOUT

UEDOUT

UEDDOT

UEPDOT

UEPOUT

UEPDOT

UEDOUT

UEDOUT

UEDOUT

UEDOUT

EMMDSPO 


\section{Appendix B}

\section{B.1 Mathematical Description of Algorithms}

This appendix contains a description of the FORTRAN subroutines of the EFD. 
Description: This subroutine is the main controlling module of the EFD. ELEFD initializes variables and checks a user-specified switch that determines if the trade component of the dispatch decision will be executed. This subroutine also checks if the dispatch decision has converged on the emissions limit specified by the Clean Air Act Amendments of 1990. If the result bas not converged, the emissions penalty cost is changed and the dispatch decision is re-executed.

Called by: UTIL

Source Code: UEFD

Calls: $\quad$ GETSO2, GETIN, GETBLD, GETOUT, ELSO2F, ELDISP, STROUT, STRBLD, ELSO2L,ETTPRC, STRSO2,

Equations: None 
Description: The Subroutine GETSO2 reads in total $\mathrm{SO}_{2}$ produced from the file \&6005PRJ.UTIL.SO2DAF.<scenario>. $<$ datekey $\rangle^{26}$ for the current year.

- Called by: ELEFD

Source Code: UDAF

Calls:

Equations: None

${ }^{26}$ The final model run for AEO 1994 is: scenario name - AEO94B; datekey - D1221934. 
Description: This subroutine reads in load curve, plant grouping, transmission constraints, and cost and performance data from the file \&6005PRJ.UTIL.INPTDAF.<scenario>.<datekey>. The DISPIN common block is loaded for the current model year and region with the appropriate information stored in the INPTDAF file.

\section{Called by: ELEFD}

Source Code: UDAF

Calls:

Equations: None 
Subroutine: GETBLD

Description: This subroutine reads in the file \&6005PRJ.UTIL.ECPIDAF.<scenario >.<datekey> file which contains the build decision (including the existing and planned units) from the ECP including their cost and performance information. This data is stored in the BILDIN common block.

\section{Called by: ELEFD}

Source Code: UDAF

Calls:

Equations: None 
Description: This subroutine initializes additional variables, reads in interruptible international tradic and adjusts the load curve for planned maintenance, renewable generation and trade. It also calls the subroutines which are responsible for the dispatch decision, in paricular: determining the merit order; incorporating the maintenance schedule; removing hydroelectric and other renewable facilities from the load curve; allocating the capacity; and tabulating fuel consumptions and associated costs.

Called by: ELEFD

Source Code: UEFD

Calls:

ELMRIT, ELPNM, ELRNEW, ELALOC, ELCOST, LOADNG, STRETT

Equations:

Determine the Merit Order for Dispatching

See discussion of the Subroutine ELMRIT

Adjust available capacity for each time period by the planned maintenance schedule

$\operatorname{ECACAP}(J)=(\operatorname{ECCAP}(J, I)-\operatorname{ECCOPM}(J, I))^{*} .001$

$\operatorname{ECLFR}(J)=1.0-(\operatorname{REAL}(\mathrm{KMXCP}) * \operatorname{EFACTR} /((1.0-\operatorname{REAL}(\mathrm{KFOR}) * \operatorname{EFACTR}) *(1.0-\operatorname{REAL}(\mathrm{KPMR}) *$ EFACTR)))

Where,

ECCAP = Total existing capacity

ECCOPM = Capacity Out for Planned Maintenance

KMXCP = Maximum Capacity Factor (ECMXCP)

KPMR = Planned Maintenance Rate (ECPMR)

EFACTR = Converts integer with two significant digits to a real value with four significant digits (i.e. multiplies by $.001)$

KFOR = Forced Outage Rate by Capacity Type (ECFOR)

Convert International Trade Power into gigawatts for each Season

International Economy Trade is currently determined exogenously, with energy estimates provided. This energy needs to be converted to gigawatts to be useful in the EFD in order to remove this energy from each slice of load.

INTRUP $=($ EXPANN * $($ EETIME(I) $/$ TOTHRS $))-($ IMPANN * $($ EETIME(I) $/$ TOTHRS $))$

Where,

IMPANN $=$ ETIMPE $/$ TOTHRS

EXPANN $=$ ETEXPE $/$ TOTHRS

and,

ETIMPE $=$ Economy Imports $(\mathrm{mwh})$

ETEXPE $=$ Economy Exports $(m w h)$

EETIME $=$ Number of Hours per Season

TOTHRS $=$ Total Hours in the Year 
ETYVAL $($ IVCT $)=$ ELYVAL $(I V C T, I)+$ EEITAJ (I) + INTRUP

Where,

ELYVAL $=\mathrm{Y}$ value of Seasonal Load Curve where $\mathrm{X}$ is time and $\mathrm{Y}$ is $\mathrm{GW}$.

EEITAJ $=$ Net Exports (from firm power commitments and cogen)

INTRUP = Net International Economy Exports

Calculate Load (before renewables are removed from load)

The area under the curve is calculated using the midpoints of the $y$-values on the load duration curve.

ETAREA $($ IVCT $)=($ ETXVAL $(I V C T+1)-\operatorname{ETXVAL}(I V C T)) * .05 *($ ETYVAL $(I V C T)+$ ETYVAL $(I V C T+1))$

ETXVAL $=X$ point on original demand curve $(G W)$, where $X$ is time and $Y$ is GW.

ETYVAL $=Y$ value on original demand curve $(G W)$, where $X$ is time and $Y$ is $G W$.

IVCT $=$ Load Slice Number

Remove Hydroelectric and Other Renewables from the Load Curve

See discussion of the Subroutine ELRNEW.

\section{Calculate Import and Export Load Curve}

Calculations are performed by region and season that create load curves representing 1) areas of generation that could be displaced by imports, referred to as "import curves", and 2) areas of generation that could be available for export, referred to as "export curves". These curves are calculated as the original load curve (XY pairs) plus or minus the region/seasonal maximum transmission constraint.

TTYVAL $=$ ETYVAL + TRNCWT $($ Winter $)$

TIYVAL $=$ ETYVAL - TRNCWI (Winter)

TTYVAL = ETYVAL + TRNCST (Summer)

TIYVAL = ETYVAL - TRNCSI (Summer)

Where,

ETYVAL $=Y$ value on original demand curve

TRNCWT $=$ Winter Export Transmission Constraint

TRNCWI = Winter Import Transmission Constraint

TRNCST $=$ Summer Export Transmission Constraint

TRNCSI = Summer Import Transmission Constraint

Note: Regions 2, 5 and 7 (ERCOT, MAPP and NPCC/New England) are excluded from economy trade; i.e. their maximum transmission constraints are set to zero.

Calculate Load (Energy) Under the Import and Export Curves

ETAREA $($ IVCT $)=($ ETXVAL $($ IVCT +1$)-$ ETXVAL $(I V C T)) * .05 *($ ETYVAL(IVCT $)+$ ETYVAL $(I V C T+1))$

\section{Allocate Capacity to Meet Demand}


See discussion of the Subroutine ELALOC.

Calculate Trade Amounts Available to Replace Native Supply

***Need additional discussion

The export and import capacity available for trade is calculated by subtracting the area of the original demand curve from the export load curve and hy subtracting the import load curve from the original demand curve, respectively.

CUMAREA $=$ AREATT - AREANT (Export Available)

CUMAREI $=$ AREANT - AREAIT (Import Available)

Where,

AREATT $=$ Area under the export load curve

AREANT = Area under the original load curve

AREAIT = Area under the import load curve

Tabulate Fuel Consumption, Cost and Operations and Maintenance Costs Associated with a Set of Dispatch Decisions

See discussion of the ELCOST subroutine.

Load Nonutility Revenue Variables

See discussion of the LOADNG subroutine.

Write Out ETT Direct Access File

See discussion of the STRETT subroutine. 
Description: This subroutine determines the merit order for dispatching by listing equipment types in order of increasing operating costs. However, before the merit order is determined, the fuel shares used by each capacity type is determined based on maximum/minimum allowed and elative fuel prices.

Called by: ELDISP

. Source Code: UEFD

Calls: $\quad$ ELFSHR

Equations:

\section{Calculate Fuel Shares}

See discussion of the ELFSHR Subroutine.

Calculate Unit Costs for Each Equipment Type

Units costs for each equipment type are calculated by first determining total costs and then factoring the total cost by the fuel shares for each capacity group.

CST_TOT $=$ CST_OM + CST_FL + CST_SO2

Where,

CST_OM $=$ ECOMR(I J)

CST_FL $=$ ZCFL $*$ ECHTRT $(1, \mathrm{~J}) * .001$

CST_SO2 $=$ PSO $2 *$ ZSO2 $* .000001 *$ ECHTRT $(\mathrm{I}, \mathrm{J}) *(1.0-$ REAL $(\mathrm{KSCRB}) *$ EFACTR $)$

and,

ECOMR = Variable O\&M

ZCFL $=$ UPFUEL $=$ Delivered Fuel Prices

ECHTRT $=$ Heat rate

$\mathrm{PSO} 2=\mathrm{EPSO} 2=\mathrm{SO}_{2}$ Penalty Cost

$\mathrm{ZSO} 2=\mathrm{UFRSO} 2=\mathrm{SO}_{2}$ Emission Rate

$\mathrm{KSCRB}=\mathrm{ECSCRB}=$ Scrubber Efficiency

UNTCST $(\mathrm{I})=$ UNTCST $(\mathrm{I})+$ ECFSHR $(\mathrm{I}, \mathrm{J}) *$ CST_TOT $($ Total Costs multiplied by fuel share $)$

Sort by Unit Costs

The costs are sorted by creating an index which refers to the order. The sort is executed by searching through the costs to find the smallest cost and assigning this capacity group and index of one. This sort is executed with the remaining capacity groups, finding the next smallest cost, until the sort is complete. The sort is completed as follows:

Do $30 \mathrm{I}=1$, ECNTP

$\operatorname{INDEX}(\mathrm{I})=\mathrm{I}$

30 CONTINUE

ILST $=$ ECNTP -1

DO $60 \mathrm{I}=1, \mathrm{ILST}$

JFRST $=1+1$

DO $50 \mathrm{~J}=\mathrm{JFRST}$, ECNTP

IF (UNTCST(J).GE.UNTCST(I))GO TO 40 
TEMP=UNTCST $(\mathrm{J})$

UNTCST $(\mathrm{J})=$ UNTCST $(\mathrm{I})$

UNTCST $(\mathrm{I})=$ TEMP

ITEMP $=\operatorname{INDEX}(\mathrm{J})$

$\operatorname{INDEX}(\mathrm{J})=\operatorname{INDEX}(\mathrm{I})$

$\operatorname{INDEX}(\mathrm{I})=$ ITEMP

40 CONTINUE

50 CONTINUE

60 CONTINUE 
Description: This subroutine calculate fuel shares by determining first if an equipment type is dual-fired or not. If the equipment type is dual-fired, then the cheapest fuel is used up to its maximum share, followed by the next least costly, etc., until all the capacity is allocated.

\section{Called by: $\quad$ ELMRIT, ETTCOST}

Source Code: UEFD

Calls:

Equations:

Determine Weights for Seasonal Fuel Shares

SWGHT(JSP) $=$ EESSHR(JSP) $*$ ECCAP(I,JSP)

TWGHT $=$ TWGHT + SWGHT(JSP)

Where,

EESSHR $=$ Seasonal Demand Share

ECCAP = Conventional Capacity

$I$ = Capacity Type

JSP $=$ Season

SWGHT(JSP) $=$ SWGHT(JSP) $/$ TWGHT

ECFSHR(I,J)=ECFSHR(I,J) + ECMFSH(IPGRP,J,JSP) * SWGHT(JSP)

FSHR $=$ FSHR + ECFSHR $(I, J)$

$\operatorname{ECFSHR}(\mathrm{I}, \mathrm{J})=\mathrm{ECFSHR}(\mathrm{I}, \mathrm{J}) /$ FSHR

Where,

$\mathrm{J}=$ Fuel Type

ECMFSH $=$ Maximum Fuel Share

If the Capacity is Dual-Fired, Determine Shares

First, Sort by Costs

If Prices are Close, Smooth Shares Between Fuels

If the Capacity is Dual-Fired, Use the Maximum Fuel Share for the Cheapest fuel, and adjust the Other Shares so that Total Share Equals 1

$\operatorname{ECFSHR}(\mathrm{I}, \mathrm{IR}(\mathrm{J}))=\operatorname{MIN}(\mathrm{ECFSHR}(\mathrm{I}, \mathrm{IR}(\mathrm{J})), \mathrm{FSHR})$

FSHR $=$ FSHR - ECFSHR(I,IR(J))

Add Parity Stuff 
Description: After the merit order has been deternined, a maintenance schedule is determined for the units. This maintenance schedule is based on the seasonal reserve margin, with the maintenance scheduled from the smallest to the largest units.

Called by: ELDISP

Source Code: UEFD

Calls:

Equations:

Calculate Required Capacity Usilization Lost to Planned Maintenance and Sum Total Available Capacity

If the Planned Maintenance Rate is greater than zero then:

$\mathrm{RQ}=\mathrm{ECCAP}(\mathrm{IPLNT}, \mathrm{ISP}) * \mathrm{REAL}(\mathrm{KPMR}) * \mathrm{EFACTR} * \mathrm{EETIME}(\mathrm{ISP}) * 0.001$

Where,

ECCAP = Conventional Capacity

KPMR = Planned Maintenance Rate

EETIME $=$ Time in Season

If the Planned Maintenance Rate is zero then:

$\mathrm{RQ}=\mathrm{ECCOPM}(\mathrm{IPLNT}, \mathrm{ISP}) * \mathrm{EETIME}(\mathrm{ISP}) * 0.001$

Where,

ECCOPM = Capacity Net of Planned Maintenance

REQIR = RQ + REQIR

CAP(ISP) $=$ ECCAP(IPLNT,ISP) $* 0.001 *$ EETIME(ISP) + CAP(ISP)

TOTAL $=$ ECCAP(IPLNT,ISP $) * 0.001 *$ EETIME(ISP) + TOTAL

\section{Add in Hydroelectric Capacity}

TOTAL $=$ TOTAL + EHCA.P(IRNEW,ISP) $* .001 *$ EETIME(ISP)

$\mathrm{CAP}(\mathrm{ISP})=\mathrm{CAP}(\mathrm{ISP})+\mathrm{EHCAP}($ IRNEW,ISP) * $.001 *$ EETIME(ISP)

Calculate Capacity Required to Meet Peak Demand in Each Time Period and Average Over All Time Periods

In this section, the $y$-value (demand) of the xy pair that describes the load is adjusted by International economy exports, planned domestic trade transactions and purchases from cogenerators and interregional transmission constraints to most accurately portray planned maintenance schedules.

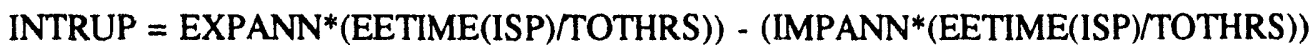

Where, 
IMPANN $=$ ETIMPE/TOTHRS

EXPANN $=$ ETEXPE/TOTHRS

ETIMPE $=$ Economy Imports $(\mathrm{mwh})$

ETEXPE $=$ Economy Exports $(\mathrm{mwh})$

TOTHRS $=$ Total Hours in Year

EETIME $=$ Total Hours in Season

During the Winter Seasons, the peak is calculated as follows:

PEAK(ISP) $=$ ELYVAL $(1, I S P)+$ INTRUP + EEITAJ(ISP) + TRNCWT

While during the Summer Seasons, the peak is calculated as:

PEAK(ISP) $=$ ELYVAL $(1, I S P)+$ INTRUP + EEITAJ(ISP) + TRNCST

Where,

ELYVAL $=Y$ value on original demand curve (GW), where $X$ is time and $Y$ is $G W$.

EEITAJ $=$ Net Exports

TRNCWT $=$ Winter Export Transmission Constraint

TRNCST $=$ Summer Export Transmission Constraint

If the Trade Model is not Executing, the peak is calculated as:

PEAK(ISP) $=$ ELYVAL(1,ISP) + INTRUP + EEITJA(ISP)

DEMAND $=$ PEAK(ISP) $*$ EETIME(ISP) + DEMAND

Determine the Maximum Reserve Margin Which Can Be Achieved

EEMRM $=$ MAX(DBLE(0.0),((TOTAL - REQIR) $/$ DEMAND - DBLE(1.0))

Determine Seasonal and Annual Maintenance Time Availability Measured in Potential Energy Lost to Maintenance

Available time is calculated as total capacity less the maximum reserve margin and capacity scheduled for maintenance

AVAIL(ISP) $=$ CAP(ISP) - PEAK(ISP) $*(1+$ EEMRM $) *$ EETIME(ISP) - SCHDLD(ISP)

TOTAVL = TOTAVL + AVAIL(ISP)

Schedule Maintenance from the Seasonal Period with the Largest Reserve Margin to the Seasonal Period with the Smallest Reserve Margin

Maintenance is scheduled for capacity based on the minimum of remaining time available during the season for planned maintenance (AVAIL) and the planned maintenance time necessary for the unit.

ECCOPM $($ PLNT,ISP) $=$ MIN(AVAIL(ISP),RQ,DBLE(ECCAP(IPLNT,ISP) * EETIME(ISP) *.001)

AVAIL(ISP) $=$ AVAIL(ISP) - ECCOPM(IPLNT,ISP)

Total available and total required are calculated to determine remaining scheduling.

TOTAVL $=$ TOTAVL - ECCOPM(IPLNT,ISP)

$R Q=R Q-E C C O M P(I P L N T, I S P)$ 
Description: This subroutine removes the hydroelectric and other renewable units from the load curve, with the capacity removed in the appropriate slices to meet their capacity factor requirements. The resulting generation is maintained for reporting and to be passed to the Renewable Fuels Module.

Called by: ELDISP

Source Code: UEFD

Calls: $\quad$ ELGETY

Equations:

The purpose of this section is to describe how hydroelectric and other renewable generating capacity is dispatched (operated). Hydroelectric and other renewable capacity typically has the lowest variable cost (since its fuel, water, wind, sun, etc. is considered to have no cost), which implies that it would be the first plant type placed on the curve so that its utilization is maximized. However, bydroelectric plants generally cannot be operated as baseload capacity because their output is constrained by the available water supply.

In the EFD, hydroelectric generating capacity is dispatched before other plant types in order to insure that the energy constraint is satisfied. Subsequently, the other plant types are then dispatched on the load duration curve, excluding the portion met by hydroelectric generating capacity, on a merit-order basis.

The energy constraint is incorporated using an average utilization rate for hydroelectric plants, which specifies the fraction of time water is available to operate these plants. For example, a utilization rate of 0.50 indicates that the average hours of operation, would be limited to 4,380 of the total 8,760 hours in this example. Currently, the utilization rates for hydroelectric plants are based on historical data. If regulations to protect fish by restricting water flow are enacted then these utilization rates would be adjusted downward. The total energy (S_AREA) that could be produced by the available hydroelectric capacity is given by the following equation.

Calculate the $X$-value exactly between each point on the load curve

A_CRV $($ IVCT $)=\operatorname{ETXVAL}($ IVCT +1$)+\operatorname{ETXVAL}($ IVCT $)) * .5$

Where,

ETXVAL $=X$ value of the point which defines the load curve, where the $x$ value represents time and the $y$ value represents demand $(\mathrm{gw})$.

IVCT $=$ Number of points which define the load curve.

\section{Determine Capacity and Energy to Remove from Load Curve}

The capacity of the renewable type is to be removed from the load curve unless the renewable capacity is greater than the load.

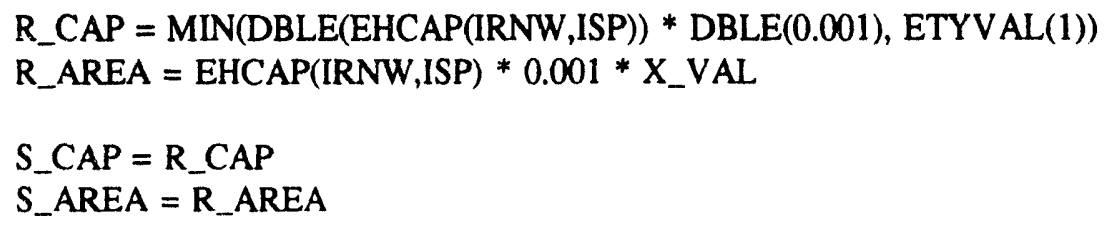

Where, 
EHCAP(IRNW,ISP) $=$ Renewable Capacity

ETYVAL $=\mathrm{y}$ value of the point which defines the load curve, where the $\mathrm{x}$ value represents time and the $\mathrm{y}$ value represents demand (gw).

X_VAL $=\operatorname{Real}(\mathrm{KHYCF})=\mathrm{EHHYCF}(\mathrm{IRNW}, \mathrm{ISP})=$ Renewable Capacity Factor

The model places the hydroelectric capacity using a trigger point, which indicates where on the load duration curve placement is initiated such that the energy constraint can be matched while using all of the capacity. There are three possible cases where both of these objectives can be satisfied.

- All of the capacity is used for base load (i.e. placement is entirely below the knee)

- None of the capacity is used for base load (i.e. placement is between the knee and the peak)

- Some of the capacity is used for base load (i.e. placement begins below the knee but extends above it).

The minimum amount of energy that could be generated while allocating all of the capacity (A_MIN) occurs when the capacity is placed at the top of the curve. The maximum amount that could be produced (A_MAX) results by operating the capacity at the bottom of the curve. Therefore, in order to meet the energy constraint while allocating all of the capacity, the product of the available hydroelectric capacity and the average utilization rate must be greater than or equal to A_MIN and less than or equal to A_MAX.

However, there may be some instances where it may not be possible to allocate all of the available hydroelectric capacity such that the assumed utilization rate is achieved. Consequently, the following cases are also considered in the EMM.

The assumed utilization rate for hydroelectric plants results in generation S_AREA/R_AREA) that is less than the minimum output (A_MIN)

The assumed utilization rate for hydroelectric plants results in generation that is greater than the maximum amount (A_MAX). 
Description: This subroutine allocates the "dispatchable" capacity by capacity type for each of the seasonal load curves (defining the capacity type by a line with crosses the load duration curve and each of the segments) with the capacity dispatched by the least expensive units first. (Note the merit order of the capacity may be different across seasons because of fuel supply constraints in certain regions during certain seasons.)

First, ELALOC calculates a trigger point, i.e., the $y$-value after which only certain peaking units can be dispatched. Next, the capacity is allocated under the trigger point utilizing all available capacity and then peaking capacity is determined after the trigger point. Next, after the capacity has been dispatched, the area under the original load curve and the import and export load curves are determined.

Called by: ELDISP

Source Code: UEFD

Calls: $\quad$ ELGETY, ELLOAD, ETLOAD, EILOAD

Equations:

Initialize Capacity Bound Trigger Points (Minimum Capacity Factors for Available Capacity) and Capacity Switches

Trigger Points

For Utility Units

TRIGER(3,NMTRGR) $=1$

$\operatorname{TRIGER}(1, N M T R G R)=1$

$\operatorname{TRIGER}(2, \mathrm{NMTRGR})=\mathrm{I}$

For Nonutility Units

TRIGER(3,NMTRGR) $=2$

TRIGER(1,NMTRGR)=I

$\operatorname{TRIGER}(2, N M T R G R)=I$

Where,

NMTRGR = Number of Capacity Types below the Trigger Point (The placement of the "trigger" point is based on available capacity and capacity factor lower bounds - note, both minimum and maximum capacity factors are provided)

$\mathrm{I}=$ Capacity Type, in increasing cost order

The $\mathrm{x}$-value of the trigger point equals the minimum capacity factor for that capacity type/group (ECCFBD(JCAP,2)) \{in general, this value is equal to .08 for baseload and intermediate units\} while the $y$-value is the corresponding value on the load duration curve. This $y$-value signifies the point where baseload and intermediate capacity are no longer available and peak capacity is required (i.e., only peaking units can be dispatched beyond this point so the algorithm needs to check if the capacity is a baseload, intermediate or peaking unit). The subroutine ELGETY is called to determine this $y$ value and the step number of the trigger point on the load duration curve.

CALL ELGETY(XPVPNT(MNTRGR),YVAL,IVAL) - See description of the subroutine ELGETY

Where,

XPVPNT $=$ Maximum Capacity Factor Bounds

MNTRGR = Trigger Number

YVAL $=\mathrm{Y}$ value on the load duration curve 
IVAL $=$ Step number

Capacity Switch

Determines if Capacity is Available and/or the capacity factor is within range (i.e. greater than 0 and less than 1).

Order Trigger Points in Order of Increasing Load

Loop Through Trigger Points Under Capacity Line (Capacity Lines are 'Loaded' in order of increasing costs) Crosses Load Curve at Trigger Point

(i.e. where ESLCUT(1) < CPIVOT)

$$
\text { CPIVOT }=\text { YPVPNT(NT) }- \text { XPVPNT(NT)*ESLCUT(2) }- \text { TOLRNC }
$$

Where,

YPVPNT $=y$ value associated with the maximum capacity factor ( $x$ value)

$\mathrm{NT}=$ Trigger Number

ESLCUT $=$ Line which describes the capacity, $y$ intercept (index $=1$ ) and slope (index $=2$ )

TOLRNC $=.000001$

Check for Unallocated Capacity

Check if Capacity Can Operate at this Utilization Level

Determine Next Trigger Point which Impacts Current Capacity

Commit Capacity to Load (Call Subroutines ELLOAD, ETLOAD and EILOAD

Update Intercept and Slope of Current Cutting Line

ESLCUT(1) $=$ ESLCUT(1) + SHGHT(SOLSW)

$\operatorname{ESLCUT}(2)=\operatorname{ESLCUT}(2)-\operatorname{SHGHT}($ SOLSW $) *$ SLFR $($ SOLSW $) * 2.0$

Where,

ESLCUT $(1)=y$ intercept of cutting line

$\operatorname{ESLCUT}(2)=$ slope of the cutting line

SHGHT = Available Capacity

SLFR = Capacity Committed to Load

$\underline{\text { Store Dispatch Decision }}$

Update Cumulative Load Satisfied

Check if Total Demand Has Been Met

Tum Cápacity Off if All Capacity Has Been Met

Index to the Next Capacity Type in the Merit Order

Resolve without Capacity Bounds (i.e.. Lower Limit on baseload and intermediate units) if Demand is not Satisfied and All Capacity Has Not Been Utilized 
Description: This subroutine calculates the area under the load curve to determine generation from the capacity type chosen. In order to determine this area, the point at which the line which defines the capacity being dispatched crosses the load duration curve needs to be determined.

Called by: ELALOC

Source Code: UEFD

Calls:

\section{ELGETXY}

Equations:

The slope and intercept of the cutting line are calculated as:

$\operatorname{CUT}(1)=\operatorname{ESLCUT}(1)+$ SHGHT

CUT(2) $=$ ESLCUT(2) - SHGHT * $2 *$ SLFR

Where:

CUT $(1)=$ intercept of cutting line

$\operatorname{CUT}(2)=$ intercept

ELGTXY is called to find where the cutting line crosses the load curve.

The area below the knee of the load curve is calculated and loaded into AREANT which stores data by horizontal and vertical slice. AREANT is cumulative within the vertical slice.

If CUT(1) > TIYVAL

AREANT(HN,IE-1) $=.5((\mathrm{CUT}(1)+\mathrm{CUT}(2) *$ ETXVAL (IE-1)) $)+$

$(\mathrm{CUT}(1)+\mathrm{CUT}(2) * \operatorname{ETXVAL}(\mathrm{IE}))) *(\mathrm{ETXVAL}(\mathrm{IE})$.

ETXVAL(IE-1))

If the cutting line is below the load curve (IABOVE $=0$ ), area is calculated under the cutting line from the intersection of the $\mathrm{Y}$-axis (ISTRT) to the intersection point of the load curve and the cutting line (XINT, YINT), and area is added from under the load curve from the intersection point of the load curve and the cutting line (XINT,YINT) to the knee (XVAL(INTNUM+1)).

If before the crossover point:

AREANT(HN,IE-1) $=.5((\mathrm{CUT}(1)+\mathrm{CUT}(2) *$ ETXVAL(IE-1) $)+$ $($ CUT(1) + CUT(2) * ETXVAL(IE))) *

(ETXVAL(IE) - ETXVAL(IE-1))

If left of the crossover point:

AREANT(HN,INTNUM $)=.5($ CUT(1) + CUT(2) * ETXVAL(INTNUM $)+$ YINT $) *\left(\begin{array}{llll}* & \text { X } & \text { I } & T\end{array}\right.$ ETXVAL(INTNUM))

If right of the crossover point:

AREANT $($ HN, INTNUM $)=$ AREANT + .5(YINT + ETYVAL $($ INTNUM+1) $) *($ ETXVAL(INTNUM+1) - XINT $)$

If the cutting line is above the load curve, area is calculated under the load curve from the intersection of the $\mathrm{Y}$-axis (ISTRT) to the intersection of the cutting line and the load curve (XINT,YINT), and area is added from under the cutting line from the intersection of the cutting line and the load curve (XINT, YINT) to the knee (INTNUM +1 ). 
If before the crossover point:

$\operatorname{AREANT}(H N, \mathrm{I})=.5(\operatorname{ETYVAL}(\mathrm{I})+\operatorname{ETYVAL}(1+1)) *$

(ETXVAL(1+1) - ETXVAL(1))

If left of the crossover point:

AREANT $($ HN,INTNUM $)=($ YINT + ETYVAL(INTNUM $) * .5 *($ XINT - ETXVAL(INTNUM $))$

If right of the crossover point:

AREANT(HN,INTNUM) $=$ AREANT + .5 (YINT + CUT(1) + CUT(2) * ETXVAL(INTNUM+1)) (ETXVAL(INTNUM+1) - XINT) 
Figure B-1

PLACE DANA'S DIAGRAM HERE

Calculation of Area under Load Curve 
Description: This subroutine evaluates a piecewise load duration curve to find the $y$ value and step i for a given $x$ coordinate (i.e., to find the $y$ coordinate on the load curve).

Called by: ELRNEW

Source Code: UEFD

. Calls:

Equations:

This subroutine searches amongst the $x$ values to find the closest $x$ value along the load curve to deternine the $y$ value and step for the $x$ value. First, it determines the relative position of the $x$ value to narrow the search for the $x, y$ pair. The technique is as follows:

Determine relative position of the $x$ value

XSHR $=$ X / (ETXVAL(ETNVCT) $\cdot \operatorname{ETXVAL(1))~}$

Where,

ETXVAL(ETNVCT) $=$ Last $x$ value which defines the load duration curve.

ETXVAL(1) $=$ First $x$ value which defines the load duration curve.

Determine First X Coordinate on Load Curve to Search for Pair

IFRST $=$ MAX $(\mathrm{DBL}(1.0)$, ETNVCT $*$ XSHR)

If the input $x$ value is greater than IFRST, search for the $x, y$ pair from IFRST to the last $x, y$ pairs that defines the load curve. Once the location on the load curve is determined, the $y$-value is calculated as follows:

YOUT $=$ ETYVAL(I) $-(($ ETYVAL(I)-ETYVAL(I+1)) * (ETXVAL(I)-X) $/($ ETXVAL(I) - ETXVAL(I+1) IOUT $=\mathrm{I}$

Where,

ETYVAL $=y$ value of the $x, y$ pair that define a point on the demand curve ETXVAL $=x$ value of the $x, y$ pair that define a point on the demand curve $I=$ Step on the Load Curve

If the input $x$ value is less than IFRST, search for the $x, y$ pair from IFRST to the second point on the load curve. Once the location on the load curve is determined, the $y$-value is calculated as follows:

YOUT $=$ ETYVAL(I) $-(($ ETYVAL(I)-ETYVAL(I+1)) $*(\operatorname{ETXVAL(I)-X)~} /(\operatorname{ETXVAL(I)~}-$ ETXVAL(I+1) IOUT $=\mathrm{I}$ 
Description: This subroutine calculates the load under the "export" load duration curve and saves the information into the variable AREATT. As in ELLOAD, the point at which the lines which defines the capacity being dispatched crosses the load duration curve needs to be determined. This is calculated in the following subroutine

Called by: ELALOC

Source Code: UETT

Calls:

Equations: Similar to ELLOAD subroutine. See ELLOAD subroutine for mathematical description.

Interim calculations are performed to collect information regarding the area under the curves that is available for export or that could be displaced.

Area available for export is calculated as:

CUMAREA $=$ AREATT - AREANT

where

CUMAREA = cumulative area available for export

AREATT $=$ all area under "export" curve

AREANT $=$ all area under original curve

Incremental areas are calculated as:

EXTMP = CUMAREA(current) - CUMAREA(previous)

where

EXTMP = incremental area (horizonal/vertical) available for export

Last, since less than 30 of the 180 or so possible plant groups that are allocated are generally available for trade, the above data are stored into arrays dimensioned only by 30 horizontal slices. The original horizontal slice index is saved into a mapping variable for later use. The following describes the data elements preserved for the ETT.

\section{Exports}

- EXMAP - map to original horizontal slice index

- AREATR = EXTMP * EETIME (generation)

- CAPTR $=$ AREATR $/[($ ETXVAL(neXt) $-\operatorname{ETXVAL}($ current $)) *$ EETTME $]$

Next, ELCOST is called to store non-trade dispatch summary results and to store some pointers needed later in the trade algorithm.

Pointers preserved include:

ECDSPN $=$ horizonal slice index

ECDSPT $=$ equipment type index

ECASTS = capacity type

ECFSHR $=$ fuel share index

STRETT is called to write out the ETTDAF (stores trade opportunities arrays into DAF). 
Description: This subroutine evaluates a piecewise load duration curve to find the $x, y$ pair and step I at which a given cutting line crosses the load duration curve.

Called by: ELLOAD

Source Code: UEFD

. Calls:

Equations:

If the Cutting Line is Below the Load Duration Curve

Given the equation of the line, determine the $y$-value for each $x$-value along the line.

$\mathrm{YINT}=\mathrm{Y} 0+\mathrm{SLOPE} *$ ETXVAL$(\mathrm{I}+1)$

Where,

Y0 $=$ The $y$-intercept of the line

SLOPE $=$ Slope of the Line

ETXVAL = The $x$ value of the $x, y$ pair that define points on the load curve.

If the resulting $y$-value (on the line) is greater than the $y$-value which defines the load duration curve then the $x, y$ pair and step are defined as:

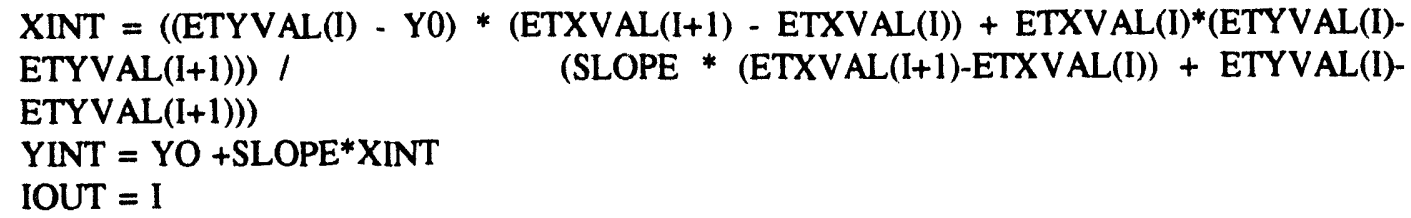

If the resulting $y$-value (on the line) is never greater than any $y$-value which defines the load duration curve, then the line crosses the load duration curve at the last point; i.e. the $x, y$ pair and the step are defined as:

IOUT $=$ ETNVCT

YINT $=$ YO + SLOPE * ETXVAL(ETNVCT)

XINT $=$ ETXVAL $(E T N V C T)$

If the Cutting Line is Above the Load Duration Curve

The algorithm searches through each point on the load duration curve and checks if the line crosses, i.e.. is the $y$ value on the line less than the $y$ value on the load duration curve. Since the line began with the $y$ value greater than the $y$ value on the load curve, the line must intersect the load curve at the first point at which the $y$ value on the line is less than the $y$ value on the load curve. When this occurs, the $x, y$ pair and the step number are defined as:

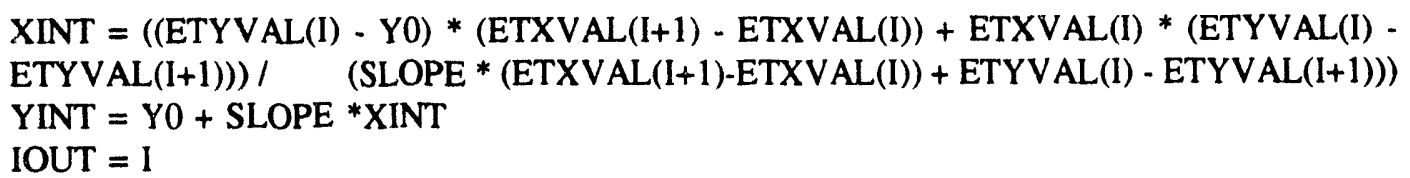


If the $y$-value on the line is never less than the $y$-value on the next step in the load curve, the line must cross the curve in the last step; i.e.,

IOUT $=$ ETNVCT
YINT $=$ ETYVAL(ETNVCT)
XINT $=$ ETXVAL(ETNVCT) 
Description: This subroutine also calculates the load under the "import" load duration curve and saves the information into the variable AREATI. As in ELLOAD, the point at which the lines which defines the capacity being dispatched crosses the load duration curve needs to be determined. This is calculated in the following subroutine.

- Called by: ELALOC

Source Code: UETT

Calls: $\quad$ ELITXY

Equations: Similar to ELLOAD subroutine. See Mathematical Description for ELLOAD.

Area available for displacement is calculated as:

where

CUMAREI $=$ AREAINT - AREAIT

CUMAREI = cumulative area that could be displaced

AREAIT $=$ all area under "import" curve

AREANT = all area under original curve

Incremental areas are calculated as:

w',ere

IMTMP = CUMAREI(current) - CUMAREI(previous)

IMTMP = incremental area (horizonal/vertical) available for displacement

Last, since less than 30 of the 180 or so possible plant groups that are allocated are generally available for trade, the above data are stored into arrays dimensioned only by 30 horizontal slices. The original horizontal slice index is saved into a mapping variable for later use. The following describes the data elements preserved for the ETT.

Area available to be displaced

- IMMAP - map to original horizontal slice index

- AREATI = IMTMP * EETIME (generation)

- CAPTRI = AREATl / [(ETXVAL(neXt) - ETXVAL(current)) * EETIME]

Next, ELCOST is called to store non-trade dispatch summary results and to store some pointers needed later in the trade algorithm.

Pointers preserved include:

$$
\begin{aligned}
& \text { ECDSPN }=\text { horizonal slice index } \\
& \text { ECDSPT = equipment type index } \\
& \text { ECASTS = capacity type } \\
& \text { ECFSHR }=\text { fuel share index }
\end{aligned}
$$

STRETT is called to write out the ETTDAF (stores trade opportunities arrays into DAF). 
Subroutine: ELITXY

Description: This subroutine evaluates a piecewise linear load duration curve to find a $x, y$ pair and step I at which a given cutting line crosses the import load duration curve.

Called by: EILOAD

Source Code: UETT

Calls:

Equations: See discussion of ELGTXY. The algorithm is the same in the ELTTXY subroutine, however, the y-value which describes the load curve is the $y$ value for the original load curve less the seasonal transmission capacity. 
Description: This subroutine evaluates a piecewise load duration curve to find the $x, y$ pair and step I at which a given cutting line crosses the export load duration curve.

Called by: ETLOAD

Source Code: UETT

Calls:

Equations: See discussion of ELGTXY. The algorithm is the same in the ELTTXY subroutine, however, the $y$-value which describes the load curve is the $y$ value for the original load curve plus the seasonal transmission capacity. 
Description: This subroutine tabulates fuel consumptions, fuel costs and O\&M costs associated with a set of dispatch decisions.

Called by: ELDISP

Source Code: UEFD

Calls:

Equations:

Add Plant Group Data to Running Totals

Capacity

ECAPPS(IPGRP,ISP) $=$ ECAPPS(IPGRP,ISP) + ECDSPC(I)

Where,

ECDSPC $=$ Capacity in Each Horizontal Slice

Generation Totals - By Season and Ownership

GEN $=$ ECDSPE(I) $*$ EETIME(ISP)

ETGEN $=$ ETGEN + GEN

EQPGN(IPGRP,IFOWN $)=$ EQPGN $($ IPGRP, IFOWN $)+$ GEN

EGENPS $(I P G R P, I S P)=$ EGENPS(IPGRP,ISP $)+$ GEN

Where,

ECDSPE = Energy in each Horizontal Slice

I = Horizontal Slice

EETIME $=$ Hours in Seasonal Slice

IFOWN = Ownership Type (Utility, Nonutility)

ISP $=$ Season

Calculate Fuel Consumption, Emissions and O\&M Costs

Fuel Consumption

FUEL $=$ GEN $*$ ECFSHR(N,IFP) $*$ ECHTRT(N,ISP) $* 0.001$

GEN $=$ Energy Generated

ECFSHR = Fuel Share

$\mathrm{N}=$ Plant Group

IFP $=$ Fuel Type

ISP $=$ Season

Total Fuel Consumption by Plant Type and by Fuel Type and Ownership

EQPFL (IPGRP) $=$ EQPFL $($ IPGRP $)+$ FUEL

EQFFL (IFL TP,IFOWN $)=$ EQFFL $($ IFL TP,IFOWN $)+$ FUEL

\section{Aggregate Totals}

This section outlines the equations for determining the aggregate totals of the dispatch decision. The following describes the totals by NERC region, plant type and ownership type (utility and 
nonutility). Totals by Census division and fuel supply regions and by fuel type are calculated in the same manner, only the totals are maintained by a different dimension.

Generation

UQPGENN(IPGRP,INR,IFOWN) = UQPGENN(IPGRP,INR,IFOWN $)+$ GEN * ECFSHR(N,IFP)

Consumption

UQPCONN(IPGRP,INR,IFOWN $)=$ UQPCONN (IPGRP,INR,IFOWN $)+$ FUEL

Variable O\&M

$\operatorname{ERTOM}($ IFOWN $)=\operatorname{ERTOM}($ IFOWN $)+$ GEN $* \operatorname{ECFSHR}(N, I F P) * \operatorname{ECOMR}(N, I F P) * 0.001$

Where,

GEN $=$ Energy

FUEL = Fuel Consumption

ECOMR = Variable O\&M

$\mathrm{SO}_{2}$ Emissions

UTSO2N(IFLTP,INR) $=$ UTSO2N(IFLTP,INR) + FUEL * UFRSO2(IFLTP,IFLRG) * $(1.0$ UFRASH(IFLTP)) *

$(1.0-$ REAL $(\mathrm{KSCRB}) *$ EFACTR $) * 0.5$

$\mathrm{NO}_{\mathrm{x}}$ Emissions

UTNOXN(IFLTP,INR) $=$ UTNOXN(IFLTP,INR) + FUEL * UFRNOX(IFLTP,IFLRG) * 0.5

$\mathrm{CO}_{2}$ Emissions

UTCO2N(IFLTP,INR) $=$ UTCO2N(IFLTP,INR) + FUEL * UFRCO2(IFLTP,IFLRG) $* 0.5$

Carbon Emissions

UTCARN(IFL TP,INR) = UTCAR(IFLTP,INR) + FUEL * UFRCAR(IFLTP,IFLRG) * 0.5

$\mathrm{CO}$, Emissions

UTCO1N $($ IFLTP,INR $)=$ UTCO1 (IFLTP,INR + FUEL * UFRCO1(IFLTP,IFLRG) $* 0.5$

Where,

IFLTP $=$ Fuel Type

INR $=$ Nerc Region

UFRSO2 = SO2 Emission Rate

UFRNOX $=$ NOx Emission Rate

UFRCO2 $=\mathrm{CO} 2$ Emission Rate

UFRCAR = Carbon Emission Rate

UFRCO1 = CO1 Emission Rate

FUEL = Fuel Consumption

IFLTP $=$ Fuel Type

KSCRB = Scrubber Efficiency 
Description: This subroutine computes the revenues associated with nonutilities including exempt wholesale generators, small power producers (Renewables) and commercial, industrial and other cogenerators/facilities for the EFP.

Called by: ELDISP

Source Code: UNUGS

Calls:

Equations:

Total O\&M Expense

Calculate Nonutility (EWG - Not Cogen) Renewable and Total Renewables (including Utilities)

HOMALL = HOMALL + ERHOM $(I, J)$
LOCRNW = LOCRNW + ERHOM(I,3)
EWGRNW = EWGRNW + LOCRNW

Where,

ERHOM = Variable O\&M

$\mathrm{I}=$ Renewable Technology Type

$\mathrm{J}=$ Ownership Type; $1 \& 2=$ Utility; $3=$ Nonutility

$3=$ Ownership Type $=3$; i.e. nonutility

Calculate Total Nonutility Renewable Generation

TOTGENR $=$ TOTGENR + EQHGN $(1,3)$

$\mathrm{EQHGN}=$ Generation

I = Renewable Technology Type

$3=$ Ownership Type; i.e., nonutility

Calculate Utility, Total (Utility plus nonutility) and Nonutility Variable Costs

TOTREV $=$ TOTREV + (ERTFL(I) + ERTOM(I))

LOCEWG $=$ LOCEWG + ERTFL (3) $+\operatorname{ERTOM(3)}$

INTNCOST $=$ INTNCOST + (ERTFL $(1)+$ ERTFL $(2)+$ ERTOM(1) + ERTOM(2) $)+($ HOMALL EWGRNW)

Where,

ERTFL $=$ Total Fuel Cost

ERTOM = Variable O\&M

I = Ownership Type; $1 \& 2=$ Utility; 3 = Nonutility

\section{Calculate EWG Revenues and Price}

Total EWG Revenues are equal to the fixed plus the variable component. The fixed component (EWGFIX) is determined in the ECP where the capacity expansion decision is determined.

EWGREV $=$ EWGFIX + LOCEWG 
EWGAVP = TOTREV $/$ TOTGEN

EWGFIX = EWG Fixed (Capital) Component

Calculate Commercial Nonutility Revenues (Sold to Utilities)

Calculate Generation and Capacity Sold to Utilities

TOTGENC $=$ TOTGENC $+\left(\right.$ CSHARE $(I R G, I) *\left(\right.$ GRIDSHR $\left.\left.(I, I Y R)^{*}(\operatorname{CGCOMGEN}(1, I Y R, J))\right)\right)$ TO T C A P C $=$ TO TCAPC + ( C S HARE (IR G, I ) (GRIDSHR(I,IYR)*(CGCOMCAP(I,IYR,J,K)/1000)))

Where,

CSHARE $=$ Census to NERC regional Map

IRG = NERC Region

$I=$ Census Division

GRIDSHR = Share of Total Sold to Utilities

CGCOMGEN = Commercial Cogeneration - Energy

CGCOMCAP = Commercial Cogeneration - Capacity

$\mathrm{K}=$ Vintage (Existing/Planned or Unplanned)

Commercial Revenues

LOCRCC $=$ LOCRCC $+($ EWGAVP $*$ TOTGENC $)+($ CGCOMPF $*$ TOTCAPC $)$

EWGRCC $=$ EWGRCC + LOCRCC

Where,

CGCOMPF $=$ Commercial Cogen Fixed Cost

Calculate Industrial and Other Nonutility Revenues

Calculate Industrial and Other, Generation and Capacity Sold to Utilities

Generation

TOTGENI $=$ TOTGENI + (ISHARE $(I R G, K) *($ CGINDGEN $(K, I Y R, I, 1)))$

TOTGENO $=$ TOTGENO $+($ CGOTGEN $($ IRG,IYR,I)/1000 $)$

Capacity

TOTCAPI $=$ TOTCAPI + (ISHARE $(\mathrm{IRG}, \mathrm{K}) *(\mathrm{CGINDCAP}(\mathrm{K}, \mathrm{IYR}, \mathrm{I}, 1, \mathrm{~L}) / 1000))$

TOTCAPO $=$ TOTCAPO $+($ CGOTCAP(IRG,IYR,I)/1000)

Revenues

LOCRIC $=$ LOCRIC + $($ EWGAVP $*$ TOTGENI $)+($ CGINDPF * TOTCAPI $)+$ CGOTPV *

TOTGENO) +

(CGOTPF * TOTCAPO)

Where,

ISHARE = Cersus to NERC region map CGINDGEN = Industrial Cogeneration (Energy)

$\mathrm{K}=$ Census Division

IYR $=$ Model Year

$I=$ Fuel $T$ 'pe

CGOTGEN = Generation at Other Cogen Facilities (i.e., not industrial or commercial)

CGINDCAP = Industrial Cogen Capacity

$\mathrm{L}=$ Vintage (Existing/Planned or Unplanned)

CGOTCAP $=$ Other Cogen Capacity (i.e., not industrial or commercial) 
CGINDPF $=$ Industrial Fixed Component Price

CGOTPV $=$ Other Cogen Variable Component Price

CGOTPF $=$ Other Cogen Fixed Component Price

Calculate Revenues from International Electricity Trade

ETIMPD $=($ EWGAVP $*$ ETIMPE)

ETEXPD $=($ EWGAVP*ETEXPE $)$

Where,

ETIMPE = International Economy Imports (mwh)

ETEXPE = International Economy Exports (mwh) 
Description: This subroutine captures the area available for displacement and the area available for export by region, season and vertical and horizontal slice into the file \&6005PRJ.UTIL.ETTDF.<scenario>. <datekey>.

, Called by: ELDISP

Source Code: UDAF

Calls:

Equations: None 
Description: This subroutine accumulates $\mathrm{SO} 2$ emissions and allowances across regions for each compliance group.

Called by: ELEFD

Source Code: UEFD

Calls:

Equations: None 
Description: This subroutine store the results of the dispatch decision in the file \&6005PRJ.UTIL.OUTDAF.<scenario >.<datekey>.

Called by: ELEFD

Source Code: UDAF

. Calls:

Equations: None 
Subroutine: STRBLD

Description: This subroutine store the build decision information in the file \&6005PRJ.UTIL.ECPIDAF. <scenario>.<datekey>.

Called by: ELEFD

Source Code: UDAF

Calls: $\quad$.-

Equations: None 
Description: This subroutine checks to see if the emission meet the allowances in each of the compliance groups.

Called by: ELEFD

Source Code: UEFD

-Calls: $\quad$-.

Equations: None 
Subroutine: ETTPRC

Description: This subroutine determines economy transactions by allowing importing regions to replace their more costly generation with generation from utilities in surrounding regions. First, transmission constraints are read in from the file \&6005PRJ.UTIL.ETTIN.AEO93B.D1111931 and trade variables are initialized.

Called by: ELEFD

Source Code: UETT

Calls: $\quad$ DAFRD, SORTNV, SORTEX, ETRADE, ETTCOST

Equations: This subroutine is the main calling routine of the ETT. There are no major equations in this subroutine. 
Description: This subroutine reads the trade opportunities DAF file which was created in the above described EFD submodule. It then maps the sequential vertical slice index to the chronological vertical slice (creating a uniform time frame) based on group and segment numbers.

Called by: ETTPRC

- Source Code: UETT

Calls:

GETETT, GETIN

Equations:

This subroutine loads "native" arrays with generation, capacity, and unit price information associated with native generation that could be displaced by trade. Native (import) arrays (NATIVE, CAPNV, COSTNV) are loaded if the import generation is greater than 0 .

native generation (MWH): $\quad$ NATIVE = AREATI

native capacity $(\mathrm{MW}): \quad$ CAPNV $=$ CAPTRI

native unit price $(\$ / m w h): \quad \operatorname{COSTNV}=$ UNTCOS

It loads "export" arrays with generation, capacity, and unit price information associated with generation available for export. Export arrays (EXAVAIL, CAPEX, COSTEX) are loaded if the export generation is greater than 0. Before loading the capacity and generation, the line loss percentage is taken out.

export generation (MWH): EXAVAIL = AREATR * $(1-$ LINELOSS $)$

export capacity $(M W): \quad$ CAPEX $=$ CAPTR * $(1-$ LINELOSS $)$

export unit price $(\$ / \mathrm{mwh}): \quad$ COSTEX $=$ UNTCOS

It saves the region index into a variable for subsequent processing, and loads the original (1-180 version) borizontal slice reference into mapping variables (MAPIM, MAPEX) for later use.

The data are then sorted by costs. 
Description: This subroutine sorts native (the importing region's) supply in decreasing order; i.e. an importing region wants to replace its most expensive supply with the cheapest alternative available. This 'ordering' is achieved through creating an index (pointer) to the cost arrays which reflects the decreasing costs. This indexing is done in the subroutine INDEXD.

Called by: ETTPRC

Source Code: UETT

Calls: $\quad$ INDEXD

Equations: None 


\section{Subroutine: INDEXD}

Description: This subroutine creates an index to an array reflecting the values of the array in decreasing order.

Called by: SORTNV

Source Code: UETT

Calls:

Equations: None 
Description: This subroutine sorts the exporting region's supply in increasing order; i.e. an exporting region will sell capacity which is the lowest cost to maximize profits. This 'ordering' is achieved through creating an index (pointer) to the cost arrays which reflects the increasing costs. This indexing is done in the subroutine INDEXI.

Called by: ETTPRC

Source Code: UETT

Calls: $\quad$ INDEXI

Equations: None 
Subroutine: INDEXI

Description: This subroutine creates an index to an array reflecting the values of the array in increasing order for the export curve; i.e, the least expensive energy will be sold first.

Called by: SORTEX

Source Code: UETT

-Calls:

Equations: None 
Description: This subroutine determines the best trade among the regions by comparing the relative costs in each vertical slice. This subroutine calls the subroutine QUALFY to insure that the region's about to engage in trade are in fact 'trading partners' (i.e. allowed to trade based on historical relationships, physical locations and additional constraints currently imposed on the model during this time) and to check if transmission capability is available.

Called by: ETTPRC

Source Code: UETT

Calls: $\quad$ QUALFY

Equations: For each native capacity and generation amount, all the export capacity and generation that is available in the same vertical slice (seasonal and time of day time period) is considered for a potential trade. In order for trade to occur, the following conditions must be met:

- The cost of buying from another region must be less than the cost of producing at home. COSTEX $<$ COSTNV

- The difference between the native cost and the export cost must be greater than the price threshold.

- The potential export region must be one that can physically trade with the import region. (This is determined by looking up the records in the Constraints File.)

- If the 2 regions are trading regions, there must also be room in the pipeline (i.e. all the constraint values not used up yet by contracts).

The first 2 of these are determined in ETRADE. The latter 2 are determined by calling the subroutine QUALFY.

Once the trade algorithm is complete, the generation and capacity amounts traded are loaded into arrays so that generation that will be displaced by trade is subtracted out of the DISPOUT arrays and so that generation that is produced for export is added to DISPOUT arrays.

Displaced generation arrays:

ETCAPO $=$ TEMPC

ETGENO $=$ TEMPG

ETCSTO $=$ COSTNV $*$ TEMPG

Arrays associated with generation produced for export:

ETCAPN $=$ TEMPC $/(1-$ LINELOSS $)$

ETGENN $=$ TEMPG $/(1-$ LINELOSS $)$

ETCSTN $=$ COSTEX $*($ TEMPG $/(1-$ LINELOSS $))$

Where,

TEMPC $=$ the capacity $(\mathrm{MW})$ that is being traded

TEMPG = the generation (MWH) that is being traded

Note: Generation and capacity have been scaled back up by the line loss factor.

Next the report writer variables for the export region are calculated as follows: 
ZTDMDE $=$ ZTDMDE $+($ COSTEX $*($ TEMPG $/(1$-LINELOSS $))) / 1000$

$\mathrm{ZTDMPE}=\mathrm{ZTDMPE}+(((\mathrm{COSTNV}-\mathrm{COSTEX}) * 0.5) *$

(TEMPG / ( 1 - LINELOSS $))) / 1000$

ZTDMME = ZTDMME + TEMPG / ( - LINELOSS $)$

Where,

TEMPG = the generation being traded

ZTDMDE = Domestic economy sales (MM\$)

ZTDMPE = Domestic economy profit (MM\$)

ZTDMME = Domestic economy generation (Gwh)

The report writer variables for the import region are calculated as follows:

Import revenues:

ETFLPI $=$ ETFLPI $+($ COSTEX $+($ COSTNV - COSTEX $) * 0.5)+$ (TEMPG / ( 1 - LINELOSS))

ZTDMDE = ZTDMDE - ETFLPI $/ 1000$

ZTDMME $=$ ZTDMME - TRANSGEN

ZTDMPE $=$ ZTDMPE $-(($ COSTNV $*($ TRANSGEN $/(1-$ LINELOSS $))-$ ETFLPI $)) / 1000$

Where,

TRANSGEN = total generation being imported in a particular trade transaction 


\section{Subroutine: QUALFY}

Description: This subroutine checks to make sure the region's engaging in trade are linked and within transmission constraints.

Called by: ETRADE

Source Code: UETT

Calls:

Equations: None 
Description: This subroutine modifies the results of the original dispatch decision (generations, consumption and revenues), unique trade results are also stored.

- Called by: ETTPRC

Source Code: UETT

Calls:

GETOUT, GETBLD, GETIN, ELFSHRS, STROUT, STRBLD

Equations:

The subroutine begins by reading in the old ELCOST results from DISPOUT DAF file (by calling GETOUT). Next capacity and generation that was traded is calculated.

ECAPPS $=$ ECAPPS + ETCAPN - ETCAPO

EQGEN $=$ ETGENN - ETGENO

DISPOUT variables are modified (generation, consumption, revenues) for the trade, and the unique trade variables are loaded with summary results.

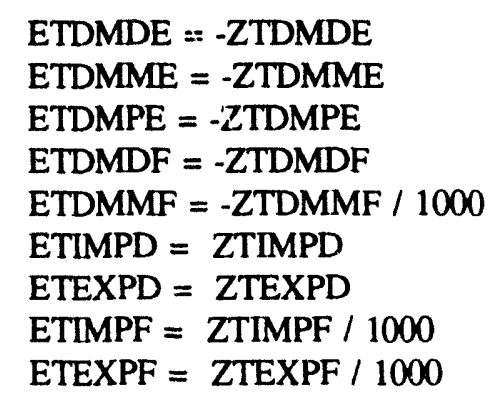

Note:

a) scale changes in ZTDMMF, ZTIMPF, and ZTEXPF (to Thous. Mwh)

b) sign changes for ZTDMDE, ZTDMME, ZTDMPE ZTDMDF, and ZTDMMF (to net exports)

Outputs

DISPOUT

Variable Description

Domestic Economy Sales

Domestic Economy Sales

Domestic Economy Trade Profit

Domestic Firm Power Sales

Domestic Firm Power Sales

Import Revenues

Export Revenues

Imports (Firm)

Exports (Firm)

Imports - Economy

Economy
Variable Name

ETDMDE

ETDMME

ETDMPE

ETDMDF

ETDMMF

ETIMPD

ETEXPD

ETIMPF

ETEXPF

ETIMPE

ETEXPE
Units

MM\$

Thous.MWH

MM\$

MM\$

Thous.MWH

MM\$

MM\$

Thous.MWH

Thous.MWH

Thous.MWH

Thous.MWH 
Description: This subroutine opens the file \&6005PRJ.UTIL.OUTDAF.<scenario $>$.<datekey>.

Called by: ETTCOST, ELEFD

Source Code: UDAF

Calls:

Equations: None 
Description: This subroutine store the results of the dispatch decision in the file \&6005PRJ.UTIL.OUTDAF.<scenario>.<datekey>.

Called by: $\quad$ ETTCOST, ELEFD

Source Code: UDAF

.Calls:

Equations: None 
Subroutine: STRBLD

Description: This subroutine store the build decision information in the file \&6005PRJ.UTIL.ECPIDAF. <scenario>.<datekey>.

Called by: ETTCOST, ELEFD

Source Code: UDAF

Calls:

Equations: None 
Description: This subroutine checks to see if the emission meet the allowances in each of the compliance groups.

Called by: ELEFD

Source Code: UEFD

- Calls:

Equations: None 
Description: This subroutine saves information temporarily stored in the common block USO2GRP in the file \&6005PRJ.UTIL. SO2DAF.<scenario>.<datekey>, in particular, the total $\mathrm{SO}_{2}$ produced, the penalty cost, and the $\mathrm{SO} 2$ allowances.

Called by: ELEFD

Source Code: UDAF

Calls:

Equations: None 


\section{Appendix C}

\section{C.1 Bibliography}

1. Energy Information Administration, Requirements for a National Energy Modeling System, Draft Paper, Washington, DC,

- $\quad$ November 1991.

2. Energy Information Administration, Near-Term, Midterm, and Long-term Forecasting in the National Energy Modeling - $\quad$ System, Issue Paper, Washington, DC, May 1991.

3. Energy Information Administration, A Recommended Design for the National Energy Modeling System, Draft Paper, Washington, DC, May 1991.

4. Energy Information Administration, Intermediate Future Forecasting System: Executive Summary, DOE/EIA-0430, Washington, DC, October 1983.

5. Energy Information Administration, Model Methodology and Data Description of the Electricity Market Module, Volume I: Overview, DOE/EIA-M038, Washington, DC, August, 1989.

6. Energy Information Administration, Model Methodology and Data Description of the Electricity Market Module, Volume I: Overview, DOE/EIA-M038, Washington, DC, August, 1989.

7. Energy Informati n Administration, Annual Outlook for U.S. Electric Power 1989, DOE/EIA-0474(89), Washington, DC, June 1989.

8. Energy Information Administration, Annual Outlook for U.S. Electric Power 1991, DOE/EIA-0474(91), Washington, DC, July 1991.

9. Energy Information Administration, National Coal Model: Executive Summary, DOE/EIA-0325, Washington, DC, April 1982.

10. Decision Analysis Corporation and ICF Resources Incorporated, Environmental Modeling Review Acid Deposition Control, Draft Report, Washington, DC, July 1991.

11. Argonne National Laboratory, Introduction to the Argonne Utility Simulation (ARGUS) Model, ANL/EAiS/TM-10, Argonne, Illinois, March 1990.

12. ICF Resources Incorporated, Reference Manual, Coal and Electric Utilities Model (CEUM), Fairfax, Virginia, 1991.

13. Electric Power Research Institute (EPRI), Electric Generation Expansion Analysis System (EGLAS), EPRI Final Report EL2561.

14. ICF Resources Incorporated, Overview of the Integrated Planning Model (IPM), Fairfax, Virginia, 1990.

15. Energy Management Associates, PROMOD III Overview, Production Cost and Reliability Systems, Atlanta, Georgia, 1992.

16. On Location, Inc, prepared for the Department of Energy, under Contract Number DE-AC01-89-EI21033, Nonutility Generation Supply Model, Final Documentation, October 24, 1991.

December 1991.

17. Applied Energy Services, prepared for the Department of Energy, The National Energy Strategy Integrating Energy Model Fossil2.

18. Gas Research Institute, Nonutility Generation Simulation Model, Arlington, VA, October 1991.

19. Prepared by Applied Energy Services and the University of Southern Califormia under contract number DE-AM799-88BP3721 
to Bonneville Power Administration, Dynamic Analysis of Pacific Northwest Non-Utility Power Generation, September 1990.

20. Applied Energy Services, The AES Non-Utility' Generation Model Documentation, Arlington, VA, March 1991.

21. The General Electric Company, The Non-Urility Generation Market for the 1990's: A Comprehensive Economic Model-Based Forecast, Schenectady, New York, December 1991.

22. North American Electric Reliability Council, Supply and Demand 1991-2000, July 1991.

23. Energy Information Administration, Annual Energy Outlook, DOE/EIA-0383(93), Washington, DC, January 1993. 


\section{Appendix D}

\section{D.1 Summary of Title IV \\ to the Clean Air Act Amendments of 1990}

Unlike the previous New Source Performance Standards (NSPS) and Revised New Source Performance Standards (RNSPS) programs which set plant and unit specific emission rate limits, the CAAA program employs a unique, market-based approach to $\mathrm{SO}_{2}$ emission reductions, while relying on more traditional methods for $\mathrm{NO}_{\mathrm{x}}$ reductions. Under the market-based approach, utilities receive a limited "number of marketable emission permits or "allowances" each year. ${ }^{27}$ Each allowance permits the emission of 1 ton of $\mathrm{SO}_{2}$ for that year or any year thereafter. In the EMM-NEMS these $\mathrm{SO}_{2}$ allowances are treated as emission constraints on utility and nonutility planning and operations.

The acid deposition provisions of the CAAA are instituted in two phases. In Phase I, 1995 through 1999, allowances are allocated to large, electric-utility steam generating units fired by fossil fuels in an effort to limit their average $\mathrm{SO}_{2}$ emissions to 2.5 pounds per million Btu of heat input. ${ }^{28}$ No additional control is required at other units.

In Phase II, beginning in 2000, "basic" allowances are allocated to all electric-utility steam units greater than 25 megawatts in existence between 1985 and $1995 .{ }^{29}$ New utility and nonutility units that begin operating after 1995 are required to have allowances beginning in 2000 , which they must acquire through the market or in some other manner. In general, the amount of allowances allocated to a particular unit is determined by its size, primary fuel, 1985 emission rate, average fuel consumption from 1985 through 1987, and the year it began operation. The annual "basic" allowance allocation is limited to 8.95 million tons. In addition, almost 0.5 million "bonus" allowances are distributed each year for the first 10 years of Phase II.

In both phases, 2.8 percent of the "basic" allowances intended to be allocated each year will be placed in a special reserve, a portion of which may be sold directly, the remainder to be auctioned. The auction is intended to stimulate the market and to give new entrants, such as independent power producers, access to allowances. The direct sale is intended to be a market of last resort for anyone needing but unable to acquire allowances. Proceeds from both the auction and the direct sale are returned to the original owners of the allowances. These auctions and direct sales of allowances are not explicitly represented in the EMM-NEMS because of their small impact on the allowance market. However, they are included in the original allocation of allowances, and, thus captured in trading.

The CAAA establishes incentives (e.g., extra allowances and compliance-deadline extensions) for installing scrubbers during Phase I, instituting energy conservation, using new renewable energy sources, and using clean coal technologies. Presently the Environmental Protection Agency is finalizing procedures for a utility to take advantage of these incentives. When these procedures are finalized the EMM-NEMS allowance constraints will be modified to reflect the distribution of these incentive allowances.

Allowances can also be banked (saved) for future use. Because fewer emissions are allowed after 1999, allowances will increase in value beginning in 2000. A utility may find it advantageous to overcomply from 1995 through 1999, saving allowances for use in Phase II. Because banking decisions are dependent on unit and utility specific information (including each utility's assumptions about future allowance costs), banking algorithms is not endogenized within EMM-NEMS. Analysis will be done exogenous to the model to access the economics of banking and the EMM-NEMS allowances constraints will be adjusted to reflect the estimated levels of banking in future versions of NEMS.

Utilities must also submit compliance plans for and install continuous emission-monitoring devices at all affected units. A utility that does not comply (emits $\mathrm{SO}_{2}$ in excess of the allowances it holds) must pay $\$ 2,000$ for each ton of $\mathrm{SO}_{2}$ it emits in excess of its allowances and must offset those emissions the following year.

The CAAA also requires the Environmental Protection Agency (EPA) to set new $\mathrm{NO}_{x}$ emission standards for existing and new utility

${ }^{27}$ Electricity generators must still meet the emission standards in existence before the passage of the CAAA.

${ }^{28}$ Phase I affects electric utility steam generating units with a nameplate capacity of 100 megawatts or greater and an actual $1985 \mathrm{SO}_{2}$ emission rate of 2.5 pounds per million Btu or greater. The names of the units and their Phase I allowances are listed in the CAAA.

${ }^{29}$ Units less than or equal to 25 megawatts, combustion turbines, solar units, wind turbines, geothermal units, and hydroelectric units are not subject to the requirements of the CAAA. 
boilers. For existing tangentially-fired boilers ${ }^{30}$ the maximum emission rate the EPA can set is 0.45 pounds of NO, per million $\mathrm{Btu}$ of heat input; for existing dry-bottom wall-fired boilers ${ }^{31}$ (excluding cell-burner technology ${ }^{32}$ ) the maximum is 0.50 pounds per million Btu. These new standards must be met by 1995 . For cyclones, ${ }^{33}$ wet-bottom wall-fired boilers, ${ }^{34}$ cell-burner technology, and other utility boilers, the EPA has until 1997 to set new standards, taking into account available technology and environmental considerations. In addition, by 1993, the EPA must revise the performance standards for $\mathrm{NO}_{\mathrm{x}}$ emissions from new units to account for improved emission-reduction methods since the 1979 revision.

The $\mathrm{SO}_{2}$ emission allowance program established in the CAAA offer a more economical approach to emissions control compared with the NSPS and RNSPS programs established in the original Clean Air Act and its earlier amendments. By establishing a market for emission permits, utilities with relatively high cost emissions reduction options will be able to purchase allowances from other utilities with lower cost options. These allowance trades among utilities are expected to continue until there are no gains or savings to be made, resulting in the most cost-effective solution.

${ }^{30}$ Tangentially-fired boilers are fired from the corners of the furnace; the fireball can be directed upward or downward.

${ }^{31}$ Wall-fired boilers have burners mounted on their front and back walls. Dry-bottom wall-fired boilers use coal with high ash-fusion temperatures. Most of the fly ash is removed just ahead of the stack.

${ }^{32}$ Cell-burner technology is used in dry-bottom wall-fired boilers. The burners are arranged in clusters on the firing wall to reduce $\mathrm{NO}_{x}$ emissions.

${ }^{33}$ In a cyclone boiler, combustion occurs in water-cooled horizontal cylinders connected to the furnace walls. High-velocity air is fed tangentially to the cylinders, and the combustion gases exit into the furnace.

${ }^{34}$ Wet-bottom wall-fired boilers use coal with low-ash fusion temperatures, where the slag tends to cling to the walls and bottom of the furnace. In a wet-bottom furnace, the slag drops into a tank of water. 


\section{Appendix E}

\section{E.1 Model Abstract}

Description: The Electricity Fuel Dispatch (EFD) determines the yearly operation of the electric power industry. The EFD uses merit order dispatching, meaning that plants (excluding intermittent, renewable technologies and cogenerators) are dispatched until demand "is satisfied based on their operation costs, with least-cost plants being operated first. Limits on emissions of pollutants (such as sulfur dioxide, nitrogen oxides and carbon dioxide) from generating units are also accounted for during dispatching as are emission allowances. During off-peak periods, the EFD institutes load following, which is the practice of running plants near their minimum operating levels rather than shutting them down and incurring shut-off and start-up costs. In addition, to account for scheduled and unscheduled maintenance, the capacity of each plant is derated (lowered) to the expected availability level. Finally, the EMM-NEMS simulates the operation of utility and nonutility (excluding cogenerators) plants for each region on a seasonal basis to reflect the seasonal variation in electricity demand.

Last Model Update: December 1993

Part of Another Model?: Electricity Market Module (EMM) of the National Energy Modeling System (NEMS)

Model Interfaces: The EFD interfaces with other components of the EMM and NEMS. Electricity demand, available capacity and fuel costs are provided by the Load and Demand Side Management Submodule, the Electricity Capacity Planning Submodule (ECP), and the Fuel Supply Modules, respectively. In turn, the EFD provides the Electricity Finance and Pricing (EFP), the Fuel Supply, Renewables and Systems Modules the resulting operating expenses, generation, fuel use and emissions.

\section{Sponsor:}

$\begin{array}{lll}\text { - } & \text { Office: } & \text { Office of Integrated Analysis and Forecasting } \\ \text { - } & \text { Division: } & \text { Energy Supply and Conversion Division } \\ \text { Branch: } & \text { Nuclear and Electricity Analysis Branch, EI-821 } \\ \text { - } & \text { Model Contact: } & \text { Patricia Toner } \\ & \text { Telephone: } & \text { (202) 586-2048 }\end{array}$

Archive Media and Installation Manuals(s): The EFD is archived as part of the NEMS system. The installation handbook and tape information can be obtained from the National Energy Information Center at (202) 586-8800.

Non-DOE Input Sources:

North American Electric Reliability Council

- Hourly load data

Environmental Protection Agency

Emissions allowances for sulfur dioxide

DOE Data Input Sources:

Argonne National Laboratories t:

- $\quad$ Fixed Operations and Maintenance

- Variable Operations and Maintenance

- $\quad$ Planned Outages

- $\quad$ Forced Outages 
- Heat Rate

- $\quad$ Operating Profile (Percent of Available Hours at Indicated Load Levels)

- Maximum Capacity Factor (percent)

- Maximum Availability Hours (hours)

- Duty Cycle

- Scrubber $\mathrm{SO}_{2}$ Removal Efficiency

- Retrofit Factor

- Particulate Remoyal Efficiency

- $\quad$ Sludge Disposal Costs

- Fly and Bottom Ash Disposal Costs

On Location, Inc., Deliverable 6, Draft Data Inputs for Implementation of ETT, Task 92086, Contract DE-ACO1-88EI21033, memorandum from Less Goudarzi/Joanne Shore to Pat Toner, Energy Information Administration, March 5, 1993.

- Transmission flow constraints

- Transmission capacity expenditure coefficients

- Transmission losses

Federal Energy Regulatory Commission, Form FERC-1, "Annual Report of Major Electric Utilities, Licensees and Others" .

Transmission Operations and Maintenance Data

International Affairs and Energy Emergencies, Form IE-411, "Coordinated Regional Bulk Power Supply Program Report"

- Existing and Planned Interregional and International Transfers

- $\quad$ Fuel Cost Adjustment for Purchased Power

- $\quad$ Adjustment to Revenues for Bulk Power Sales

Energy Information Administration, Form EIA-759, "Monthly Power Plant Report"

- Maximum fuel shares for existing capacity

Energy Information Administration, Office of Integrated Analysis and Forecasting

- $\quad$ Nuclear Maximum Capacity Factors

- Annual Fuel Costs

- International Economy Transactions

Energy Information Administration, Electric Power Annual 1992, (DOE/EIA-0349(92)), draft report, 1994.

- Historic (1990, 1991, and 1992) utility and nonutility generation and fuel consumption data by fuel

- Historic Emissions

Energy Information Administration, Form EIA-860, "Annual Electric Generator Report"

$\begin{array}{ll}\text { - } & \text { Existing Utility Capacity } \\ \text { - } & \text { Heat rates for existing capacity } \\ \text { - } & \text { Planned utility capacity additions } \\ & \text { utility capacity retirements }\end{array}$

Energy Information Administration, Form EIA-867, "Annual Nonutility Power Prodıcer Report"

- $\quad$ Existing nonutility capacity by plant type

- $\quad$ Planned nonutility capacity additions by plant type

- $\quad$ Planned nonutility capacity retirements by plant type 
Energy Information Administration, Form-767, "Steam-Electric Plant Operation and Design Report"

- Emission rates for existing generating units

- Pollution control equipment installed at existing generating units

Energy Information Administration, Office of Integrated Analysis and Forecasting

- $\quad$ Maximum Nuclear Capacity Factors

- Annual Nuclear Fuel Costs

- International Economy Transactions

-

General Output Descriptions: The EFD provides electricity generation, fuel consumption at electric utilities, variable cost and emissions information to various components of the EMM and NEMS. This information is used to compute electricity prices (in the Electricity Finance and Pricing Submodule), to determine fuel prices (in the Fuel Supply Modules) and to account for emissions in the Systems Module.

\section{Computing Environment:}

$\begin{array}{lll}\text { - } & \text { Hardware Used: } & \text { IBM } 3090 \text { mainframe } \\ \text { Operating System: } & \text { MVS } \\ \text { - } & \text { Language/Software Used: } \quad \text { FORTRAN } 77 \\ \text { - } & \text { Memory Requirement: } & 16,000 \mathrm{~K} \text { (All EMM) } \\ \text { - } & \text { Storage Requirement: } & 6,075 \mathrm{~K} \text { (All EMM) } \\ \text { Estimates Run Time: } & 10 \text { CPU seconds per iteration per year }\end{array}$

\section{Independent Expert Reviews Conducted:}

- $\quad$ Roger Naill, AES, National Energy Modeling System Conference, February 1 and 2, 1993.

- Vance Mullis, Southern Company Services, National Energy Modeling System Conference, February 1 and 2, 1993.

- $\quad$ Larry Makovich, DRI, McGraw-Hill, National Energy Modeling System Conference, February 1 and 2, 1993.

Status of Evaluation Efforts by Sponsor: The EFD documentation is currently undergoing independent expert review. The office is also involved in completing Volume II of the documentation, the Model Developers Report, which will provide sensitivity analysis and scenario output in support of the documentation of model performance. The Model Developers Report is scheduled to be completed in December 1994. 


\section{Appendix F}

\section{F.1 Data Quality and Estimation}

This section describes the quality of the data used in the EFD and the estimation techniques used to prepare the data for use in the model.

\section{Exogenous Inputs}

Sulfur Dioxide, Nitrogen Oxide, and Carbon Dioxide Emission Factors

See the Electric Power Annual 1991, (DOE/EIA-0348(91)), January 1993, for a description of the methodology and the data sources used to determine these factors.

\section{Transmission Constraints}

Transmission constraints were obtained from the April 1992 NERC regional publications of the Coordinated Bulk Power Supply Program Report (DOE Form OE-411). This report contains the bulk power supply plans for utilities over the next decade; in particular, the first order contingency plan for utilities, which is the measure for transmission capacity used as input to NEMS. This measure was used since most transmission networks are designed and operated on this basis. First order contingency planning entails operating and designing the system so that any one component can fail or be removed from service without causing the remaining facilities in service to be overloaded. This measure of transmission capability is conservative but necessary to ensure reliability yet consistent with normal utility operations.

\section{Interregional Transmission Losses}

Form EIA-861 data were used to explore national average line losses to points of resale versus end-use customers. The data does not provide this information directly. The data contains total losses, sales to ultimate customer and sales for resale. A regression was run over the 1990 and 199 ! data to estimate $a$ and $b$ as follows:

$$
\mathrm{L}=\mathrm{aQ}+\mathrm{bS}
$$

Where: $\mathrm{L} \quad=\quad$ Total Losses

$\begin{array}{lll}\mathrm{Q} & = & \text { Ultimate Customer Sales } \\ \mathrm{S} & = & \text { Sales for Resale } \\ \mathrm{a} & = & \text { Percent losses associated with ultimate customer sales } \\ \mathrm{b} & = & \text { Percent losses associated with sales for resale }\end{array}$

Theoretically, wheeling and gross exchanges should be included, but the data were not readily available, and the purpose of this calculation was to determine a rough magnitude for transmission losses, as represented by the loss factor associated with sales for resale. The transmission losses were 1.8 percent in 1990 and 2.4 percent in 1991, on average. A more detailed summary of the results follows:

1990 data:

$\begin{array}{lcc}\text { Standard Error of Y Estimate } & 115.1536 & \\ \text { a } & 0.07309 & \text { T-value } 159.1525 \\ \text { b } & 0.01822 & \text { T-value } 20.74191 \\ \text { R Squared } & 90.2 \text { percent } & \end{array}$

1991 data:

Standard Error of Y Estimate $\quad 92.9042$

a 
In future versions of NEMS, refinement of this calculation will be considered.

(Source: Memorandum from Less Goudarzi and Joanne Shore, OnLocation Inc., to Pat Toner, dated March 5, 1993, Eeliverable 6, "Draft Data Inputs for Implementation of ETT, Task 92086, Contract DE-AC01-88EI21033".)

Intraregional Transmission and Distribution Loss Factor

The transmission and distribution loss factor for each electricity supply region was derived using the following equation:

$$
\text { Losses }=((\text { Net Energy for Load/Sales })-1) * 100
$$

Note: 1990 data were used.

Source: Memorandum from Less Goudarzi, Dana Griswold, and Laura Train, OnLocation Inc., to Pat Toner, dated July 30, 1993, Deliverable 2, "ETT Data Inputs Deliverable Subtask 93108, Contract DE-AC01-89EI21033".)

\section{Firm Power Trade Contracts}

Data were obtained from the April 1992 NERC regional publications of the Coordinated Bulk Power Supply Program Report (LOE Form OE-411). This report contains estimates for the next 10 years. These contracts reflect individual utility's estimates of future firm power trades. In some instances, there were discrepancies between the reporting of the purchasing and the selling utility (for example, there are two trading trading partners, A and B, and A sells capacity to B. A reports that it will sell 50 megawatts to B while B reports that it plans to purchase 75 megawatts from A), analyst judgement was used to determine the contracted trade. In general, the larger reported value was used. Data for post 2001 are not available so existing contracts in 2001 were assumed to continue through 2010 . This assumption will remain until further information is available.

\section{Load Data}

Load shapes were determined using historic load data obtained from NERC. This regional (NERC region and subregion) load information is the aggregation of individual utility load data.

\section{Economy Trade Thresholds}

There is currently an assumed minimum price threshold (i.e., difference between the purchasing and selling utilities cost) of 1 mill per kilowatthour for economy trade to occur. This is based on the assumption that there must be an economic incentive to trade. If the costs are the same between the purchasing and selling utilities, there is not an incentive to trade.

This variable needs further research and will be included in the sensitivity analysis in Volume II of the Documentation, The Model Developers Report.

\section{Inputs from Other Modules}

\section{Available Generating Capacity by Plant Type - Utility and Nonutility}

The existing and planned capacity and performance for utilities and nonutilities is as reported on the EIA Forms 860, "Annual Electric Generator Report" and the EIA Form 867, "Annual Nonutility Power Producer Report", respectively. These forms contain the universe for utility and nonutility units. The "universe" of nonutility projects lags a year because the forms are sent to nonutility power producers which report sales to utilities on the ElA Form 860 . Unplanned capacity additions result from the decision-making process in the ECP which is based on cost and performance characteristics from the Argonne National Laboratory Cost and Performance database. See the ECP documentation for a description of the data quality and estimation methods used in its model inputs. 
Renewable Generation by Fuel Type

See the Renewable Fuels Module Documentation.

Demand by Sector

See the Commercial, Industrial, Residential and Transportation Models Documentation.

Fossil Fuel Prices

See the Coal Supply, and Oil and Gas Supply Models Documentation. 

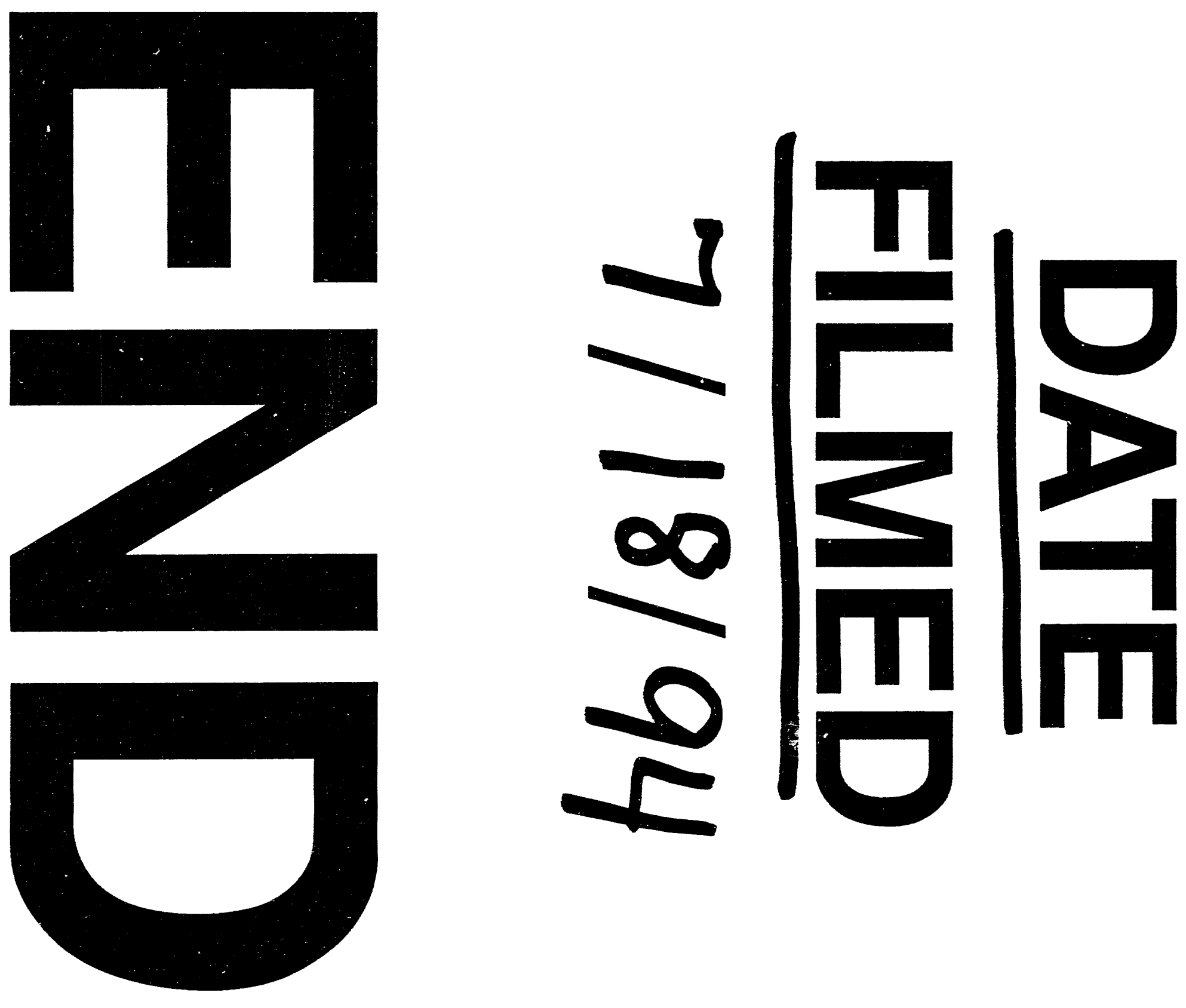
